\title{
PELLETIZING/RESLURRYING AS A MEANS OF DISTRIBUTING AND FIRING CLEAN COAL
}

Contract No. DE-AC22-90PC90166

Contract Period: August 3, 1990 to August 2, 1992

\section{Final Report}

\author{
Battelle \\ 505 King Avenue \\ Columbus, Ohio 43201-2693
}

Principal Investigator: H. Nicholas Conkle Phone No. (614) 424-5616

Date Submitted: September 29, 1992

Prepared for

PETC Project Manager: Anthony E. Mayne

Pittsburgh Energy Technology Center

U. S. Department of Energy

P. O. Box 10940

Pittsburgh, Pennsylvania 15236 


\section{EXECUTIVE SUMMARY}

Battelle-Columbus and Amax Research \& Development conducted a program to develop a process to transport, handle, store, and utilize ultra-fine, ultra-clean (UFUC) coals. The primary objective was to devise a cost-effective method, based on conventional pelletization techniques: to transform the sludge-like filter cake produced in advanced flotation cleaning processes into a product which could be used like lump coal. A secondary objective was the production of a pellet which could be readily converted into a coal water fuel (CWF) because the UFUC coal would ultimately be utilized as CWF. The resulting product would be a hard, waterproof pellet which could be easily reduced to small particle sizes and formulated with water into a liquid fuel. This Executive Summary has been expanded to be a stand alone document. Supporting data, discussions, and analysis are provided in the body of the report.

The following three pelletization techniques and three bituminous coals were evaluated:

$\begin{array}{ll}\text { Techniques } & \text { Coals } \\ \text { Roller-and-die } & \text { Elkhorn } \\ \text { Disk } & \text { Illinois No. } 6 \\ \text { Extrusion } & \text { Utah. }\end{array}$

The results of this 24-month program indicate that strong, durable pellets can be produced by each technique from each coal using one of several binders. Use of a petroleum-based binder (Shur Bond) allowed production of waterproof, weather resistant pellets. The pellets were also successfully formulated into stable CWF with low viscosities. Pelletization adds $\$ 7$ to $\$ 13 /$ ton depending on the coal, pelletization process and binder. Overall, pelletization transportation, handling, storage, and conversion of the pellets into CWF costs from $\$ 0.79 / \mathrm{MM}$ Btu to $\$ 1.04 / \mathrm{MM}$ Btu for a 1,000 ton/day plant transporting the pellets 100 miles to 20 separate end users. Cost to convert the Elkhorn coal directly into CWF and tran, handle, and store the liquid fuel was estimated at $\$ 1.83 / \mathrm{MM}$ Btu (excluding in all cases the cost of coal and beneficiation. These encouraging results indicate that pelletization is on 
economical, as well as practical, solution to the transportation, handling, and storage problem associated with UFUC.

The results of the project should be applicable to many clean-coal producers faced with fine coal problems. Successful combinations of coal type, binder type and dosage, and pelletization techniques were readily found. The following three important factors were identified:

- Coal - coal type was found to be a significant factor. Coal type dictated proper pelletization moisture level, binder dosage, and CWF dispersant requirements. Good quality pellets and pellet-CWF could be produced from any of the bituminous coals studied.

- Binder - binder type affected pellet physical properties, amenability to slurry formulation, CWF dispersant dosage, and pellet and CWF costs. Corn starch imparted the greatest strength but was the most expensive. Shur Bond (a petroleum-water emulsion) provided moderate-to-good strength, good weather resistance, and was the least expensive.

- Technique - pelletization technique, while more suited to some coals than others, could be used to successfully pelletize any of the three coals studied. Pelletization technique did, however, affect costs, with the roller-and-die being the most economic followed by disk and extrusion pelletization.

\section{The Need}

The Pittsburgh Energy Technology Center (PETC) is supporting the development of processes that can produce beneficiated coal products that have significantly reduced levels of ash and pyritic sulfur. A coordinated effort has been made by PETC to develop systems for transporting, storing and handling these products. A number of physical coal cleaning processes yield wet filter cake, which is intractable to handling and is susceptible to freezing conditions during transport and storage. Therefore, alternative product forms are needed to 
facilitate the storage and handling of ber ficiated coals. One such form is the pellet, which is a candidate for handling and transporting : equipment of conventional design. The need to find an efficient and economic solution to the transportation, handling, and storage problem was the basis for the DOE contract with Battelle.

\section{The Proposed Solution}

Battelle and Amax proposed to convert the wet filter cake into low moisture coal pellets which could be transported, handled, and stored like lump coal and then converted into CWF at the poirt of use (Pellet-CWF approach). This approach provided an alternative to the standard CWF route where the filter cake is converted at the preparation plant site into a slurry (Direct-CWF approach). The Pellet-CWF and Direct-CWF approaches are illustrated in the Figure below.

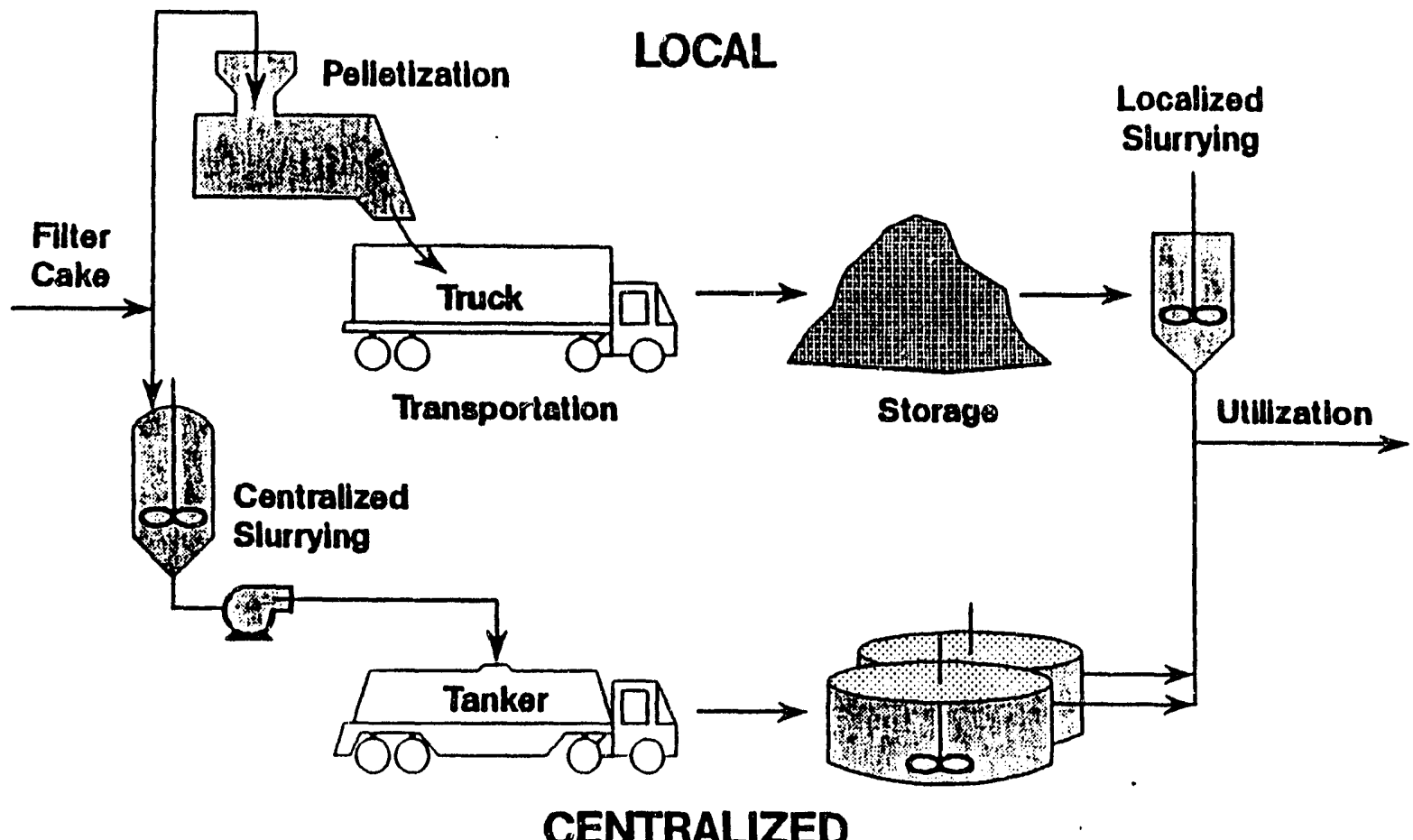

\section{ALTERNATIVE CLEAN COAL TRANSPORTATION, STORAGE, AND HANDLING APPROACHES}




\section{Conclusions}

Significant accomplishments in the area of fine coal pelletization and pellet reslurrying have been achieved. This project has demonstrated that the coal pelletization processes can produce strong, durable clean-coal pellets which can be readily formulated into good quality CWF. The following conclusions were reached:

- Bench- and pilot-scale pellet production tests indicated that roller-and-die, disk, and extrusion pelletization techniques could be used to produce strong, durable, and waterproof pellets from ultra-fine, ultra-clean Elkhorn, Illinois, and Utah coals

- Binders, including corn starch, Shur Bond, and lignin sulfonate were demonstrated to be suitable for the Pellet-CWF approach

- Pellets from disk and extrusion pelletization could be handled similar to lump coal and transported via trucks or rail immediately from production. Also, these pellets could be stored in most of the storage modes for periods as long as ten weeks. However, under the exposed-outdoor storage mode, storage periods longer than 4 weeks should be avoided.

- Roller-and-die pellets require about one-day of curing time before being subjected to handling, transportation and storage operations. These pellets could also survive most of the storage modes for as long as 10 weeks. Again, under exposed-outdoor storage mode the pellets survivability is reduced significantly.

- All pellets could be transported by trucks or rail-cars similarly to raw mined coal with less than 5 percent fines generated over 4-5 hours of transportation.

- Siurry production tests indicated that low viscosity, stable, CWF could be produced. Pellets could be converted into CWF with viscosities below $500 \mathrm{cP}$ ( $100 \mathrm{sec}^{-1}$ shear rates at coal loadings of 55 wt. percent.

- CWF formulation dosage for pellet reslurrying was typically about $50 \mathrm{wt}$. percent less than that required to reslurry the filter-cake directly. Since PelletCWF is intended to be used immediately, no stabilizer is required. 
- Economic analysis showed that among the three pelletization processes evaluated in the Pellet-CWF approach, the roller-and-die technique had the lowest annualized cost with all three coals. It was also estimated that plant sizes greater than 500 TPD are more economical.

- Annualized cost for CWF formulation in either of the two approaches was closely controlled by the amount of reslurrying additives required. For the Pellet-CWF approach, the formulation cost was estimated to be most economical for plant sizes greater than 25 TPD.

- Transportation distance was a major variable that impacted the total annualized cost. In the Pellet-CWF approach the pellets were handled like lump coal, resulting in a lower transportation cost than the Direct-CWF approach.

- The total annualized cost estimate for processing, handling, storing, and transportation by the Pellet-CWF approach was lower than the Direct-CWF approach for distances greater than 20 miles.

- Estimated pelletization, handling, storage, transportation (100 miles), and reslurrying costs for Elkhorn coal bound with Shur Bond binder was (\$0.79/MM Btu total) exclusive of coal and beneficiation costs.

- Estimated direct CWF formulation, handling, storage, transportation (100 miles) costs for Elkhorn coal was (\$1.83/MM Btu) exclusive of coal and beneficiation costs. The Pellet-CWF approach became even more attractive as transportation distances increased.

- The Pellet-CWF approach offers several technical and economic incentives for further development and commercialization.

\section{Potential Benefits}

Potential benefits derived from the successful application of fine coal pelletization include the following:

Increased preparation plant production -- since all the clean coal could be sold (typically 10 or more percent of the production is too fine for sale) 
- Environmentally acceptable transportation of fine and ultra-fine coal

- Dust-free storage

- Coal handling that avoids the problems associated with high-moisture fines, and freezing

- Modified coal physical properties (increased ash fusion temperature, lower free swelling index) and modified chemical properties (allowing in-situ sulfur capture during combustion or gasification) by incorporation of additives.

The Pellet-CWF approach has several additional benefits, including:

- Elimination of stabilizer requirements in the CWF (needed to prevent the coal from settling during extended storage)

- Reduction in transportation costs (since the fuel moisture content is reduced from 45 percent to 10 percent through pelletization)

- Reduction of freezing problems (otherwise encountered with CWF handling/storage)

- Simplification of storage requirements (since the coal pellets can be stored as lump coal instead of heated agitated slurry tanks necessary for CWF)

- Prevention of bacterial action (bacteria frequently attack the CWF additives during extended slurry storage, ultimately promoting segregation and settling and increasing slurry viscosity).

\section{Objectives}

This objective of this program develop the technology that is economical for:

- Producin clean coal pellets from wet filter cake

- Transporting, storing and handling these pellets

- Reslurrying the pellets at the point of utilization to form CWF with properties suitable for pumping, atomizing, and firing.

The overall focus of the research was to displace oil used in small- and medium-size commercial and industrial boilers, furnaces, and engines with clean coal water slurries. 


\section{Approach}

This program integrated the pelletizing and reslurrying technologies, by selecting binders that produced strong pellets and could subsequently assist in the formation of coalwater fuels (CWF). Specifically, the experimental program was designed to identify the effect of coal types, binder types, and pelletization techniques on ultra-fine, ultra-clean coal pellets' transportation, handling, storage, and CWF conversion properties.

The program began with the identification of appropriate reconstitution techniques and binders, quality testing procedures, establishment of acceptance criteria, and a bench-scale experimental development program. Battelle emphasized two approaches to prepare coal pellets. The first approach was the use of an internal binder to prepare pellets having sufficient strength to be transported, handled and stored in a manner similar to raw coal. The second approach was to prepare low-cost pellets by accepting a lower strength and the need for specialized transportation, handling and/or storage. CWF from pellets was included as part of the pellet development activities. Therefore, preference was given to binders that would contribute to the production of a suitable slurry.

Once successful pelletization techniques were identified, which also permitted the preparation of CWF with low viscosity, stable, shear thinning/pseudoplastic CWF behavior, the best formulations were selected for pilot-scale evaluation. Tests included multi-ton lot pellet productions using three different pelletization techniques, two (and in some cases three) different binders, and three bituminous coals. CWF evaluations were also made to confirm that the pilot-scale pellets could also be converted into acceptable CWF. Some of these pellets were also formulated into CWF in a continuous mode in a "pellet-to-slurry" system. The slurries were evaluated for atomization characteristics.

Next, extensive transportation, handling, and storage testing was conducted to determine if coal pellets could survive the harsh conditions similar to raw lump coal. Testing was conducted over the winter months so pellets were subjected to cold temperatures, rain, snow, 
freezing and thawing conditions. Extended storage tests of exposed and covered pellets prepared with different binders and pelletization techniques were conducted.

Finally, to evaluate the economics of the Pellet-CWF approach, binder requirements and CWF additive dosage data were combined with information on 1) pelletization costs, 2) CWF formulation costs, 3) transportation costs, and 4) handling and storage costs to estimate total system costs. The estimated Pellet-CWF capital and operating costs were estimated for different coals, plant sizes, and different transportation distances when employing the selected binders and pelletization techniques. These costs were compared with conventional CWF preparation, transportation, and handling costs prepared from similar coals, for similar applications and transportation distances.

\section{Scope of Work}

The project activities includes the following 10 tasks:

- Task 0. Acquire Coal - which consisted of obtaining ultra-fine, ultraclean coal for the research and development efforts. Suitable material could not be provided by DOE; therefore, an additional task (Task 9) was added to the program to acquired and beneficiate the required coal.

- Task 1. Identify Technology - which consisted of identifying and selecting the most promising pelletization and CWF formulation techniques and testing procedures, and establishing acceptance criteria to judge the quality of pellets and slurry produced from pellets.

- Task 2. Prepare and Test Small Batches - which consisted of preparing small batches of pellets, Pellet-CWF, and filter cake/CWF; performing atomization testing on the Pellet-CWF and filter cake/CWF; and selecting the preferred techniques for pilot-scale evaluation. 
- Task 3. Prepare Bench/Pilot-scale Pellets - which consisted of preparing several tons of pellets from three different coals using three different pelletization techniques, following the preferred binder type/dosage levels established in Task 2.

- Tasks 4, 5, Evaluate Transportation, Handling and Storage and 6 Characteristics - evaluated the effectiveness of physical property specifications included in the acceptance criteria for the prediction of pellet- survivability when subjected to actual transportation, handling and storage trials.

- Task 7. Reslurry Pellets and Evaluate CWF - which consisted of reslurrying the pilot-scale pellets and performing atomization tests to confirm that Pellet-CWF could meet the CWF acceptance criteria.

- Task 8. Utilization/Commercialization - which consisted of establishing process flowsheets for the three pelletization techniques and estimating the costs to commercially produce pellets; transport, handle, and store the pellets; and reslurry them into CWF at the point of utilization. Costs were compared with conventional CWF preparation, transportation, handling, and storage costs.

- Task 9. $\quad$ Prepare Additional Cake - which consisted of an optional task, added after the project was started to: acquire, ultra-fine grind, flotation beneficiate the three project coals, and ship the clean coal filter cake to Battelle for pelletization testing. 


\section{Bench-Scale Development}

Bench-scale pellet production and evaluation showed that the three bituminous coals studied (Elkhorn, Illinois No. 6, and Utah) could be pelletized into acceptable pellets by the three techniques. In each of these techniques, tests indicated that among the several binders studied, com starch, lignin sulfonate and petroleum-water emulsion (Shur Bond) binders were compatible for both pellet production and slurry production.

Slurry formulation from pellets was also examined in great detail. Specifically, dispersant additive dosages (A-23) and rheological characteristics were determined for all the pellets. The additive dosages were found to be dependent on the type of binder used in the pellets. Com starch-bound pellets required the maximum A-23 dosages in its slurries. Also, the required dispersant additive dosage was about 40-60 percent lower for slurries prepared from pellets that for slurries prepared from clean-coal filter cakes. Other variables that influence the slurry preparation from pellets such as air-drying versus thermal drying, mixing techniques, pellet aging, etc., were also examined.

Finally, based on the pellet and CWF formulation results and preliminary econumic analysis, the roller-and-die pelletization technique was determined to be the preferred technique for the Pellet-CWF approach. Hence, pilot-scale pellet production with roller-anddie was recommended for all the three coals. Preliminary economic analysis also projected that Shur Bond-bound pellets would be the most economical pelletizing binder.

\section{Pilot-Scale Development}

Several thousand pounds of pellet were produced by roller-and-die, disk, and extrusion pelletization techniques from the three coals. Uniform, acceptable pellets were produced after a startup period of 100 to 200 minutes of pellet production. The three binders recommended from the bench-scale evaluation were found to be acceptable for pilot-scale pellet production and slurry formulation. Shur Bond bound pellets, however, showed slightly 
lower cured strength compared with the bench-scale tests. In most extrusion and in some disk pelletization tests, the liquid binders, i.e., Shur Bond and lignin sulfonate, required about 0.5 percent corn starch as secondary binder to provide adequate green/cured pellet strength.

The pellets from the three techniques were also assessed for CWF amenability and for continuous slurry production. A novel, 8 gallon/hr "pellet-to-slurry" system was designed, fabricated and tested for slurry production. The unit performed satisfactorily. The slurries were also successfully atomized in an AGT research nozzle. Atomization characteristics of the slurries prepared from pellets indicated the Pellet-CWF to be suitable for the various applications targeted in the project.

\section{Transportation, Handling, and Storage}

Pellets produced in the pilot-scale pellet procition processes were studied for survivability during transportation, handling and storage. The pellets were found to behave similar to lump coal in all of these test modes. Transportation simulation tests were conducted in a test unit designed in this project. The unit controlled the vibration intensities on the pellets. Through the simulated and actual transportation tests, it was found that all the pellets show excellent potential to survive transportation. Typically, less than 5 percent fines (-48 mesh) were generated.

Storage simulation tests were conducted over 2, 4 and 10 week test periods in exposed-outdoor, covered-outdoor, silo, and bag type storage units. All the pellets survived the above modes, except with exposed-outdoor mode, during the 2, 4 and 10 week test periods. In the exposed-outdoor mode, the pellets typically survive easily for first two weeks. Beyond this, extreme structural disintegration occurred, particularly with lignin sulfonate and corn starch bound pellets. 
No specific degradation effects were observed when pellets were subjected to the reactivity tests to simulate the effects of spontaneous combustion. Therefore, it is believed that the pellets have a very low potential for spontaneous combustion.

\section{Economic Assessment}

The overall production costs for preparing CWF by the Pellet-CWF and Direct-CWF approaches were compared. Briefly, in the pellet-CWF approach, the clean coal filter-cake was pelletized, transported to the user-site, stored and slurried a few hours prior to use. In contrast, in the direct-CWF approach, the filter-cake was converted into slurry at the beneficiation site, transported to the end-user, where the slurry was stored and used. The two approaches are shown schematically below.

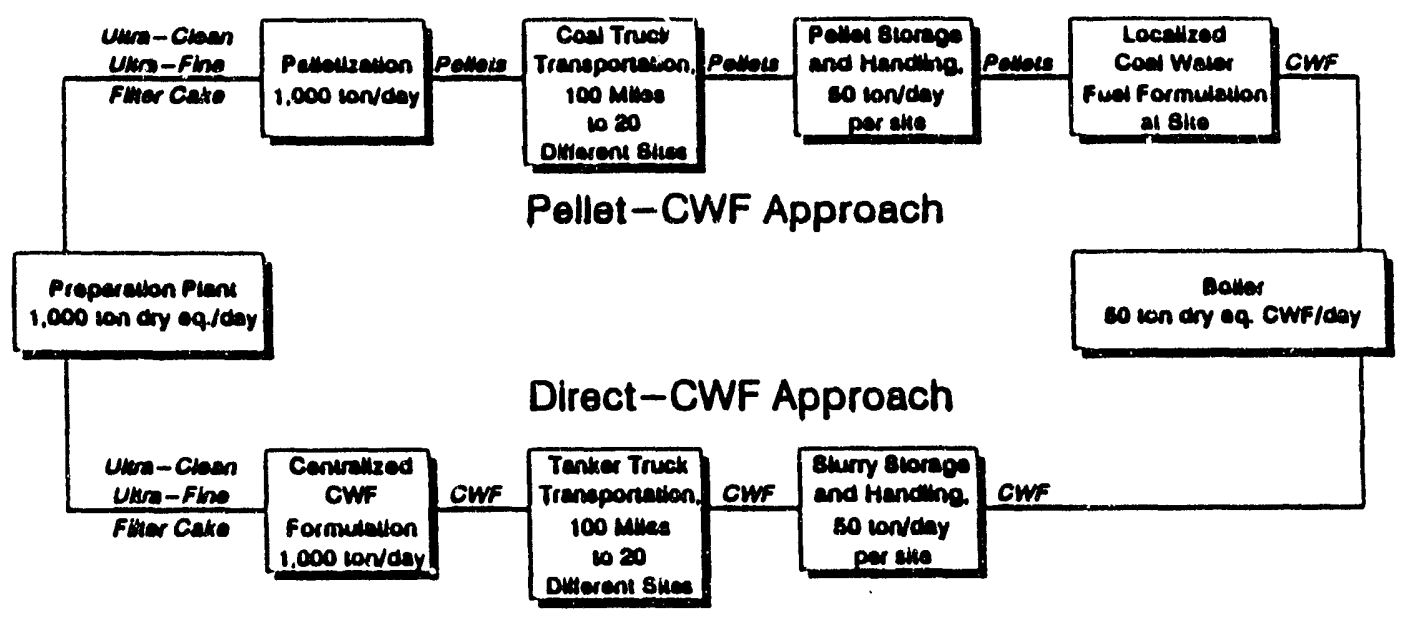

In the following sub-sections, operating cost for the various process areas are compared for the two approaches. 


\section{Pelletization Costs}

In the Pellet-CWF approach, peiletization cost is a significant variable. Operating cost estimates for a 1,000 dry ton/day coal pelletization facility using either corn starch or Shur Bond binder and Elkhorn coal are summarized in the table below.

Pelletizing via the roller-and-die technique is clearly seen as the most cost effective method; Elkhorn coal mixed with Shur Bond binder could be pelletized for about $\$ 7.53 /$ dry ton equivalent ( $\$ 0.25 / \mathrm{MM} \mathrm{Btu)}$. The pellets prepared by this technique also required low binder dosage levels to produce pellets with acceptable pellet strength and durability, etc. Other pelletization methods require slightly more binders and/or require more processing, resulting in higher annual operating costs.

\section{ANNUAL OPERATING COST ESTIMATE FOR PROCESSING ELKHORN COAL AT 1,000 DRY TON/DAY CAPACITY}

\begin{tabular}{|c|c|c|c|c|c|c|}
\hline \multirow[b]{3}{*}{$\begin{array}{l}\text { Binder } \\
\text { and Concentration }\end{array}$} & \multicolumn{6}{|c|}{ Operating Cost Estimate, \$/dry ton (4th Qtr 1991) } \\
\hline & \multicolumn{2}{|c|}{ Roller-and-Die } & \multicolumn{2}{|c|}{ Disk } & \multicolumn{2}{|c|}{ Extrusion } \\
\hline & $\begin{array}{l}\text { Corn } \\
\text { Starch } \\
(2.0 \%)\end{array}$ & $\begin{array}{l}\text { Shur } \\
\text { Bond } \\
(4.5 \%)\end{array}$ & $\begin{array}{c}\text { Corn } \\
\text { Starch } \\
(4.0 \%)\end{array}$ & $\begin{array}{l}\text { Shur Bond } \\
(4.5 \%)^{(a)}\end{array}$ & $\begin{array}{c}\text { Corn } \\
\text { Starch } \\
(2.0 \%)\end{array}$ & $\begin{array}{c}\text { Shur } \\
\text { Bond } \\
(4.5 \%)^{(u)}\end{array}$ \\
\hline Pelletizing & 8.42 & 7.58 & 12.66 & 11.24 & 12.10 & 11.35 \\
\hline $\begin{array}{l}\text { Transportation (100 } \\
\text { miles), Storage and } \\
\text { Handling }\end{array}$ & 7.97 & 7.91 & 7.97 & 7.91 & 7.97 & 7.91 \\
\hline $\begin{array}{l}\text { CWF Formulation } \\
(20 @ 50 \text { ton/day } \\
\text { plants), (\$/MM Btu) }\end{array}$ & $\begin{array}{l}9.78 \\
(0.33) \\
\end{array}$ & $\begin{array}{r}7.80 \\
(0.26) \\
\end{array}$ & $\begin{array}{l}12.48 \\
(0.43) \\
\end{array}$ & $\begin{array}{r}8.45 \\
(0.29) \\
\end{array}$ & $\begin{array}{r}10.59 \\
\cdot(0.36) \\
\end{array}$ & $\begin{array}{r}9.14 \\
(0.31) \\
\end{array}$ \\
\hline $\begin{array}{c}\text { Total } \\
(\$ / \mathrm{MM} \mathrm{Btu})\end{array}$ & $\begin{array}{l}26.17 \\
0.88\end{array}$ & $\begin{array}{l}23.29 \\
0.79\end{array}$ & $\begin{array}{l}33.11 \\
1.19\end{array}$ & $\begin{array}{r}27.60 \\
0.93\end{array}$ & $\begin{array}{l}30.66 \\
1.04\end{array}$ & $\begin{array}{l}28.40 \\
0.96\end{array}$ \\
\hline
\end{tabular}

(a) Includes $\sim 0.5$ percent corn starch used as secondary binder 
A breakdown of the operating cost components for pelletizing Elkhorn coal with Shur Bond binder as a function of plant size is shown in the figure (next page). The three pelletization techniques are also compared in this figure. Clearly, as plant size increases, cost per ton drops rapidly. For the roller-and-die technique, major cost elements are labor (30 percent) and maintenance ( 25 percent). Much of the cost associated with maintenance was for rollers and dies replacement or resurfacing. A die life of 16,000 tons and a roller life of 8,000 tons were assumed for this purpose. For the disk and extrusion techniques, the major cost elements included utilities ( -30 percent) and labor ( $\sim 28$ percent). The cost of thermal drying the pellets directly influenced the utilities cost. Among the three pelletization techniques, it was quite clear that the roller-and-die technique was the most attractive.

The cost estimates presented above were based on an optimized binder requirement. For roller-and-die pelletization, 4.5 weight percent of binder solution made up of 5 parts water and 1 part Shur Bond was determined to be adequate. However, with extrusion and disk pelletization, about 0.5 percent com starch was always required as a secondary binder. This directly increased the raw material cost for these two techniques. Cost elements such as depreciation, taxes, and maintenance, which are functions of capital cost, were estimated to be higher with disk and extrusion than with roller-and-die pelletization due primarily to the requirement for thermal drying before use.

\section{Coal Water Fuel Formulation Costs}

Comparison of reslurrying costs for Pellet-CWF and the direct-CWF approaches is summarized in this section. It was assumed in the Pellet-CWF approach, pellet reslurrying would be done at one of 20 localized reslurrying plants whereas for the direct-CWF approach, all the filter cake-to-slurry conversion would be performed at a centralized facility located at the cleaning plant. Conversion of pellets to CWF involved moving pellets from the storage area where they were mixed with water and a minimum of dispersant in a special agitated tank, then pumped to the boiler or furnace. For a 50 ton coal/day, Elkhorn coal, Shur Bond bound, roller-and-die pellet conversion to CWF facility, the reslurrying costs 

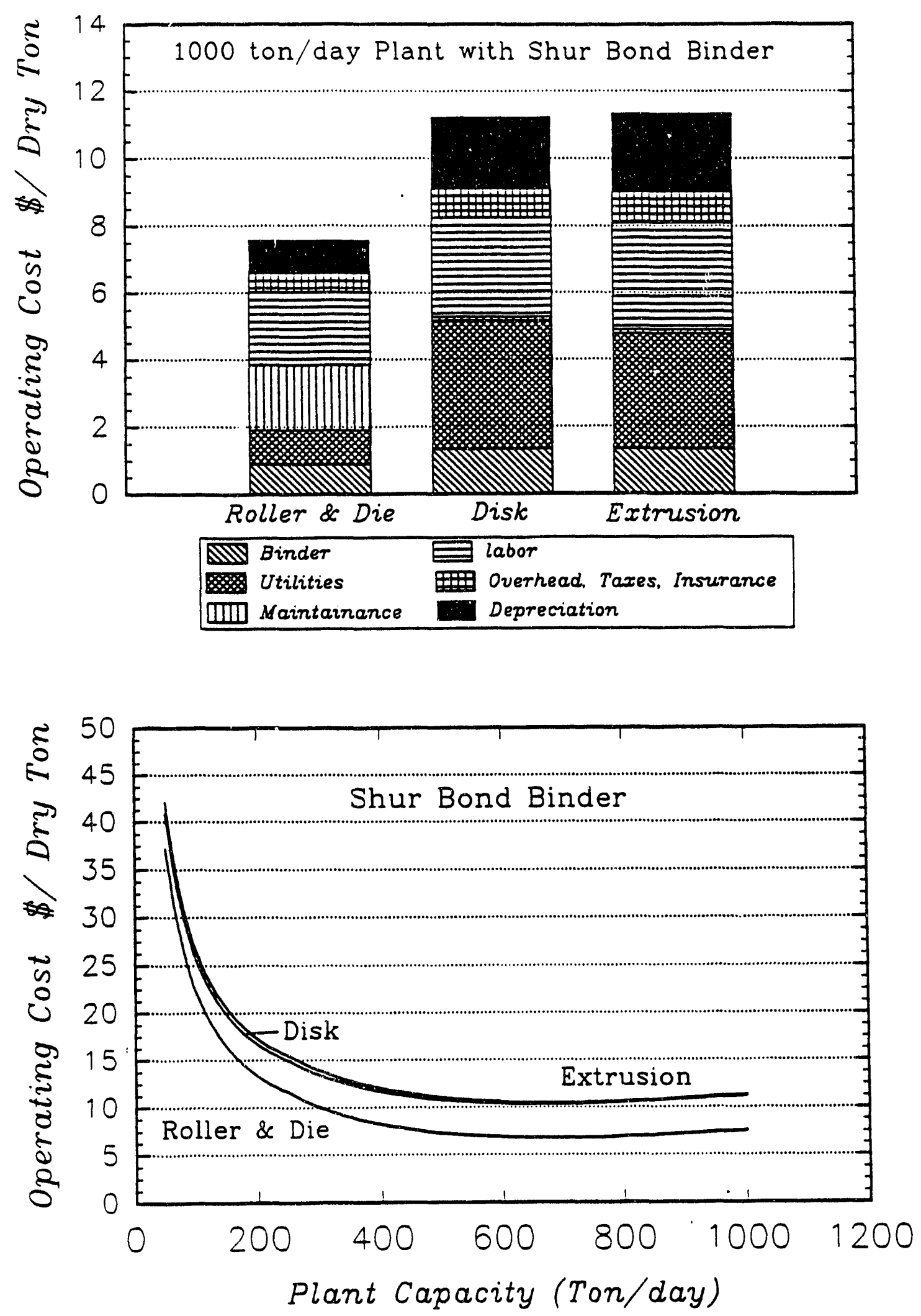

PELLETIZATION OPERATING COST BY TECHNIQUE AS A FUNCTION OF PLANT CAPACITY 
were approximately $\$ 7.80 /$ dry ton fed $(\$ 0.26 / \mathrm{MM} \mathrm{Btu})$. A summary of similar reslurrying cost estimates for disk and extrusion pellets was shown in the table presented earlier. The major cost elements were dispersant ( 34 percent) and labor (45 percent).

For the direct-CWF approach the CWF formulation costs were estimated to be $\$ 23.09 /$ dry ton fed (\$0.78/MM Btu). The major elements were similar to the Pellet-CWF approach. But costs were greater because more dispersant was required and a stabilization chemical (Flocon) was needed to prevent the coal particles in the slurry from settling into an un-pumpable cake during extended, un-agitated storage. The cost of CWF formulation by the two approaches is shown in the figure next page. Clearly the costs for converting Elkhorn coal pellets into slurry at multiple small facilities were significantly less than preparing slurry at a centralized facility. Lower chemical requirements for pellets conversion of this coal and binder outweighed the economies of scale achieved at the centralized CWF plant.

\section{Transportation Costs}

The transportation of coal pellets is compared with CWF. It was assumed that the 1,000 dry ton/day of clean coal filter cake would be either converted into pellets or CWF. As a design basis, we assumed 20 users each consuming approximaiely 50 dry tons of clean coal each day. A transportation distance of 100 miles was chosen as reasonable. The pellets after curing were loaded into 30-ton capacity trucks and transported to the various end users. A 1991 transportation cost of $\$ 0.078 /$ dry ton-mile was used; thus, the pellet transportation cost was $\$ 7.80 /$ ton $(\$ 0.27 / \mathrm{MM}$ Btu) for the 100 mile trip. 


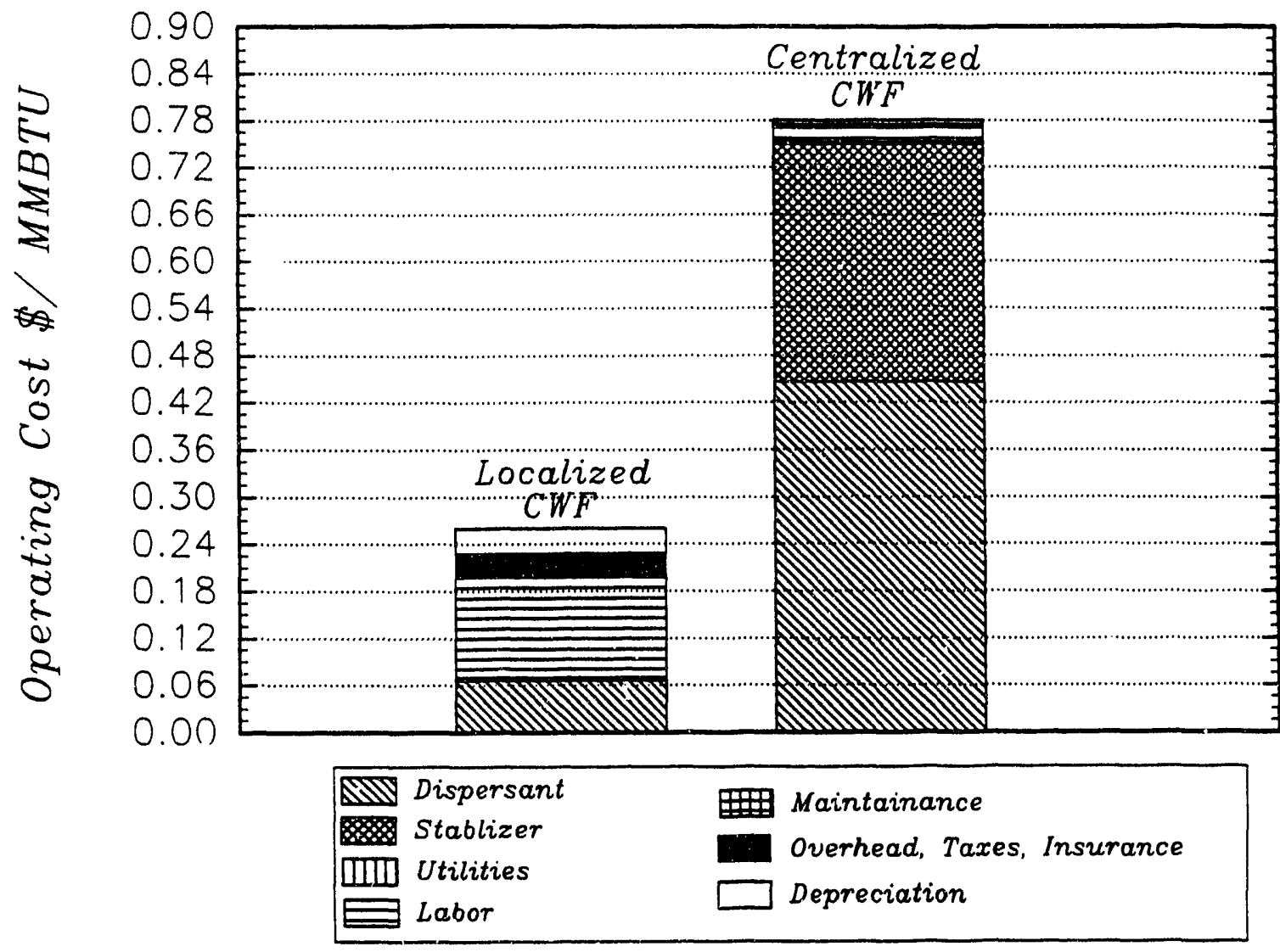

\section{RESLURRYING OPERATING COSTS FOR PELLETS AND FILTER-CAKE BY COST COMPONENT}

In the direct coal-to-CWF approach, the CWF was transferred into 4,500 gal capacity tanker trucks and transported to the users. A 1991 transportation cost of $\$ 0.304 /$ dry ton-mile was used. Slurry transportation costs were greater due to the need to transport more water (10 percent moisture coal pellets versus 45 percent moisture CWF) plus the need to use specialized tanker cars rather than conventional coal trucks. The CWF transportation cost was $\$ 30.4 / \mathrm{dry}$ ton $(\$ 1.04 / \mathrm{MM}$ Btu) for 100 miles. Savings in transportation costs between 
pellets and slurry was very significant. As transportation distances increases, the savings would become even more pronounced.

\section{Storage and Handling Costs}

The costs of storage and handling of the fuel once it reached the 20 users site was estimated for both the pellets and the CWF. Pellet handling and storage included a concrete pad for unloading the pellets received each day, and a front-end loader to move the pellets to the feed conveyor of the conversion facility. No labor was included (front-end loader labor costs were included with the reslurrying costs) and the only operating costs were related to the depreciation of the handling and storage facilities. Costs were estimated at $\$ 0.17 /$ dry ton (\$0.006/MM Btu). Estimated operating costs for the pellet transportation, handling, and storage were also presented earlier.

In the case of the direct-CWF appruach, CWF storage and handling included facilities to unload the tanker trucks each day, pumps to move the slurry to a 5-day, unheated, unagitated storage tank, and pumps to transfer the stored CWF to the boiler or furnace feed tank. Again no labor was assumed. Operating costs were estimated to be $\$ 0.84 /$ dry ton (\$0.030/MM Btu). The savings for the pellet approach were still significant.

\section{Total Cost}

A comparison of the estimated operating costs for the Pellet-CWF and direct-CWF approach is shown in the figure on Page XX. Costs did not include the cleaned coal cost, nor the cost of beneficiation. The cost basis included facilities for 1,000 dry tons of Elkhorn coal/day of froth-flotation cleaned coal converted into CWF. The CWF was used at 20 separate sites each utilizing approximately 50 dry tons equivalent of slurry. The Pellet-CWF approach included: 
- Roller-and-die pelletization with Shur Bond binder

- Transportation by 30 -ton coal trucks for 100 miles to 20 sites

- Storage on an outdoor, exposed concrete pad (5 day)

- Handling by front-end loader

- Reslurrying in a specialized pellet-to-slurry machine with A-23 dispersant (including holding tank and slurry-to-boiler delivery pumps).

The Pellet-CWF costs are compared with the direct coal-to-CWF approach which included:

- CWF formulation (1,000 dry ton/day) with A-23 dispersant and Flocon stabilizer

- Transportation in 4,500 gal tanker trucks for 100 miles to 20 sites

- Storage in a 100,000 gal un-agitated, unheated storage tank

- Handling by centrifugal pumps.

The total operating cost for Pellet-CWF approach was estimated at $\$ 0.79 / \mathrm{MM}$ Btu, and $\$ 1.83 / \mathrm{MM}$ Btu for the direct-CWF approach. The cost of dispersant and stabilizer required for preparing the Elkhorn-coal CWF directly without pelletizing was estimated to be significantly greater than preparing CWF at the user site after pelletizing. This combined with the lower transportation costs and lower storage and handling costs showed the pelletization approach to offer good incentives for development. 


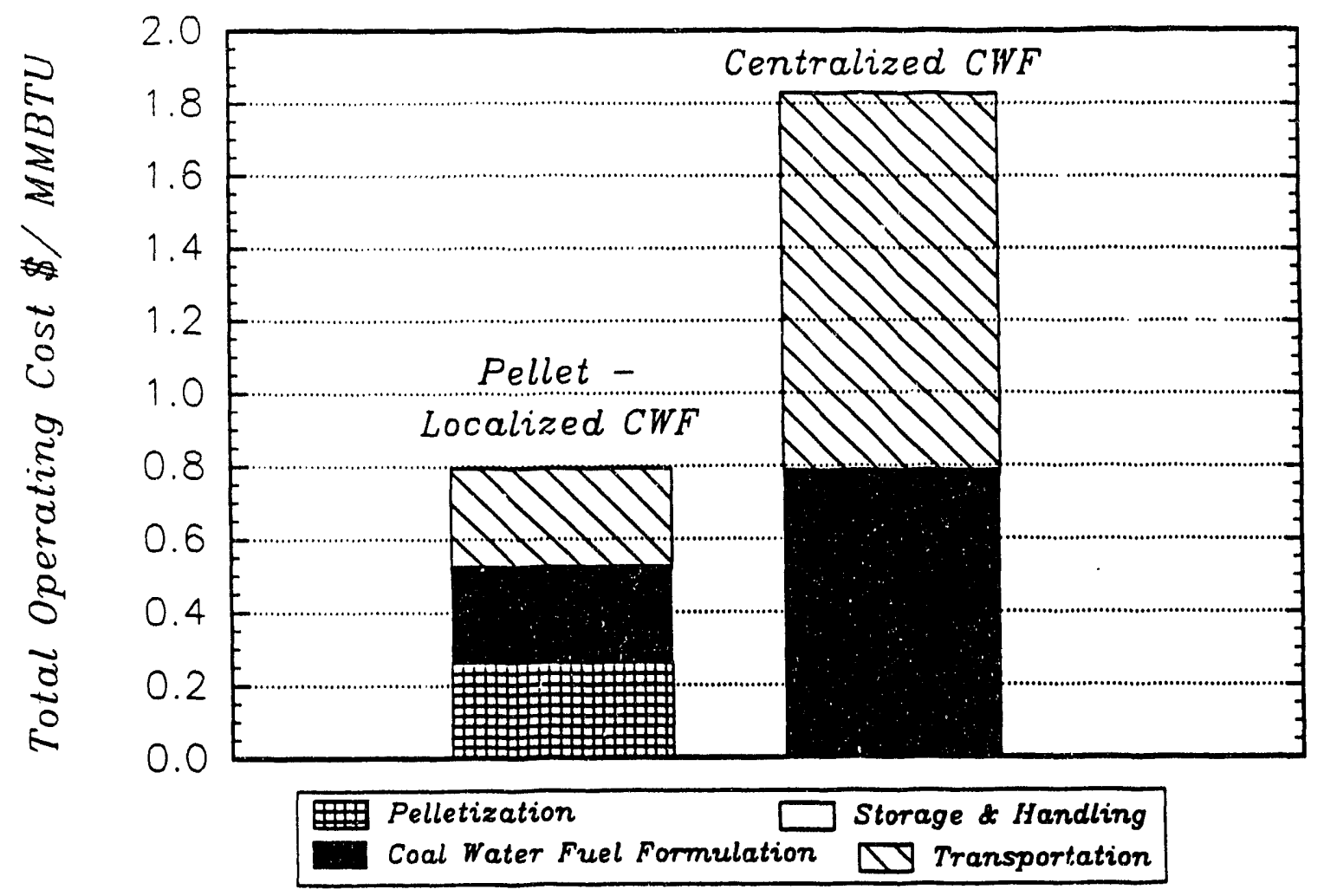

COAL PELLETIZATION, TRANSPORTATION, STORAGE, HANDLING AND CWF CONVERSION OPERATING COSTS COMPARISON FOR THE TWO APPROACHES

\section{Recommendations}

Battelle recommends, based on the positive project results, that the Pellet-CWF process be further developed. We suggest a two-step approach: (1) more testing in a pilotplant scale (1 to 5 ton $/ \mathrm{hr}$ ) pelletization facility operated for longer durations and in conjunction with a pellet combustion program, and (2) evaluation and economic analysis based on the pilot-plant data combined with data from the two commercial roller-and-die pelletization plants now in operation. The data would provide the foundation for commercial plant design and technology transfer. 
The objectives of the recommended effort would be to obtain more design data for the following areas:

- Maintenance requirements - determine the true wear rate of dies and rollers; this is needed because pelletizer maintenance is one of the major cost factors of roller-and-die pelletization costs.

- Pellet storage and handling characteristics - small scale tests indicate the pellets should be acceptable; larger scale tests more closely simulating true handling, storage, and transportation conditions are needed to better evaluate the pellets.

- Pellet grinding characteristics - testing indicated that the pellets could be broken down to approximately the same size as the feed clean coal before reconstitution; needed is an evaluation in a true air-swept roller-and-race pulverizer as used in pulverized coal combustion equipment to ensure acceptability.

- Pellet combustion characteristics - pellets made in previous programs have been successfully combusted and gasified; testing is needed, however, to assure that these ultra-low ash and sulfur coals can be burned with the same emission levels as the cleaned, un-pelletized coal.

- Pellet production costs - preliminary estimates of production costs indicate the pellets are an attractive method to store, handle, and transport ultra-fine, ultraclean coals; these estimates should be expanded to include the experiences and data being generated in the two $30,000+$ tons per year commercial roller-anddie pelietization plants now in operation. 


\section{TABLE OF CONTENTS}

Page

EXECUTIVE SUMMARY

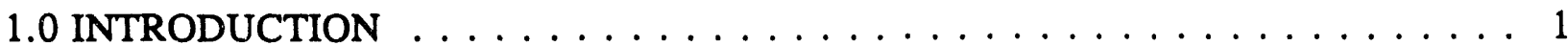

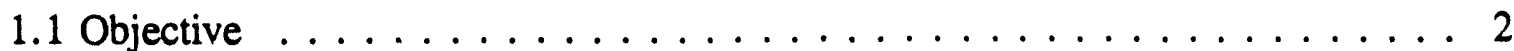

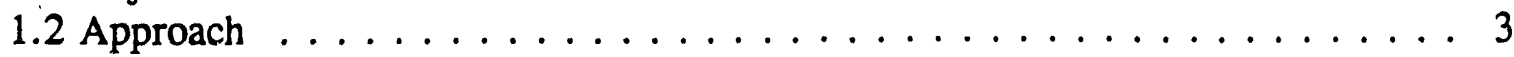

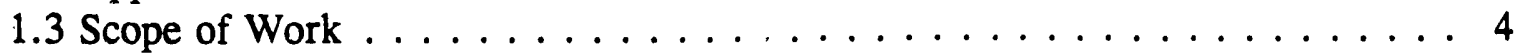

1.4 Contents of This Report $\ldots \ldots \ldots \ldots \ldots \ldots \ldots \ldots \ldots$

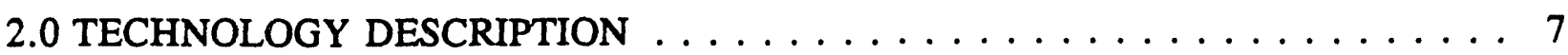

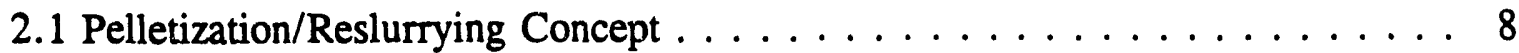

2.2 Results Achieved Prior to this Project $\ldots \ldots \ldots \ldots \ldots \ldots \ldots \ldots$

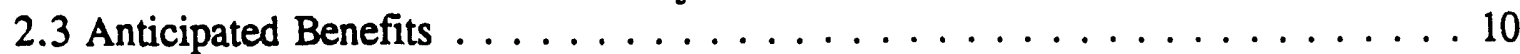

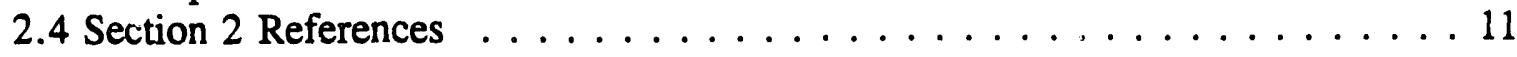

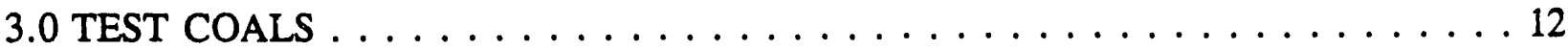

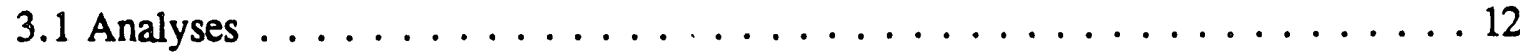

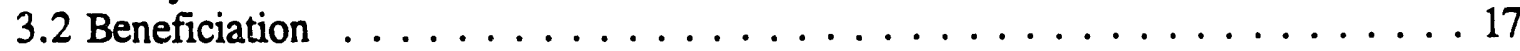

4.0 TECHNOLOGY IDENTIFICATION AND ACCEPTANCE CRITERIA . . . . . 23

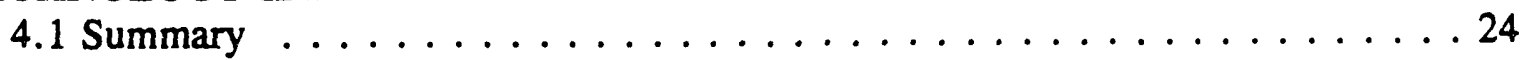

4.2 Reconstitution Technology . . . . . . . . . . . . . . . . 25

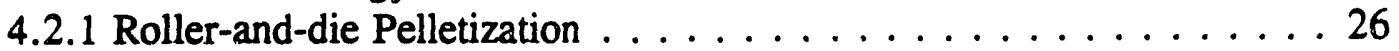

4.2.2 Disk Pelletization . . . . . . . . . . . . . . . . . 27

4.2.3 Extrusion Pelletization ................. 28

4.3 Pellet Testing and Acceptance Criteria . . . . . . . . . . . . . 29

4.3.1 Standard Quality Measures . . . . . . . . . . . . . . 29

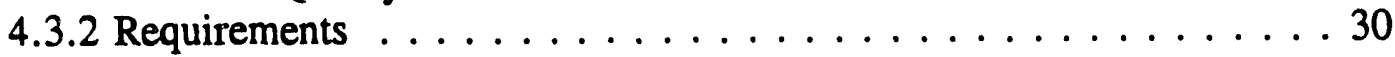

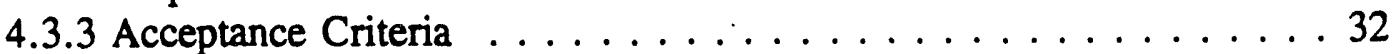

4.4 Reslurrying Tests and Acceptance Criteria $\ldots \ldots \ldots \ldots \ldots \ldots \ldots \ldots$

4.4.1 Standard Quality Measures . . . . . . . . . . . . . 33

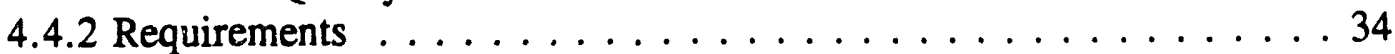

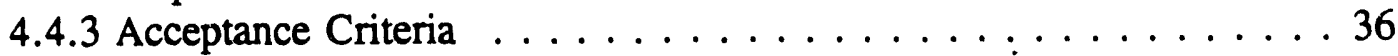

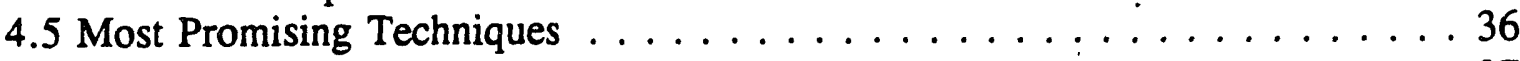

4.6 Section 4 References . . . . . . . . . . . . . . . . . . 37

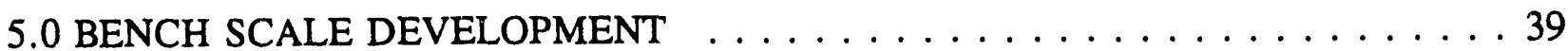

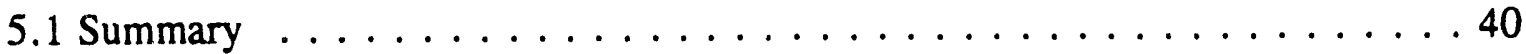

5.2 Pelletization Development $\ldots \ldots \ldots \ldots \ldots \ldots \ldots \ldots \ldots$ 


\section{TABLE OF CONTENTS}

Page

5.2.1 Roller-and-Die Pelletization ................. 41

5.2 .2 Disk Pelletization . . . . . . . . . . . . . . . . . 46

5.2 .3 Extrusion Pelletization . . . . . . . . . . . . . 51

5.3 Reslurrying Development . . . . . . . . . . . . . . . . . 54

5.3 .1 Slurry Formulation Methodology . . . . . . . . . . . . . 54

5.3 .2 Slurry Rheology . . . . . . . . . . . . . . . . . . . 54

5.3.3 Slurry Formulation- Temperature Effects ............ 58

5.3 .4 Mixing Technique Effects .................. 67

5.3.5. Dilution, Aging, and Dispersant Dosages Effects . . . . . . . 68

5.4 Initial Atomization Testing . . . . . . . . . . . . . . . 75

5.4.1 Atomization Test Procedure . . . . . . . . . . . . . . 75

5.5 Coals/Techniques/Binders Selected For Pilot Scale Testing . . . . . . . . . 78

5.6 Section 5 References . . . . . . . . . . . . . . . . . . . 79

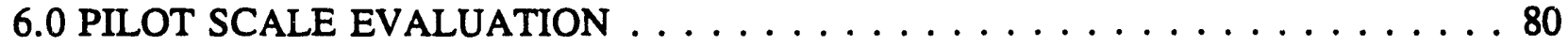

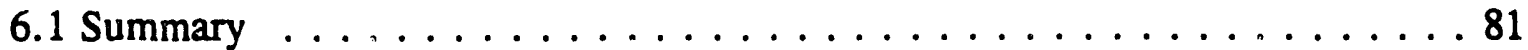

6.2 Pelletization Evaluation . . . . . . . . . . . . . . 81

6.2 .1 Binder Optimization . . . . . . . . . . . . . . . . . 82

6.2 .2 Roller-and-Die Pelletization . . . . . . . . . . . . . 83

6.2 .3 Disk Pelletization . . . . . . . . . . . . . . . . . . . 89

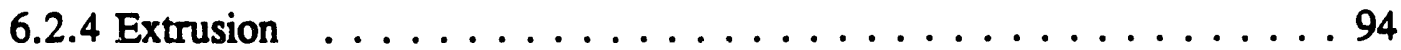

6.3 Reslurrying Evaluation . . . . . . . . . . . . . . . . . . 98

6.3.1 Slurry Formulation Amenability Tests . . . . . . . . . . . . . 100

6.3.2 Continuous "Pellet-to-Slurry" Demonstration . . . . . . . . . . . 106

Test 1 - Utah Coal Extrusion Pellets . . . . . . . . . . . . . . . . . . . . . . 110

Test 2 - Illinois No. 6 Coal Disk Pellets . . . . . . . . . . . . . . . . . . 114

Test 3 - Illinois No. 6 Roller-and-Die Pellets . . . . . . . . . . . . . . . . 114

Test 4 - Elkhorn Coal, Roller-and-Die Pellets . . . . . . . . . . . . . 115

6.4 Atomization Evaluation . . . . . . . . . . . . . . . . 116

6.4.1 Pilot-Scale Slurry Atomization . . . . . . . . . . . . 116

6.5 Section 6 References . . . . . . . . . . . . . . . . . . 118

7.0 TRANSPORTATION, HANDLING AND STORAGE . . . . . . . . . . . 119

7.1 Summary . . . . . . . . . . . . . . . . . . . 120

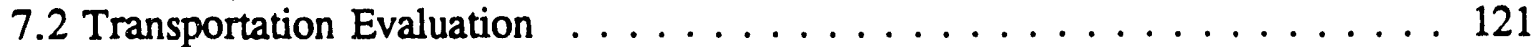

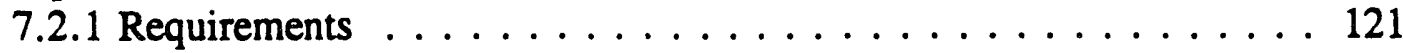

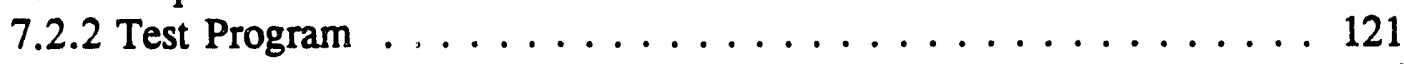

7.2 .3 Specifications . . . . . . . . . . . . . . . 126

xxiii 


\section{TABLE OF CONTENTS}

(Contents)

7.3 Handling and Storage Evaluation $\ldots \ldots \ldots \ldots \ldots \ldots \ldots \ldots \ldots$

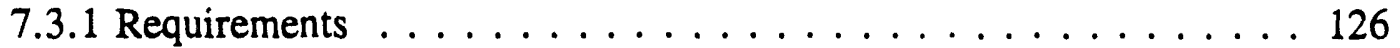

7.3.2 Test Program . . . . . . . . . . . . . . . . . 127

7.3.3 Storage Mode Selection . . . . . . . . . . . . . . 138

7.4 Spontaneous Combustion Characteristics $\ldots \ldots \ldots \ldots \ldots \ldots \ldots 148$

7.5 Section 7 References . . . . . . . . . . . . . . . . 150

8.0 UTILIZATION AND COMMERCIALIZATION $\ldots \ldots \ldots \ldots \ldots \ldots \ldots 151$

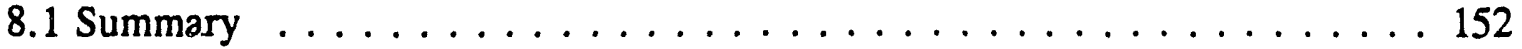

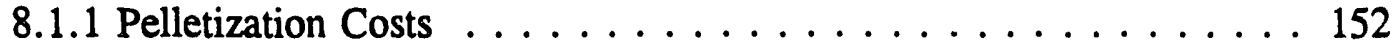

8.1.2 Coal Water Fuel Formulation Costs . . . . . . . . . 155

8.1.3 Transportation Costs . . . . . . . . . . . . . . . . 157

8.1.4 Storage and Handling Costs $\ldots \ldots \ldots \ldots \ldots \ldots . \ldots \ldots$

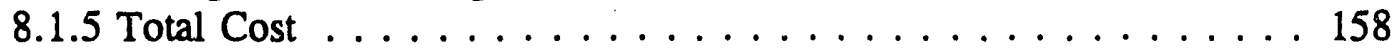

8.2 Pelletization Cost Assessment . . . . . . . . . . . . . . . 160

8.2 .1 Fixed Capital Estimate $\ldots \ldots \ldots \ldots \ldots \ldots$

8.2.3 Operating Cost Estimate $\ldots \ldots \ldots \ldots \ldots \ldots \ldots \ldots$

8.3 Reslurrying Cost Assessment $\ldots \ldots \ldots \ldots \ldots \ldots \ldots \ldots \ldots \ldots$

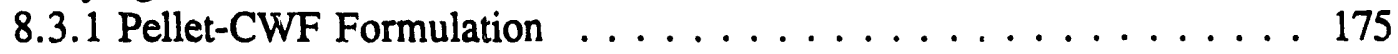

8.3.2 Capital Cost Estimates . . . . . . . . . . . . . . . 177

8.3.3 Operating Cost Estimates . . . . . . . . . . . . . . . 177

8.3.2 Direct-CWF Formulation . . . . . . . . . . . . . . . 187

8.4 Transportation, Handling and Storage Cost Assessment . . . . . . . . . 189

8.4.1 Pellet-C.WF Transportation . . . . . . . . . . . . . . . . 189

8.4.2 Direct-CWF Transportation . . . . . . . . . . . . . 190

8.4.3 Handling and Storage Cost for Pellet-CWF . . . . . . . . . 193

8.4.4 Handling and Storage Cost for Direct-CWF . . . . . . . . 193

8.5 Comparison of CWF Production Approaches . . . . . . . . . . . 194

8.5.1 Pellet-CWF Approach . . . . . . . . . . . . . . . . 196

8.5.2 Direct-CWF Approach $\ldots \ldots \ldots \ldots \ldots \ldots . \ldots \ldots$

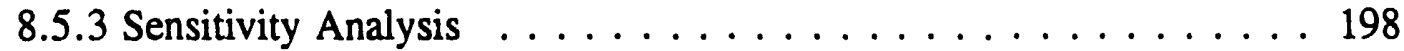

8.6 Section 8 References . . . . . . . . . . . . . . . . . . 214

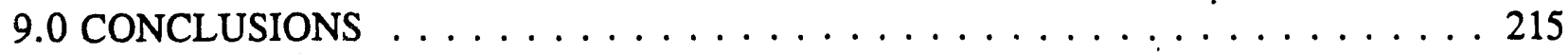

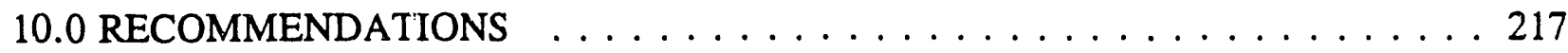

APPENDIX A PELLET TEST PROCEDURES

APPENDIX B RESLURRYING AMENABILITY TEST PROCEDURE 


\section{LIST OF TABLES}

Page

Table 3.1

Table 3.2

Table 3.3

Table 3.4

Table 3.5

Table 4.1

Table 4.2

Table 4.3

Table 5.1

Table 5.2

Table 5.3

Table 5.4

Table 5.5

Table 5.6

Table 5.7

Tabie 5.8

Table 5.9

Table 5.10

Table 5.11

Table 5.12

Table 6.1

Table 6.2

Table 6.3

Table 6.4

Table 6.5.

Table 6.6

Table 6.7

Table 8.1

Table 8.2

Table 8.3

Table 8.4

Table 8.5

Table 8.6

Table 8.7

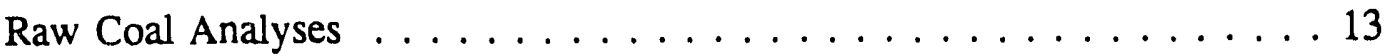

Clean Coal Analyses . . . . . . . . . . . . . . . . 14

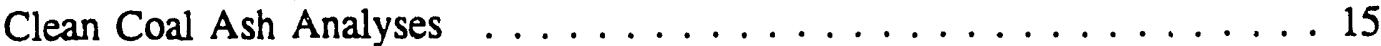

Clean Coal Particle Size Distribution $\ldots \ldots \ldots \ldots \ldots \ldots \ldots \ldots$

Flotation Conditions Used to Clean $\ldots \ldots \ldots \ldots \ldots \ldots \ldots \ldots \ldots$

Pellet Acceptance Criteria . . . . . . . . . . . . . . . . 33

Coal Slurry Fuel Specifications For Commerical/Industrial Combustion

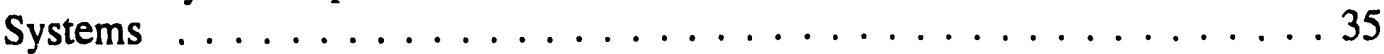

Coal Water Fuel Acceptance Criteria . . . . . . . . . . . . 36

Binders Evaluated in the Bench-Scale Pelletization Tests . . . . . . . 42

Elkhorn Coal Roller-and-Die Pellet Evaluation From Bench-Scale Tests . . 45

Elkhom Coal Disk Pellet Evaluation From Bench-Scale Tests . . . . . . 50

Elkhorn Coal Extrusion Pellet Evaluation From Bench-Scale Tests . . . . 53

CWF Formulation of Elkhorn Coal Roller-and-Die Pellets . . . . . . 55

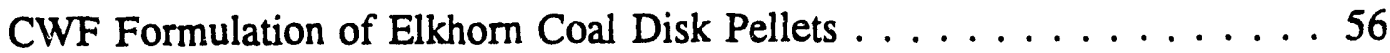

CWF Formulation of Elkhorn Coal Extrusion Pellets . . . . . . . . . 57

Effect of Heating on the Viscosity of Slurries Prepared From Illinois

No. 6 Pellets . . . . . . . . . . . . . . . . . . . . . . . 60

Effect of Blade Type on Slurry Production . . . . . . . . . . 68

Results of Dilution Tests on Reslurrying Illinois No. 6 Disk Pellets . . . . 70

Comparisons of Slurry Viscosities Before and After One-Month Storage . . 71

Effect of Incremental A-23 Additions on the Viscosity of Fresh Slurry

Prepared From Air-Dried Pellets Containing Corn Starch Binder . . . . . 71

Optimized Binder Dosage for Each Coal and Pelletization Process . . . . 82

Slurry Formulation Data for Illinois No. 6 Production Pellets . . . . . 101

Slurry Formualtion Data for Elkhorn Production Pellets . . . . . . . . 103

Slurry Formulation Data for Utah Production Pellets . . . . . . . . . 104

+48 Mesh Fragment Percentage Remaining After Pellet Conversion

Into CWF . . . . . . . . . . . . . . . . . . . . . . . 105

Amount of A-23 Dispersant Required to Prepare Quality Slurries as a

Function of Pelletization Method and Binder . . . . . . . . . . . 105

Continuous Slurry Production for Atomization Tests at Jim Walter

Resources . . . . . . . . . . . . . . . . . . . . 111

Annual Operating Cost Estimate for Processing Elkhorn Coal at 1,000

Dry Ton/Day Capacity . . . . . . . . . . . . . . . . 153

Process Assumptions Used in the Cost-Model . . . . . . . . . . . . . 163

Fixed Capital Investment Estimates for Roller-and-Die Pelletization . . . . 164

Fixed Capital Investment Estimates for Disk Pelletization . . . . . . . 165

Fixed Capital Investment Estimates for Extrusion Pelletization . . . . . . 165

Operating Cost Estimates for Roller-and-Die Pelletization . . . . . . . 172

Operating Cost Estimates for Disk Pelletization . . . . . . . . . . 173 


\section{LIST OF TABLES}

(Continued)

Page

Table 8.8

Table 8.9

Table 8.10

Table 8.11

Table 8.12

Table 8.13

Table 8.14

Table 8.15

Table 8.16

Table 8.17

Table 8.18

Table 8.19

Table 8.20

Table 8.21

Table 8.22

Table 8.23

Table 8.24

Table 8.25

Table 8.26

Table 8.27

Table 8.28

Operating Cost Estimates for Extrusion Pelletization . . . . . . . . . . . . 174

Fixed Capital Investment Estimates for CWF Formulation of Pellets . . . 178 Operating Costs Estimate for CWF Formulation of Roller-and-Die Pellets . . . . . . . . . . . . . . . . . . . . . . . . . . . . . . 180

Operating Cost Estimates for CWF Formulation of Disk Pellets . . . . . 181 Operating Costs Estimates for CWF Formulation of Extrusion Pellets . . 182 Direct CWF Capital Investment Costs as a Function of Plant Size . . . . . 187 Operating Cost Estimates for "Direct-CWF" Formulation of Clean Coal Filter-Cake . . . . . . . . . . . . . . . . . . . . 188 Truck Transportation Costs for Pellets . . . . . . . . . . . . . . . . . 190

Rail Transportation Costs for Pellets . . . . . . . . . . . . . . . . . . . . . 190 Truck Transportation Costs for CWF . . . . . . . . . . . . . . . . 191 Rail Transportation Costs for CWF . . . . . . . . . . . . . . . . . . 191 Handling and Storage Cost for Pellet-CWF Approach . . . . . . . . . . . 194 Handling and Storage Cost for Direct-CWF Approach . . . . . . . . . . . 194 Annualized Cost Estimate for Processing Elkhorn Coal at 1000 TPD (Dry) - (100 Miles Truck Transportation) . . . . . . . . . . . . . . . . . . . 199 Annualized Cost Estimate for Processing Elkhorn Coal at 1000 TPD (Dry) - (300 Miles Rail Transportation) . . . . . . . . . . . . . . . 200 Annualized Cost Estimate for Processing Illinois No. 6 Coal at 1000 TPD (Dry) - (100 Miles Rail Transportation) . . . . . . . . . . . . . . 201 Annualized Cost Estimate for Processing Illinois No. 6 Coal at 1000 TPD (Dry) - (300 Miles Rail Transportation) . . . . . . . . . . . . . . 202 Annualized Cost Estimate for Processing Utah Coal at 1000 TPD (Dry)-(100 Miles Rail Transportation) . . . . . . . . . . . . . . . . . 203 Annualized Cost Estimate for Processing Utah Coal at 1000 TPD (Dry)- (300 MILES RAI. TRANSPORTATION) . . . . . . . . . . . . . . . 204 Annualized Cost Estimate for Direct-CWF Approach for a 1000 TPD (Dry)- [100 Miles Truck Transportation] . . . . . . . . . . . . . . . . 206 Annualized Cost Estimate for Direct-CWF Approach for a 1000 TPD (Dry)- [300 Miles Rail Transportation] . . . . . . . . . . . . . . . 206 


\section{LIST OF FIGURES}

Page

Figure 1.1 Alternative Clean Coal Transportation, Storage, and Handling

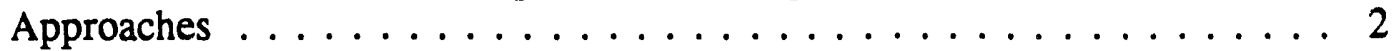

Figure 2.1 Pellet to Coal Water Fuel Concept $\ldots \ldots \ldots \ldots \ldots \ldots$

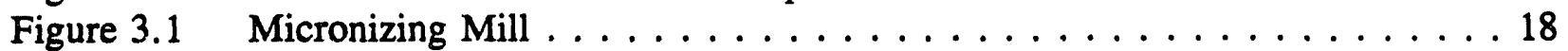

Figure 3.2 Conventional Froth-Flotation Pilot Plant $\ldots \ldots \ldots \ldots \ldots \ldots$

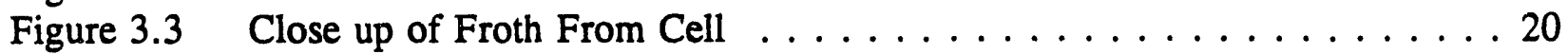

Figure 3.4 Filter Press for Micronized Coal Dewatering $\ldots \ldots \ldots \ldots \ldots \ldots 21$

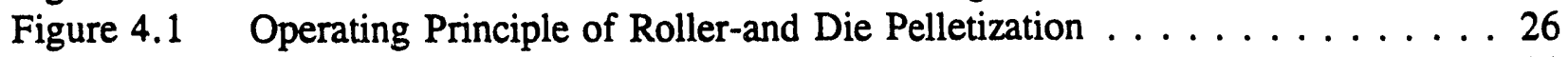

Figure 4.2 Operating Principle of Disk Pelletization $\ldots \ldots \ldots \ldots \ldots \ldots \ldots \ldots$

Figure 4.3 Operating Principle of Extrusion Pelletization $\ldots \ldots \ldots \ldots \ldots \ldots$

Figure 5.1 Laboratory Scale Roller-and Die Pellet Mill . . . . . . . . . . . . 43

Figure 5.2 Bench-Scale Roller-and-Die Pellets . . . . . . . . . . . . . . 43

Figure 5.3 Bench Scale Non-Inclined Disk Pelletization Unit . . . . . . . . . . . . 47

Figure 5.4 Model 100 Andritz Sprout-Bauer Disk Pelletizer . . . . . . . . . . . 48

Figure 5.5 Bench Scale Disk Pellets . . . . . . . . . . . . . . . . . . . 49

Figure 5.6 Bench Scale Bonnet Company Extrusion Pelletizer . . . . . . . . . . 52

Figure 5.7 Change in Relative Viscosity When Heating Slurry Prepared From

Illinois No. 6 Pellets Containing Lignin Sulfonate Binder . . . . . . . . 61

Figure 5.8 Change in Relative Viscosity When Heating Slurry Prepared from

Illinois No. 6 Pellets Containing Shur Bond Binder . . . . . . . . . 62

Figure 5.9 Change in Relative Viscosity When Heating Slurry Prepared from

Illinois No. 6 Pellets Containing Corn Starch Binder . . . . . . . . 63

Figure 5.10 Effect of Temperature on Normalized Relative Viscosity of Slurry Prepared from Pellets Containing Lignin Sulfonate Binder . . . . . . . . . 64

Figure 5.11 Effect of Temperature on Normalized Relative Viscosity of Slurry Prepared from Pellets Containing Shur Bond Binder . . . . . . . . . 65

Figure 5.12 Effect of Temperature on Normalized Relative Viscosity of Slurry Prepared from Pellets Containing Corn Starch Binder . . . . . . . 66

Figure 5.13 Effect of Small Dilutions on the Viscosity of Slurries Prepared from Air Dried and Oven Dried Illinois No. 6 Pellets Prepared with Corn

Starch Binder . . . . . . . . . . . . . . . . . . . . 72

Figure 5.14 Effect of Small Dilutions on the Viscosity of Slurries Prepared from Illinois No. 6 Pellets Prepared with Lignin Sulfonate and Shur Bond Binders . . . . . . . . . . . . . . . . . . . 73

Figure 5.15 Effect of Increased Dispersant Dosage on Viscosity of Slurries Prepared from Illinois No. 6 Pellets Containing Corn Starch Binder . . . . . . 74

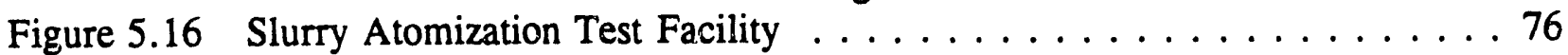

Figure 5.17 Closeup of Atomized Illinois No. 6 Pellet Slurry . . . . . . . . . . . 77

Figure 6.1 Pilot Scale Roller-and-Die Pelletizer . . . . . . . . . . . . . . . . 84

Figure 6.2 Illinois No. 6 Coal Pellet Production in the 1-Ton/Hr Pelletizer . . . . . 85

Figure 6.3 Utah Coal Pellets from Pilot Scale Pellet Production $\ldots \ldots \ldots . \ldots 86$ 


\section{LIST OF FIGURES}

(Continued)

Page

Figure 6.4 Representation of Roller-and-Die Pellet Uniformity . . . . . . . . . . 88

Figure 6.5 Pilot Scale Pellet Production Demonstration in the Model 1000 Disk

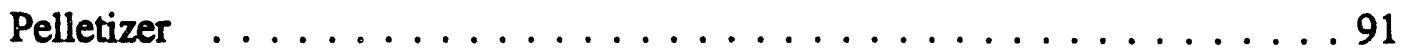

Figure 6.6 Pilot Scale Illinois No. 6 Coal Disk Pellets Produced with Corn Starch

Binder . . . . . . . . . . . . . . . . . . . .92

Figure 6.7 Representation of Disk Pellet Production Uniformity During Production . . 93

Figure 6.8 Pilot Scale Extrusion Pelletizer $\ldots \ldots \ldots \ldots \ldots \ldots 5$

Figure 6.9 Pilot Scale Extrusion Die . . . . . . . . . . . . . . . 95

Figure 6.10 Utah Coal Pilot Scale Extrusion Pellet Production . . . . . . . . . . 96

Figure 6.11 Photograph of the Lignin Sulfonate Bound Utah Coal Extrusion Pellets . . 97

Figure 6.12 Representation of Extrusion Pellet Uniformity During Production . . . 999

Figure 6.13 Schematic Representation of the "Pellet-to-Slurry" System . . . . . . . 107

Figure 6.14 Photograph of the 8-Gallon/hr Pellet-to-Slurry System . . . . . . . . . . 109

Figure 6.15 Particle Size Distribution of Test 1 Slurry . . . . . . . . . . . . 112

Figure 6.16 Particle Size Distribution of Test 2 Slurry . . . . . . . . . . . . 112

Figure 6.17 Particle Size Distribution of Test 3 Slurry $\ldots \ldots \ldots \ldots \ldots \ldots 113$

Figure 6.18 Particle Size Distribution of Test 4 Slurry . . . . . . . . . . . 113

Figure 6.19 SMD Variation with AFR for the Four Slurries . . . . . . . . . 117

Figure 7.1 Photograph of the Transportation Simulation Device . . . . . . . . . 123

Figure 7.2 Comparison of Fines Generated from Transportation Simulation Against

Truck Transportation . . . . . . . . . . . . . . . . . . . . 124

Figure 7.3 One Hour Transportation Simulation . . . . . . . . . . . . . . 125

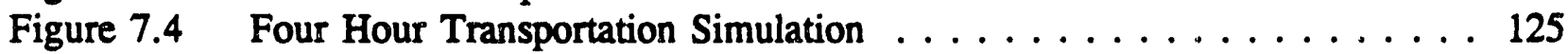

Figure 7.5 Exposed-Outdoor Storage Test-Site . . . . . . . . . . . . . . . . 128

Figure 7.6 Condition of Elkhorn-Corn Starch Roller-and-Die Pellets After (a) 2

Weeks and (b) 4 Weeks of Exposed-Outdoor Storage . . . . . . . . . . 129

Figure 7.7 Photograph of Elkhorn Coal Disk Pellet After Two Weeks of Storage . . 131

Figure 7.8 Photographs of the Cubicles for Covered-Outdoor Pellet Storage . . . . 133

Figure 7.9 Photograph of Elkhom Roller-and Die Pellets After Two Weeks of

Storage . . . . . . . . . . . . . . . . . . . . . . . . . . 134

Figure 7.10 Simulated Silo Columns for Pellet Storage Evaluation . . . . . . . . . 136

Figure 7.11 Elkhorn Roller-and-Die Pellets After Two Weeks of Storage in Silos . . 137

Figure 7.12 Pellet Storage in Super-Sack "Nylon" Bags . . . . . . . . . . . . . . . . 139

Figure 7.13 Condition of Elkhorn-Corn Starch Roller-and-Die Pellets After 2 Weeks of Bag Storage . . . . . . . . . . . . . . . . . . 140

Figure 7.14 Comparison of the Compressive Strengths of Illinois No. 6 Coal Pellets in Various Storage Modes After 4 Weeks . . . . . . . . . . 141

Figure 7.15 Comparison of Compressive Strengths of Elkhorn Coal Pellets in Various Storage Modes After 4 Weeks of Storage . . . . . . . . . 143 


\section{LIST OF FIGURES}

(Continued)

\section{Page}

Figure 7.16 Comparison of Compressive Strengths of Utah Coal Pellets in Various Storage Modes After 4 Weeks of Storage . . . . . . . . . . . . . . . . . 144

Figure 7.17 Two Week Storage Evaluation of Roller-and-Die Pellets Prepared with Corn Starch . . . . . . . . . . . . . . . . . . . . . . . . . . . . 145

Figure 7.18 Four Week Storage Evaluation of Roller-and-Die Pellets Prepared with Corn Starch . . . . . . . . . . . . . . . . . . . . . . . . . . 146

Figure 7.19 Illustration on the Effect of Pelletization Technique on Pellet Storage . . 147

Figure 7.20 Schematic of the Pellet Reactivity Test Set-Up . . . . . . . . . . . . . . . . 149

Figure 8.1 Pelletization Operating Cost by Technique and Plant Capacity . . . . . . 154

Figure 8.2 Reslurrying Operating Costs for Pellets and Filter-Cake By Cost Component ... . . . . . . . . . . . . . . . . . . 156

Figure 8.3 Coal Pelletization, Transportation, Storage, Handling and CWF Conversion Operating Costs Comparison for the Two Approaches . . . . . . . 159

Figure 8.4 Typical Flowsheet Prepared for Process Cost Estimation (Flowsheet for Roller-and-Die Pelletization Process) . . . . . . . . . . . . . . . . 161

Figure 8.5 Typical Output for Equipment Selection and Sizing Generated by the Cost-Model . . . . . . . . . . . . . . . . . . . . . . . . . . . . . . . 162

Figure 8.6 Fixed Capital Investment Profile for Pelletization of Elkhorn Coal _ . . 166 Figure 8.7 Operating Cost Estimates Sensitivity with Plant Size for Pelletization of Elkhorn Coal . . . . . . . . . . . . . . . . . . . . . . . . 168

Figure 8.8 Distribution of Operating Cost Elements for Pelletization of Elkhorn Coal at 50 TPD Capacity . . . . . . . . . . . . . . . . . 169

Figure 8.9 Distribution of Operating Cost Elements for Pelletization of Elkhom Coal at 250 TPD Capacity . . . . . . . . . . . . . . . . . . . . . . 170

Figure 8.10 Distribution of Operating Cost Elements for Pelletization of Elkhorn Coal at 1000 TPD Capacity . . . . . . . . . . . . . . . . . . . 171

Figure 8.11 Pellet-CWF and Direct-CWF Approaches for Clean Coal Transportation, Handling and Storage $\ldots \ldots \ldots$. . . . . . . . . . 176

Figure 8.12 Sensitivity of Fixed Capital Investment for Formulation of CWF From Pellets with Plant Size . . . . . . . . . . . . . . . . . . . . . . . 179

Figure 8.13 Operating Cost Distribution for Pellet-CWF Formulation in a 2 TPD Plant . . . . . . . . . . . . . . . . . . . . . 183

Figure 8.14 Operating Cost Distribution for Pellet-CWF Formulation in a 10 TPD Plant . . . . . . . . . . . . . . . . . . . . . . . . . . . . 184

Figure 8.15 Operating Cost Distribution for Pellet-CWF Formulation in a 50 TPD Plant . . . . . . . . . . . . . . . . . . . . . . . . . . . 185

Figure 8.16 Operating Cost for Pellet-CWF Formulation with Respect to Plant Size for Various Pellet Types . . . . . . . . . . . . . . . . 186 


\section{LIST OF FIGURES}

(Continued)

Page

Figure 8.17 Comparison of Transportation Cost for Pellet-CWF and Direct-CWF Approaches . . . . . . . . . . . . . . . . . . . . . . . . . . . . 192

Figure 8.18 Comparison of Storage and Handling Costs for Pellet-CWF and DirectCWF Approaches . . . . . . . . . . . . . . . . . . . . . . . . . . . 195

Figure 8.19 Flow Diagram to Estimate Total Operating Cost for the Pellet-CWF Approach . . . . . . . . . . . . . . . . . . . . . . . . . . . . . 197

Figure 8.20 Flow Diagram to Estimate Total Annualized Cost for the Direct-CWF

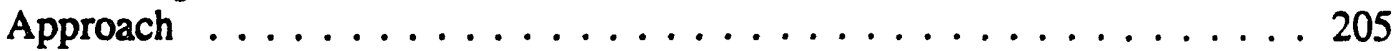

Figure 8.21 Comparison of the Two CWF Approaches for Elkhorn Coal for 100 mile Transportation . . . . . . . . . . . . . . . . . . . 207

Figure 8.22 Comparison of the Two CWF Approaches with Illinois No. 6 for 100 Mile Transportation . . . . . . . . . . . . . . . . . . . . . . . 208

Figure 8.23 Comparison of the Two CWF Approaches for Utah Coal for 100 Mile Transportation . . . . . . . . . . . . . . . . . . . . . . . . . 209

Figure 8.24 Total Annualized Cost Comparison for the Two Approaches as a Function of Transportation Distance for Elkhorn Coal Pellets from Rollerand-Die Pelletization ..................... 211

Figure 8.25 Total Annualized Cost Comparison for the Two Approaches as a Function of Transportation Distance for Illinois No. 6 Coal Pellets from Roller-and-Die Pelletization . . . . . . . . . . . . . . . . . . . 212

Figure 8.26 Total Annualized Cost Comparison for ine Two Approaches as a Function of Transportation Distance foi Utah Coal Pellets from Rollerand-Die Pelletization . . . . . . . . . . . . . . . . . . 213 


\section{LIST OF ABBREVIATION AND ACRONYMS}

$\begin{array}{ll}\text { AFR } & \text { Air to Fuel Ratio } \\ \text { ASTF } & \text { Air Spray Test Facility } \\ \text { BET } & \begin{array}{l}\text { Brunauer, Emmett, and Teller (equation for determination of surface area of an } \\ \text { absorbent such as coal) }\end{array} \\ \text { CPM } & \text { California Peliet Mill } \\ \text { CWF } & \text { Coal Water Fuel } \\ \text { DI } & \text { Durability Index } \\ \text { HGI } & \text { Hardgrove Grindability Index } \\ \text { JWRI } & \text { Jim Walter Resources Incorporated } \\ \text { MIBC } & \text { Methyl Isobutyl Carbinol } \\ \text { MMD } & \text { Mass Mean Diameter } \\ \text { RDI } & \text { Ro-Tap Durability Index } \\ \text { SMD } & \text { Sauter Mean Diameter } \\ \text { TPD } & \text { Ton Per Day } \\ \text { UFUC } & \text { Ultra Fine Ultra Clean } \\ \text { WI } & \text { Weatherability Index } \\ & \\ \text { H } & \end{array}$




\section{LIST OF DEFINITIONS}

A-23

cP

Dilatant

Flocon

MIBC

Near Newtonian

Newtonian

Pseudoplastic

Shur Bond

Thixotropic

Allbond 200

Lignosite
A CWF dispersant consisting of an aqueous ammonium salt of a naphthalene sulfonate distributed by the Henkel Corp.

Centipoise (unit of viscosity)

A rheological description of slurry behavior, specifically if viscosity at $1,000 \mathrm{sec}^{-1}$ shear rate is more than 1.5 times the viscosity at $100 \mathrm{sec}^{-1}$ shear rate, i.e., shear thickening

A CWF stabilizer consisting of xanthan gum distributed by Pfizer Chemical Company

Methyl isobutyl carbinol, a frothing agent used in flotation coal cleaning

A rheological description of slurry behavior, specifically if viscosity at $1,000 \mathrm{sec}^{-1}$ shear rate is between 0.8 and 1.5 times the viscosity at 100 $\sec ^{-1}$ shear rate

A rheological description of slurry behavior, specifically when viscosity is insensitive to changes in shear rate

A rheological description of slurry behavior, specifically if viscosity at $1,000 \mathrm{sec}^{-1}$ shear rate is less than 0.8 times the viscosity at $100 \mathrm{sec}^{-1}$ shear rate, i.e., shear thinning

A water-petroleum emulsion binder distributed by Sherex Chemical Company

A rheological description of slurry behavior, specifically when the viscosity changes as a function of time at a constant shear rate; slurry viscosity typically drops after extended shear periods

A pre-gelatinized corn starch binder distributed by the Lauhoff Grain Company

A calcium lignin sulfonate binder distributed by Georgia Pacific 


\section{Final Report}

Contract No. DE-AC22-90PC90166

on

\section{PELLETIZING/RESLURRYING AS A MEANS OF DISTRIBUTING AND FIRING CLEAN COAL}

by

H.N. Conkle, J.K. Raghavan, F.J. Smit, and M.C. Jha

\subsection{INTRODUCTION}

The Pittsburgh Energy Technology Center (PETC) is supporting the development of processes that can produce beneficiated coal products that have significantly reduced levels of ash and pyritic sulfur. A coordinated effort has been made by PETC to develop systems for transporting, storing and handling these products. A number of physical coal cleaning processes yield wet filter cake, which is intractable to handling and is susceptible to freezing conditions during transport and storage. Therefore, alternative product forms have been considered to facilitate the storage and movement of beneficiated coals. One such form is the pellet, which is a candidate for handling and transporting in equipments of conventional design. For maximum viability, pellets should be prepared in such a way that they could be easily converted to a form that is desired at the point of use. The need to find an efficient and economic solution to the transportation, handling, and stor?.ge problem was the basis for the DOE contract with Battelle.

Battelle and AMAX proposed to convert the wet filter cake into low moisture coal pellets which could be transported, stored and handled like lump coal then converted into a coal water fuel (CWF) at the point of use (Pellet-CWF approach). This approach provided an alternative to the standard CWF route where the filter cake is converted at the preparation plant site into a slurry (Direct-CWF approach). The Pellet-CWF and conventional-CWF preparation, transportation, handling and storage approaches are illustrated in Figure 1.1. 


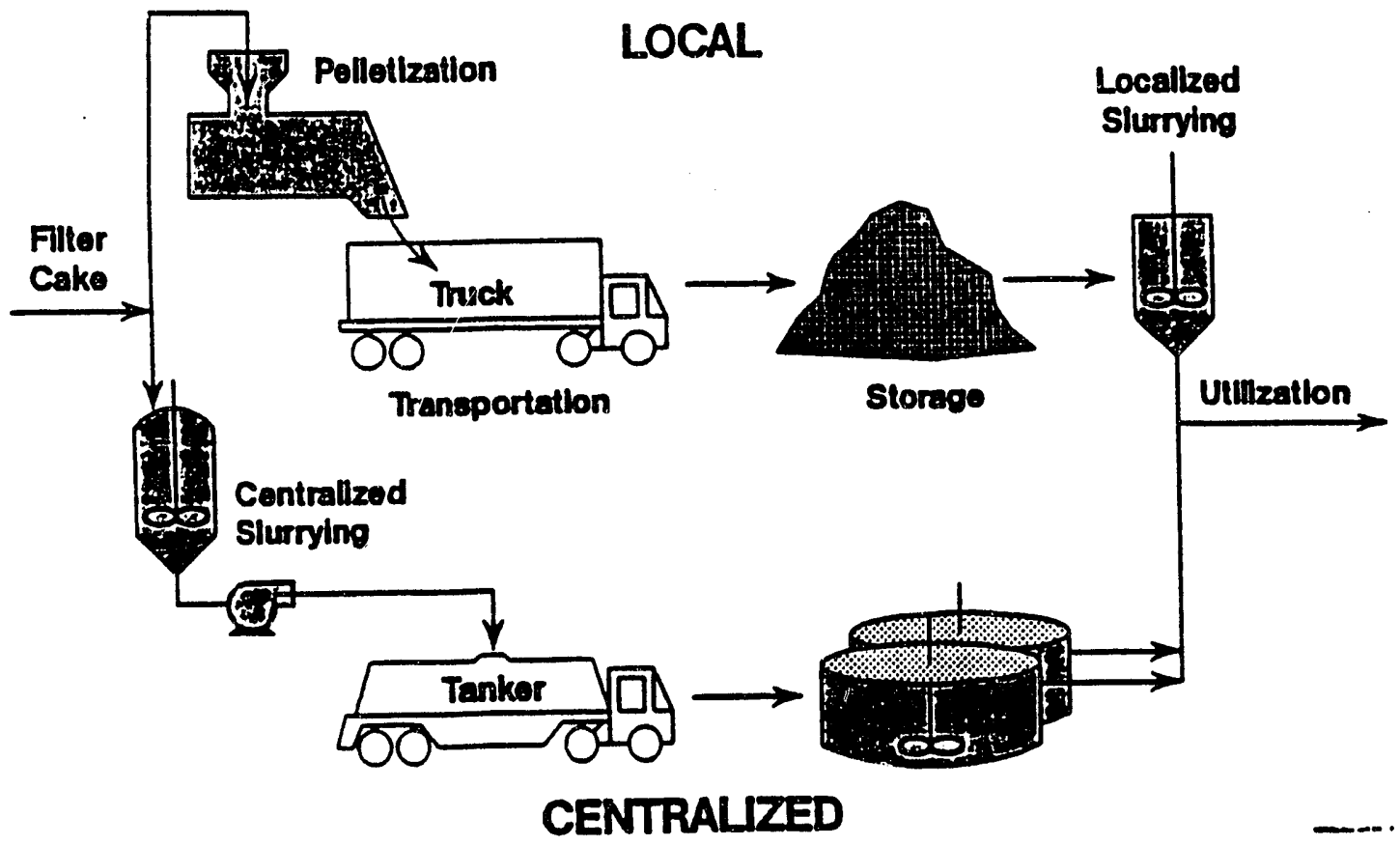

FIGURE 1.1. ALTERNATIVE CLEAN COAL TRANSPORTATION, STORAGE, AND HANDLING APPROACHES

\subsection{Objective}

The objective of this program was to develop the technology that is economical for:

- Producing clean coal pellets from wet filter cake

- Transporting, storing and handling these pellets

- Reslurrying the pellets at the point of utilization to form CWF with properties suitable for pumping, atomizing, and firing.

The overall focus of the research was to displace oil used in small- and medium-size commercial and industrial boilers, furnaces, and engines with clean coal water slurries. 


\subsection{Approach}

The approach taken in this program was to integrate the pelletizing and reslurrying technologies, by selecting binders that produced strong pellets and could subsequently assist in the formation of coal-water fuels (CWF). Specifically, the experimental part of this project was designed to identify the effect of coal types, binder types, and pelletization techniques on ultra-fine, ultra-clean coal pellets' transportation, handling, storage and CWF conversion properties.

The program began with the identification of appropriate reconstitution techniques and binders, quality testing procedures, establishment of acceptance criteria, and a bench-scale experimental development program. Battelle emphasized two approaches to prepare coal pellets. The first approach was the use of an internal binder to prepare pellets having sufficient strength to be transported, handled and stored in a manner similar to raw coal. The second approach was to prepare low-cost pellets by accepting a lower strength and the need for specialized transportation, handling and/or storage. A second part of the effort was the development of a pellet that could be readily converted into a CWF. Therefore, preference was given to binders that would contribute to the production of a suitable slurry.

Once successful pelletization techniques were identified, which also permitted the preparation of CWF with low viscosity, and stable CWF behavior, the best formulations were selected for pilot-scale evaluation. Tests included multi-ton lot pellet productions using three different pelletization techniques, two (and in some cases three) different binders, and three bituminous coals. CWF evaluations were also made to confirm that the pilot-scale pellets could also be converted into acceptable CWF. Some of these pellets were also formulated into CWF in a continuous mode in a "pellet-to-slurry" system. The slurries were evaluated for atomization characteristics. 
Next, extensive transportation, handling, and storage testing was conducted to determine if coal pellets could survive the harsh conditions similar to raw lump coal. Testing was conducted over the winter months so pellets were subjected to cold temperatures, rain, snow, freezing and thawing conditions. Extended storage tests of exposed and covered pellets prepared with different binders and pelletization techniques were conducted.

Finally, to evaluate the economics of the Pellet-CWF approach, binder requirements and CWF additive dosage data were combined with information on 1) pelletization costs, 2) CWF formulation costs, 3) transportation costs, and 4) handling and storage costs to estimate total system costs. The estimated Pellet-CWF capital and operating costs were estimated for different coals, plant sizes, and different transportation distances when employing the selected binders and pelletization techniques. These costs were compared with conventional CWF preparation, transportation, and handling costs prepared from similar coals, for similar applications and transportation distances.

\subsection{Scope of Work}

The project activities includes the following 10 tasks:

- Task 0. Acquire Coal - which consisted of obtaining ultra-fine, ultraclean coal for the research and development efforts. Suitable material could not be provided by DOE; therefore, an additional task (Task 9) was added to the program to acquired and beneficiate the required coal.

- Task 1. Identify Technology - which consisted of identifying and selecting the most promising pelletization and CWF formulation techniques and testing procedures, and establishing acceptance criteria to judge the quality of pellets and slurry produced from pellets. 
- Task 2. $\quad$ Prepare and Test Small Batches - which consisted of preparing small batches of pellets, Pellet-CWF, and filter cake/CWF; performing atomization testing on the Pellet-CWF and filter cake/CWF; and selecting the preferred techniques for pilot-scale evaluation.

- Task 3. Prepare Bench/Pilot-scale Pellets - which consisted of preparing several tons of pellets from three different coals using three different pelletization techniques, following the preferred binder type/dosage levels established in Task 2.

\section{Tasks 4, 5, Evaluate Transportation, Handling and Storage} and 6

Characteristics - evaluated the effectiveness of physical property specifications included in the acceptance criteria for the prediction of pellet survivability when subjected to actual transportation, handling and storage trials.

- Task 7. Reslurry Pellets and Evaluate CWF - which consisted of reslurrying the pilot-scale pellets and performing atomization tests to confirm that Pellet-CWF could meet the CWF acceptance criteria.

- Task 8. Utilization/Commercialization - which consisted of establishing process flowsheets for the three pelletization techniques and estimating the costs to commercially produce pellets; transport, handle, and store the pellets; and reslurry them into CWF at the point of utilization. Costs were compared with conventional CWF preparation, transportation, handling, and storage costs.

- Task 9. $\quad$ Prepare Additional Cake - which consisted of an optional task, added after the project was started to acquire, ultra-fine grind, flotation beneficiate the three project coals, and ship the clean coal filter cake to Battelle for pelletization testing. 


\subsection{Contents of This Report}

This final report summarizes the major findings of this research effort. It is organized into the following 9 sections:

Section 1 - Introduction

Section 2 - Technology Description

Section 3 - Test Coals

Section 4 - Technology Identification and Acceptance Criteria

Section 5 - Bench Scale Development

Section 6 - Pilot Scale Evaluation

Section 7 - Transportation, Handling and Storage

Section 8 - Utilization and Commercialization

Section 9 - Conclusions

Section 10 - Recommendations.

Since some sections are lengthy and contain voluminous amounts of data, experimental results, and analysis, the work objectives are restated along with an extended summary at the beginning of each section to provide a quick overview of the important results and conclusions. 


\subsection{TECHNOLOGY DESCRIPTION}

Several advanced coal preparation techniques, designed to clean -100 mesh to -325 mesh sized coal particles, have been developed in recent years. Nearly all the techniques involve the use of an aqueous medium and produce a relatively high moisture filter cake. The clean coal must be transported from the preparation plant to the user. Typically for the -28 mesh flotation product produced in many operational cleaning plants, the filter cake is mixed with more coarsely sized clean coal and sent directly to the user via rail or truck. (Some is also dried prior to being mixed with the coarse product.) For many anticipated future needs nearly all the plant production must be pre-ground to fine sizes in order to obtain the necessary removal of sulfur or ash. In these cases, direct transport of the fine coal filter cake is nist an acceptable solution -- either from a technical or environmental point of view. Two filter cake conversion alternatives are generally regarded as most feasible:

- Conversion to Coal Water Fuel (CWF)

- Conversion to pellets or briquettes.

Transportation of CWF in a special slurry pipeline would provide both a technicaily acceptable and also an economic solution. ${ }^{(1)}$ However, pipelines for such service do not exist, nor are they like to become into widespread use in the foreseeable future. Tanker truck or tanker rail-car transportation has been demonstrated and is considered technically

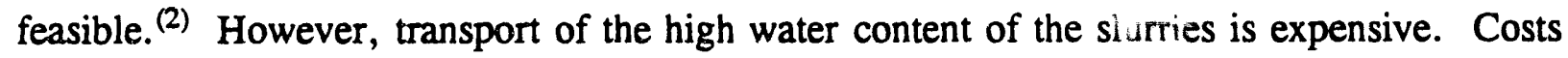
are typically twice the lump coal transportation and handling costs. ${ }^{(3)}$ Therefore, an effective and economic alternative is needed.

Pelletization or briquetting has been suggested as a solution to the general fine-coalhandling-and-transportation problem for years. The pelletization process and binders used must not, however, interfere with the ultimate end use of the coal. Since in this project the planned end use is as CWF, the pellets should be amenable to further conversion into slurry. This presents a significant technical challenge. The pellets must meet two simultaneous objectives; they must: 
(1) Meet physical requirement to allow storage and handling

- Strong

- Resistant to disintegration during transportation, handling and storage

- Weatherproof

(2) Meet end use requirements

- Readily crushed and ground to ine sizes

- Easily mixed with water to form a low viscosity, stable fuel, without requiring excessive amourts of chemical dispersants or stabilizers.

Battelle and Amax R\&D have developed the technology to simultaneous solve these two seemingly conflicting objectives.

\subsection{Pelletization/Reslurrying Concept}

In the Pellet-CWF concept the fine coal filter cake is mi vd with biriders and converted into pellets. After cooling and/or curing, the pellets cbtain a high degree of strength and durability. Proper selection of the processing conditions, binder type and dosage allowed production of pellets with properties approaching thuse of raw lump coai. The pellets could be handled and stored at the production site until they were ready for transportation to the user. At the end-user's site pellets must again be handled (i.e., unloaded from truck or train and moved to the storage yard) and storid (in a manner similar to lump coal or under cover) until use. The pellets are then loaded into a feed bin, mixed with water and dispersant, converted into CWF, ard pumped to the boiler feed tank. Because the coal water slurry is to be formulated only a few hours before use, the need for stabilizer (to prevent settling during extended storage) was completely eliminated. Also, some of the ultra-fine coal remained micro-agglomerated even after disintegration in the CWF reslurrying tank. This provided a broader particle size distribution which was better matched to the distribution needed for highly loaded CWF and allowed a lower dispersant dosage in the reslurrying process. The Pellet-CWF concept is shown in Figure 2.1. 


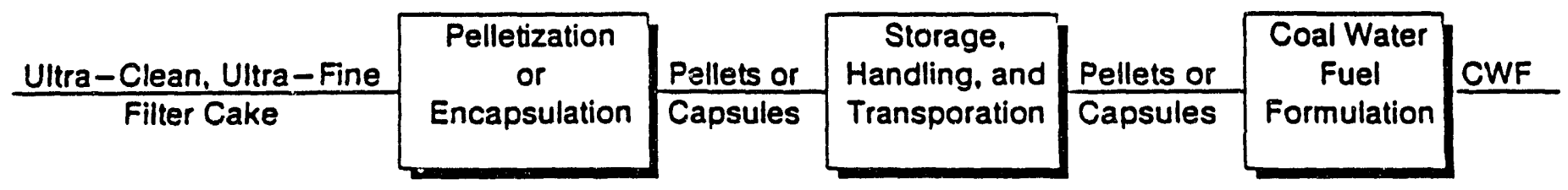

FIGURE 2.1. PELLET TO COAL WATER FUEL CONCEPT

In contrast, in the direct CWF approach, ultra-fine, ultra-clean coal is conveyed to a mixing station where dispersants and stabilizers are added. The slurry will then be pumped to an on-site holding tark until loaded into tanker cars for transport to the end user's facility. At the site, the slurry will be pumped from the tanker to a storage tank, and as needed to the boiler feed tank. In this approach, stabilizers are absolutely necessary to maintain the slutry in suspension during transportation to, and storage at, the users site. Also, an increased dispersant dosage is necessary to compensate for the very fine coal particles and the narrow' disti Jution of the coal particles, and the presence of stabilizers.

\subsection{Results Achieved Prior to this Project}

The profuction of coal pellets from coarse (i.e., -28 mesh) coal has been jemonstrated by a number of reseathers. Various techniques including roller-and-die, disk, and extrusion pelletization have been evaluated. Briquetting has been used for dry, or low moisture, coal reconstitution applications; briquetting, however, is not well suited for the high moisture fine-coal filter cake.

Battelle, through its previous projects has demonstrated technical. feasibility, but economics for reconstitution were a major factor in limiting applications. High reconstitution costs, ranging from $\$ 22$ to $\$ 29 /$ ton $^{(4)}$, have been cited as a major constraint. It did not appear that the benefits from reconstitution could justify the cost. However, today with the ever increasing quantity of fines being generated, especially from advanced preparation techniques, more extensive underground mining operations, and environmental pressures to prevent acid leaching and run off from coal-fines piles, some producers are re-examining the 
reconstitution option. Currently, there are at least two commercial roller-and-die pelletization operations in the United States. These plants normally produce over 30 thousand tons of pellets from coal fines each year. ${ }^{(5)}$ Two additional roller-and-die coal pelletization facilities are now being planned.

However, research for pelletizing ultra-fine (95 percent -325 mesh) and ultra-clean coal is more limited. Additionally, the technology to convert the coal pellet easily into CWF is unprecedented. If a successful, economical process could be developed this could provide a new solution to the growing transportation, handling and storage problem facing both current and future advanced-technology coal preparation plant operators.

\subsection{Anticipated Benefits}

Fine coal pelletization is expected to allow: ${ }^{(6)}$

- Increased preparation plant production -- since all the clean coal could be sold (typically 10 or more percent of the production is too fine for sale)

- Enrironmentally acceptable transportation of fine and ultra-fine coal

- Dust-free storage

- Coal handling that avoids the problems associated with high-moisture fines, and freezing

- Modified coal physical properties (increased ash fusion temperature, lower free swelling index) and modified chemical properties (allowing in-situ sulfur capture during combustion or gasification) by incorporation of additives. ${ }^{(3,7)}$

The Pellet-CWF has several benefits, particularly substitution in boiler originally designed for firing oil. The ultra-fine coal pellets could be handled as lump coal and not as a high-moisture, oil-like liquid. The benefits include:

- Elimination of stabilizer requirements in the CWF (needed to prevent the coal from settling during extended storage)

- Reduction in transportation costs (since the fuel moisture content is reduced from 45 percent to 10 percent through pelletization) 
- Reduction of freezing problems (otherwise encountered with CWF handling/storage)

- Simplification of storage requirer..ents (since the coal pellets can be stored as lump coal, whereas CWF is stored in heated, agitated slurry tanks)

- Prevention of bacterial action (bacteria frequently attack the CWF additives during extended slurry storage, ultimately promoting segregation and settling and increasing slurry viscosity).

\subsection{Section 2 References}

1. Brandle, U. et. al., "CWS (DENSECOAL) from North America for the Foreign Market," Proceedings of the 16th International Conference on Coal \& Slurry Technology, Clearwater, Florida, April 22-25, 1991, pp 229-238.

2. Miller, B. G., and Scaroni, A. W., "Penn State's Superclean Coal-Water Slurry Demonstration Program," Proceedings of the 17th International Conference on Coal \& Slurry Technology, Clearwater, Florida, April 28-May 1, 1992, pp 341-352.

3. Private Communication, Frank Smit, Amax R\&D, April, 1992.

4. Conkle, H. N., Dawson, W. J., and Rising, B. W., "Reconstitution of Coal and Limestone for Use in Industrial Stoker Boilers", paper presented at the 18th Biennial Conference of the Institute of Briquettes and Agglomeration, Colorado Springs, Colorado (August 8-10, 1983).

5. Private Conversation, Bob Mulligan, Pyro Mining Company, January, 1992.

6. Conkle, H. N., Raghavan, J. K., Jha, M. C., and Smit, F. J., "Pelletizing and Reslurry Characteristics of Ultrafine Coal," Proceedings of the 22nd Biennial Conference of The Institute of Briquetting and Agglomeration, San Antonio, Texas, November 4-6, 1991.

7. Rising, B. W., Conkle, H. N., Dawson, W. J., and Litt, R. D., "Advanced Development of a Coal-Limestone Fuel Pellet for Industrial Boilers," Final Report prepared by Battelle Memorial Institute for the U.S. Environmental Protection Agency, Contract No. 68-02-3189, 1983. 


\subsection{TEST COALS}

This section describes work on Task 0 and Task 9 devoted to the acquisition and preparation of ultra-fine, ultra-clean (UFUC) coal filter-cake. Initially the DOE had planned to supply the coal filter-cake from the DOE-EPRI advanced cleaning cooperative development program. Suitable materials were not available, hence a new task was added (Task 9) to acquire raw coal, grind to 95 percent -325 mesh, and clean to remove most of the ash and pyritic sulfur by froth flotation.

Three bituminous coals were selected from three different geographical areas. The coals were:

- Elkhorn bituminous coal (Westmoreland Coal Company, Wentz No. 1 Mine, Virginia): $1000 \mathrm{lb}$ (dry basis) clean coal prepared by Virginia Polytechnic Institute and 5,700 lb prepared by Amax R\&D, respectively

- Illinois No. 6 bituminous coal (Amax Coal Company, Delta Mine, Illinois):

6,050 lb (dry) clean coal prepared by Amax R\&D

- Utah bituminous coal (Coastal Corp., Utah Fuels Company, Sky Line Mine):

$6,150 \mathrm{lb}$ (dry basis) clean coal prepared by Amax R\&D.

\subsection{Analyses}

The proximate analysis, Hardgrove Grindability Index, equilibrium moisture, and oxidation index were determined for each raw coal (prior to cleaning) and are shown on Table 3.1. Each cleaned coal was analyzed for proximate analysis, oxidation index, and sulfur forms, see Table 3.2; ash fusion temperatures, ash analysis, see Table 3.3; and particle size distribution, and BET surface area, see Table 3.4. A description of the Amax R\&D froth flotation cleaning procedures is presented below. 
TABLE 3.1. RAW COAL ANALYSES

\begin{tabular}{||l|c|c|c|}
\hline \multirow{2}{*}{ Analysis } & \multicolumn{3}{|c|}{ Coal Type } \\
\cline { 2 - 4 } & Elkhorn & Illinois No. 6 & Utah \\
\hline Proximate Analysis, \% dry & & & \\
\hline Volatile Matter & 36.22 & 36.87 & 46.57 \\
\hline Fixed Carbon & 61.71 & 52.49 & 46.75 \\
\hline Ash & 3.07 & 10.64 & 6.68 \\
\hline Moisture, \% As Received & 1.39 & 7.44 & 9.49 \\
\hline Heating Value, Btu/lb dry & 15,009 & 13,139 & 13,273 \\
\hline Sulfur, \% dry & 0.59 & 2.78 & 0.67 \\
\hline Hardgrove Grindability Index & $47 @ 0.88$ & $55 @ 3.88$ & 53 @ 4.03 \\
at noted moisture & & & 7.1 \\
\hline Equilibrium Moisture, \% & 2.1 & 6.7 & 91.6 \\
\hline Oxidation Index (a) & 98.5 & 98 & \\
\hline
\end{tabular}

(a) US Steel technique: coal is boiled in a caustic solution that dissolves the oxidized coal and darkens the solution. The solution is then tested for light transmittance, with the transmittance decreasing with increased coal oxidation. A coal with an transmittance less than 80 percent is considered too oxidized for metallurgical use in most by-product coking operations. 
TABLE 3.2. CLEAN COAL ANALYSES

\begin{tabular}{||l|c|c|c|}
\hline \multirow{2}{*}{ Analysis } & \multicolumn{3}{c|}{ Coal Type } \\
\cline { 2 - 4 } & Elkhorn & Illinois No. 6 & Utah \\
\hline Proximate Analysis, \% dry & & & \\
\hline Volatile Matter & 36.88 & 38.88 & 49.02 \\
\hline Fixed Carbon & 61.34 & 56.77 & 48.32 \\
\hline Ash & 1.48 & 4.35 & 2.66 \\
\hline Moisture, \% As Received & 12.03 & 39.62 & 41.42 \\
\hline Heating Value, Btu/lb, dry & 14,632 & 13,918 & 13,708 \\
\hline Alkalies as Sodium Oxide, \% dry & Not Determined & 0.09 & 0.06 \\
\hline Oxidation Index & 98 & 91 & $59.4^{(\mathbf{a})}$ \\
\hline Sulfur Forms, \% dry & & & \\
\hline Total & 0.59 & 2.08 & 0.51 \\
\hline Pyritic & 0.04 & 1.13 & 0.04 \\
\hline Sulfate & 0.01 & 0.03 & 0.01 \\
\hline Organic (by Difference) & 0.55 & 0.92 & 0.46 \\
\hline
\end{tabular}

(a) The low oxidation index indiciates the Utah is much more highly oxidized than the other two bituminous coals included in this study. It may also be indicative of a younger coal, closer to subbituminous than bituminous coal. 
TABLE 3.3. CLEAN COAL ASH ANALYSES

\begin{tabular}{|c|c|c|c|}
\hline \multirow[b]{2}{*}{ Analysis } & \multicolumn{3}{|c|}{ Coal Type } \\
\hline & Elkhorn & Illinois No. 6 & Utah \\
\hline \multicolumn{4}{|l|}{$\begin{array}{l}\text { Ash Fusion Temperatures, F } \\
\text { Reducing/Oxidizing }\end{array}$} \\
\hline Initial Deformation & $2340 / 2655$ & $1930 / 2425$ & $2000 / 2230$ \\
\hline Softening & $2460 / 2700+$ & $2130 / 2490$ & $2025 / 2265$ \\
\hline Hemispherical & $2580 / 2700+$ & $2275 / 2545$ & $2050 / 2300$ \\
\hline Fluid & $2700 / 2700+$ & $2430 / 2600$ & $2070 / 2325$ \\
\hline \multicolumn{4}{|l|}{$\begin{array}{l}\text { Analysis of Ash, \% of Ash, dry } \\
\text { basis }\end{array}$} \\
\hline Silicon dioxide & 37.40 & 45.24 & 26.52 \\
\hline Aluminum oxide & 26.11 & 19.88 & 13.08 \\
\hline Titanium dioxide & 2.70 & 2.04 & 1.26 \\
\hline Iron oxide & 21.45 & 25.73 & 20.23 \\
\hline Calcium oxide & 3.84 & 2.14 & 14.85 \\
\hline Magnesium oxide & 1.52 & 1.06 & 2.48 \\
\hline Potassium oxide & 1.98 & 2.57 & 0.58 \\
\hline Sodium oxide & 1.35 & 0.27 & 1.86 \\
\hline Sulfur trioxide & 1.64 & 0.54 & 17.84 \\
\hline Phosphorus pentoxide & 0.30 & 0.18 & 0.41 \\
\hline Strontium oxide & Not Determined & 0.12 & 0.56 \\
\hline Barium oxide & ND & 0.06 & 0.13 \\
\hline Magnesium oxide & ND & 0.17 & 0.20 \\
\hline Undetermined & 1.71 & 0.00 & 0.00 \\
\hline Silica Value & ND & 61.00 & 41.39 \\
\hline Base:Acid Ratio & ND & 0.47 & 0.98 \\
\hline $\mathrm{T}_{250}$ Temperature, $\mathrm{F}$ & ND & 2333 & $<2150$ \\
\hline Type of Ash & ND & Bituminous & Bituminous \\
\hline Fouling Index/Slagging Index & ND & $0.13 / 0.98$ & $1.82 / 0.50$ \\
\hline
\end{tabular}


TABLE 3.4. CLEAN COAL PARTICLE SIZE DISTRIBUTION

\begin{tabular}{|c|c|c|c|}
\hline \multirow[b]{2}{*}{ Particle Size, $\mu \mathrm{m}^{(\mathrm{a})}$} & \multicolumn{3}{|c|}{$\begin{array}{c}\text { Coal Type } \\
\text { (Weight Passing, \%) }\end{array}$} \\
\hline & Elkhorn & Illinois No. 6 & Utah \\
\hline 75 & 99.32 & 99.87 & 99.97 \\
\hline 53 & 98.97 & 99.58 & 99.85 \\
\hline 45 & 98.54 & 98.89 & 99.58 \\
\hline 38 & 97.93 & 98.56 & 99.38 \\
\hline 30 & 96.03 & 96.14 & 94.2 \\
\hline 20 & 87.99 & 80.03 & 81.24 \\
\hline 15 & 76.37 & 69.89 & 69.79 \\
\hline 10 & 62.91 & 46.27 & 50.69 \\
\hline 8 & 54.24 & 32.75 & 39.8 \\
\hline 6 & 43.35 & 17.93 & 29.21 \\
\hline 4 & 29.80 & 7.45 & 18.96 \\
\hline 3 & 20.82 & 4.16 & 13.36 \\
\hline 2 & 12.20 & 2.24 & 7.24 \\
\hline 1 & 3.06 & 0.81 & 1.39 \\
\hline $\begin{array}{l}\text { Mass Mean Diameter, } \\
\mu \mathrm{m}^{(\mathrm{b})}\end{array}$ & 10.7 & 13.3 & 12.4 \\
\hline $\begin{array}{l}\text { Specific Surface Area (BET), } \\
\mathrm{m}^{2} / \mathrm{g}^{(\mathrm{c})}\end{array}$ & 5.2 & 11.0 & Not Determined \\
\hline
\end{tabular}

(a) Combination of sieving and SediGraph determinations

(b) Calculated from particle size distribution

(c) Multi-point nitrogen absorption/BET determination at $-320 \mathrm{~F}$ (-196 C) on air dried filter cake outgassed at $117 \mathrm{~F}$ under vacuum. 


\subsection{Beneficiation}

The raw coals were received, preground through a crusher, a ball mill, and then reduced to final micronized size using a 40-liter Draiswerke stirred ball mill. The slurry was diluted to 2 to 3 percent solids, mixed with diesel oil collector and MIBC, or Dowfroth frother and fed to two banks in series of conventional pilot-scale flotation cells. The product coal froth was collected in a holding tank and subsequently dewatered in an Eimco Shriver Press. The cleaning equipment is shown in Figures 3.1 through 3.4. Estimated yield varied from 65 to 79 percent. Flotation conditions used to prepare the clean coal, and yields achieved, are shown in Table 3.5. 


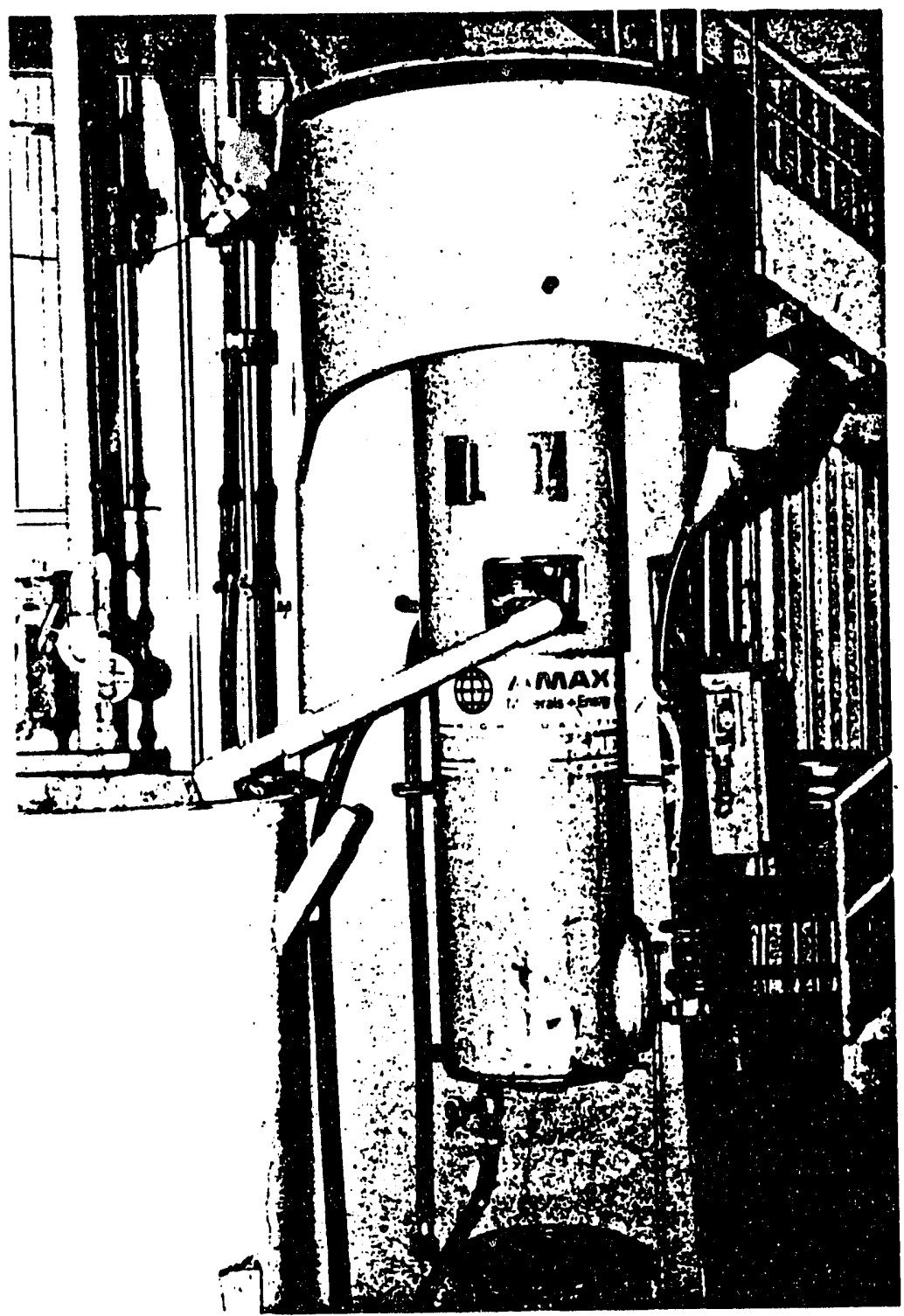

FIGURE 3.1. MICRONIZING MILL 


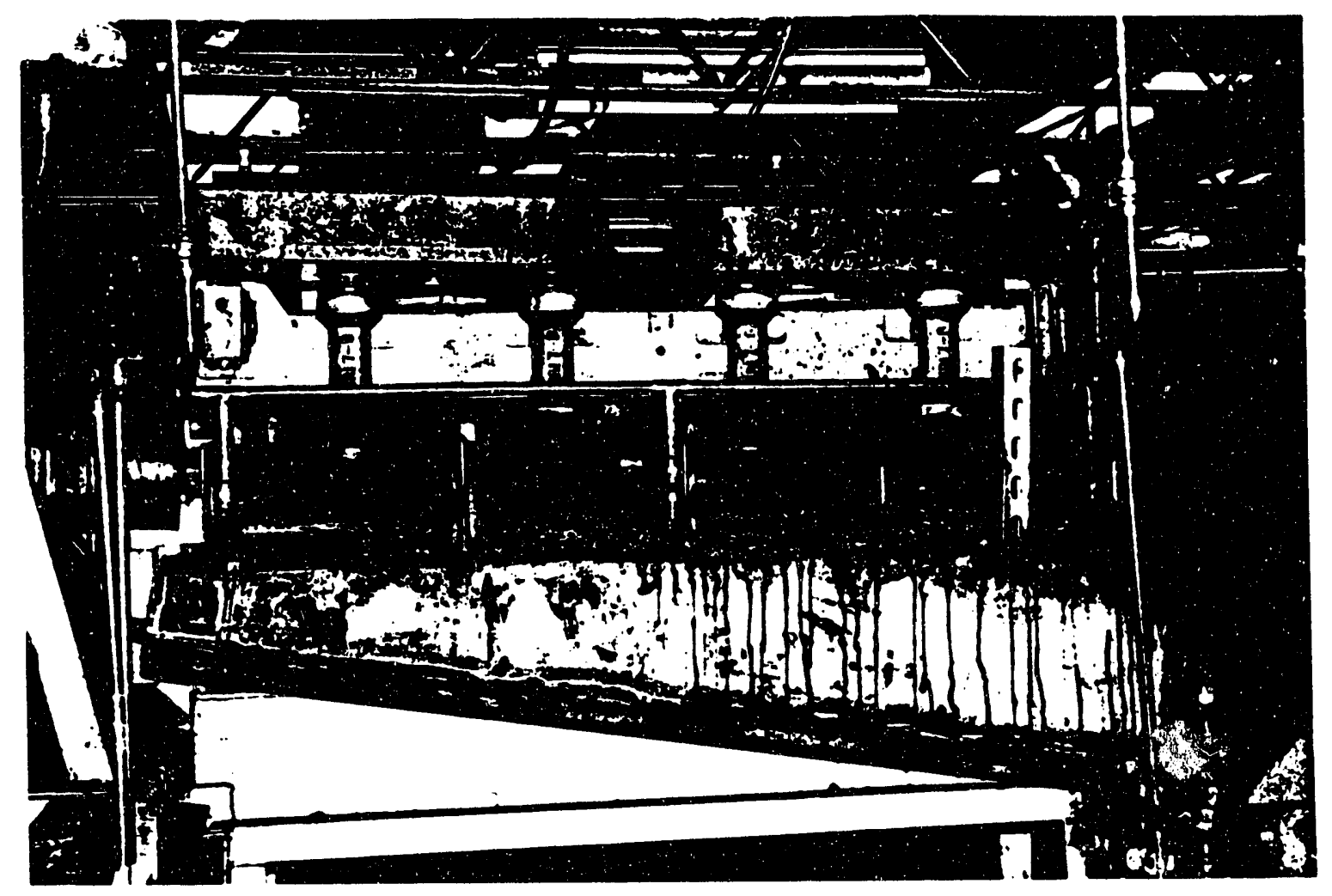

FIGURE 3.2. CONVENTIONAL FROTH-FLOTATION PILOT PLANT 


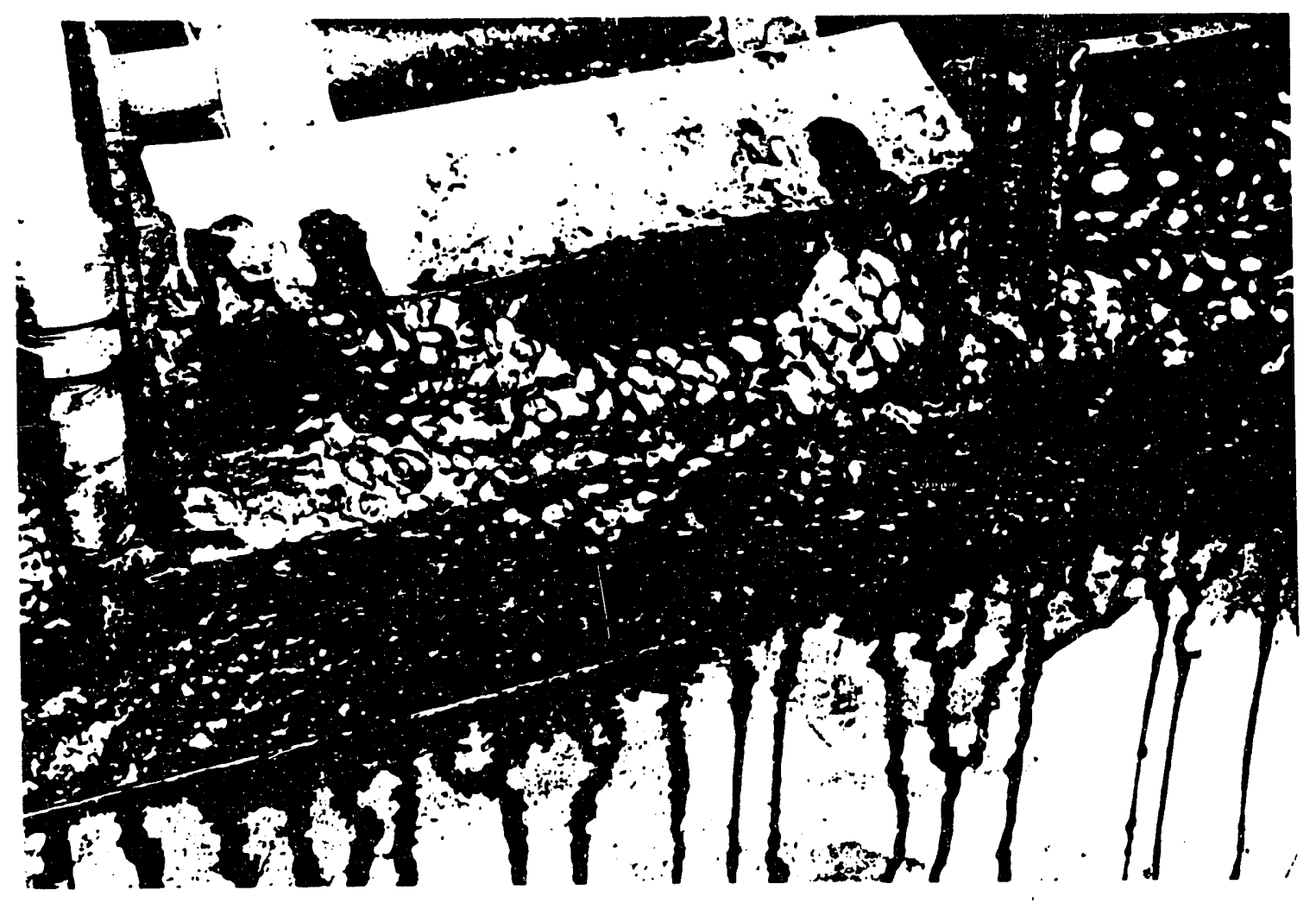

FIGIIRE 3.3. CLOSE UP OF FROTH FROM CELL 


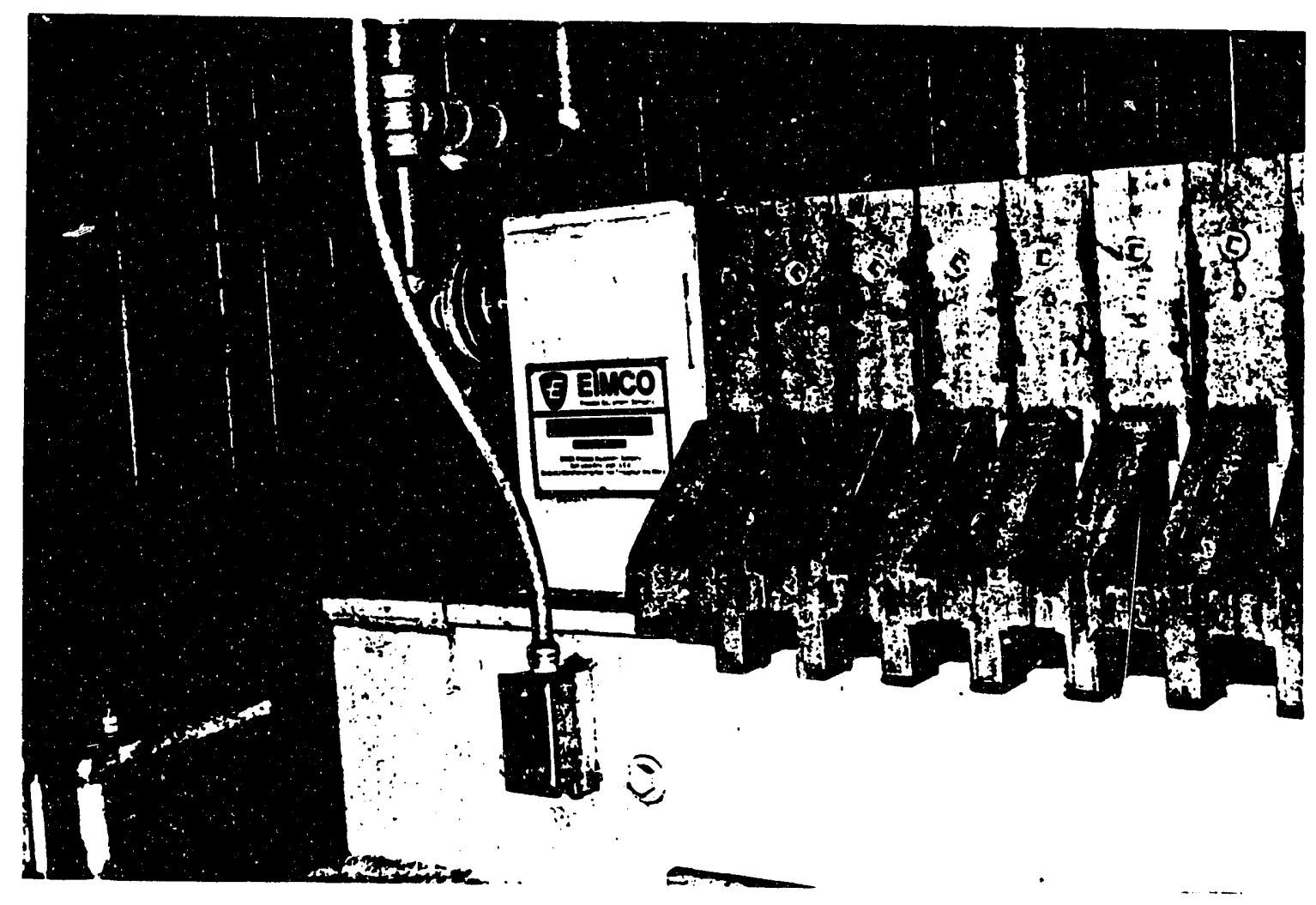

FIGURE 3.4. FILTER PRESS FOR MICRONIZED COAL DEWATERING 
TABLE 3.5. FLOTATION CONDITIONS USED TO CLEAN

\begin{tabular}{|l|c|c|c||}
\hline & \multicolumn{3}{|c|}{ Coal Type } \\
\cline { 2 - 4 } & Elkhorn & Illinois No. 6 & Utah \\
\hline Circuit Configuration & & & \\
Number of 1-cubic foot Hazen-Quinn & 4 & 7 & 7 \\
subaeration cells & 1 & 2 & 2 \\
Number of banks & 0 & 1 & 1 \\
Number of separate conditioner cells & 4 & 6 & 5 \\
Number of active aerated cells & & & \\
\hline Flotation Feed & 113.6 & 104.1 & 93.7 \\
Dry Coal, !b/hr & 4,751 & 3,676 & 3,302 \\
Slurry, lb/hr & 3.03 & 11.1 & 6.73 \\
Dry Ash, \% & 2.4 & 2.8 & 2.8 \\
Solids, \% & & & \\
\hline Reagents & $9.5^{(\mathrm{a})}$ & $16.0^{(\mathrm{b})}$ & $18.0^{(\mathrm{b})}$ \\
Frother, ppm slurry & 0.93 & 1.27 & 1.40 \\
Frother, lb/t dry coal & 0.92 & 2.41 & 4.23 \\
Diesel Fuel, lb/t dry coal & & & \\
\hline Nominal Retention & 3.2 & 5.5 & 5.7 \\
\hline Time, minutes & & & \\
\hline Clean Coal & 1.48 & 4.28 & 2.60 \\
\hline Dry Ash, \% & 78.8 & 77.5 & 64.5 \\
Weight Yield, \% & 80.1 & 83.4 & 67.2 \\
Combustible Recovery, \% & 26.9 & 38.4 & $42.5 / 37.3$ \\
Filter Cake Moisture, \% & & & \\
\hline Residue & 8.08 & 34.4 & 14.2 \\
\hline Dry Ash, \% & \multicolumn{3}{|c||}{} \\
\hline
\end{tabular}

(a) Frother:Dowfroth 250

(b) Frother: MIBC (Methyl Isobutyl Carbinol) 


\subsection{TECHNOLOGY IDENTIFICATION AND ACCEPTANCE CRITERIA}

This section describes work on Task 1 activities to identify the technology for conversion of clean-coal filter cake into pellets and into CWF. Literature and past Battelle and Amax R\&D experience was used to identify pelletization processes and to establish acceptance criteria.

The primary objectives of the task were to (1) identify reconstitution technique(s) which could produce acceptable pellets and Pellet-CWF for each coal type, (2) identify test procedures and define acceptance criteria for pellets and slurry, and (3) select the most promising techniques for further evaluation.

The following subtasks were carried out:

- Subtask 1.1 Review CWF Specifications

- Subtask 1.2 Define Acceptance Criteria

- Subtask 1.3 Identify Pellet Technology

- Subtask 1.4 Identify Capsule Technology

- Subtask 1.5 Define Storage Tests

- Subtask 1.6 Define Handling Tests

- Subtask 1.7 Define Transportation Tests

- Subtask 1.8 Health and Environmental Effects

- Subtask 1.9 Select Most Promising Techniques.

Provided in this section are:

- Reconstitution technology

- Pellet testing and acceptance criteria

- Reslurrying testing and acceptance criteria, and

- Most promising techniques. 


\subsection{Summary}

Evaluation of available reconstitution options showed that three different types of pelletization offered the potential to make strong, durable pellets suitable for use in a PelletCWF system. They were the roller-and-die, disk, and extrusion pelletization techniques. Briquetting, which requires a relatively dry feedstock, was also reviewed but rejected due to the high moisture present in the coal filter cake.

Prior to effective development of a Pellet-CWF system, a standard to assess the suitability of pellets produced from ultra-fine, ultra-clean coal was required. Review of the literature indicated that no clear standards existed. There were no consistent measures for a quality pellet, in terms of test procedures, or criteria to assess success. Therefore, based on Battelle's and Amax R\&D's experience, literature references, contacts with coal and CWF users, and through limited pelletization tests, the Pellet-CWF acceptance tests and criteria were established.

The pellet acceptance criteria established are listed as follows:

- Crushing strength, green/cured/wet: $\geq 25 / 100 / 5 \mathrm{lb}_{\mathrm{f}} / \mathrm{in}^{3}$ (based on crushing a pellet in a standard spring-load tester and expressing the load at breakage or deformation; by expressing the strength on a unit volume basis, size and shape effects are included in the criteria)

- Durability Index: $\geq 28$ percent survive (after $10 \mathrm{~min}$. tumbling in a steel box rotated at $50 \mathrm{rpm}$ )

- Ro-Tap Durability Index: $\geq 90$ percent survive (after $10 \mathrm{~min}$. on a standard particle size "Ro Tap" machine)

- Drop Resistance: Pass (little or only minimal breakup from $5 \mathrm{ft}$ drop)

- Weatherability Index: $\geq 60$ percent survive (after three successive periods of water immersion, freezing, and thawing) 
- Final Moisture: $\leq 15$ percent

- Grindability: Hardgrove Grindability Index $\geq$ parent coal.

The CWF acceptance criteria established is listed as follows:

- Top size: 45-micron

- Viscosity: < 500 centipoise (cP) at $100 \mathrm{sec}^{-1}$ shear rate

- Loading: > 55 percent solids

- Stability: no settling hard pack formation after 8 hours storage (without stirring).

Based on the limited tests conducted with the different pelletization techniques, all the three techniques were found to have the potential for the Pellet-CWF concept. Depending on the coal type, moisture level, binder type and dosage, etc. they could meet the pellet acceptance criteria noted above. Therefore, all three pelletization processes were recommended for further analysis.

\subsection{Reconstitution Technology}

Agglomeration or reconstitution of fine particles is currently commercially practiced for many materials including coal. Primary techniques include briquetting and pelletization. Briquetting is employed for dry coal. In order to adopt the briquetting technique with the high moisture filter cake an initial drying step would be required. Drying of fine coal is di.ificult and expensive. Analysis of pre-drying/briquetting versus pelletization for -20 mesh coal filter cake, under another DOE contract, indicated pelletization to be more attractive. ${ }^{(1)}$. Also, drying and briquetting of ultra-fine coal would technically be even more difficult. Therefore, it was decided to focus our attentions on pelletization.

Pellets carı be formed by forcing a plastic mixture of coal, water, and binder through a die (by roller-and-die or extrusion techniques) or by rolling into a ball on a rotating disk. Each of the techniques is discussed below. 


\section{2,1 Roller-and-die Pelletization}

In roller-and-die pelletization a roller, or set of rollers, operate within a perforated ring. The roller forces the particulate, granular, or pasty feed (in our case pasty coal filter cake) into the holes of the die and compacts it to form a continuous solid rod. A knife blade cuts the coal rods at the die periphery to produce 3/4- to 1 -in. long pellets. The process is shown schematically in Figure 4.1 below.

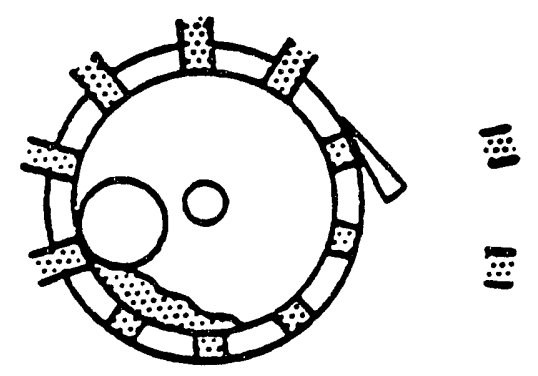

\section{FIGURE 4.1 OPERATING PRINCIPLE OF ROLLER-AND-DIE PELLETIZATION}

All bench-scale and pilot-scale pelletization tests for the three coals were conducted in Battelle's laboratory scale California Pellet Mill (CPM) or in a 1-ton/hr CPM mill. Details on the pellet production, pellet quality, and assessment of this technique are presented in the next section. Initial pelletization and CWF formulation tests were conducted with Elkhorn roller-and-die pellets to determine the suitability of binders in the Pellet-CWF concept. Among the various binders tested, corn starch, Shur Bond (a petroleum-water emulsion) and lignin sulfonate were found to be quite suitable. CWF slurries prepared from pellets with 
these three binders showed low viscosities and good stability. Overall, the roller-and-die pelletization technique showed good promise of producing an economically and technically acceptable product that could meet the fuel specification.

\subsubsection{Disk Pelletization}

In the disk pelletization process a charge of moist coal is fed to a rotating, inclined disk or drum. Water sprayed onto the rotating filter-cake material promotes nucleation, ball formation, and ball growth. As the disk rotates the centrifugal force generated throws the balls toward the periphery, allowing controlled discharge of sized product (typically $1 / 2 \mathrm{in}$. to 1 -in. diameter). The process is shown schematically in Figure 4.2 below.
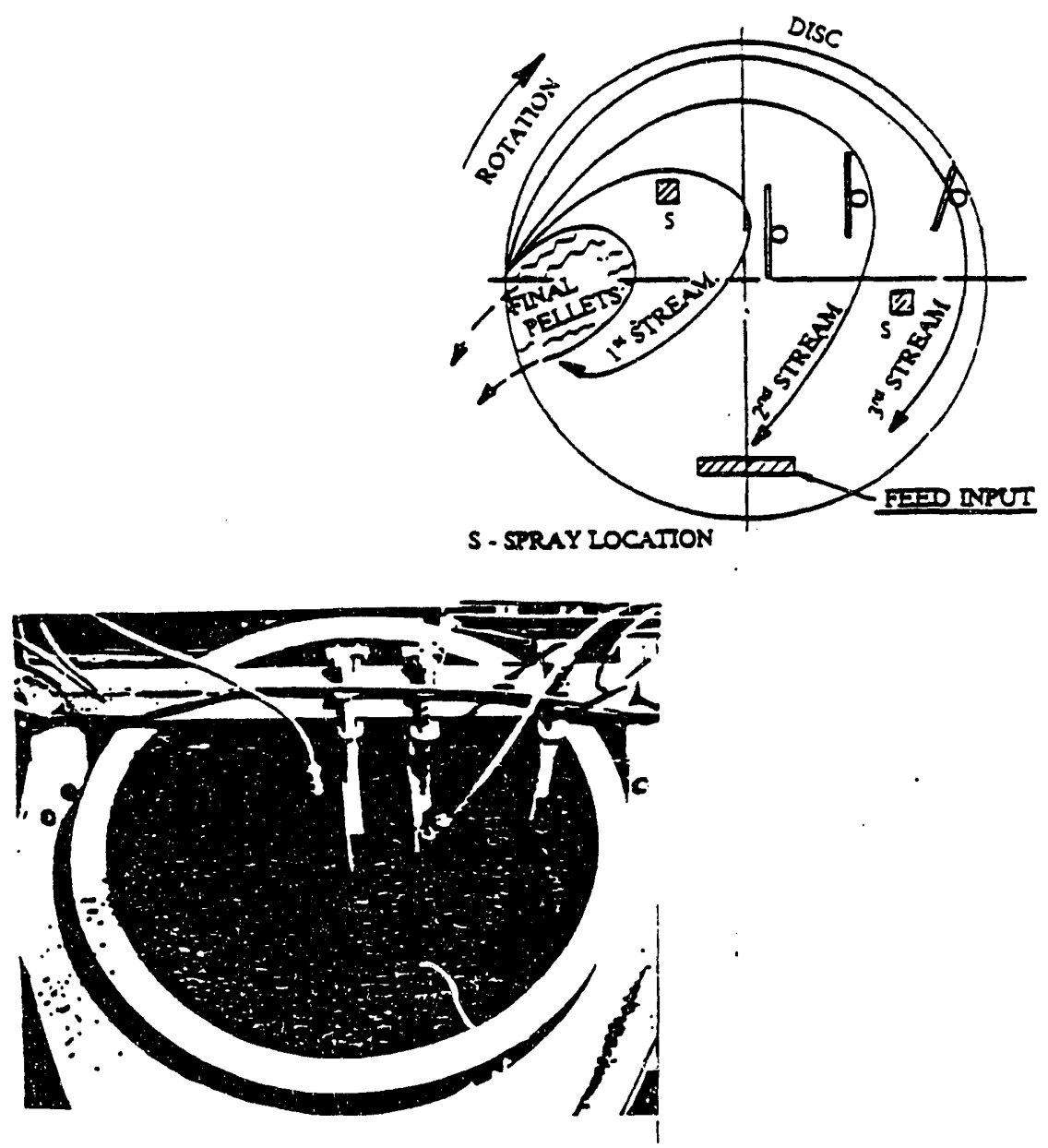

FIGURE 4.2 OPERATING PRINCIPLE OF DISK PELLETIZATION 
Initial tests were conducted in Battelle's large rotary mixer, which simulates a non-inclined disk pelletizer. Subsequent pelletization tests were conducted in an Andritz SproutBauer disk pelletizer. Tests conducted with the three coals showed that at the proper moisture level, the filter-cake mix could easily be rolled into balls of controlled size; even without binder. However, a binder was necessary to provide the required strength and durability to the pellets. Typical disk pellets size ranged from 1/4- to 1 -in. diameter at 32 to 36 percent moisture. Pellets with 3 percent corn starch and 3 to 5 percent lignin sulfonate binders had physical properties which exceeded many of the physical properties of raw western coal. The pellets had good strength and durability. Thus, the disk pelletization technique also appeared to be suitable for pellet production from filter-cake.

\subsubsection{Extrusion Pelletization}

In the extrusion pelletization process a charge of moist coal is fed by an auger which progressively compresses and compacts the coal. Ultimately, it is extruded through a die to produce a continuous rod of coal typically $1 / 2$-in. to 1 -in. diameter. The process is shown schematically in Figure 4.3.

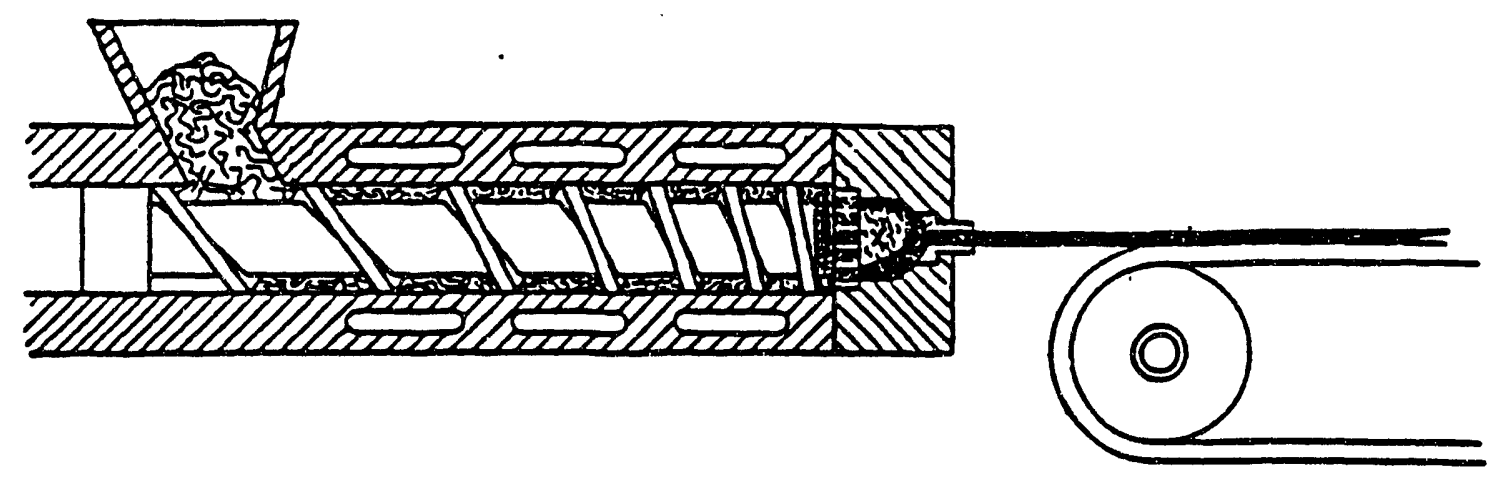

FIGURE 4.3. OPERATING PRINCIPLE OF EXTRUSION PELLETIZATION 
Initial tests were conducted in Amax R\&D's bench-scale extruder. Later, additional bench-scale and pilot-scale extrusion pelletization tests were conducted in a commercial unit; a Model 1000 Bonnot Company extruder. The 0.5 -in. extruded pellets, once thermally dried, had good strength and showed excellent potential for the Pellet-CWF system.

\subsection{Pellet Testing and Acceptance Criteria}

\subsubsection{Standard Quality Measures}

No universally recognized pellet quality tests exists ${ }^{(2-15)}$ in the literature. Even when a common test is referenced, e.g., the "standard" compression test, the actual test procedure is not well defined, nor are means identified to account for different particle sizes and shapes. Finally, values for acceptable pellet performance are rarely noted.

Therefore, based on Battelle's prior experience and the published literature the following seven tests were selected to define a pellet acceptance criteria:

- Crushing strength: green, cured, wet

- Tumble durability

- $\quad$ "Ro-Tap" durability

- Drop resistance

- Freeze/thaw resistance

- Final moisture: cured, after immersion, and

- Grindability.

Details on these test procedures are provided in Appendix A. 


\subsubsection{Requirements}

The pellet acceptance criteria were established after reviewing the requirements for pellet transportation, handling and storage as well as economic, combustion, and environmental considerations. These requirements were broadly defined as follows:

- "Pellets" are expected to survive under outdoor storage and are expected to be handled in a manner similar to raw coal, and

- "Capsules" which are a low cost alternate to pellets are expected to have lower strength and also require covered transportation and storage.

The specifics for each pellet criterion element are discussed below.

4.3.2.1 Crushing Strength. The compressive or crushing strength is the maximum crushing load a pellet or capsule can withstand before cracking or breaking. Pellets are intended to be handled using equipment and procedures now used with raw coal and therefore require a high crushing strength. Capsules are intended to be transported in smaller, covered lots - their requirements could be substantially lower than for pellets.

The green strength acceptance standard was established from green-pellet handling and storage considerations. A 10-ft high stack of 1 -in. long, 1/2 in. diameter pellets exerts a 0.9 to $1.7 \mathrm{lb}$ weight (depending on orientation) on the bottom pellet, or about $5 \mathrm{lb}_{\mathrm{f}} / \mathrm{in}^{3}$. Therefore, a minimum green strength of five times this value or $25 \mathrm{lb}_{\mathrm{f}} / \mathrm{in}^{3}$ was selected for both pellets and capsules.

The cured strength standard was established based on handling considerations. Powder River Basin coal, a high moisture western coal, is considered to be weak and highly friable. It is however commercially transported hundreds of miles by rail. Tests of coal specimens, with similar geometries to roller-and-die and disk pellets, indicate Amax's Belle Ayre mine Powder River Basin coal has a crushing strength of $256 \pm 88 \mathrm{lb}_{\mathrm{f}} / \mathrm{in}^{3}$ or a minimum of approximately $200 \mathrm{lb}_{\mathrm{f}} / \mathrm{in}^{3}$. Battelle has prepared reconstituted coal with crushing strengths of about $50 \mathrm{lb}_{\mathrm{f}} / \mathrm{in}^{3}\left(24 \mathrm{lb}_{\mathrm{f}}\right.$ for 1.9 -in. long, 1.3-in. wide by 0.35 in. deep pillow 
shape briquettes) which have been successfully produced in multi-ton lots, transported, conveyed, fed by augers into commercial combustion equipment, etc. without unacceptable breakup (established in a US Environmental Protection Agency study on coal-limestone pellets ${ }^{(5)}$ ). A cured capsule crushing strength standard of $100 \mathrm{lb}_{\mathrm{f}} / \mathrm{in}^{3}$ (which corresponds to $10 \mathrm{lb}_{\mathrm{f}}$ for a $0.5 \mathrm{in}$. diameter 1 -in. long pellet) was established based on handling experience and discussion with pellet producers.

The wet strength was set at $25 \mathrm{lb}_{\mathrm{f}} / \mathrm{in}^{3}$ based on the green strength requirements (note that the force exerted on the bottom of a 10 -ft. high coal pile is approximately $25 \mathrm{lb}_{\mathrm{f}} / \mathrm{in}^{3}$ ). Pellets that meet the minimum wet strength criteria have been able to survive outdoor storage. There is no suggested criteria for capsules wet strength since capsules will be stored under cover.

4.3.2.2 Durability. This parameter is used to characterize the resilience of the pellet against abrasion caused by the tumbling action and vibration forces encountered in handling operations. During the Tumble test, the pellets are subjected to extreme handling conditions, . while with the mechanical sieving (i.e., Ro-Tap) test, the pellets experience more mild handling conditions. We recommend that a minimum Durability Index (DI) of 28 (i.e., 28 percent of the pellets are larger than 4 mesh at the end of the 10 minute tumble test) be adopted for both pellets and capsules, and a minimum Ro-Tap Durability Index (RDI) of 90 (90 percent larger than 4 mesh after the 10 minute sieving test) be set for pellets and 60 for capsules. The recommended DI value for pellets and capsules was established based on previous Battelle work on pellet handling ${ }^{(1)}$. The RDI value for pellets was established based on Battelle/Amax studies on western-coal briquetting. The RDI for capsules, which do not require the same degree of resiliency, was arbitrarily set 30 percentage points lower than the RDI for pellets.

4.3.2.3 Drop Resistance. This test determines the pellet's ability to survive under impact. Typical situations of impact occur when pellets are dropped from a fixed height during production, transportation or in storage areas. Acceptable pellets should pass both the 
1- and 5-ft drop tests. Acceptable capsules must pass the 1 - $\mathrm{ft}$ test but can be rated "pass/fail" on the 5-ft test.

4.3.2.4 Freeze/Thaw Resistance. Coal pellets during transportation may be subjected to cold climatic conditions that could alter the physical structure of the pellet. A Weatherability Index (WI) of 60 percent or greater is recommended for pellets. No WI acceptance criteria is suggested for capsules, however, a value less than 20 could be advantageous for rapid capsule-to-CWF conversion (by immersion in water or limited mixing).

4.3.2.5 Final Moisture. The moisture level of the pellet/capsule is another important quality measure. A final cured pellet moisture less than 15 percent is suggested for both pellets and capsules. No acceptance criterion is specified for the immersed-pellet final moisture; however it is suggested that immersed-pellet moisture not exceed 20 percent.

4.3.2.6 Grindability. Grindability relates to the difficulty in reducing the pellets to micronized size for injection into the combustor. The suggested acceptance criterion for pellet and capsule is a Hardgrove Grindability Index (HGI) equal to or greater than the parent coal. It is further suggested that capsules have a significantly greater HGI than the parent coal. (Note: while the HGI should provide an acceptable measure of grindability, there is no conclusive evidence that HGI correlates well with a coal's ease of ultra-fine grinding.)

\subsubsection{Acceptance Criteria}

The Pellet Acceptance Criteria established is listed on Table 4.1. 
TABLE 4.1 PELLET ACCEPTANCE CRITERIA ${ }^{(16)}$

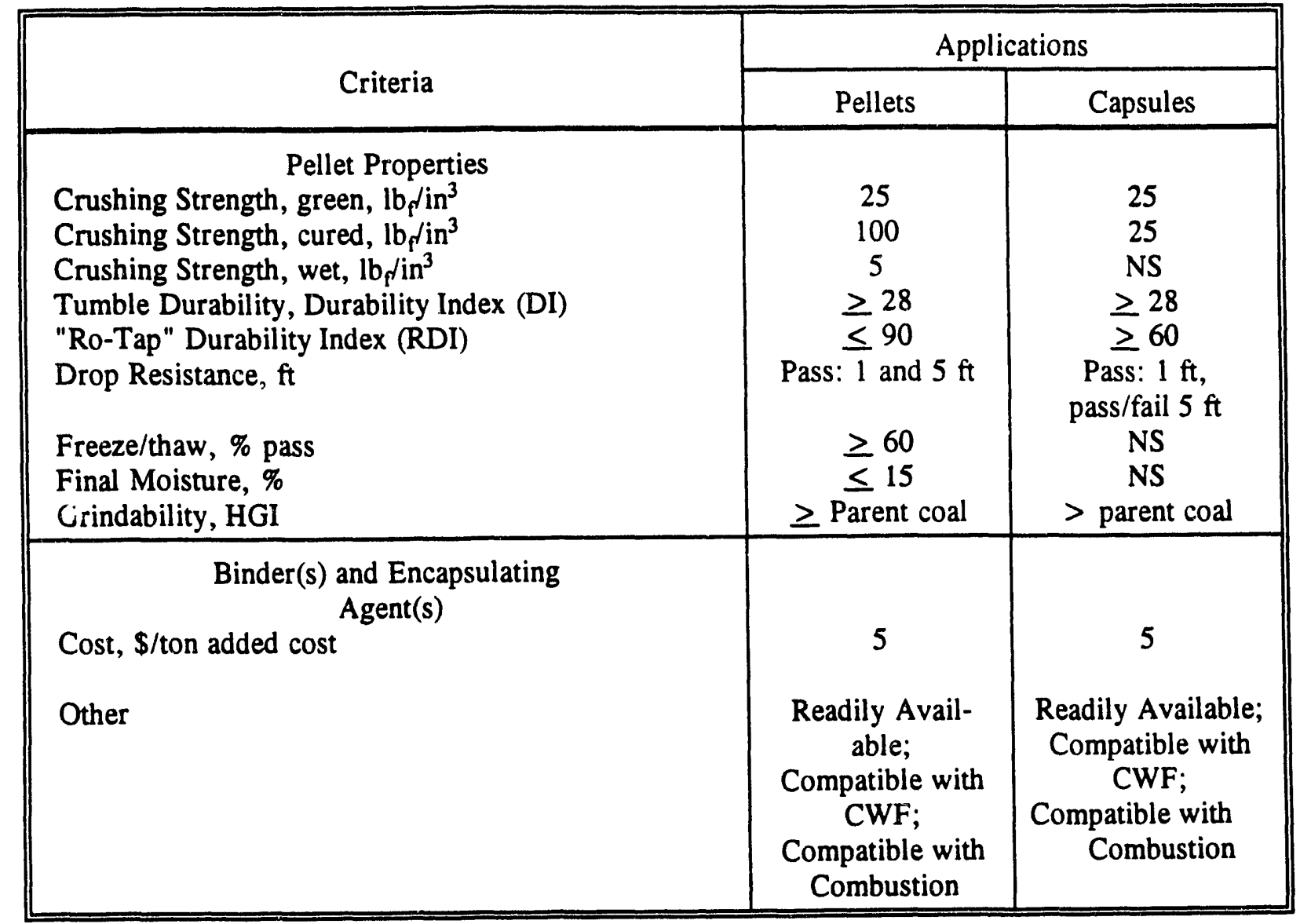

NS: No standard specified

\subsection{Reslurrying Tests and Acceptance Criteria}

\subsubsection{Standard Quality Measures}

The requirements for CWF intended for residential, commercial and industrial applications were compiled as a first step in establishing the CWF acceptance criteria. The primary factors specified include top particle size, percent solids, ash content, and viscosity. 


\subsubsection{Requirements}

A survey was made to determine existing fuel specifications for commercial- and industrial-scale coal slurry combustion systems in order to learn what specifications must be met when reslurrying pellets. Prospective suppliers and users of such systems were asked to list the required fuel specifications for their particular systems. Responses were obtained from six groups, three of which employed steam boilers systems. The other three groups were interested in either heat engines or alternative combustion systems. Energy International identified three types of fuel which it has supplied for various DOE programs, and also supplied data for a proposed utility retrofit in Puerto Rico. The survey results, shown in Table 4.2 were divided into two categories: (1) steam/fire tube boilers, and (2) alternative systems (small scale units: diesels, turbines, residential furnaces, etc.).

The results of the survey indicate that a $45-\mu \mathrm{m}$ nominal top size appears acceptable for most users, and for all but large utility boilers, viscosities under $500 \mathrm{cp}$ at $100 \mathrm{sec}^{-1}$ seems to be a reasonable expectation. The preferred particle size and loading values, and acceptable values for other properties, varied according to end use. With the exception of Penn State, the boiler users seem to prefer a more highly loaded slurry than the "alternative combustion" users. It looks like the boiler operators would also accept coarser and higher viscosity slurries. On the other hand, the diesel-engine (Cooper-Bessemer) and gas-turbine (Solar Turbine) developers accept (and seem to prefer) quite low coal loadings in fuel for their systems.

Some of the prospective slurry fuel users were concerned about properties that are not listed on Table 4.3. Many specified that slurries should not settle to a hard pack condition within a certain number of days. Others request near-Newtonian or near pseudoplastic rheology. Mass-mean particle diameter, ash fusion properties, sulfur and alkali contents, coal rank, compatibility with oils, and temperature effects upon rheology could also be important depending on the application. 
TABLE 4.2. COAL SLURRY FUEL SPECIFICATIONS FOR COMMERCIAL/INDUSTRIAL COMBUSTION SYSTEMS

\begin{tabular}{|c|c|c|c|c|}
\hline $\begin{array}{c}\text { Combustion } \\
\text { Type }\end{array}$ & $\begin{array}{c}\text { Nominal } \\
\text { Top Size, } \\
\mu \mathrm{m}\end{array}$ & $\begin{array}{c}\text { Coal } \\
\text { Loading, } \\
\%\end{array}$ & $\begin{array}{l}\text { Ash, } \\
\%\end{array}$ & $\begin{array}{c}\text { Viscosity, } \\
\text { Centipoise } \\
\text { (cP) @ } 100 \\
\text { sec }^{-1}\end{array}$ \\
\hline Steam/Fire Tube Boilers & \multirow{2}{*}{$75-100$} & \multirow[b]{2}{*}{60} & \multirow[b]{2}{*}{$<3.0$} & \multirow[b]{2}{*}{$100-120$} \\
\hline Penn State & & & & \\
\hline $\begin{array}{l}\text { Energy \& Environmental } \\
\text { Research Corp }\end{array}$ & 300 & 65 & $2.0-5.0$ & $<1,070$ \\
\hline Foster Wheeler & 250 & 70 & Any ${ }^{(a)}$ & $<1,000$ \\
\hline $\begin{array}{l}\text { Energy International } \\
\text { Utility } \\
\text { Puerto Rico Utility }\end{array}$ & $\begin{array}{l}250 \\
250\end{array}$ & $\begin{array}{l}>65 \\
>65\end{array}$ & $<6.0$ & $\begin{array}{l}600-1,200 \\
800-1,200\end{array}$ \\
\hline Alternative Systems & \multirow[b]{2}{*}{45} & \multirow[b]{2}{*}{55} & \multirow[b]{2}{*}{ Any } & \multirow[b]{2}{*}{200} \\
\hline Tecogen & & & & \\
\hline Solar Turbines & 45 & $50-58$ & Any & 250 \\
\hline Cooper-Bessemer & $45-75$ & $>48$ & $<2.0$ & $100-500^{(b)}$ \\
\hline $\begin{array}{l}\text { Energy International } \\
\text { Micronized } \\
\text { Industrial }\end{array}$ & $\begin{array}{l}45 \\
150\end{array}$ & $\begin{array}{l}>62 \\
>65\end{array}$ & $\begin{array}{l}\text { Any } \\
\text { Any }\end{array}$ & $\begin{array}{l}<500 \\
<500\end{array}$ \\
\hline
\end{tabular}

(a) Low ash levels preferred

(b) At any shear rate between $100 \mathrm{sec}^{-1}$ and $1,000 \mathrm{sec}^{-1}$. 


\subsubsection{Acceptance Criteria}

The CWF acceptance criteria are presented in Table 4.3. These were based on the survey and supplemental tests conducted on the Pellet-CWF slurries.

TABLE 4.3. COAL WATER FUEL ACCEPTANCE CRITERIA ${ }^{(17)}$

\begin{tabular}{||c|c|c||}
\hline \multirow{2}{*}{ Criteria } & \multicolumn{2}{|c|}{ Applications } \\
\cline { 2 - 3 } & $\begin{array}{c}\text { Commercial } \\
\text { (Steam Boilers) }\end{array}$ & $\begin{array}{c}\text { Industrial } \\
\text { (Alternative } \\
\text { Users) }\end{array}$ \\
\hline $\begin{array}{c}\text { Particle Size, } \\
\text { Nominal Top Size, } \\
\text { microns }\end{array}$ & 250 (60 mesh) & $45(325$ mesh) \\
\hline $\begin{array}{c}\text { Viscosity, } \\
\text { cp @ 100 sec }\end{array}$ & $<600$ & $<500$ \\
\hline $\begin{array}{c}\text { Ash Content, } \% \\
\text { Coa }\end{array}$ & $<3.0$ & $\begin{array}{c}\text { Any (But low ash } \\
\text { preferred) }\end{array}$ \\
\hline $\begin{array}{c}\text { Stability, } \% \\
\text { settling in 8 hr }\end{array}$ & $65 \%$ & $>55 \%$ \\
\hline
\end{tabular}

\subsection{Most Promising Techniques}

Limited tests were conducted with three different types of pelletization techniques: roller-and-die, disk, and extrusion. All three were found to have the potential to be acceptable for the Pellet-CWF concept. It was determined that more data on the effects of coal type, moisture level, binder type and dosage, etc., would be required before a final selection would be possible. Therefore, all three pelletization processes were recommended for further analysis in the bench-scale development task of the project. 


\subsection{Section 4 References}

1. Conkle, H. N., et al., "Utilization of Battelle-Treated Coal in Gasification and Combustion Processes to Control Sulfur Emissions," Final Report prepared by Battelle Memorial Institute for the Us Department of Energy under Contract No. W7405-Eng-92-111, Report No. BMI-2096 UC-90c, September 14, 1982.

2. Mehrotra, V. P. and Sastry, K. V. S., "Influence of Binders on the Pelletization Behavior of Coal Fines," SME Transactions, Vol. 272, 1982.

3. Richards, S. R., "Physical Testing of Fuel Briquettes," Fuel Processing Technology, Vol. 25, 1990, pp 89-100.

4. Conkle, H. N. and Dawson, W. J., "Reconstitution of Physically Cleaned Coal," Final Report, Battelle to Standard Oil Company of Ohio, 1984.

5. Rising, B. W., Conkle, H. N., Dawson, W. J., and Litt, R. D.,"Advanced Development of a Coal-Limestone Fuel Pellet for Industrial Boilers," Final Report, Battelle to U.S. Environmental Protection Agency, 1983.

6. Barker, A. F., McKeever, R. E., and Deurbrouck, A. W., "Development and Demonstration of a Lignite Pelletizing Process," Fossil Energy, U.S. DOE, March 1982.

7. Garvin, J. P., "A Statistical Evaluation of the Effects of Composition on the Strength of Fuel Pellets," Proceedings, 18th Biennial Conference, Institute of Briquetting and Agglomeration, CO, August 1983.

8. Megler, V. R. and Kennedy, G. L., "Heating of Brown Coal Briquettes to Produce Strong Char: I-Critical Assessment of Existing Theories," Page 255-263, Fuel, Vol. 40, 1961.

9. Giammar, R. D., Barnes, R. H., Hopper, D. R., Webb, P. R., and Weller, A. E., "Evaluation of Emissions and Control Technology for Industrial Stoker Boilers," Final Report Battelle, to U.S. EPA, March 1981.

10. Koerner, R. M. and Lord, Jr., A. E., "Strength Behavior of Briquettes as Determined by Acoustic Emission," Proceeding, Vol. 15, The Institute for Briquetting and Agglomeration, Aug. 1977, Montreal, Canada, pp 179-182.

11. Göksel, M. A. and Valentyik, L., "Production and Evaluation of Lignite Pellets," Proceedings, 16th Biennial Conference, Institute for Briquetting and Agglomeration, 1979, pp 263-274. 
12. Holley, C. A. and Antonetti, J. M., "Agglomeration of Coal Fines," Proceeding, Vol. 15, The Institute for Briquetting and Agglomeration, Aug. 1977, Montreal, Canada, pp 1-12.

13. Wen, W. W., Bergman, P. D., and Deurbrouck, A. W., "A Humic Acid Binder for Pelletizing of Fine Coal."

14. Kapur, P. C. and Fuerstenau, D. W., "The Dry Strength of Pelletized Spheres, " J. Am. Cer. Soc., Vol. 50, No. 1, pp 14-18.

15. Lowery, H. H., Chemistry of Coal Utilization -- Supplemental Volume, John Wiley and Sons, Inc., 1963, pp 128-133.

16. Raghavan, J. K. and Conkle, H. N., "Physical Characteristics Measurements for Reconstituted Coal Pellets," Proceedings of the 22nd Biennial Conference of The Institute of Briquetting and Agglomeration, San Antonio, Texas, November 4-6, 1991.

17. Conkle, H. N., Raghavan, J. K., Jha, M. C., and Smit, F. J., "Pelletizing/Reslurrying as a Means of Distributing and Firing Clean Coal," Proceedings of the 16th International Conference on Coal \& Slurry Technology, Clearwater, Florida, April 22-25, 1991, pp 349-360. 


\subsection{BENCH SCALE DEVELOPMENT}

This section describes work on Task 2 the bench-scale development of the PelletCWF process. Parametric studies were carried out on each of the coals, pelletization techniques, and various binders to evaluate filter-cake reconstitution. Coal Water Fuel (CWF) reslurrying work was also conducted to assess the suitability of the pellets from various coal/process/binders combinations for CWF formulation.

The primary objective of the task was to evaluate the pelletization technique(s) which could produce acceptable pellets from each of the three coals. A secondary objective was to determine preferred processing conditions including moisture level, binder type(s) and dosage(s), curing conditions, etc., to produce pellets and CWF which met the acceptance criteria. Information from the task was used to perform an initial economic assessment and to select the coals/pelletization techniques and binders for use in the pilot-scale testing.

The following subtasks were carried out:

- Subtask 2.1 Characterize Wet Filter Cake

- Subtask 2.2 Prepare/Characterize CWF

- Subtask 2.3 Prepare Small Batches

- Subtask 2.4 Evaluate Transportation, Handling, and Storage Characteristics

- Subtask 2.5 Demonstrate Reslurrying

- Subtask 2.6 Select Processes/Coal for Pilot Scale Testing. 
Provided in this section are:

- Pelletization development

- Reslurrying development

- Initial atomization testing

- Coals/techniques/binders selection for pilot-scale testing.

\subsection{Summary}

Bench-scale pellet production and evaluation showed that all three coals could be pelletized into acceptable pellets by the three techniques. In each of these techniques, tests indicated that among the several binders studied, corn starch, lignin sulfonate and Shur Bond binders were compatible for both pellet production and slurry production.

Slurry formulation from pellets was also examined in great detail. Specifically, dispersant additive dosages (A-23) and rheological characteristics were determined for all the pellets. The additive dosages were found to be dependent on the type of binder used in the pellets. Corn starch-bound pellets required the maximum A-23 dosages in its slurries. Also, the required dispersant additive dosage was about 40-60 percent lower for slurries prepared from pellets than for slurries prepared from clean-coal filter cakes. Other variables that influence the slurry preparation from pellets, such as air-drying versus thermal drying, mixing techniques, pellet aging, etc., were also examined.

Finally, based on the pellet and CWF formulation results and preliminary economic analysis, the roller-and-die pelletization technique was determined to be the preferred technique for the Pellet-CWF approach. Hence, pilot-scale pellet production with roller-anddie was recommended for all the three coals. Economic analysis also projected that Shur Bond would be the most economical pelletizing tinder. 


\subsection{Pelletization Development}

The Peilet-CWF approach was first developed in bench-scale tests. Three pelletization techniques and three coals were evaluated. Results for each technique, roller-and-die, disk, and extrusion pelletization are presented below.

\subsubsection{Roller-and-Die Pelletization}

Bench-scale roller-and-die pelletization tests with Elkhorn, Utah, and Illinois No. 6 coals were conducted at Battelle in a laboratory scale California Pellet Mill. The tests were used to evaluate the pelletization processes for the three coals and determine appropriate binders. A list of the binders found suitable in the bench-scale evaluation studies is given in Table 5.1. (Note: CWF dispersants and stabilizers information are also included in the table.)

5.2.1.1 Process Evaluation Photographs of the bench-scale roller-and-die pellet production unit and the pellets are shown in Figure 5.1 and 5.2, respectively. All the three coals pelletized with corn starch binder produced a glossy surface and exited the die at about 150-170 F. The compaction forces between the roller and die resulted in high friction levels and heat generation, causing the evaporation of some of the moisture present in the coal filter cake. Typically about 40 percent of the moisture was removed during the pelletization process.

With all the three coals, among the various binders tested, pellets with corn starch binder were much easier to produce. In the case of liquid binders, such as asphalt emulsion, lignin sulfonate, etc., the addition of moisture with the binding medium made pelletization more difficult. Moisture control was very critical, particularly when liquid binders were used in the feed mix. Excess moisture resulted in pellets with unacceptable green strength. 
TABLE 5.1. BINDERS EVALUATED IN THE BENCH-SCALE PELLETIZATION TESTS

\begin{tabular}{|c|c|c|c|c|c|}
\hline Type & Designation & Description & Source & Small Lot & st Large Lot \\
\hline Corn Starch & Allbond 200 & Pre-gelatinized & $\begin{array}{l}\text { Lauhoff } \\
\text { Grain Co.; } \\
\text { Danville, IL }\end{array}$ & $\begin{array}{l}\text { \$0.13/lb } \\
\text { solids }\end{array}$ & \$0.045/lb \\
\hline $\begin{array}{l}\text { Petroleum- } \\
\text { Water Emul- } \\
\text { sion }\end{array}$ & Shur Bond & $\begin{array}{l}\text { Petroleum } \\
\text { Liquids } \\
\text { Emulsion }\end{array}$ & $\begin{array}{l}\text { Sherex } \\
\text { Chemical } \\
\text { Co.; Dub- } \\
\text { lin, OH }\end{array}$ & $\begin{array}{l}\$ 0.04 / \mathrm{lb} \\
\text { liquid; used } \\
\text { typically by } \\
\text { mixing } 1 \\
\text { part Shur } \\
\text { Bond and } 5 \\
\text { parts water }\end{array}$ & $\begin{array}{l}\$ 0.015 / 1 b \\
\text { liquid }\end{array}$ \\
\hline $\begin{array}{l}\text { Lignin Sulfo- } \\
\text { nate }\end{array}$ & Lignosite & $\begin{array}{l}\text { Calcium Lig- } \\
\text { nin Sulfonate }\end{array}$ & $\begin{array}{l}\text { Georgia Pa- } \\
\text { cific; Taco- } \\
\text { ma, WA }\end{array}$ & $\begin{array}{l}\text { \$0.035/lb } \\
\text { liquid }\end{array}$ & $\begin{array}{l}\text { \$0.035/lb } \\
\text { liquid }\end{array}$ \\
\hline Soya Residue & & $\begin{array}{l}\text { Residue from } \\
\text { Soy Bean Pro- } \\
\text { cessing }\end{array}$ & $\begin{array}{l}\text { Capital City } \\
\text { Products; } \\
\text { Columbus, } \\
\text { OH }\end{array}$ & $\begin{array}{l}\text { - } \$ 0.15 / l b \\
\text { liquid }\end{array}$ & \\
\hline \multirow[t]{3}{*}{$\begin{array}{l}\text { Asphalt Emul- } \\
\text { sion }\end{array}$} & HR-2718 & $\begin{array}{l}\text { Cationic oil/- } \\
\text { water emul- } \\
\text { sion }\end{array}$ & \multirow{3}{*}{$\begin{array}{l}\text { Heritage } \\
\text { Foundation; } \\
\text { Indianap- } \\
\text { olis, IN }\end{array}$} & $\begin{array}{l}\$ 0.086 / 1 b \\
\text { emulsion }\end{array}$ & $\begin{array}{l}\text { \$0.10/lb } \\
\text { emulsion }\end{array}$ \\
\hline & HR-2719 & Same & & $\begin{array}{l}\text { \$0.093/lb } \\
\text { emulsion }\end{array}$ & $\begin{array}{l}\text { \$0.075/lb } \\
\text { emulsion }\end{array}$ \\
\hline & SS-1H & $\begin{array}{l}\text { Commercial } \\
\text { Anionic oil/- } \\
\text { water emul- } \\
\text { sion }\end{array}$ & & $\begin{array}{l}\text { \$0.073/lb } \\
\text { emulsion }\end{array}$ & $\begin{array}{l}\$ 0.073 / \mathrm{lb} \\
\text { emulsion }\end{array}$ \\
\hline Dispersant & A-23 & $\begin{array}{l}\text { Ammonium } \\
\text { Salt of a } \\
\text { Naphthalene } \\
\text { Sulfonate }\end{array}$ & $\begin{array}{l}\text { Henkel } \\
\text { Corp. }\end{array}$ & $\begin{array}{l}\text { \$0.33/lb } \\
\text { solids }\end{array}$ & \\
\hline Stabilizer & $\begin{array}{l}\text { Flocon } \\
4800 C\end{array}$ & Xanthan Gum & $\begin{array}{l}\text { Pfizer } \\
\text { Chemical } \\
\text { Co. }\end{array}$ & -\$3/lb solids & \\
\hline
\end{tabular}




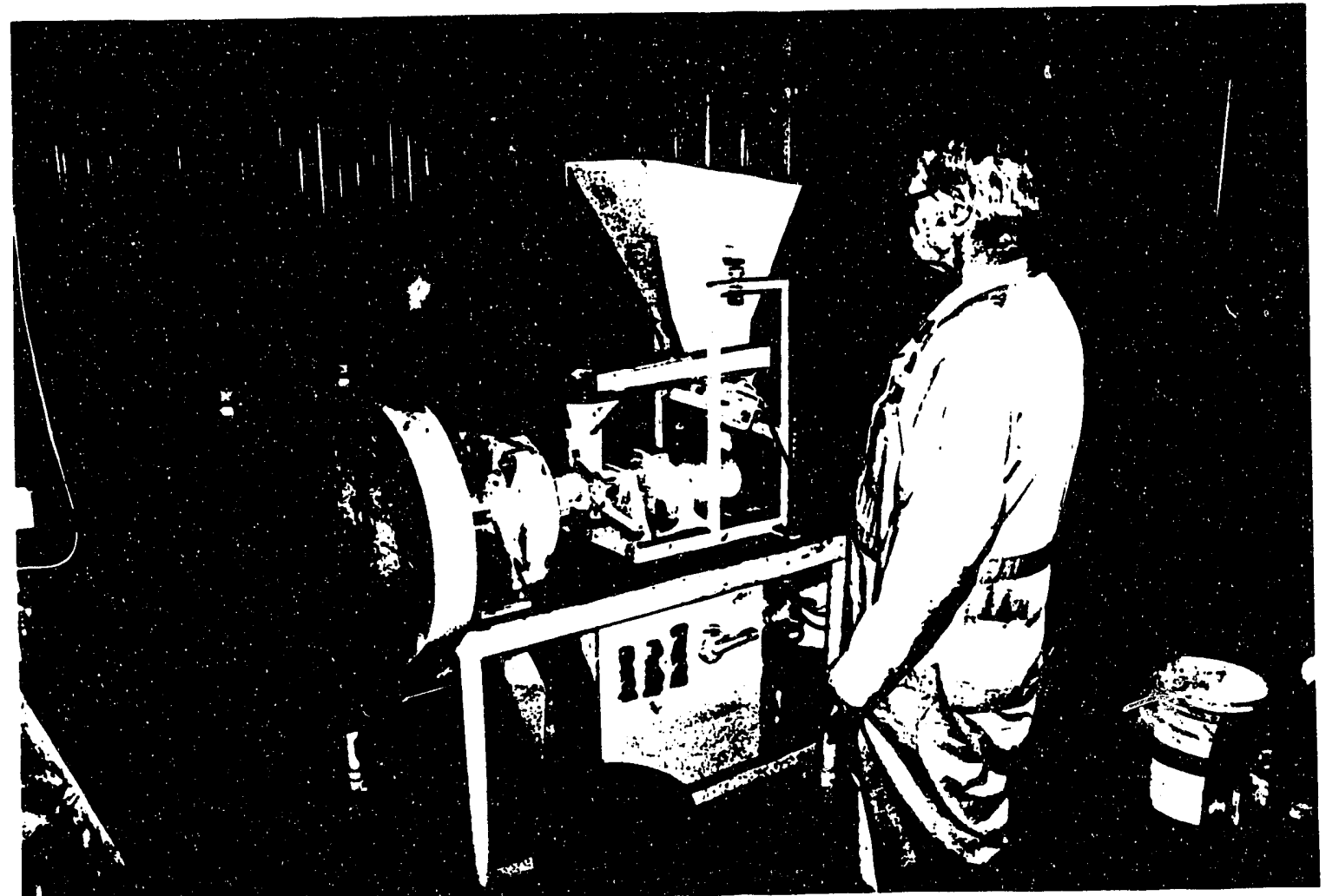

FIGURE 5.1 LABORATORY SCALE ROLLER-AND-DIE PELLET MILL

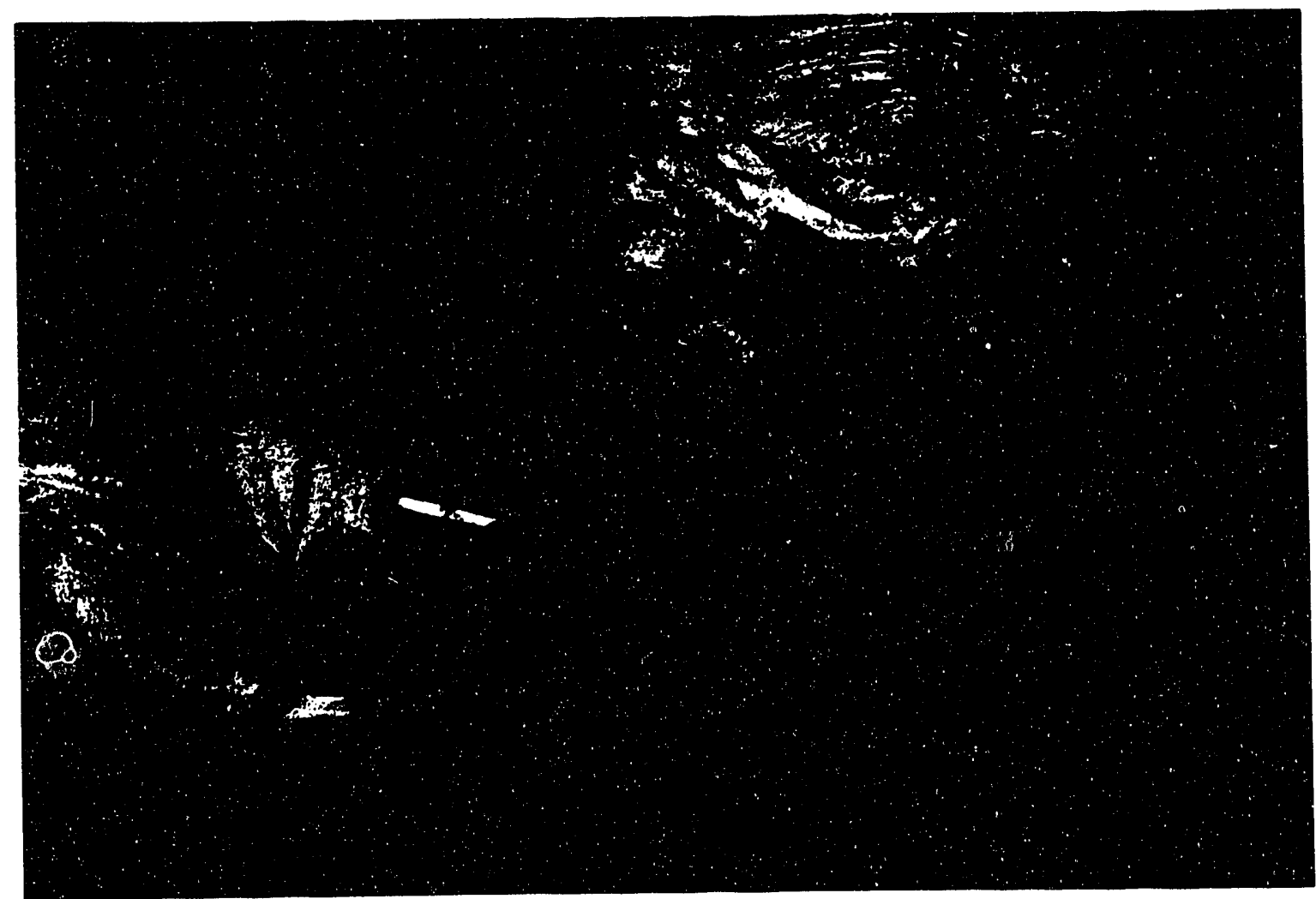

FIGURE 5.2 BENCH-SCALE ROLLER-AND-DIE PELLETS 
5.2.1.2 Pellet Evaluation. Pellet evaluation was made using the various acceptance tests discussed in the earlier section. These tests were used to determine the cured pellet's compressive strength, durability and weatherability characteristics. Data for the three coals are provided in complete detail in the Fourth Quarterly Report. ${ }^{(1)}$ A summary table of typical pellet evaluation data for the various binders obtained with Elkhorn coal is presented in Table 5.2. Since Elkhom coal was tested first, data presented in this table includes an exhaustive list of binders. On the basis of these results, many binders that were determined unsuitable were screened-out from further testing with other coals. The following binders were chosen to be technically acceptable for reconstitution:

- Corn starch

- Shur Bond

- Lignin sulfonate

- Dispersant

- Asphalt emulsion

Based on pellet production, slurry formulation, and economic considerations the com starch, Shur Bond, and lignin sulfonate binders were found to be the most acceptable. Among these three binders Shur Bond and corn starch showed good to average resistance towards weatherability. During the formulation of coal-water slurries with these pellets, Shur Bondbound pellets showed the lowest A-23 (dispersant) requirement (details to be presented later). The low cost of Shur Bond, its resistance towards water penetration, and the advantage of low dispersant requirement in reslurrying were key considerations for recommending the Shur Bond binder for pilot-scale evaluation.

In conclusion, pelletization via roller-and-die was technically successful with all the three coals and with most binders. This technique clearly provided a good reconstitution process for converting the filter cake into products that can be stored, handled, and transported. 


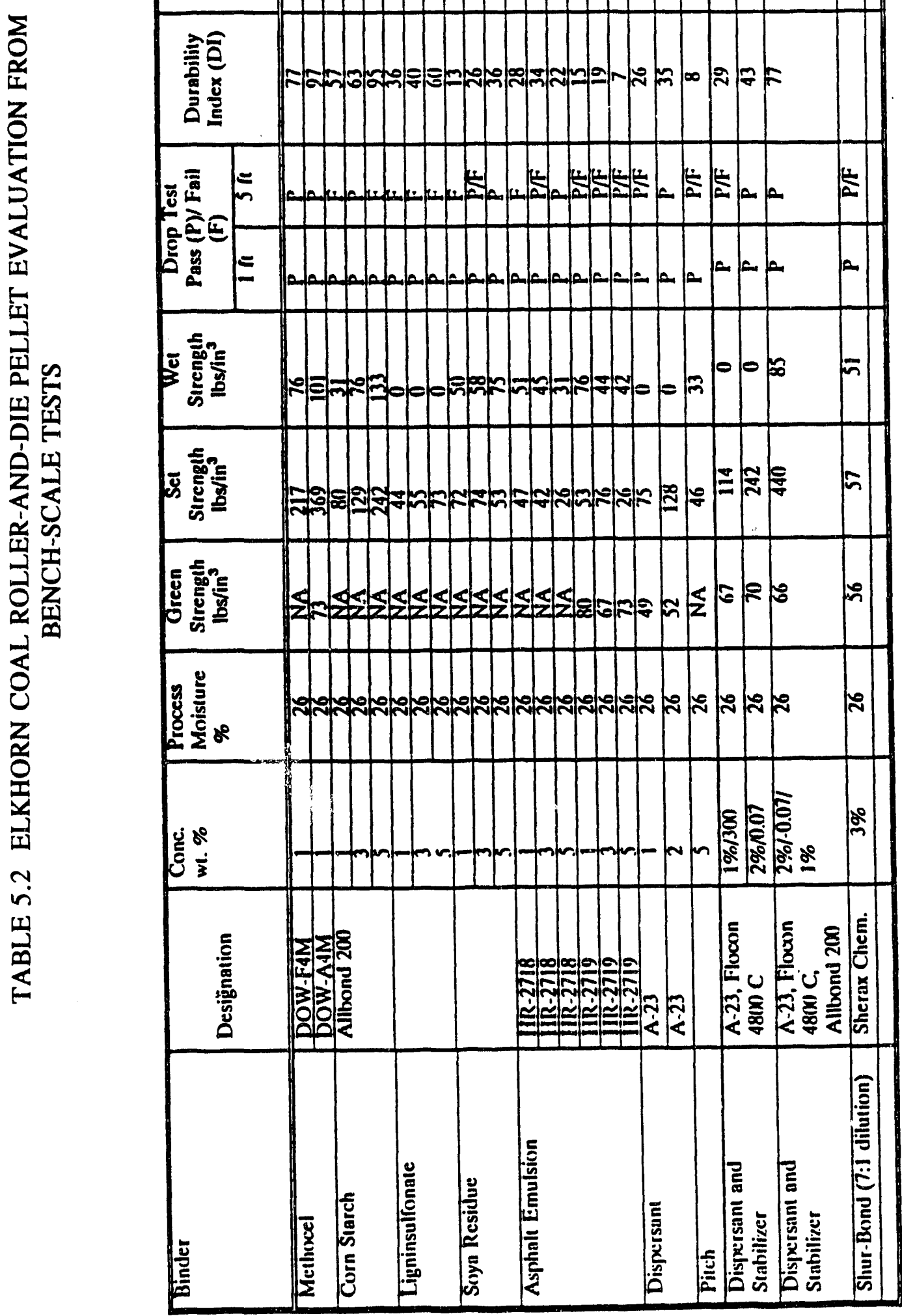




\subsubsection{Disk Pelletization}

Bench-scale disk pelletization was conducted in Battelle's large rotary mixer (which served as a non-inclined pelletizcr). All three coals were investigated. Good quality pellets were formed in the mixer when the appropriate binder and moisture levels were used. The pellets were then air-dried for a one-week or longer period. The bench-scale tests for the three coals were key in establishing process control variables prior to pilot-scale disk pelletization in a commercial unit.

5.2.2.1 Process Evaluation. A photograph of the non-inclined disk pelletizer/mixer is shown in Figure 5.3. Pellet production in this unit required very minimal process control. Once the feed mix (coal and binder) were loaded into the pelletizer, the mix was rolled. As the moisture level dropped to the 30 to 35 percent range, uniform 1/2-in. to 3/4-in. balls were formed. Since the filter-cake usually contained at least 35 percent moisture, no additional process water was required. Among the three coals pelletized, only the Utah coal required close control of the moisture content during pelletizing. Once pellets were made, they were discharged and air dried or thermally dried. The green disk pellets easily exceeded the acceptance criteria. During the later stage of the bench-scale disk pelletization evaluation, tests were also conducted in a Model 100 Andritz Sprout Bauer disk pelletizer. Photographs of the pelletizer and the disk pellets are shown in Figure 5.4 and 5.5, respectively. The green pellets obtained from this commercial unit were similar to those produced in the non-inclined disk pelletizer/mixer.

5,2.2.2 Pellet Evaluation. Similar to the roller-and-die pellets, the disk pellets prepared with the three coals were also evaluated for cured-pellet characteristics. Complete data on their strength, durability etc., are presented in the Fourth Quarterly Report. ${ }^{(1)}$ Table 5.3 presents typical data obtained with the Elkhorn-coal disk pellets. Among the binders studied, corn starch, Shur Bond, and lignin sulfonate binders showed acceptable pellet characteristics. The disk pellets exceeded the drop and durability criteria limits. The cured strength was greater than the other pellets, but, the WI indicated poor weather resistance. 


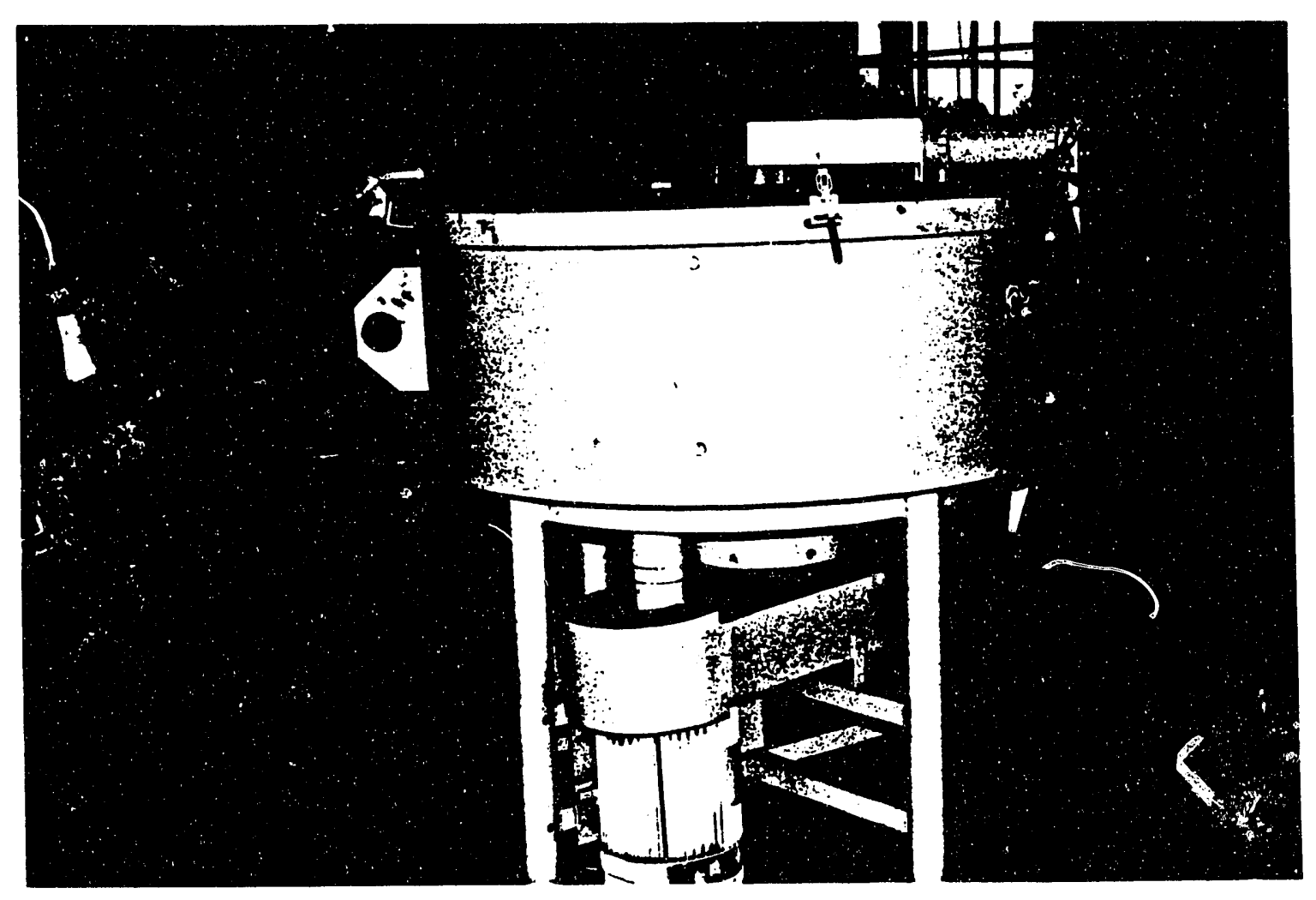

FIGURE 5.3 BENCH SCALE NON-INCLINED DISK PELLETIZATION UNIT 


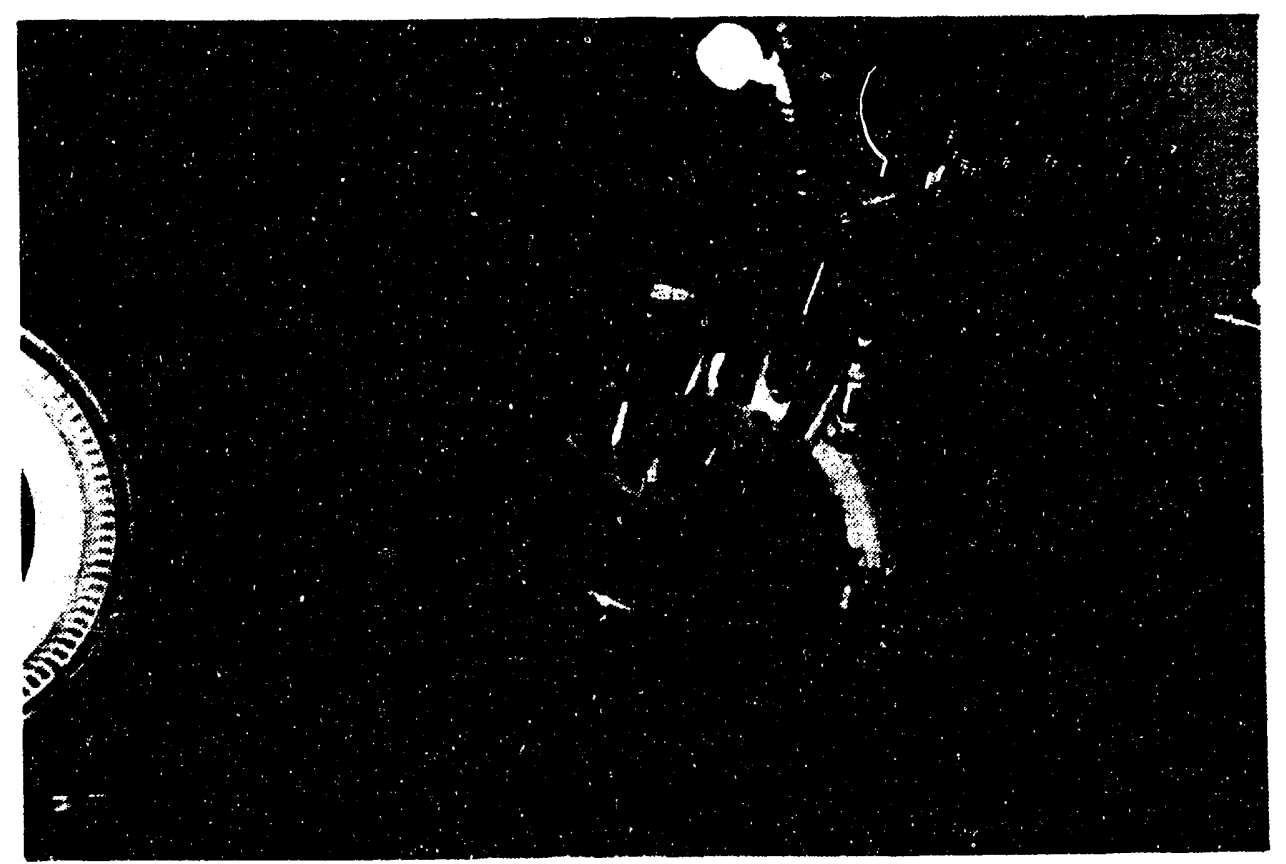

FIGURE 5.4 MODEL 100 ANDRITZ SPROUT-BAUER DISK PELLETIZER 


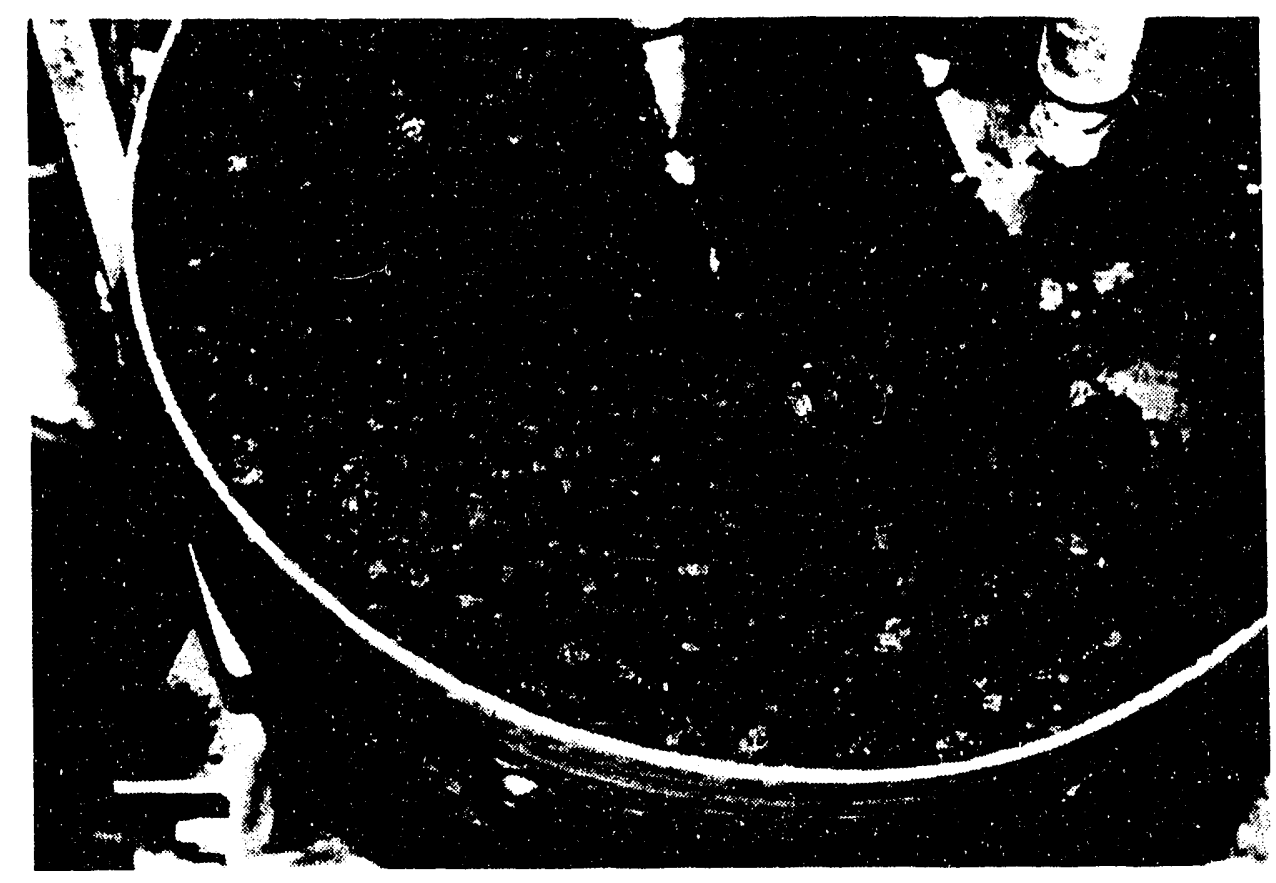

FIGURE 5.5 BENCH SCALE DISK PELLETS • 


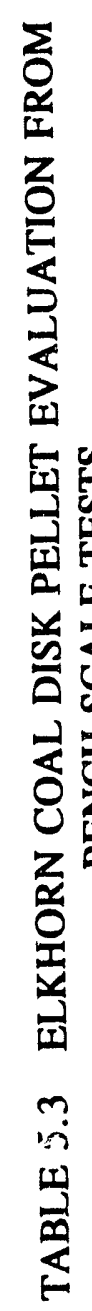

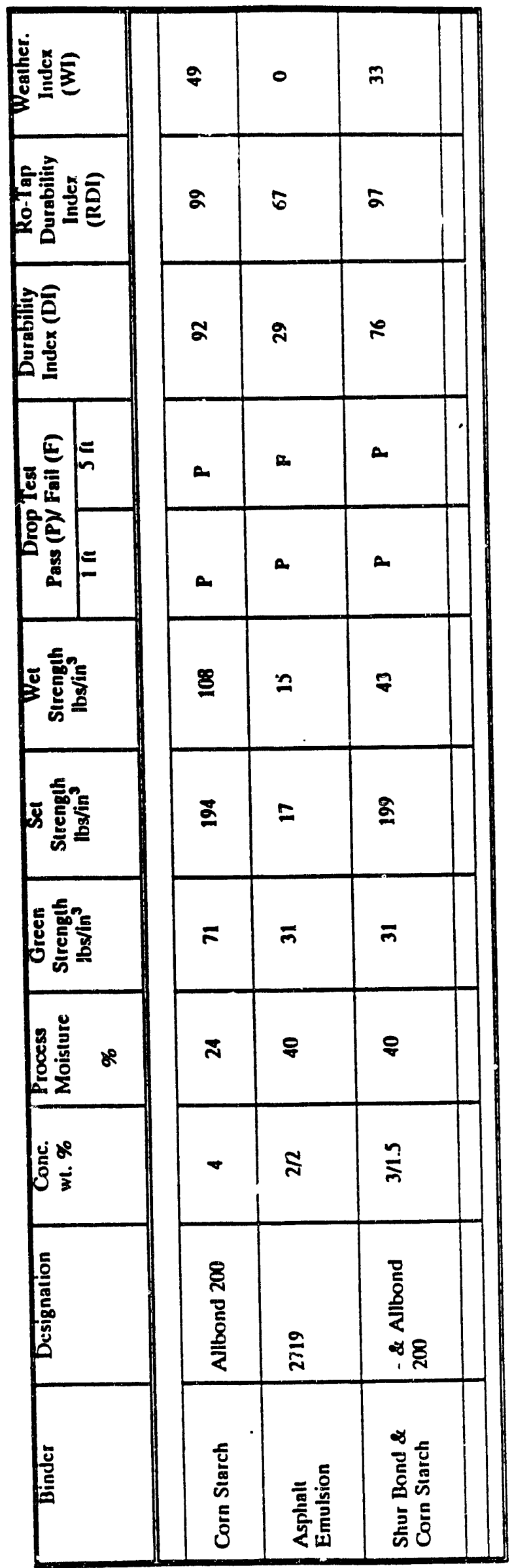




\subsubsection{Extrusion Pelletization}

The bench-scale extrusion pelletization evaluation was conducted in a Bonnot Company extruder. Extrusion tests were conducted with the Elkhorn, Utah, and Illinois No. 6 coals.

5.2.3.1 Process Evaluation. Extrusion pellet production in the Bonnot extruder is shown in Figure 5.6. In the production process, the filter-cake was mixed with the binder and was extruded continuously into 0.5 -in. diameter extrudates through the die holes. The green pellets had very little strength and often required great care in handling. These pellets were then thermally dried and were then suitable for handling as lump coal.

With all three coals, extrusion pelletization was achieved without any technical problems when corn starch was used as a binder. However, when liquid binders such as Shur Bond or lignin sulfonate were used, continuous pellet production was possible only when a small dosage of corn starch was added as a secondary binder to the mix.

5.2.3.2 Pellet Evaluation. Bench-scale pellets from the three coals were evaluated for cured pellet characteristics and were reported in detail in the Fourth Quarterly Report. ${ }^{(1)}$ Typical data obtained with Elkhorn extrusion pellets are presented in Table 5.4. Among the binders examined with the three coals, the extrusion pellets with corn starch showed very high compressive strength. The pellets also easily passed the durability criteria. Although no specific difference in coal type was evident based on pellet characteristics, Utah coal showed greater flexibility during production. 

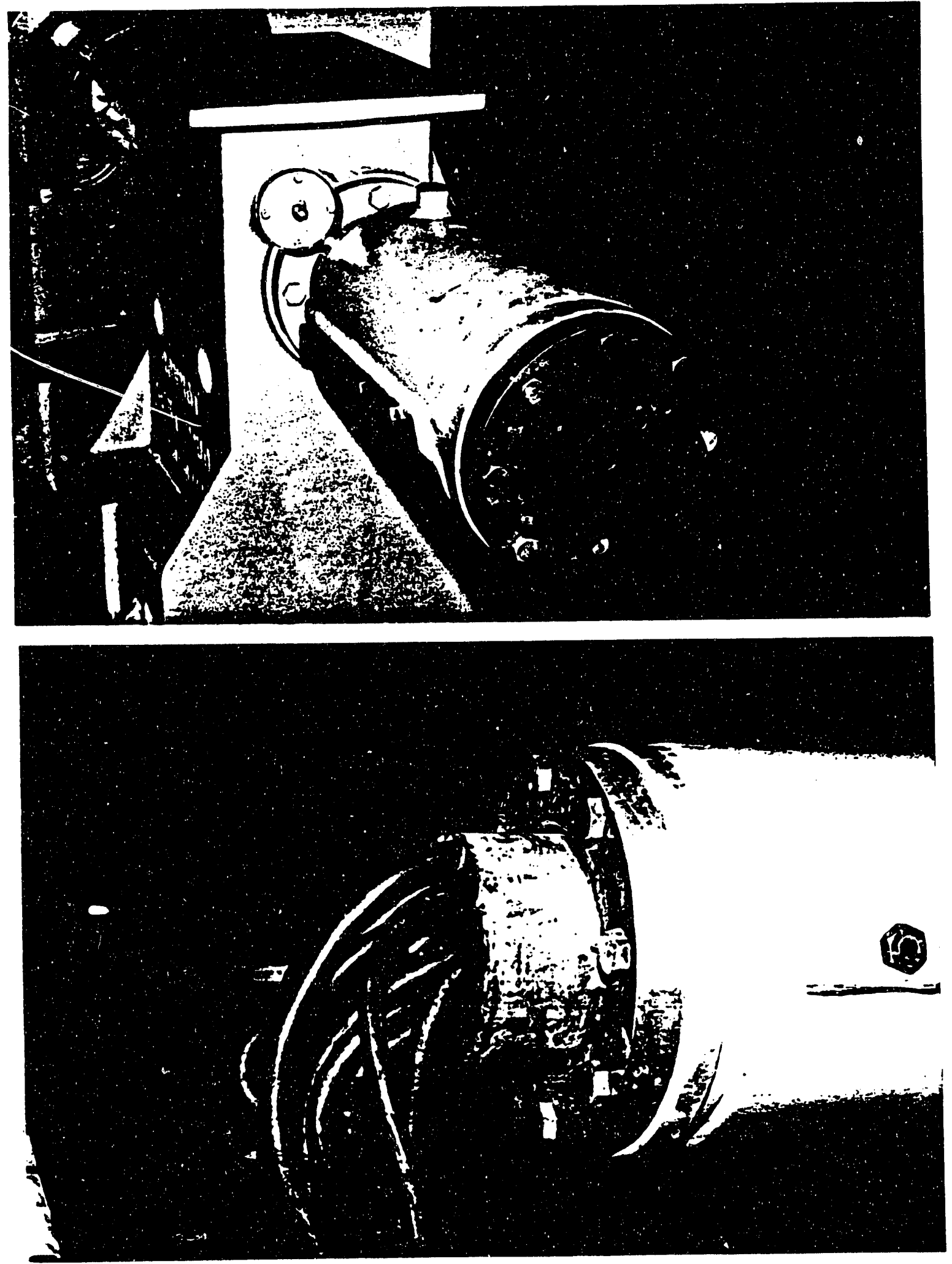

FIGURE 5.6 BENCH SCALE BONNET COMPANY EXTRUSION PELLETIZER 

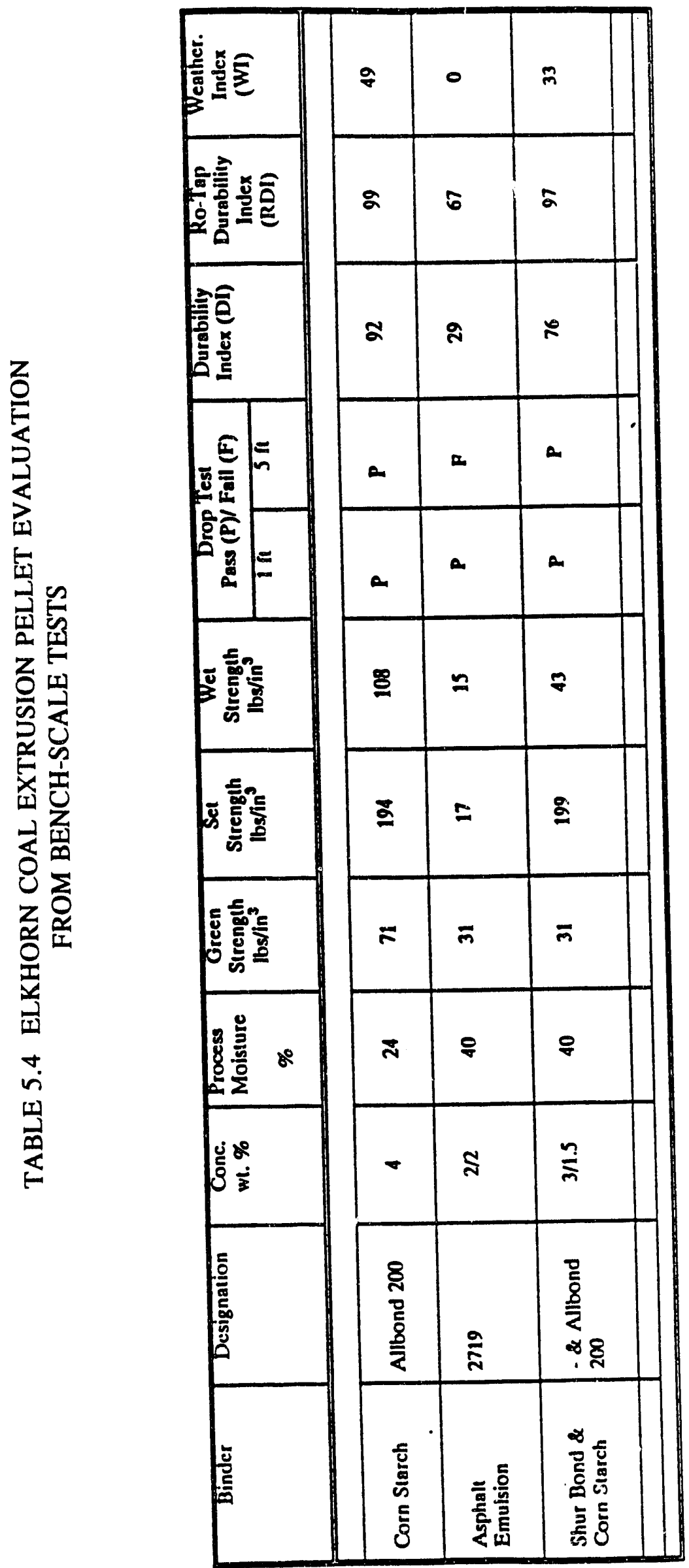


\subsection{Reslurrving Development}

Bench-scale development of the Pellet-CWF approach included evaluation of pellet suitability for CWF formulation. The purpose of this slurry formulation evaluation was to determine the slurry additive dosages, the rheology of the slurry, and to examine the effects of process variables such as coal type, pellet type, slurry loading, process temperature etc. In this section key results and information obtained from this study are presented.

\subsubsection{Slurry Formulation Methodology}

Slurry production with the bench-scale pellets was achieved in a stirred ball mill. About 500 grams of pellets were hand crushed, mixed with water and dispersant and were stirred in the ball mill for four minutes. The slurry additives were controlled to achieve 55 percent solid loading and a viscosity of $<500 \mathrm{cP}$ at $100 \mathrm{sec}^{-1}$. Typically, all the pellets made with lignin sulfonate and Shur Bond binders could be easily formulated into CWF and required only minimal dispersant. Corn starch-bound pellets were stronger and therefore more difficult to crush and also required higher dispersant dosages for formulation. Additional details on the slurry formulation are presented in the Fourth and Third Quarterly Reports. ${ }^{(1,2)}$

\subsubsection{Slurry Rheology}

Bench-scale pellets from the three coals and from the three pelletization techniques were formulated into CWF. The slurries were compared for their viscosity, solids loading, and rheological characteristics. Complete data from these evaluations were provided in the Fourth Quarterly Report. ${ }^{(1)}$ Typical CWF formulation data for the Elkhorn coal pellets from roller-and-die, disk, and extrusion pelletization techniques are presented in Table 5.5, 5.6 and 5.7, respectively. Among the various pellets evaluated, pellets with Shur Bond binder consistently required the lowest dispersant (A-23) dosage and also showed excellent suitability for slurry formulation. Lignin sulfonate binders were also found to be conducive for 


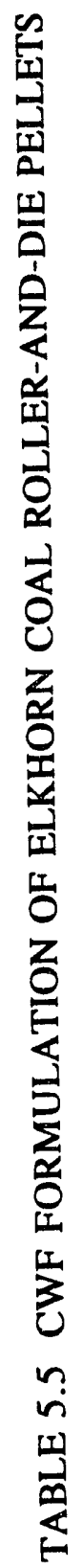

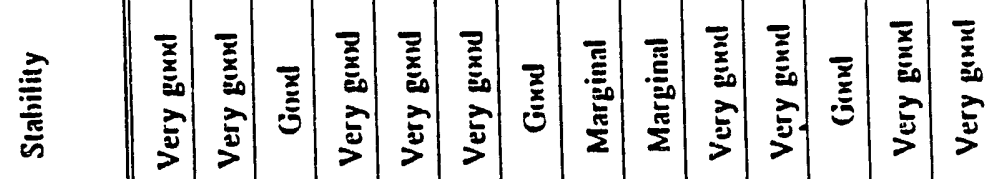

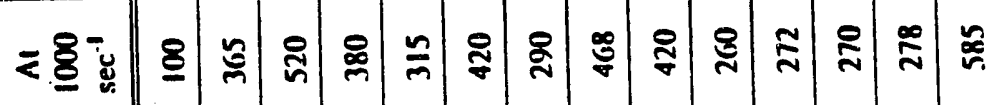

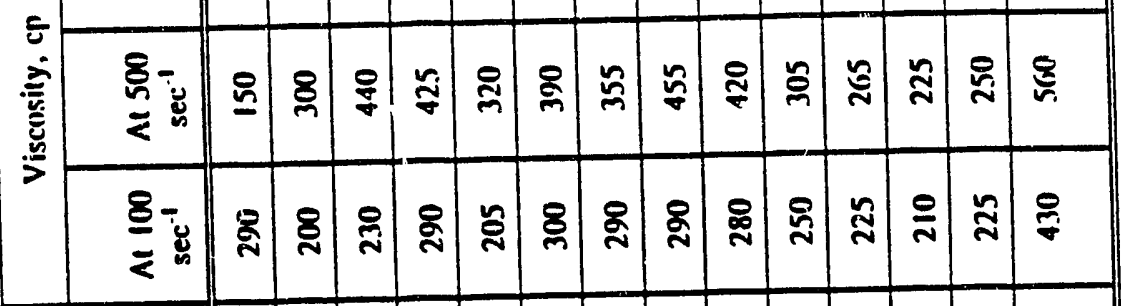

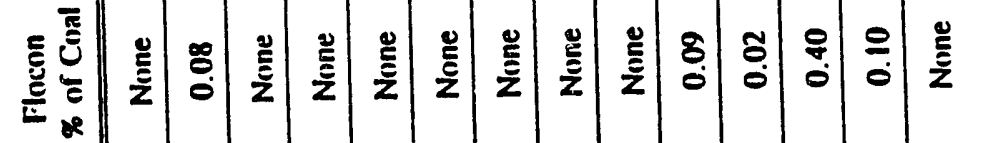

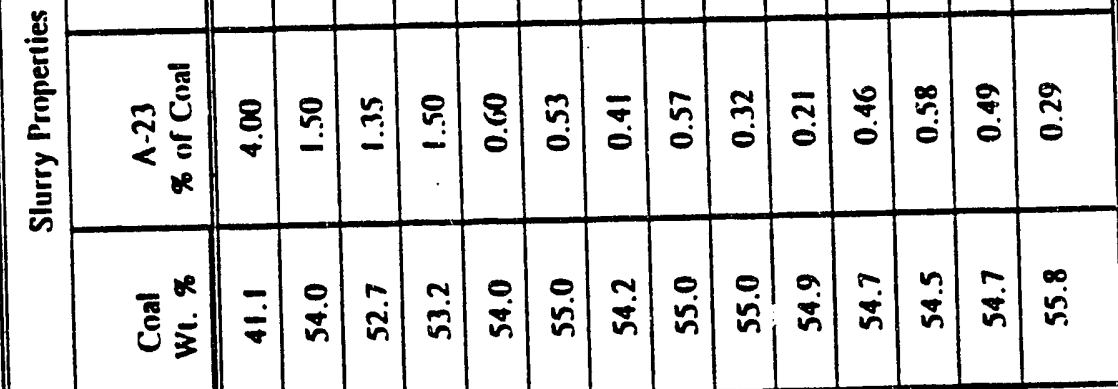

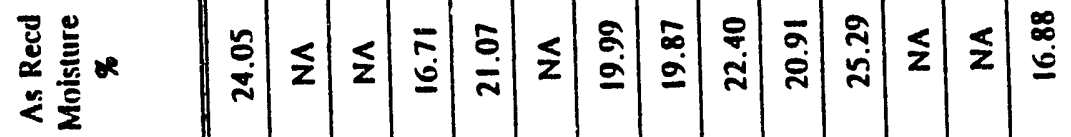

$\underbrace{\infty}_{\tilde{E}} \dot{\xi} \quad-m n-m n-m n-m n n$

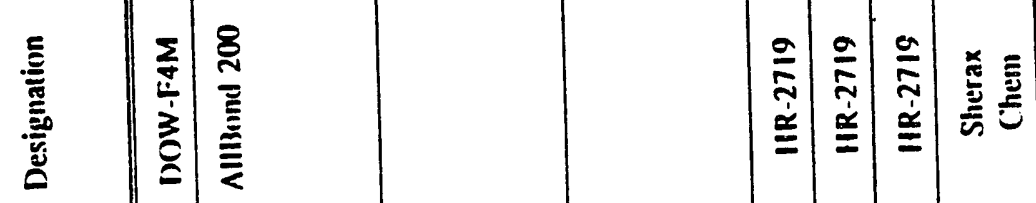

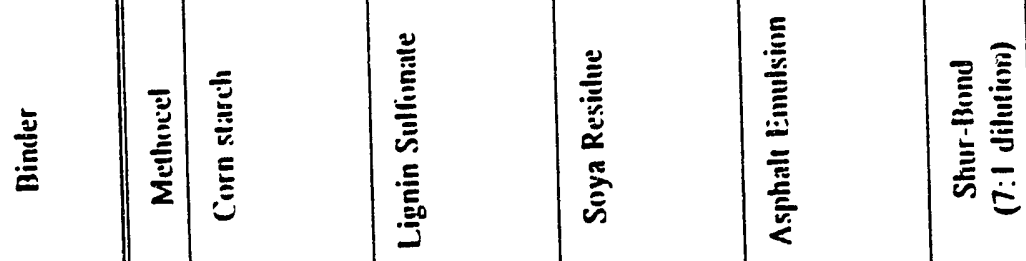




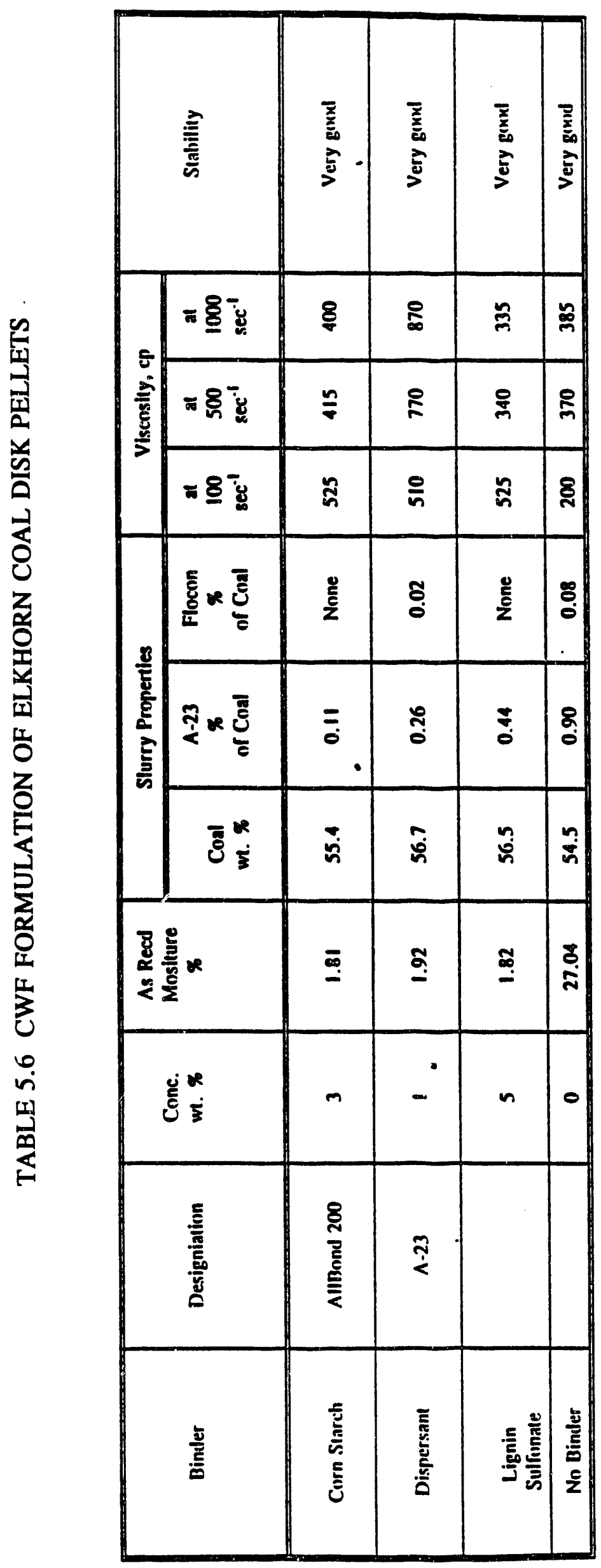




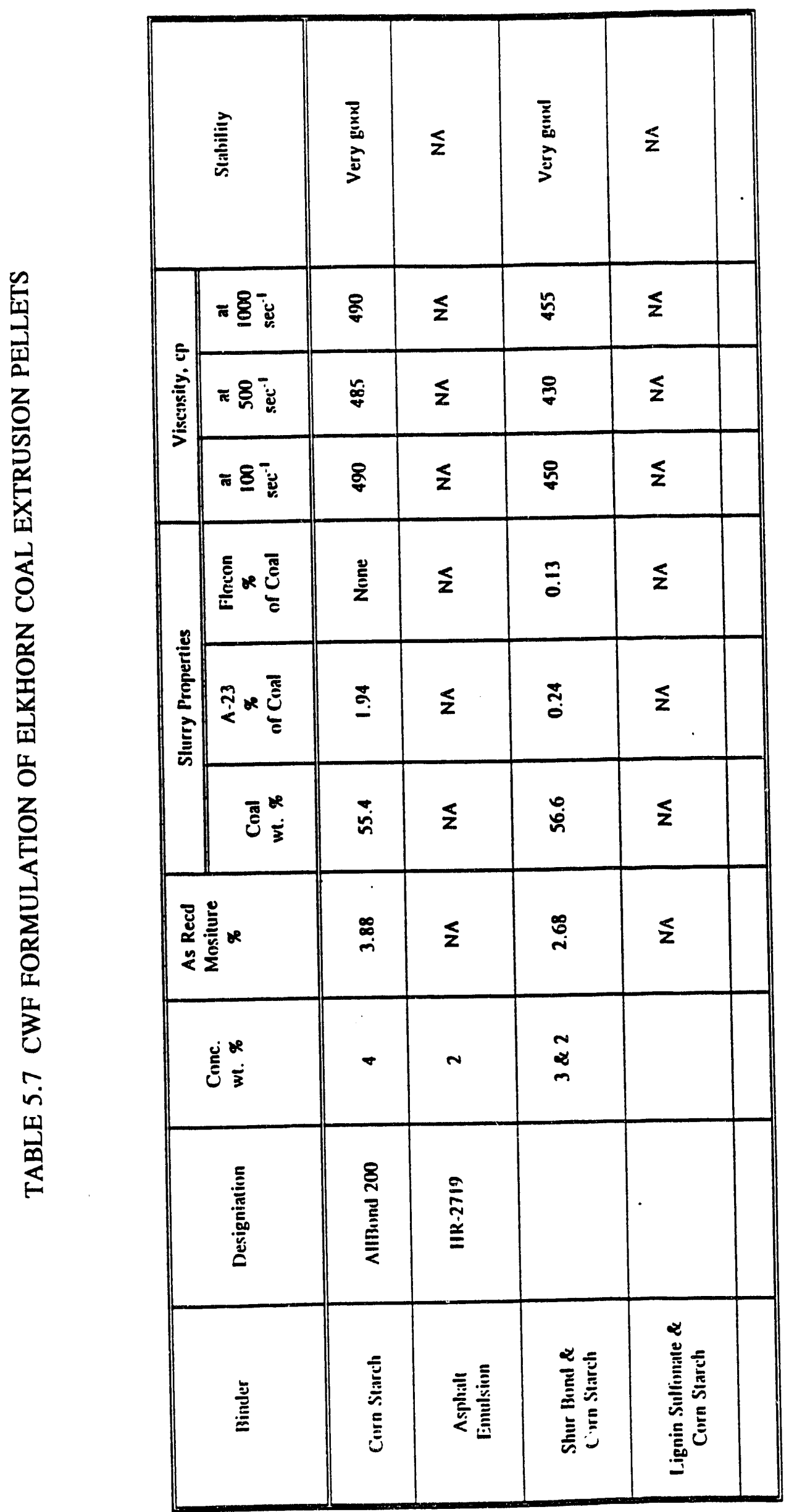


slurry formulation. These slurries had viscosities below $500 \mathrm{cP}$, shear thinning-thixotropic rheology, and good to excellent short term suitability. In general, the slurry formulation evaluation showed no specific advantage of coal or pellet type. The type of binder and binder concentration used in the pelletization step, however, were observed to have a direct influence on the dispersant requirements in the reslurrying process.

There were considerable differences in CWF formulated from pellets and clean-coal filter cake. First, the dispersant dosages for converting the filter-cake into CWF was about 75 percent to 100 percent greater than the dosages required to convert the pellets into CWF. Also, the CWF slurry prepared from pellets had a significantly larger fraction of sub $1-\mu \mathrm{m}$ particles than the slurry prepared from the filter cake. It was not clear if this increase was due to (a) the binder added during pelletization, (b) comminution which may have occurred during the various dewatering/pelletizing/reslurrying steps, or (c) the dispersion of natural agglomerates remaining from the coal cleaning process. In any event, the additional amount of fines provided a broader, more bimodal, particle size distribution which improved the rheology of the slurries.

\subsubsection{Slurry Formulation- Temperature Effects}

The effect of increasing temperature on viscosity was determined for slurries prepared from six samples of disk pellets made from Illinois No. 6 coal. Lignin sulfonate, Shur-Bond and corn starch binders were used and both air-dried and oven-dried samples of the pellets were tested. The tests on each sample were conducted over three temperature ranges: 68 to $75 \mathrm{~F}, 107$ to $111 \mathrm{~F}$, and 122 to $140 \mathrm{~F}$ ( 20 to $24 \mathrm{C}, 42$ to $44 \mathrm{C}$, and 50 to $60 \mathrm{C}$ ). The standard slurry amenability iest procedure was followed when preparing the slurries, except that splits of the slurries were heated to slightly above the target temperatures while being shaken in a water bath just before the viscosity measurements. An electric heater circulated hot air between the slurry container of the viscometer and a heat shield was placed around the container during these measurements in order to maintain the temperature of the slurry. 
The measured viscosity of the slurries dropped significantly with increasing temperature, as shown by the measurement given in Table 5.8.

This is to be expected since the viscosity (and density) of water (see data from Lange's Handbook below) decreases with temperature as follows:

\begin{tabular}{||c|c|c|}
\hline $\begin{array}{c}\text { Temperature, } \\
\text { F (C) }\end{array}$ & $\begin{array}{c}\text { Viscosity, } \\
\text { cP }\end{array}$ & $\begin{array}{c}\text { Density, } \\
\text { g/ml }\end{array}$ \\
\hline $68(20)$ & 1.0050 & 0.99823 \\
\hline $104(40)$ & 0.6560 & 0.99224 \\
\hline $140(60)$ & 0.4688 & 0.98324 \\
\hline
\end{tabular}

The viscosities of dispersed suspensions are usually evaluated in terms of relative viscosities:

$$
\mu_{\text {rel }}=\frac{\mu_{\text {slumy }}}{\mu_{\text {liquid }}}
$$

where $\mu_{\text {rel }}$ is equal to a complex function of particulate loading, dispersion, shape, and size distribution.

Figures 5.7 through 5.9 are plots of the relative viscosity versus temperature of the slurries from pellets containing the three types of binders. There did not appear to be any substantial difference in behavior between slurries prepared from the oven-dried and air-dried pellets, so results for the two types of pellets are plotted together in these figures. Figures 5.10 through 5.12 show the same data after the relative viscosities were normalized to a constant 53.6 volume percent, 54.6 weight percent at $68 \mathrm{~F}(20 \mathrm{C})$, loading to compensate for the small differences in the initial compositions of the slurries and for the greater expansion of water than coal when the slurries were heated. (The viscosity of slurries was very sensitive to loading, so the Dougherty-Krieger equation ${ }^{(3)}$ was used for the normalization.) 


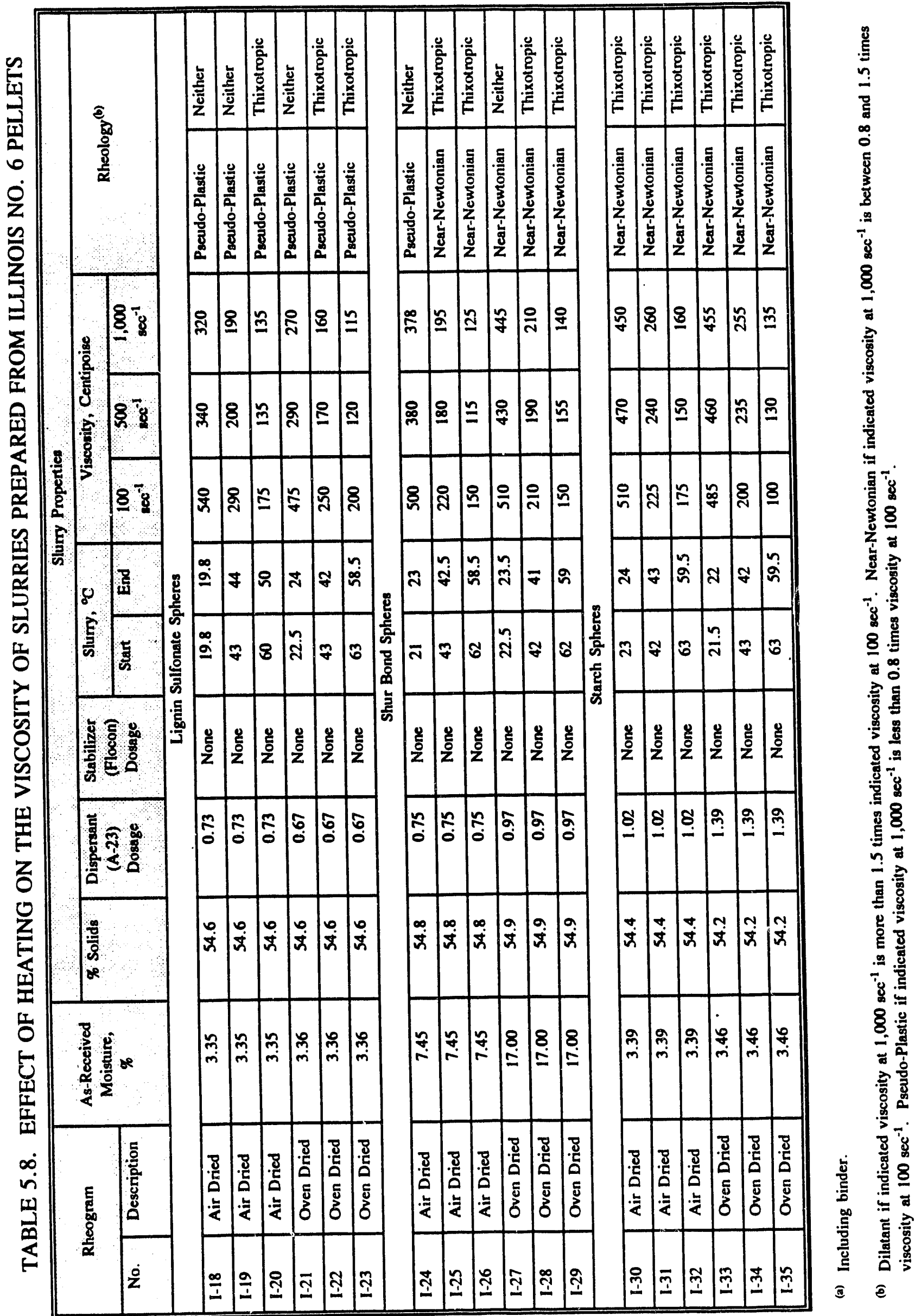




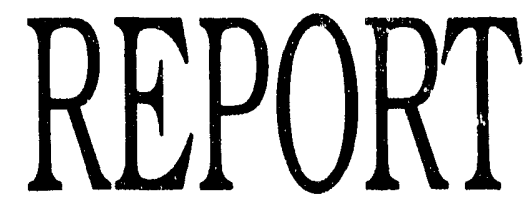

FINAL

CONTRACT PERIOD: 08/03/90 TO 08/02/92

\section{PELLETIZING/}

\section{RESLURRYING AS}

\section{A MEANS OF}

\section{DISTRIBUTING AND}

\section{FIRING CLEAN}

\section{COAL}

To

U.S. DEPARTMENT OF ENERGY

PITTSBURGH ENERGY TECHNOLOGY CENTER

PITTSBURGH, PA 15236

SEPTEMBER 29, 1992 


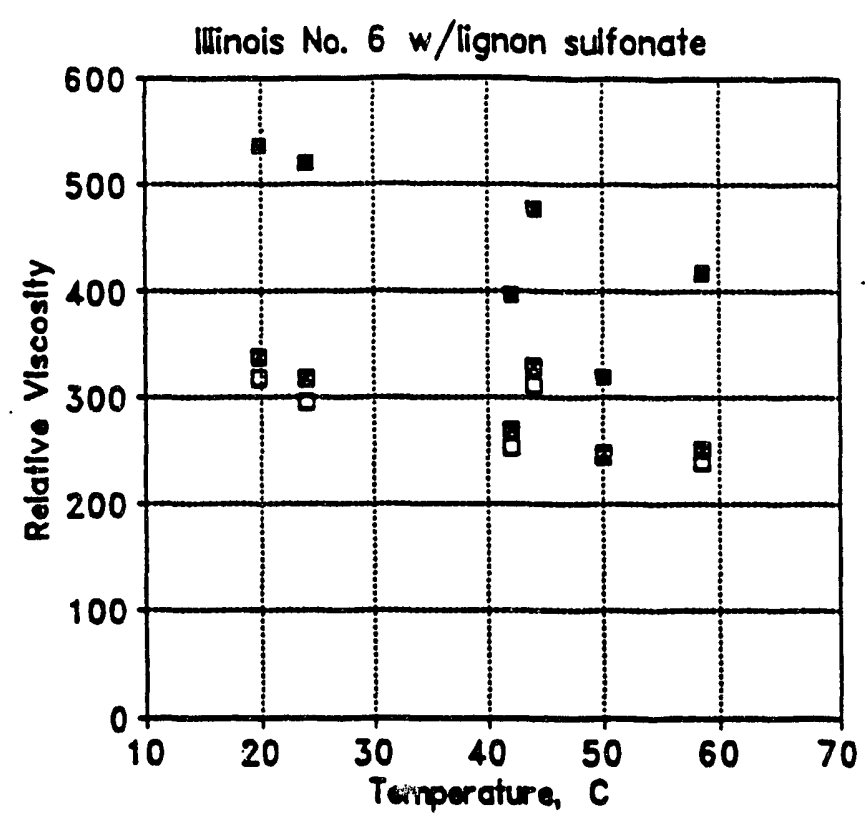

- $100 s-1$. $500 s-1$ o $1000 s-1$

FIGURE 5.7. CHANGE IN REJ_ATIVE VISCOSITY WHEN HEATING SLURRY PREPARED FROM ILLINOIS No. 6 PELLETS CONTAINING LIGNIN SULFONATE BINDER 


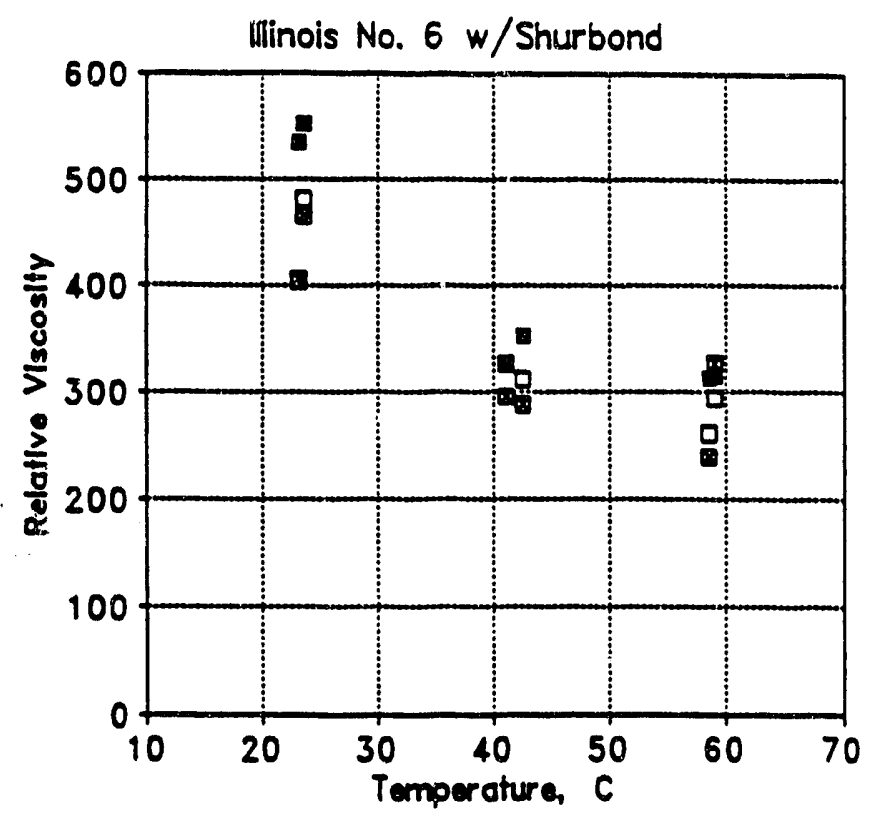

- $100 s-1 * 500 s-1$ o $1000 s-1$

FIGURE 5.8. CHANGE IN RELATIVE VISCOSITY WHEN HEATING SLURRY PREPARED FROM ILLINOIS No. 6 PELLETS CONTAINING SHUR BOND BINDER 


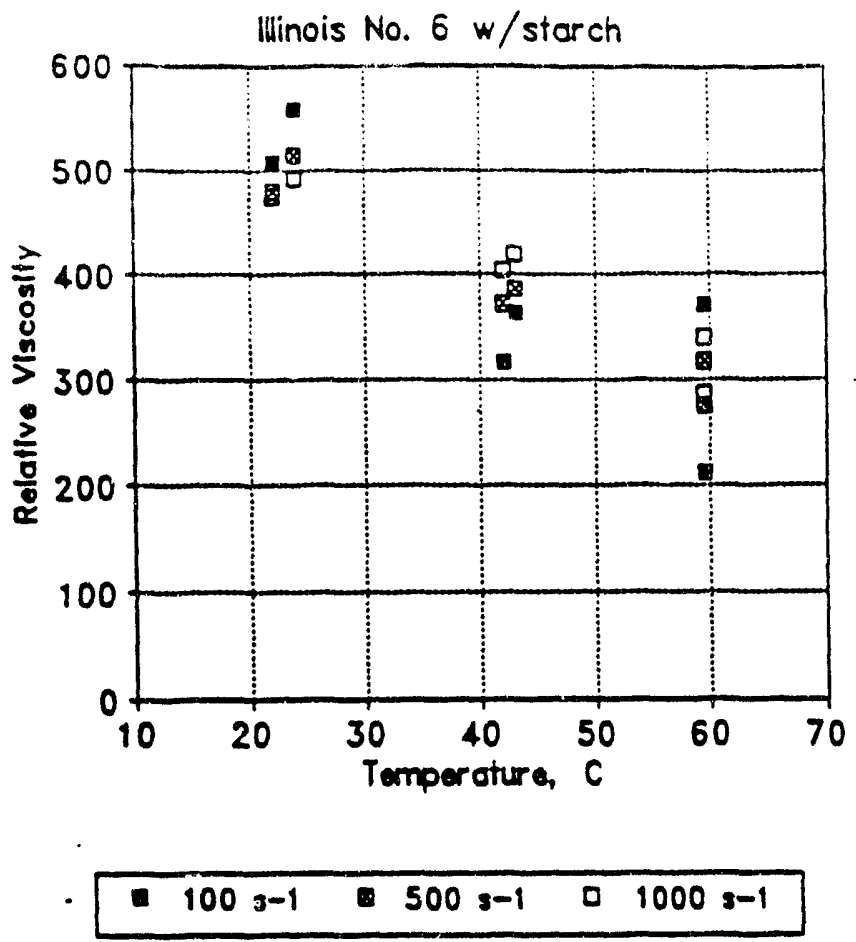

FIGURE 5.9. CHANGE IN RELATIVE VISCOSITY WHEN HEATING SLURRY PREPARED FROM ILLINOIS No. 6 PELLETS CONTAINING CORN STARCH BINDER 


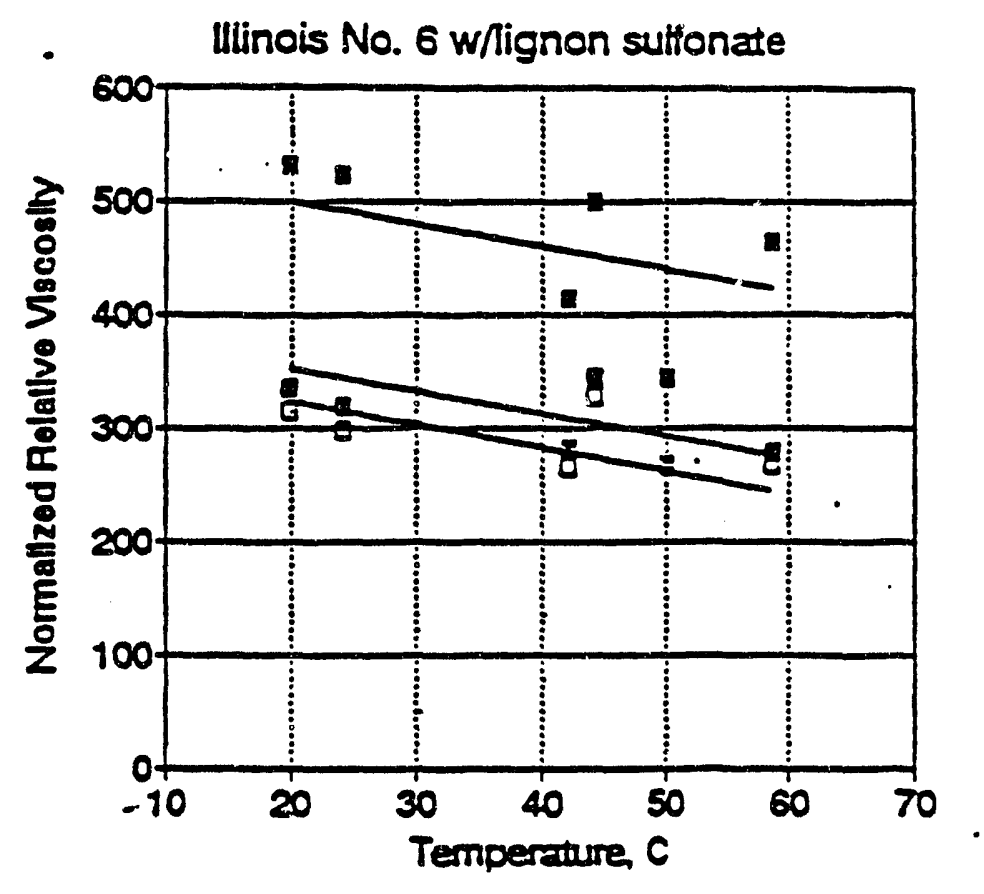

- $100=1 \quad 500=1 \quad 0 \quad 1000 \leq-1$

FIGURE 5.10. EFFECT OF TEMPERATURE ON NORMALIZED RELATIVE VISCOSITY OF SLURRY PREPARED FROM PELLETS CONTAINING LIGNIN SULFONATE BINDER 


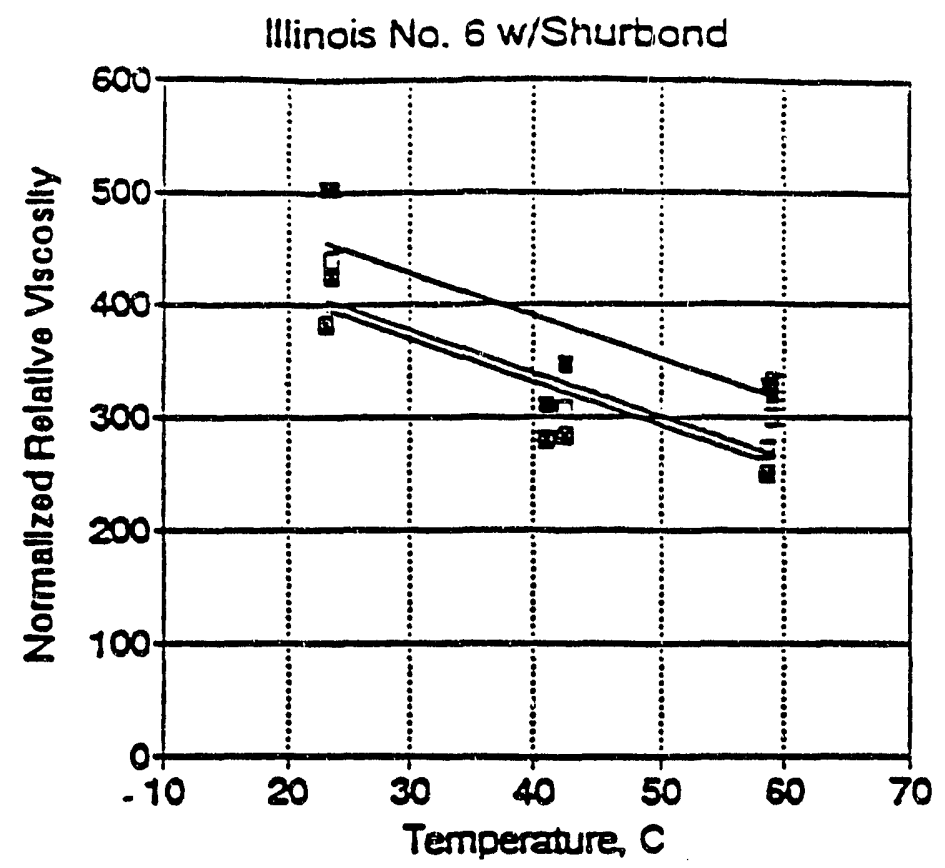

a $100 \mathrm{~s}-1 \quad 500 \mathrm{~s}-1$ a $1000 \mathrm{~s}$

FIGURE 5.11. EFFECT OF TEMPERATURE ON NORMALIZED RELATIVE VISCOSITY OF SLURRY PREPARED FROM PELLETS CONTAINING SHUR BOND BINDER 


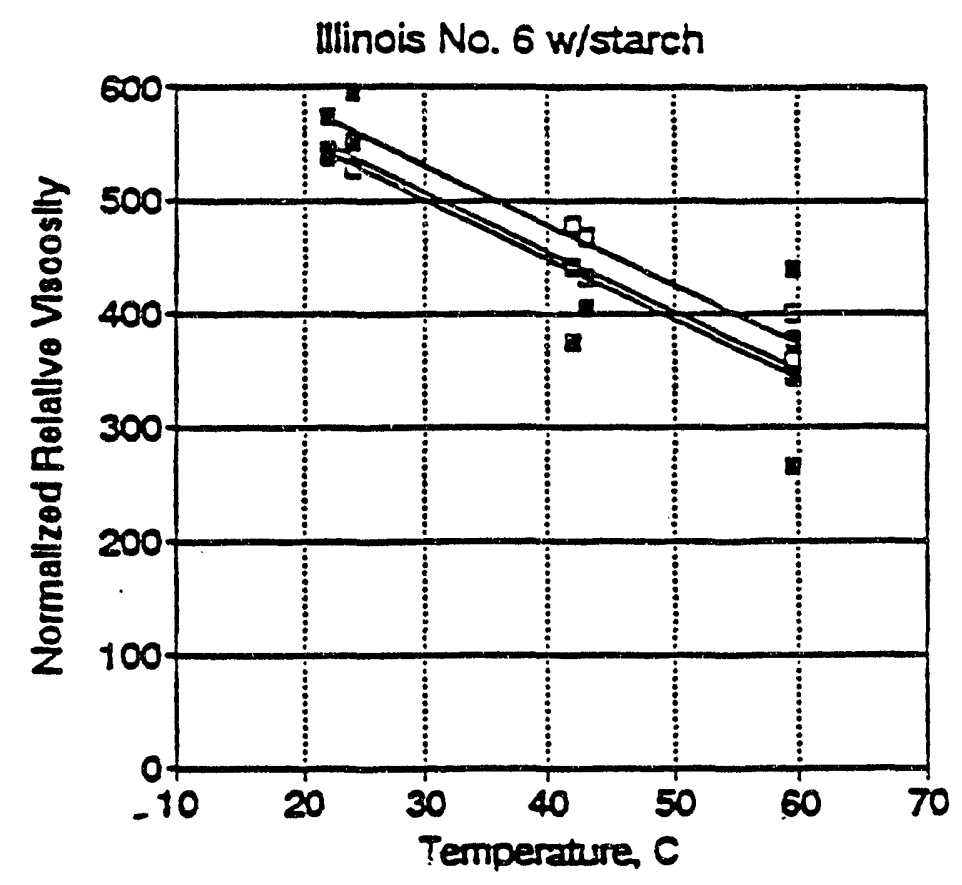

$100 s-1 \times 500 s-1$ a $1000 s-1$

FIGURE 5.12. EFFECT OF TEMPERATURE ON NORMALIZED RELATIVE VISCOSITY OF SLURRY PREPARED FROM PELLETS CONTAINING CORN STARCH BINDER 
The lines plotted in Figures 5.10 through 5.12 noted above were from a least square regression of the combined set of normalized data. The slurries prepared from the pellets with lignin sulfonate binder were shear-thinning, while slurries prepared from pellets containing the other two binders were near-newtonian over the shear rate range of 100 to $1,000 \mathrm{sec}^{-1}$.

The temperature coefficients of the normalized slurry viscosity were also different for the three binders:

\begin{tabular}{|l|c|c|c|}
\hline \multicolumn{1}{|c|}{ Binder } & $\begin{array}{c}\text { Dispersant } \\
\text { (A-23) } \\
\text { Dosage, \% }\end{array}$ & $\begin{array}{c}\text { Computed } \\
\text { Viscosity, cP } \\
68 \mathrm{~F}(20 \mathrm{C}), \\
100 \mathrm{sec}^{-1}\end{array}$ & $\begin{array}{c}\text { Relative } \\
\text { Viscosity } \\
\text { Coefficient, }\left({ }^{\circ} \mathrm{C}\right)^{-1}\end{array}$ \\
\hline Lignin Sulfonate & 0.7 & 501 & -2.0 \\
\hline Shur Bond & $0.7-1.0$ & 466 & -3.8 \\
\hline Corn Starch & $1.0-1.4$ & 589 & -5.3 \\
\hline
\end{tabular}

The negative relative viscosity coefficients suggest that the effectiveness of the A-23 dispersant improves with increasing temperatures. Positive coefficients have been reported for some types of dispersants.

\subsubsection{Mixing Technique Effects}

Alternative methods for disintegrating the pellets might offer auvantages over the stirred ball mill procedure followed in the slurry amenability testing. The alternative devices were all stirrers with various types of blades. None was quite as effective as the stirred ball mill for breaking up the fragments of pellets when reslurrying the pellets. Presented in Table 5.9 is a comparison of results for the different blade types tested on 600-gram lots of slurry. Presoaking, preheating, and ultrasonic conditioning were also investigated as methods to assist breakup, but none of the treatments increased the rate. 
TABLE 5.9. EFFECT OF BLADE TYPE ON SLURRY PRODUCTION

\begin{tabular}{|l|c|c|c||}
\hline \multicolumn{1}{|c|}{ Device } & $\mathrm{rpm}$ & $\begin{array}{c}\text { Mix Time, } \\
\text { Minutes }\end{array}$ & $\begin{array}{c}\text { +48 Mesh } \\
\text { Remaining, } \\
\text { Dry Weight \% }\end{array}$ \\
\cline { 1 - 4 } \cline { 3 - 4 } & & 3 & None \\
\hline Doubical Stirred Ball Mill & 1,200 & 5 & 20.5 \\
\hline Flat Serrated-Edge Type 1 & 1,200 & 5 & 16.1 \\
\hline Flat Serrated-Edge Type 2 & 1,200 & 5 & 17.8 \\
\hline Flat Serrated-Edge Type 3 & 2,500 & 3 & 2.8 \\
\hline Flat Serrated-Edge Type 3 & 2,500 & 12 & 1.2 \\
\hline Shrouded Flotation Prop & 1,200 & 5 & 4.9 \\
\hline
\end{tabular}

It appeared that the flat serrated-edge type blade, such as commonly used with a Cowles Dissolver, was quite effective provided it rotated at a sufficiently high speed. These blades were designed to provide an intense shearing action to viscous materials. The laboratory froth flotation machine type mechanism also performed quite well. Flotation mechanisms have a pumping action where the slurry is forced through restricted channels, which also provide an intense shearing action. After several tests it was concluded that reformulation of the pellets could be achieved in a Cowles Dissolver at appropriate speed and retention time. This procedure was therefore recommended for CWF formulation of pilotscale pellets.

\subsubsection{Dilution, Aging, and Dispersant Dosages Effects}

A brief investigation was made to determine the effect of small differences in slurry dilution and A-23 additions on viscosity. Slurry samples remaining from the temperature variation studies conducted earlier were used for this work. These slurries were made from pelletized Illinois No. 6 clean coal. For the first part of the investigation, small amounts of dilution water were added to the original slurry samples, and the viscosities were measured after each incremental dilution. Three or four water additions were made to each sample so 
that a set of viscosity measurements was obtained for samples containing between 52.8 and 54.8 percent by weight of the same dispersed particulate material. The dilution/viscosity data are listed in Table 5.10. As expected from previous work ${ }^{(3)}$, the viscosities at the three shear rates checked (at 100,500, and 1,000 sec-1 ) showed a linear relationship when plotted on a logarithmic scale against total solids or particulate solids concentration. This is illustrated in Figures 5.13 and 5.14. Judging from the plotted data, one can expect a 30 to 60 percent reduction in slurry viscosity when one reduces the solids loading of a slurry by 1 percent.

The above viscosity measurements also provided an indication of the effect that aging had upon slurry rheology since the original samples had been stored for about one month before starting the dilution studies. The viscosity measurements made before and after storage are compared in Table 5.11. In each instance, there was a considerable rise in viscosity during storage, although the increase was most pronounced at the $100 \mathrm{sec}^{-1}$ shear rate.

A freshly prepared slurry was used to determine the effect of changing dispersant concentration upon rhzology. The slurry was prepared by grinding air-dried pellets containing a corn starch binder in a stirred ball mill with the proper amount of A-23 based upon previous testing. Viscosity measurements were made before and after small increments of A-23 were added to this slurry. The data are presented in Table 5.12 and plotted in Figure 5.15. As shown in this figure, a 30 percent increase in the amount of A-23 added cut the viscosity at $100 \mathrm{sec}^{-1}$ by more than half. The extra A-23 also changed the rheology from a pseudoplastic shear-thinning behavior to a dilatant shear-thickening behavior. 
TABLE 5.10. RESULTS OF DILUTION TESTS ON RESLURRYING ILLINOIS No. 6 DISK PELLETS

\begin{tabular}{|c|c|c|c|c|c|}
\hline \multirow{2}{*}{$\begin{array}{c}\text { Slurry } \\
\text { Total } \\
\text { Solids, \% }\end{array}$} & \multicolumn{3}{|c|}{ Viscosity, cP } & \multirow{2}{*}{$\begin{array}{l}\text { Dispersant } \\
\text { (A-23), \% }\end{array}$} & \multirow{2}{*}{$\begin{array}{c}\text { Coal, } \\
\text { Weight \% }\end{array}$} \\
\hline & $100 \sec ^{-1}$ & $500 \mathrm{sec}^{-1}$ & $1,000 \mathrm{sec}^{-1}$ & & \\
\hline \multicolumn{6}{|c|}{ Air-Dried with Lignin Sulfonate Binder } \\
\hline 55.02 & 1,150 & 475 & 420 & 0.73 & 54.62 \\
\hline 54.33 & 725 & 360 & 310 & 0.73 & 53.94 \\
\hline 54.15 & 550 & 285 & 250 & 0.73 & 53.76 \\
\hline 53.60 & 350 & 210 & 190 & 0.73 & 53.21 \\
\hline \multicolumn{6}{|c|}{ Oven-Dried with Shur Bond Binder } \\
\hline 55.41 & 1,495 & 760 & 655 & 0.97 & 54.88 \\
\hline 54.93 & 1,000 & 555 & 495 & 0.97 & 54.40 \\
\hline 54.12 & 525 & 315 & 290 & 0.97 & 53.60 \\
\hline 53.66 & 400 & 240 & 220 & 0.97 & 53.14 \\
\hline \multicolumn{6}{|c|}{ Air-Dried with Corn Starch Binder } \\
\hline 55.05 & 2,050 & 695 & 550 & 1.02 & 54.49 \\
\hline 54.56 & 1,200 & 540 & 450 & 1.02 & 54.01 \\
\hline 54.04 & 800 & 425 & 360 & 1.02 & 53.49 \\
\hline 53.58 & 625 & 360 & 315 & 1.02 & 53.04 \\
\hline 53.28 & 450 & 290 & 260 & 1.02 & 52.74 \\
\hline \multicolumn{6}{|c|}{ Oven-Dried with Corn Starch Binder } \\
\hline 55.23 & 1,350 & 675 & 570 & 1.53 & 54.40 \\
\hline 54.67 & 825 & 500 & 440 & 1.53 & 53.85 \\
\hline 54.21 & 575 & 395 & 350 & 1.53 & 53.39 \\
\hline 53.81 & 425 & 320 & 295 & 1.53 & 53.00 \\
\hline
\end{tabular}


TABLE 5.11. COMPARISONS OF SLURRY VISCOSITIES BEFORE AND AFTER ONE-MONTH STORAGE

\begin{tabular}{|c|c|c|c|c|c|c|}
\hline \multirow{2}{*}{\multicolumn{2}{|c|}{$\begin{array}{c}\text { Slurry } \\
\text { Total } \\
\text { Solids, \% }\end{array}$}} & \multicolumn{3}{|c|}{ Viscosity, $c P$} & \multirow{2}{*}{$\begin{array}{c}\text { A-23 } \\
\%\end{array}$} & \multirow{2}{*}{$\begin{array}{c}\text { Coal, } \\
\text { Weight \% }\end{array}$} \\
\hline & & 100 & 500 & 1,000 & & \\
\hline \multicolumn{7}{|c|}{ Air-Dried with Lignin Sulfonate Binder } \\
\hline Before & 55.00 & 540 & 340 & 320 & 0.73 & 54.60 \\
\hline After & 55.02 & 1,150 & 475 & 420 & 0.73 & 54.62 \\
\hline \multicolumn{7}{|c|}{ Oven-Dried with Shur Bond Binder } \\
\hline Before & 55.45 & 510 & 430 & 445 & 0.97 & 54.92 \\
\hline After & 55.41 & 1,495 & 760 & 655 & 0.97 & 54.88 \\
\hline \multicolumn{7}{|c|}{ Air-Dried with Corn Starch Binder } \\
\hline Before & 55.00 & 510 & 470 & 450 & 1.02 & 54.44 \\
\hline After & 55.05 & 2,050 & 695 & 550 & 1.02 & 54.49 \\
\hline \multicolumn{7}{|c|}{ Oven-Dried with Corn Starch Binder } \\
\hline Before & 55.00 & 485 & 460 & 455 & 1.53 & 54.17 \\
\hline After & 55.23 & 1,350 & 675 & 570 & 1.53 & 54.40 \\
\hline
\end{tabular}

TABLE 5.12. EFFECT OF INCREMENTAL A-23 ADDITIONS ON THE VISCOSITY OF FRESH SLURRY PREPARED FROM AIR-DRIED PELLETS CONTAINING CORN STARCH BINDER

\begin{tabular}{|c|c|c|c|c|c|c|}
\hline \multirow{2}{*}{\multicolumn{2}{|c|}{$\begin{array}{c}\text { Slurry } \\
\text { Total } \\
\text { Solids, \% }\end{array}$}} & \multicolumn{3}{|c|}{ Viscosity, Centipoise } & \multirow{3}{*}{$\begin{array}{c}\text { Total } \\
\text { A-23, } \\
\% \\
1.01\end{array}$} & \multirow{3}{*}{$\begin{array}{c}\begin{array}{c}\text { Coal, } \\
\text { Weight \% }\end{array} \\
55.15\end{array}$} \\
\hline & & \multirow{2}{*}{$\begin{array}{c}100 \\
\sec ^{-1}\end{array}$} & \multirow{2}{*}{$\begin{array}{c}500 \\
\sec ^{-1}\end{array}$} & \multirow{2}{*}{$\begin{array}{r}1,000 \\
\sec ^{-1} \\
580\end{array}$} & & \\
\hline As Prepared & 55.71 & & & & & \\
\hline Diluted & 55.00 & 700 & 470 & 420 & 1.01 & 54.45 \\
\hline Added A-23 & 54.99 & 525 & 450 & 420 & 1.07 & 54.41 \\
\hline Added $\mathrm{A}-23$ & 54.97 & 290 & 345 & 360 & 1.19 & 54.32 \\
\hline Added $A-23$ & 54.95 & 250 & 315 & 340 & 1.31 & 54.24 \\
\hline
\end{tabular}




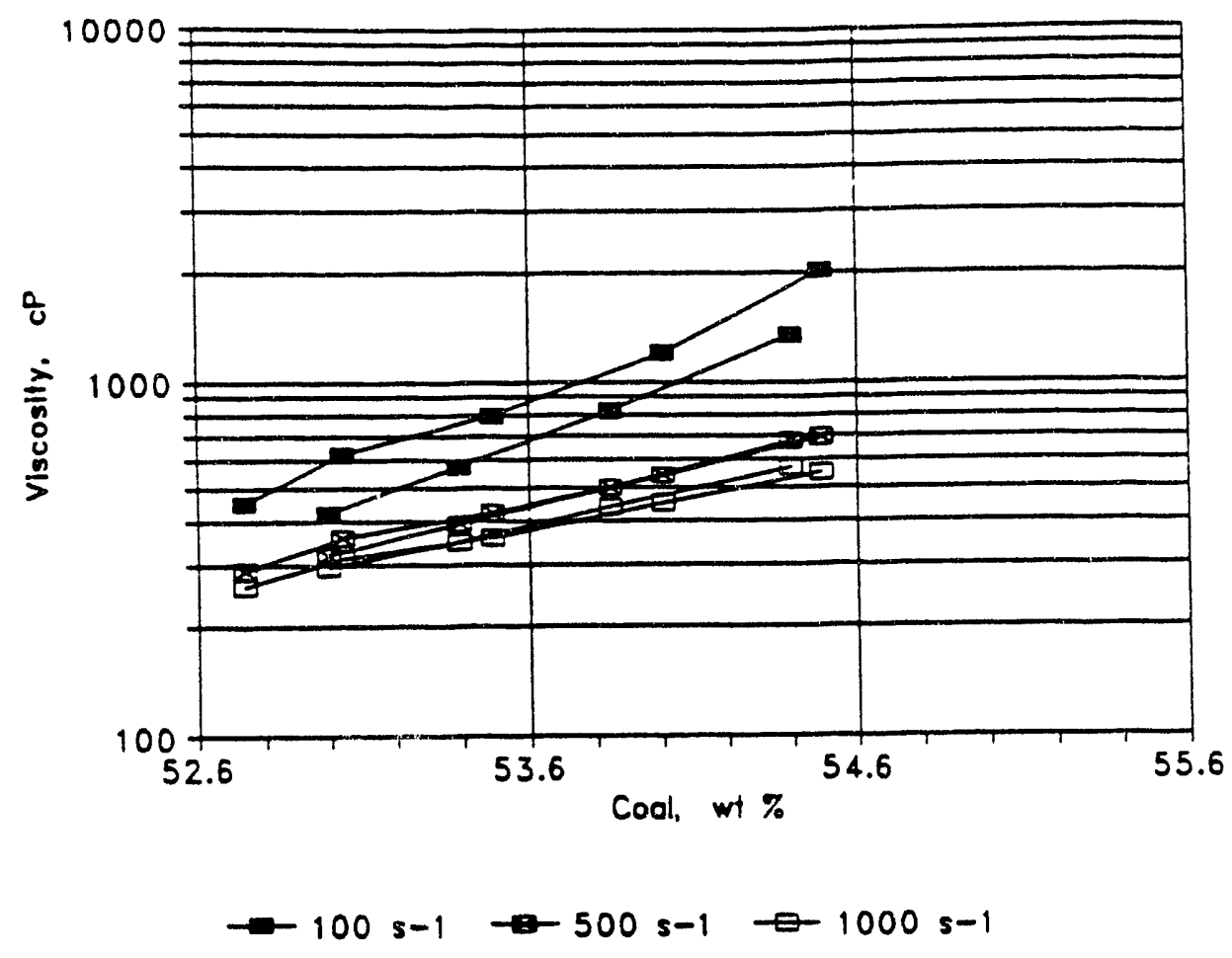

FIGURE 5.13. EFFECT OF SMALL DILUTIONS ON THE VISCOSITY OF SLURRIES PREPARED FROM AIR DRIED AND OVEN DRIED ILLINOIS No. 6 PELLETS PREPARED WITH CORN STARCH BINDER 


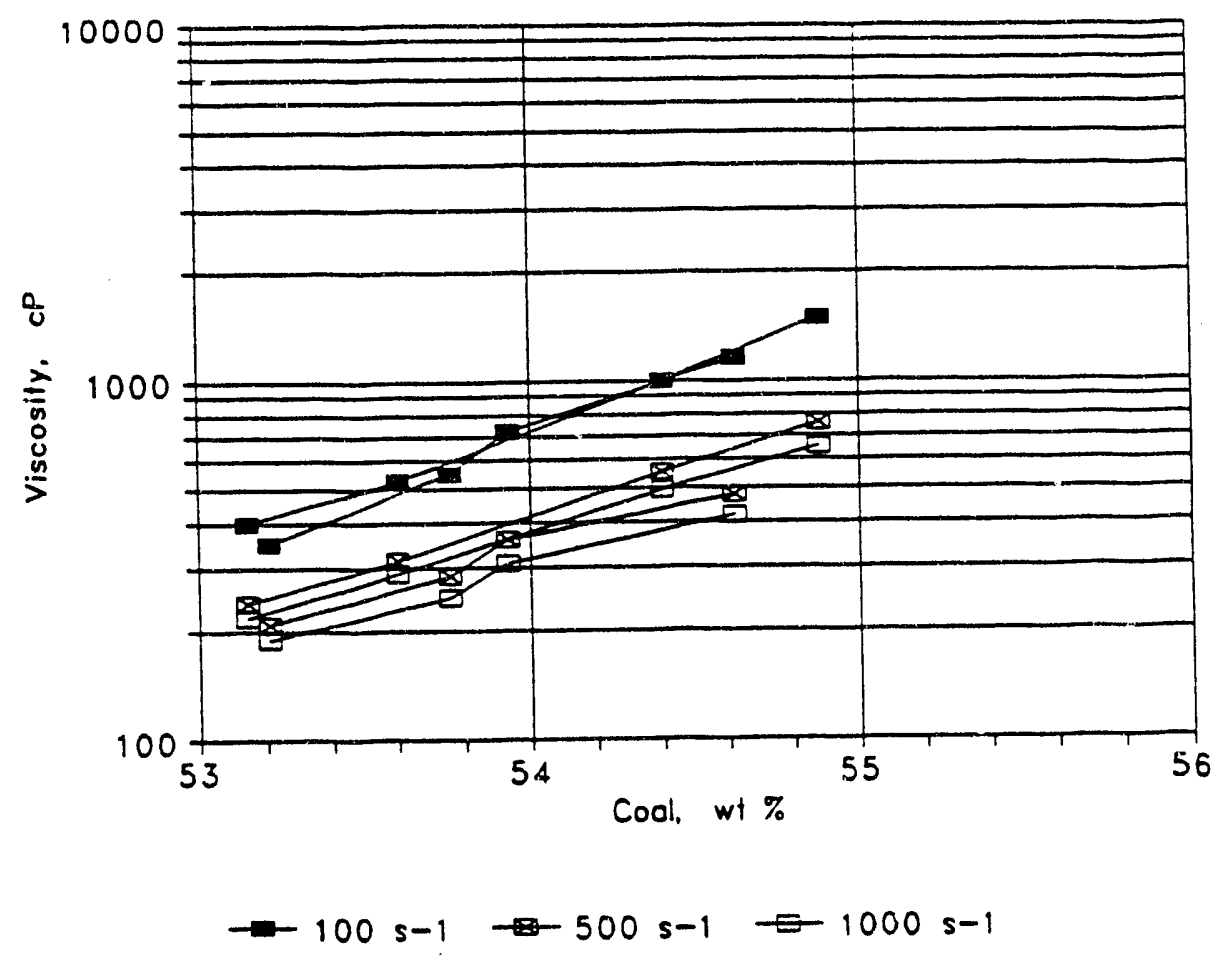

FIGURE 5.14. EFFECT OF SMALL DILUTIONS ON THE VISCOSITY OF SLURRIES PREPARED FROM ILLINOIS No. 6 PELLETS PREPARED WITH LIGNIN SULFONATE AND SHUR BOND BINDERS 


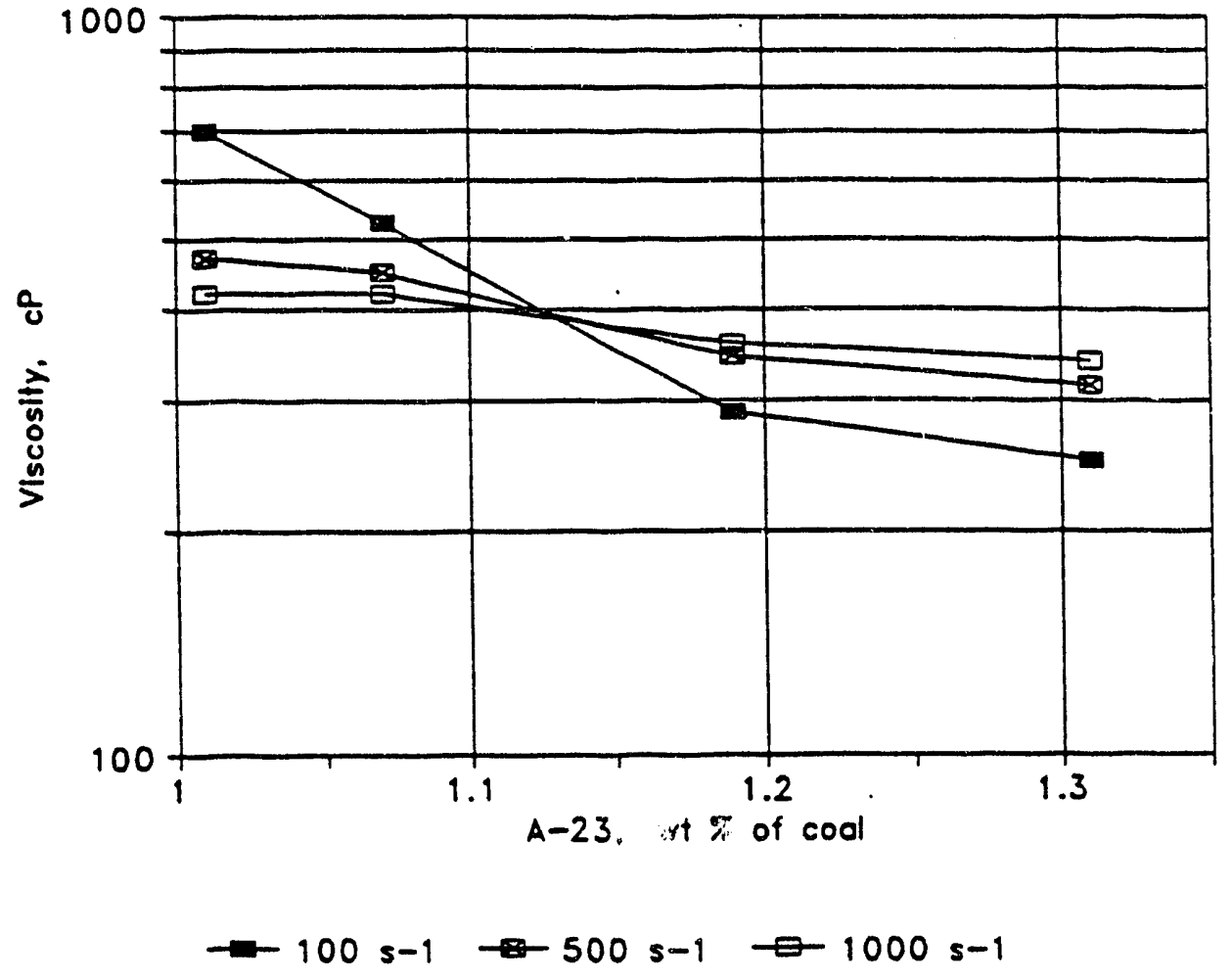

FIGURE 5.15 EFFECT OF INCREASED DISPERSANT DOSAGE ON VISCOSITY OF SLURRIES PREPARED FROM IILINOIS No. 6 PELLETS CONTAINING CORN STARCH BINDER 


\subsection{Initial Atomizairun Testing}

The objective of this effort was to compare the suitability of slurries prepared from pellets and from clean-coal filter cake (prior to pelletization), in terms of their atomization characteristics. A series of slurry atomization tests were coriducted on 200-lb lots of the following three samples:

- Illinois No. 6 coal, starch-bound disk nellets

- Illinois No. 6 clean-ccal filter cake

- Elkhorn, Shur Bond-bound, disk pellets.

The pellets were prepared at Battelle in late June, 1991 for testing at the Jim Walter Resources/The University of Alabama atomization facility. Coal Water Fuel (CWF) slurries were prepared by mixing the coal pellets (pre-ground to -20 mesh at Battelle before shipping)

$h$ water and dispersant (A-23) and agitating in an open top 55-gal drum. A simple three ... ade propeller was used to successfully convert the coal and water into CWF. No stabilizer was used or needed. The slurry showed good uniformity and short-term stability, viscosities generally below $500 \mathrm{cP} @ 100 \mathrm{sec}^{-1}$, and a shear thinning behavior up to the maximum shear rate measured $\left(1000 \mathrm{sec}^{-1}\right)$. It was also found that the quantity of A-23 dispersant used in the CWF formulation was significantly lower than the optimal dosage levels found in the labscale tests.

\subsubsection{Atomization Test Procedure}

CWF slurries from the 55-gallon container were pumped by a Moyno progressivecavity pump into the atomization test chamber. Any particles not thoroughly disintegrated during the formulation stage were reduced to -325 mesh by passage through the pump or removed in the strainer placed before the nozzle. The slurry was atomized during short test periods at flow rates of approximately $128 \mathrm{lb}$ slurry/hr, see Figures 5.16 and 5.17. The slurry droplet size was measured by a Malvern 2600 laser-based particle size counter. The test data were automatically manipulated by the Malvern to generate particie-size distributions in terms of Sauter Mean Diameter (SMD). The SMD data represents the atomization 


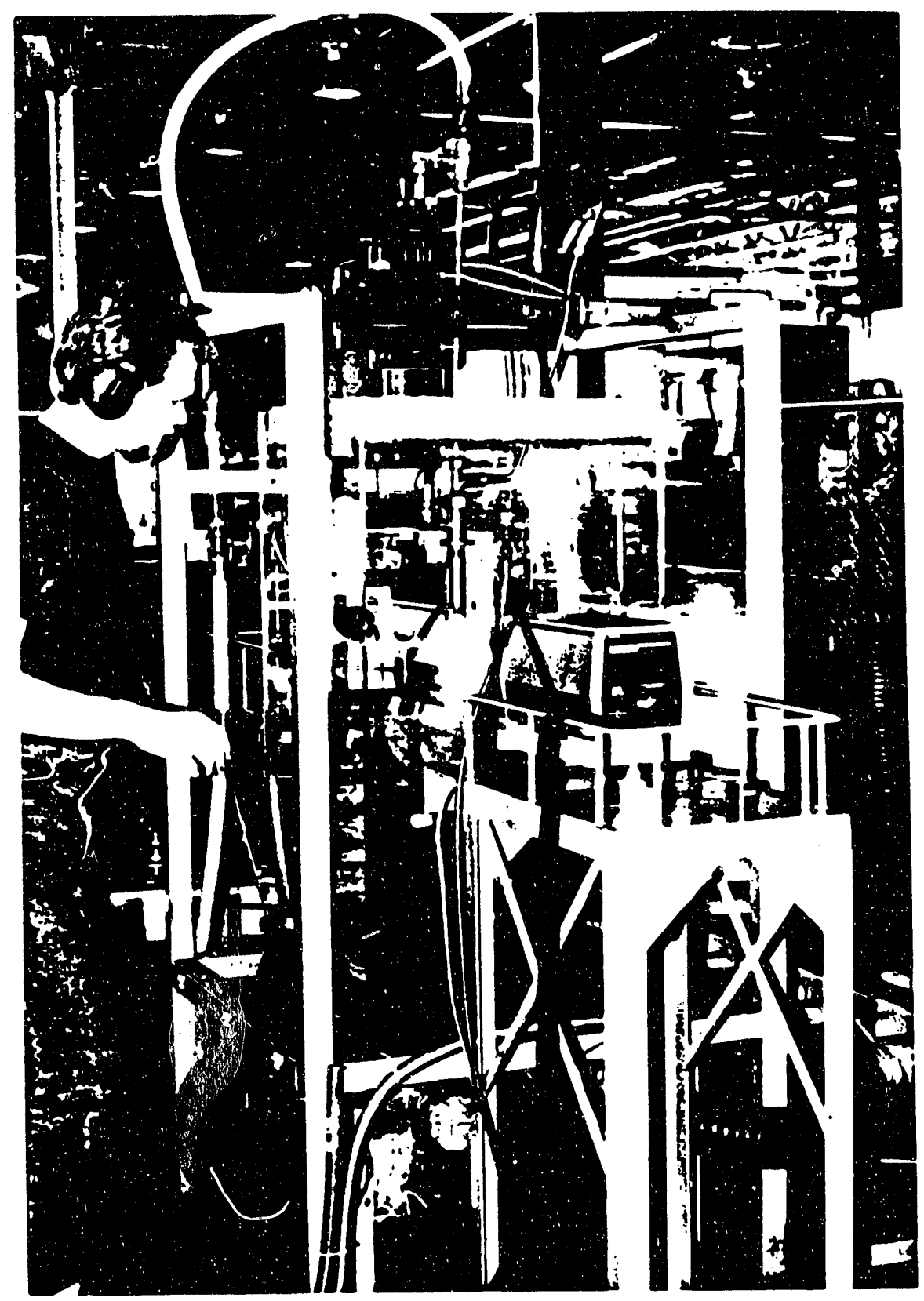

FIGURE 5.16. SLURRY ATOMIZATION TEST FACILITY 


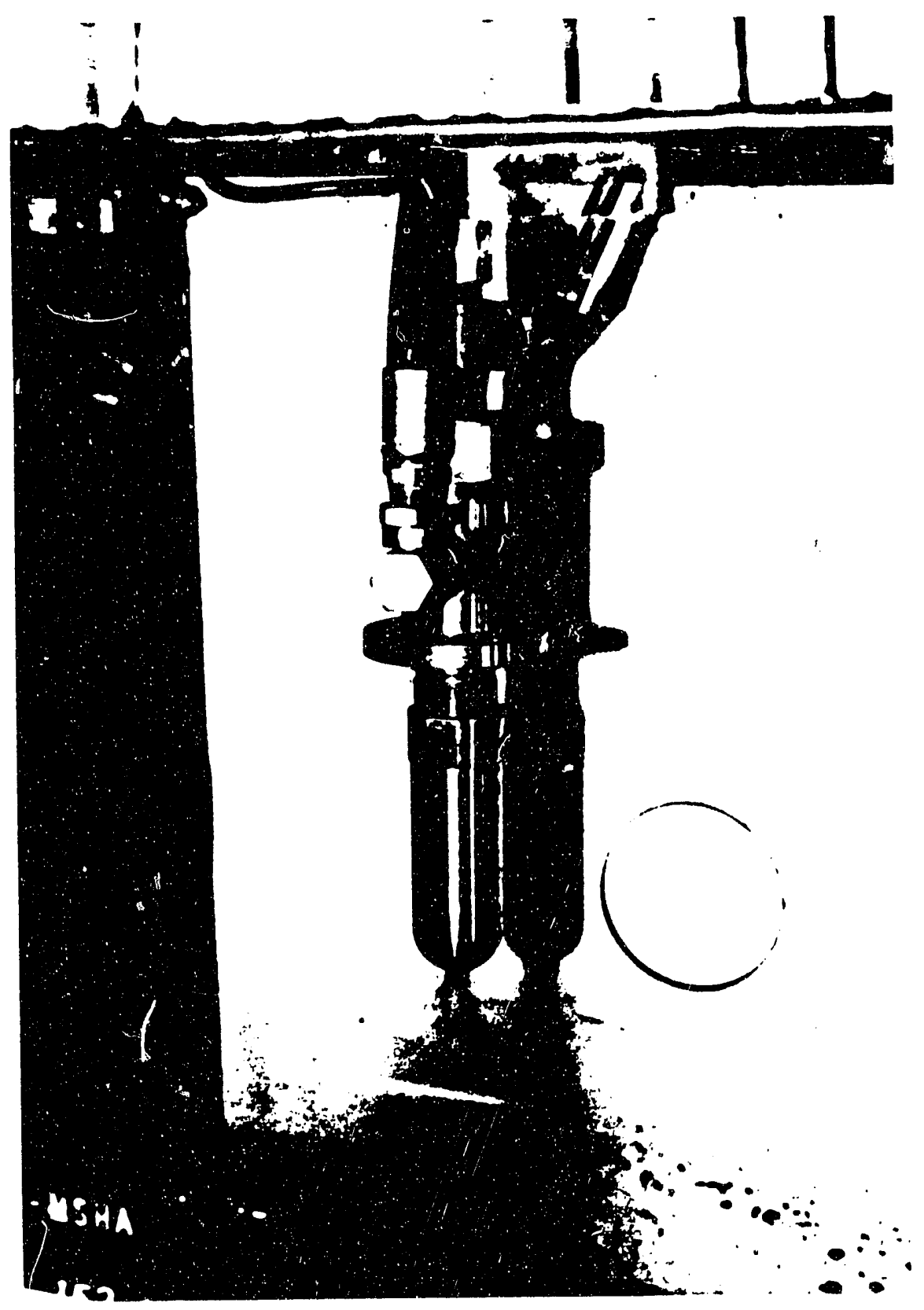

FIGURE 5.17. CLOSEUP OF ATOMIZED ILLINOIS NO. 6 PELLET SLURRY 
characteristics of the coal water fuel. The mean SMD data for the three coals, at an air to fuel (AFR) ratio of 1.12 to 1.20 , showed:

- Illinois No. 6 coal pellets, SMD: $35 \mu \mathrm{m}$

- Illinois No. 6 filter cake, SMD: $68 \mu \mathrm{m}$

- Elkhorn pellets, SMD: $38 \mu \mathrm{m}$.

The Elkhorn coal slurry was much easier to handle in the transfer system than the Illinois No. 6 coal slurries. The Elkhorn coal slurry also showed good atomization characteristics at all AFRs. Details of the Test program and results are provided in the Fourth Quarterly Report. ${ }^{(1)}$

In conclusion, the results showed that strong, durable (and, in the case of Shur Bond binder, waterproof) pellets could be readily formulated into a low viscosity, stable, atomizable slurry with low SMD droplet sizes. In addition, CWF prepared from pellets produced droplets with a smaller average size compared to CWF prepared from the filter cake. This study demonstrated that the Pellet-CWF approach was not only acceptable for reducing the problems of storage, handling and transportation of clean filter-cake, but is also capable of providing a good quality slurry at the utilization site.

\subsection{Coals/Techniques/Binders Selected For Pilot Scale Testing}

Based on the coal pelletization, slurry formulation, atomization testing, and preliminary economic analysis the following processes and binders were selected for larger scale, pilot-plant testing:

Selected Reconstitution Processes

- Elkhorn: Roller-and-die pelletization and disk pelletizing

- Illinois No. 6: Roller-and-die pelletization and disk pelletizing

- Utah: Roller-and-die pelletization and extrusion pelletization.

Selected Binders

- Pre-gelatinized corn starch

- Shur Bond. 
Limited testing of calcium lignin sulfonate binder was also recommended. Details, leading to this selection including the preliminary economic analysis are presented in the Second, Third, and Fourth Quarterly Reports. ${ }^{(4,2,1)}$

\section{$\underline{5.6}$ Section 5 References}

1. Conkle, H. N., Raghavan, J. K., Jha, M. C., and Smit, F. J., "Pelletizing/Reslurrying as a Means of Distributing and Firing Clean Coal," Fourth Quarterly Progress Report prepared by Battelle Memorial Institute for the U. S. Department of Energy under Contract No. DE-AC22-90PC90166, September 20, 1991.

2. Conkle, H. N., Raghavan, J. K., Jha, M. C., and Smit, F. J., "Pelletizing/Reslurrying as a Means of Distributing and Firing Clean Coal," Third Quarterly Progress Report prepared by Battelle Memorial Institute for the U. S. Department of Energy under Contract No. DE-AC22-90PC90166, June 5, 1991.

3. Smit, F. J. and Berggreiı, M. H., "Relative Viscosity Correlations of Micronized Coal Water Slurries", Proceedings of the 14th International Conference on Coal and Slurry Technology, Clearwater, Florida, April 24-27, 1989.

4. Conkle, H. N., Raghavan, J. K., Jks, M. C., and Smit, F. J., "Pelletizing/Reslurrying as a Means of Distributing and Firing Clean Coal," Second Quarterly Progress Report prepared by Battelle Memorial Institute for the U. S. Department of Energy under Contract No. DE-AC22-90PC90166, March 5, 1991. 


\subsection{PILOT SCALE EVALUATION}

This section describes work on Task 3, pilot-scale development of the Pellet-CWF process, and Task 7, reslurrying of pellets and evaluation of their CWF. The primary objective of the task was to verify that the selected pelletization techniques could continuously produce acceptable, uniform pellets which could be transported, handled, and stored like lump coal, and be reslurried into acceptable CWF. A secondary objective was to optimize the process conditions in order to minimize pellet production costs, and yet produce an acceptable pellet product.

This pilot-scale pellet production study included evaluation of pelletization process variables on pellet quality. Testing was conducted with each of the three coals using the selected pelletization techniques and binders. Approximately one thousand pounds of pellets were produced for each combination of coal and binder. These pellets were used for transportation, handling and storage evaluation tests. Several of the pilot-scale production pellets were also used to demonstrate the concept of continuous pellet-to-slurry production and to examine the atomization characteristics of these slurries.

Information from the task was used to assess the economics of the Pellet-CWF approach and compare it against the direct filter cake-to-CWF approach.

The following subtasks were carried out:

- Subtask 3.1 Prepare Pilot Scale Pellets

- Subtask 3.2 Evaluate Uniformity

- Subtask 7.1 Reslurry Pellets

- Subtask 7.2 Characterize CWF

- Subtask 7.3 Conduct Atomization Tests 
Provided in this section are:

- Pelletization evaluation

- Reslurrying evaluation

- Atomization evaluation.

\subsection{Summary}

Several thousand pounds of pellet were produced by the three techniques from the three coals. Uniform, acceptable pellets were produced after a startup period of 100 to 200 minutes of pellet production. The three binders recommended from the bench-scale evaluation were found to be acceptable for pilot-scale pellet production and slurry formulation. Shur Bond bound pellets, however, showed slightly lower cured strength compared with the bench-scale tests. In most extrusion and in some disk pelletization tests, the liquid binders, i.e., Shur Bond and lignin sulfonate, required about 0.5 percent corn starch as secondary binder to provide adequate green/cured pellet strength.

The pellets from the three production processes were also assessed for CWF amenability and for continuous slurry production. A novel, 8 gallon/hr "pellet-to-slurry" system was designed, fabricated and tested for slurry production. The unit performed very satisfactorily. The slurrie vere also successfully atomized in an AGT research nozzle. Atomization characteristics of the slurries prepared from pellets indicated the Pellet-CWF to be suitable for the various applications targeted in the project.

\subsection{Pelletization Evaluation}

In this section experimental results, test procedures, and key conclusions are presented for the roller-and-die, disk, and extrusion pelletization processes. In all three techniques, the critical variable in the pelletization process was the choice of binder and its dosage. Prior to the pilot-scale testing, a binder dosage optimization evaluation was conducted. 


\subsubsection{Binder Optimization}

The objective of this series of tests was to determine the binder dosage that would produce pellets that meet the acceptance criteria. Optimized binder dosages for the three coals are presented in Table 6.1.

TABLE 6.1. OPTIMIZED BINDER DOSAGE FOR EACH COAL AND PELLETIZATION PROCESS

\begin{tabular}{|c|c|c|c|c|}
\hline \multirow[b]{2}{*}{ Coal } & \multirow{2}{*}{ Binder } & \multicolumn{3}{|c|}{ Optimized Binder Dosages, \% Dry Basis } \\
\hline & & Roller \& Die & Extrusion & Disk \\
\hline Elkhorn & $\begin{array}{c}\text { Corn Starch } \\
\text { Shur Bond } \\
\text { Lignin Sulfonate }\end{array}$ & $\begin{array}{c}2.0 \\
4.5 \\
--(a)\end{array}$ & $\begin{array}{l}\cdots \\
--- \\
--\end{array}$ & $\begin{array}{c}4.0 \\
N / D^{(b)} \\
N / D\end{array}$ \\
\hline Illinois No. 6 & $\begin{array}{c}\text { Corn Starch } \\
\text { Shur Bond } \\
\text { Lignin Sulfonate }\end{array}$ & $\begin{array}{l}2.0 \\
4.5 \\
4.0\end{array}$ & $\begin{array}{l}-\cdots \\
-\cdots \\
\cdots-\end{array}$ & $\begin{array}{c}4.0 \\
N / D \\
--\end{array}$ \\
\hline Utah & $\begin{array}{c}\text { Corn Starch } \\
\text { Shur Bond } \\
\text { Lignin Sulfonate }\end{array}$ & $\begin{array}{l}2.0 \\
4.5^{(\mathrm{c})} \\
-\cdots\end{array}$ & $\begin{array}{l}2.75 \\
4.5^{(c)} \\
4.0^{(c)}\end{array}$ & -- \\
\hline
\end{tabular}

(a) --- No pilot-scale pellet production conducted

(b) N/D: No optimization test has been conducted

(c) Required 0.5-percent corn starch as secoidary binder for pelletization

The roller-and-die pelletization rechnique required the lowest binder dosage among the three pelletization techniques for the three coals. The compaction forces and the operating conditions in the roller-and-die pelletizer were sufficient to produce strong, durable fellets 
with low binder levels. in the extrusion pelletization process, when liquid binders such as Shur Bond and lignin sulfonate were used for pelletization, a small fraction of corn starch was always required as a secondary binder for successful extrusion. The need for corn starch was consistent with our earlier evaluation conducted in the bench-scale experiments. Details on these optimization tests are provided in the Sixth Quarterly Report. ${ }^{(1)}$

\subsubsection{Roller-and-Die Pelletization}

Pilot-scale roller-and-die pelletization was conducted at California Pellet Mill (CPM) in Crawfordsville, Indiana. Two aspect of pilot-scaic pellet production that differed from the bench-scale pellet production were: (1) larger pellet size (3/4-in. diameter versus 1/2-in. diameter) and (2) higher pellet discharge temperature $(180 \mathrm{~F}$ versus $120 \mathrm{~F})$. The 1 ton/hr capacity pelletizer was operated at a rate of approximately $300 \mathrm{lbs} / \mathrm{hr}$. The pr oduction unit is shown in Figure 6.1. The pelletizer's shear knife inside the pelletizer was set to make 1- to 2-in. long cylindrical pellets. The general pelletization procedure involved:

- Blending the clean coal and binder in a mixer and adjusting the moisture level

- Feeding the mix into the pelletizer

- Producing pellets that had sufficient green strength and that could pass the drop test

- Cooling the hot pellets from the pelletizer, and

- Storing the pellets in 55-gallon containers for transport back to Battelle.

6.2.2.1 Production Process Evaluation. Pelletization with corn starch, Shur Bond, and lignin sulfonate was successfully produced with Illinois No. 6 coal. Figure 6.2 shows the production of Illinois No. 6-cornstarch pellets. These pellets were easier to produce than Shur Bond- or lignin sulfonate-bound pellets. Similar to Illinois No. 6 coal, Elkhorn coal pellets were also produced without any technical difficulty. A photograph of pilot-scale Utah coal pellets is shown in Figure 6.3. With Utah coal, pellet production was easily achieved with corn-starch binder. However, with Shur Bond binder, the pellets did not 
84
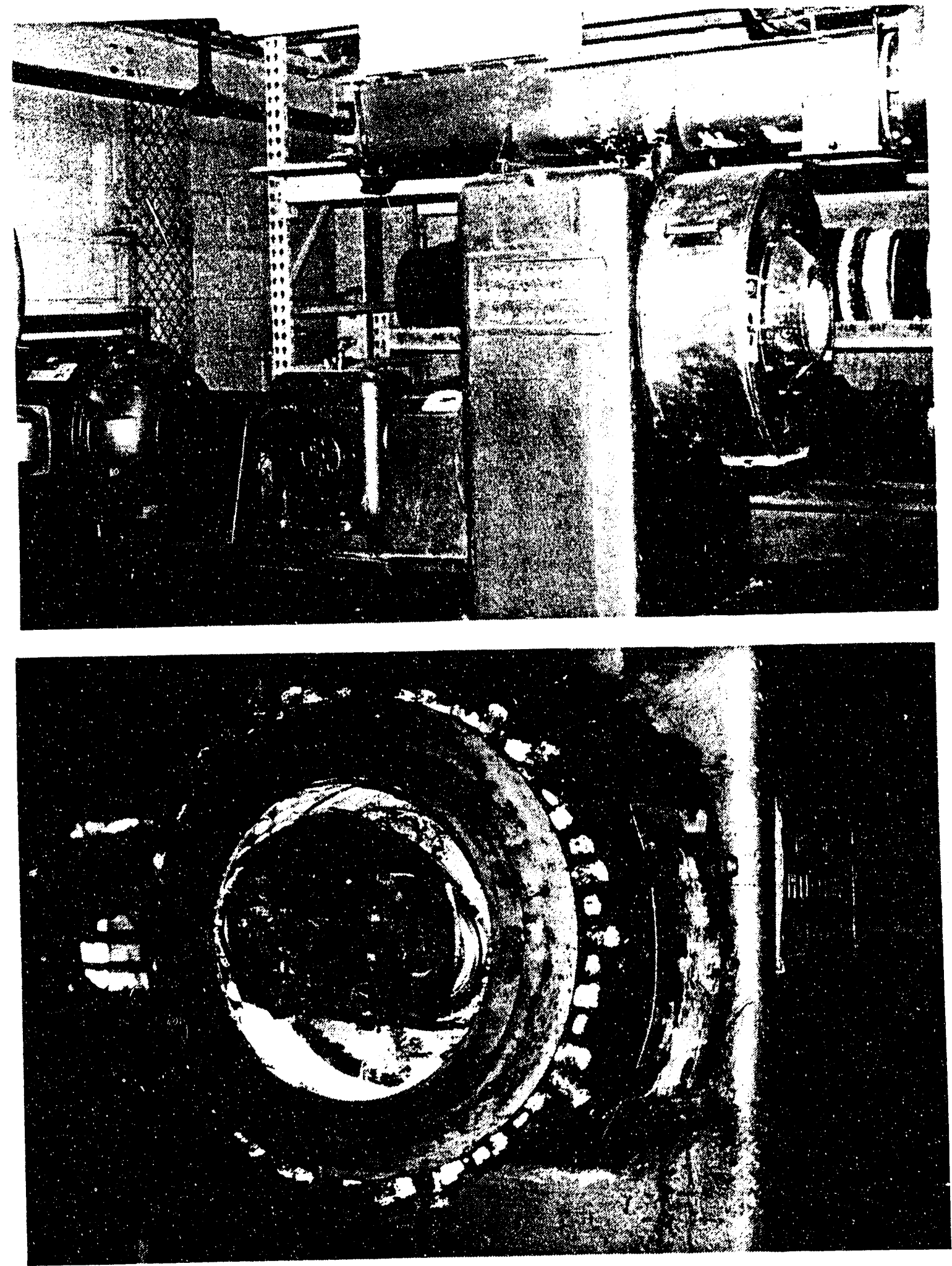

FIGURE 6.1 PILOT SCALE ROLLER-AND-DIE PELLETIZER 


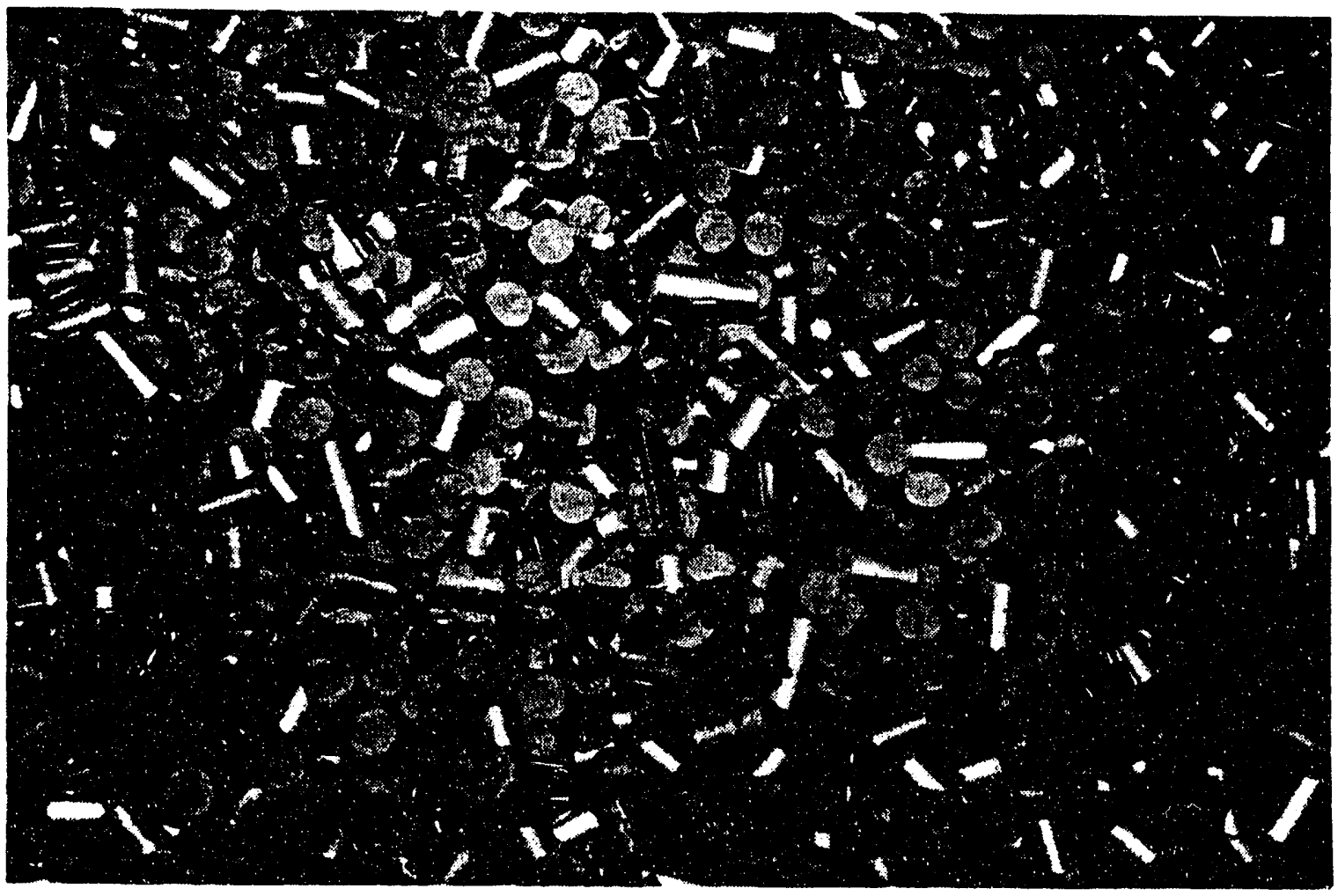

FIGURE 6.2 ILLINOIS NO. 6 COAL PELLET PRODUCTHON IN THE 1-TON/HR PELLETIZER. 


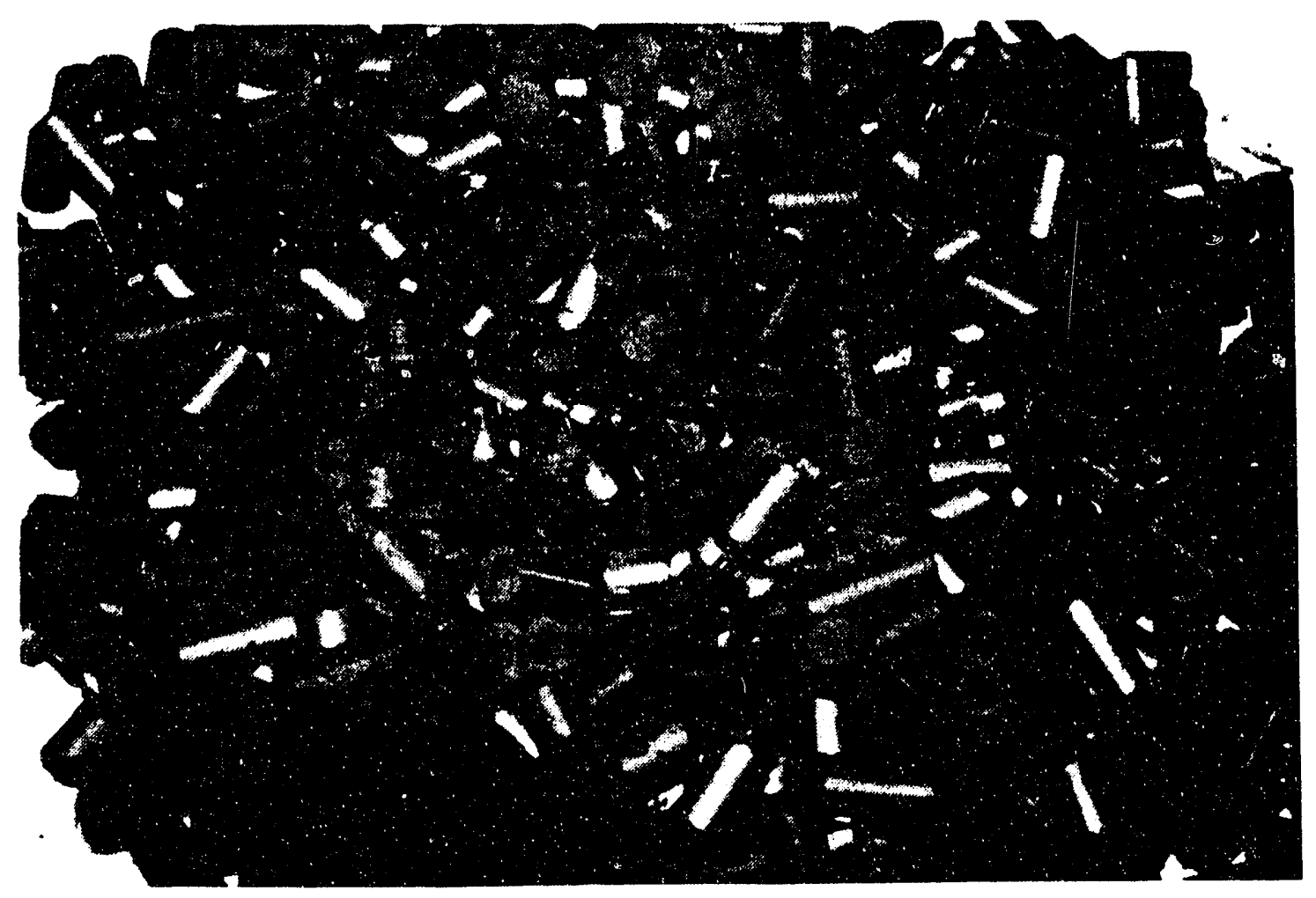

FIGURE 6.3 UTAH COAL PELLETS FROM PILOT SCALE PELLET PRODUCTION 
achieve adequate green/cured strength until an additional (secondary) binder was used. It appeared that the Utah coal had significantly different properties than other eastern coals tested.

Through optimization testing, it was determined that the addition of 0.75 percent corn starch to the Shur Bond binder was necessary. This combination of binders and coal also gave sufficient green and cured strength to pass the acceptance criteria. Note, the other coals (Illinois No. 6 and Elkhorn) required no secondary binder to pelletize with Shur Bond. In addition, Utah coal also required stringent control of feed moisture in the roller-and-die pelletizer. It is clear that the Utah coal has special requirements.

6.2.2.2 Pellet Uniformity. In the roller-and-die pe'letization process, there are several variables that control the quality of pellets. Following are some of those variables:

- Coal type

- Binder and coal homogeneity

- Feed-rate to the pelletizer

- $\quad$ Feed moisture

- Roller-and-die operating temperature.

Therefore, the objective behind testing the production pellet uniformity was to determine the combined effect of all the above variables on pellet quality. The testing procedure essentially involved:

- Sample $15 \mathrm{lb}$ of pellets at varying time intervals during pellet production

- Measure pellet properties, including

- Cured compressive strength

- Durability (Ro-Tap and Tumble)

- Weatherability.

The pellets' compressive strength during production was observed to be a good indicator of pellet quality. Figure 6.4 presents this data for all the roller-and-die pellets. With all three coals, the pellets showed a steady increase in strength with production time. The slopes observed with the binders and coals indicated that the degree of increase was dictated by the 

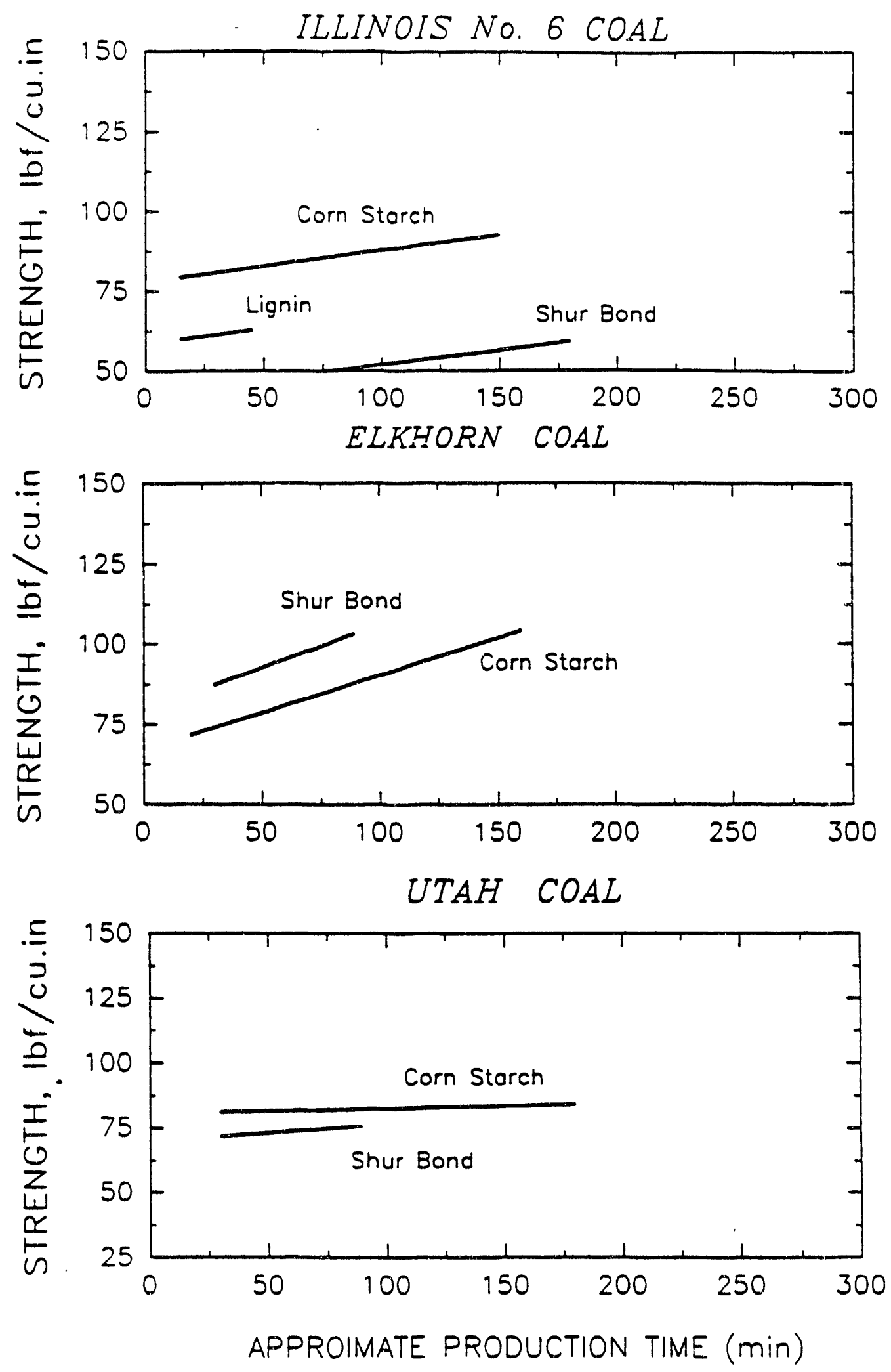

FIGURE 6.4. REPRESENTATION OF ROLLER-AND-DIE PELLET UNIFORMITY DURING PRODUCTION 
type of coal. It was also evident that pellets after $\sim 100$ minutes of production time showed stable, acceptable pellet strength measurements.

\subsubsection{Disk Pelletization}

Pilot-scale disk pelletization was conducted at Battelle, in a Andritz-Sprout Bauer, Model 1000 disk pelletizer. With Illinois No. 6 coal, pellets were prepared with two types of binders, i.e., com starch and Shur Bond, and with Elkhorn coal, pellets were prepared with corn starch, Shur Bond, and lignin sulfonate binders. The following general disk pelletization procedure was adopted:

- Blend clean coal filter cake (at 25-30 percent moisture) with binder in a mixer

- Feed the mix gradually at desired feed rates $(-70-100 \mathrm{lb} / \mathrm{hr})$, through a screw feeder

- Adjust the disk-pan angle $\left(40-42^{\circ}\right)$, pan rotation speed, and water spray locations

- When pellets were formed (nucleation), adjust feed rate and water spray levels to allow for pellet growth

- When the pellets were about 5/8-3/4-in. diameter, collect the pellets rolled over from the pan

- Thermal dry the green pellets in the batch oven at $\sim 180 \mathrm{~F}$ for about 2 hours

- Store the dried, cooled pellets in 55 gallon drums.

6.2.3.1 Production Process Evaluation. Illinois and Elkhorn coal disk pellets were produced with binder dosages provided earlier in Table 6.1. These pellets were evaluated and were found to have acceptable green and cured pellet properties. Generally, disk pelletization was observed to require more binder than the roller-and-die and extrusion technique. The high binder dosage combined with the thermal drying requirement used in disk pelletization caused this method to be economically less attractive. Also, in comparison with roller-and-die and extrusion techniques, the residence time for pelletization in the disk was considerably higher, resulting in lower throughput and a more capital intensive technique 
compared with the roller-and-die technique. The major advantage of disk pelletization technique was its simplicity and need for little process control.

With both the coals, uniform and controlled pellet production was accomplished. Figure 6.5, shows the pelletization operation as seen on the pan of the pelletizer. Clearly, three regions of pellet production can be seen. Regions I and II show pellet nucleation and growth, respectively. Fully grown pellets at about 5/8-in. to 3/4-in. diameter were discharged from Region III of the pan. Photograph of the disk pellets of Illinois No. 6 coal with corn starch binder, after the thermal drying process are shown in Figure 6.6. The pellets showed excellent structural integrity and met the acceptance criteria.

6.2.3.2 Pellet Uniformity. Some of the variables that control the disk pellet production are listed below:

- Coal type

- Binder and coal homogeneity

- Feed-rate; pan-angle, water-spray location, moisture for pellet nucleation and growth

- Feed material moisture

- Pan rotation speed.

During the pilot-scale pellet production, variables such as feed-rate, pan-angle, water-spray location, and pan rotation speed were maintained the same for each type of coal that was processed. Variables such as feed material moisture and moisture for pellet growth were varied according to the type of coal and binder. The disk pellet production uniformity was evaluated according to the procedure outlined earlier. Figure 6.7 presents the variation of cured disk-pellet uniformity during production. Again the data showed that the pellets had increased pellet strength with increasing production time. Also, corn-starch bound pellets showed higher pellet strength than Shur Bond- or lignin sulfonate-bound pellets. Disk pellets required an even longer production time (150-200 minutes) before the pellets could meet the acceptance criteria. 


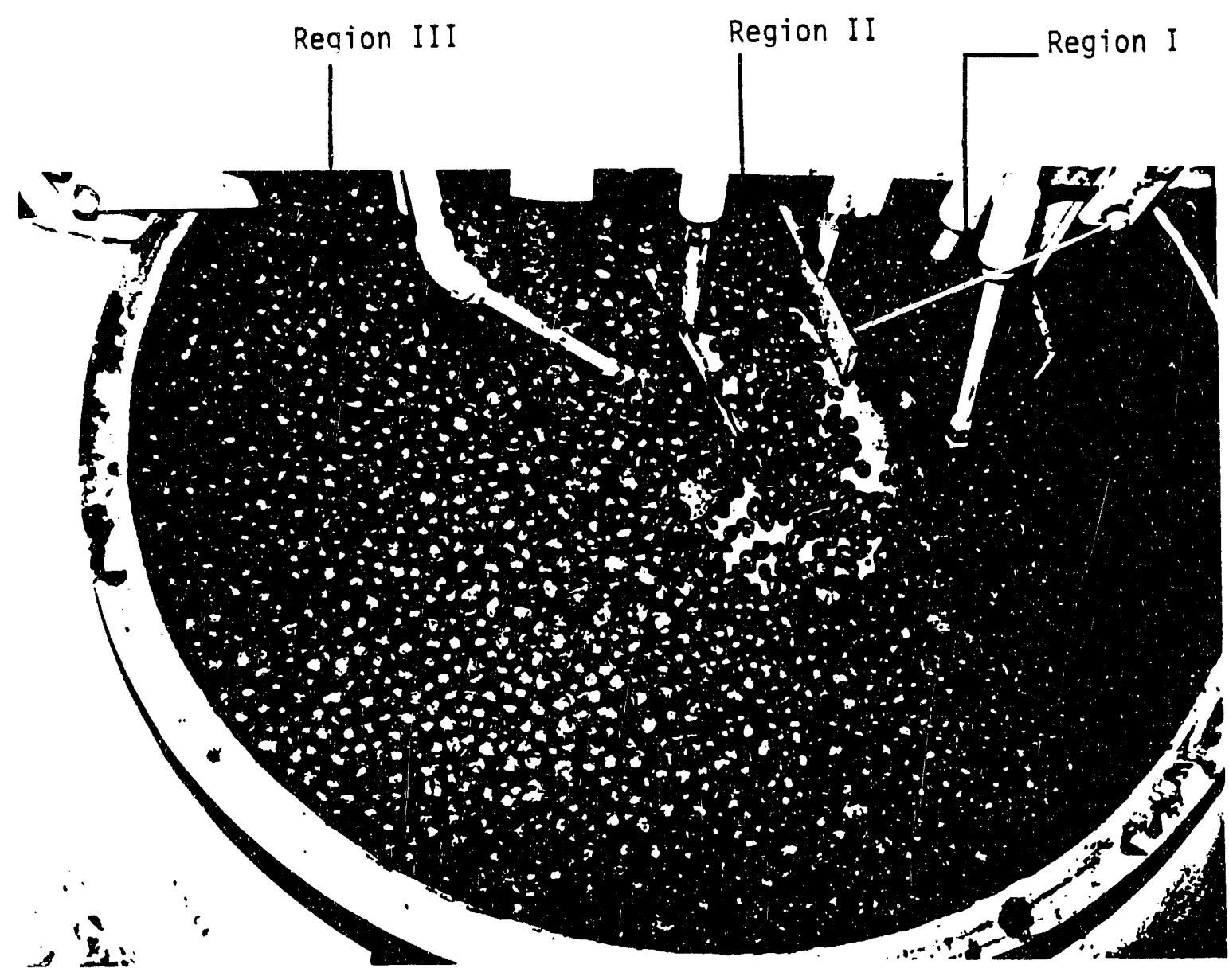

FIGURE 6.5. PILOT SCALE PELLET PRODUCTION DEMONSTRATION IN THE MODEL 1000 DISK PELLETIZER 


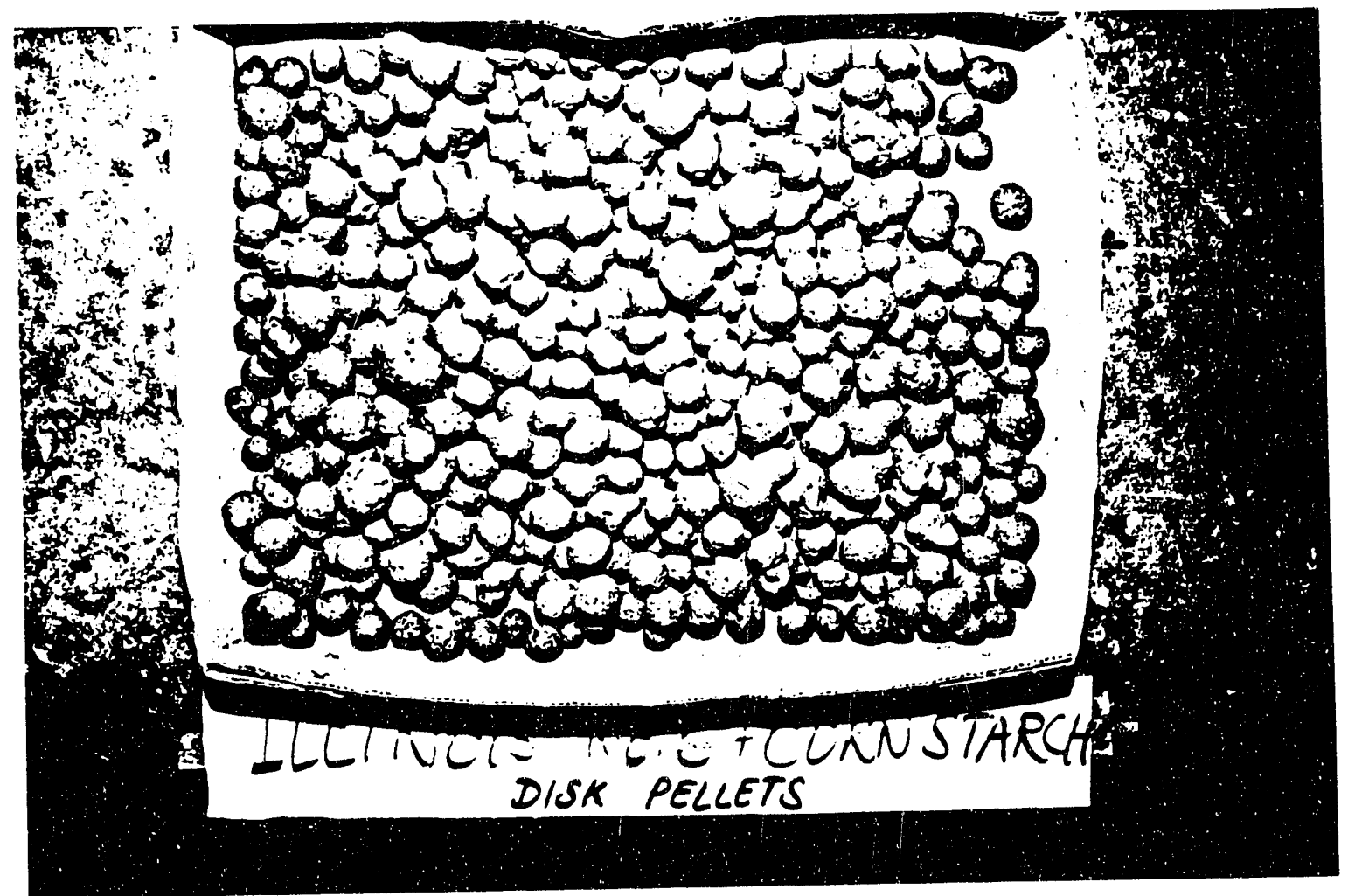

FIGURE 6.6 PILOT SCALE ILLINOIS No. 6 COAL DISK PELLETS PRODUCED WITH CORN STARCH BINDER 
93
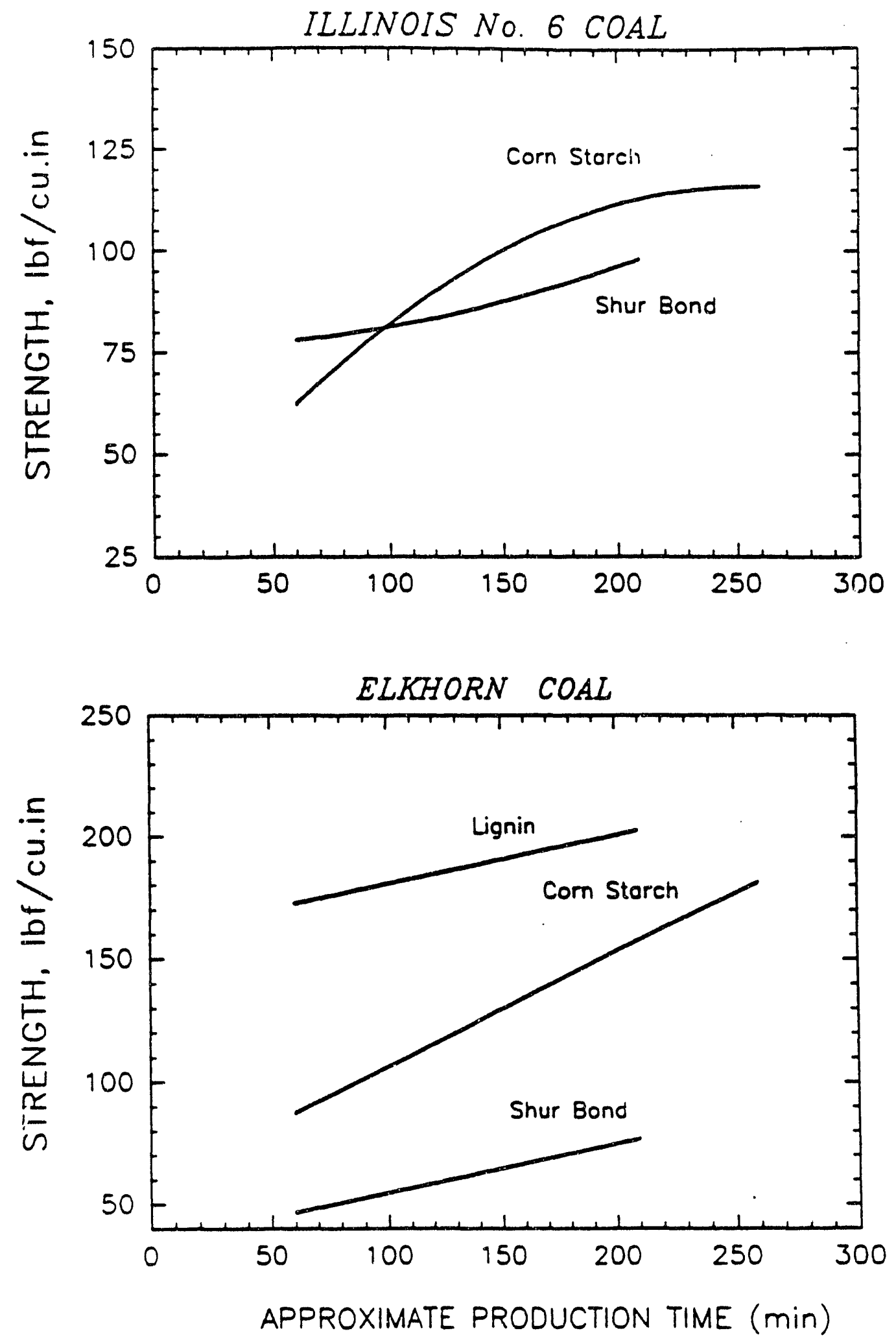

FIGURE 6.7 REPRESENTATION OF DISK PELLET PRODUCTION UNIFORMITY DURING PRODUCTION 


\subsubsection{Extrusion}

Pilot-scale extrusion pellet production was planned for only the Utah coal. Three binders, i.e. corn starch, Shur Bond, and lignin sulfonate were used to produce at least 800 lbs (dry basis) of pellets with each binder. The extrusion pelletization operation was conducted at Battelle in a 4-in. Bonnet Company extruder, at Battelle. Photographs of this extruder and the extruder die, capable of production pellets at approximately $250 \mathrm{lbs} / \mathrm{hr}$ are shown in Figure 6.8 and 6.9.

The following general extrusion-pelletization procedure was adopted:

- Blend clean Utah filter cake with binder(s) in a mixer. Adjust moisture as desired; typically 35-40 percent moisture level was appropriate.

- Feed the mix gradually through the extrusion press.

- Shear the extruded pellets into 1- to 1.5-in. lengths as they were produced.

- Thermal dry the pellets in a gas-fired batch oven at $\sim 180 \mathrm{~F}$ for about 2 hours.

- Store the dried pellets in 55 gallon drums.

6.2.4.1 Production Process Evaluation. Pelletization of Utah coal with corn starch binder was achieved without any technical problems. The pellets prepared at the optimized dosage level (2.75 percent, dry basis) showed excellent green and cured strength. A photograph of the corn starch bound pellets is shown in Figure 6.10. The pellets were thermally dried in the batch oven and air-cooled.

Pelletizing Utah coal with Shur Bond and lignin sulfonate binders was also successfully completed. With both these liquid binders, about 0.75 percent corn starch was coadded as a secondary binder to increase the compressive strength of the pellets. Thermally cured pellets made with 4.0 percent lignin sulfonate as the primary binder are shown in Figure 6.11. 


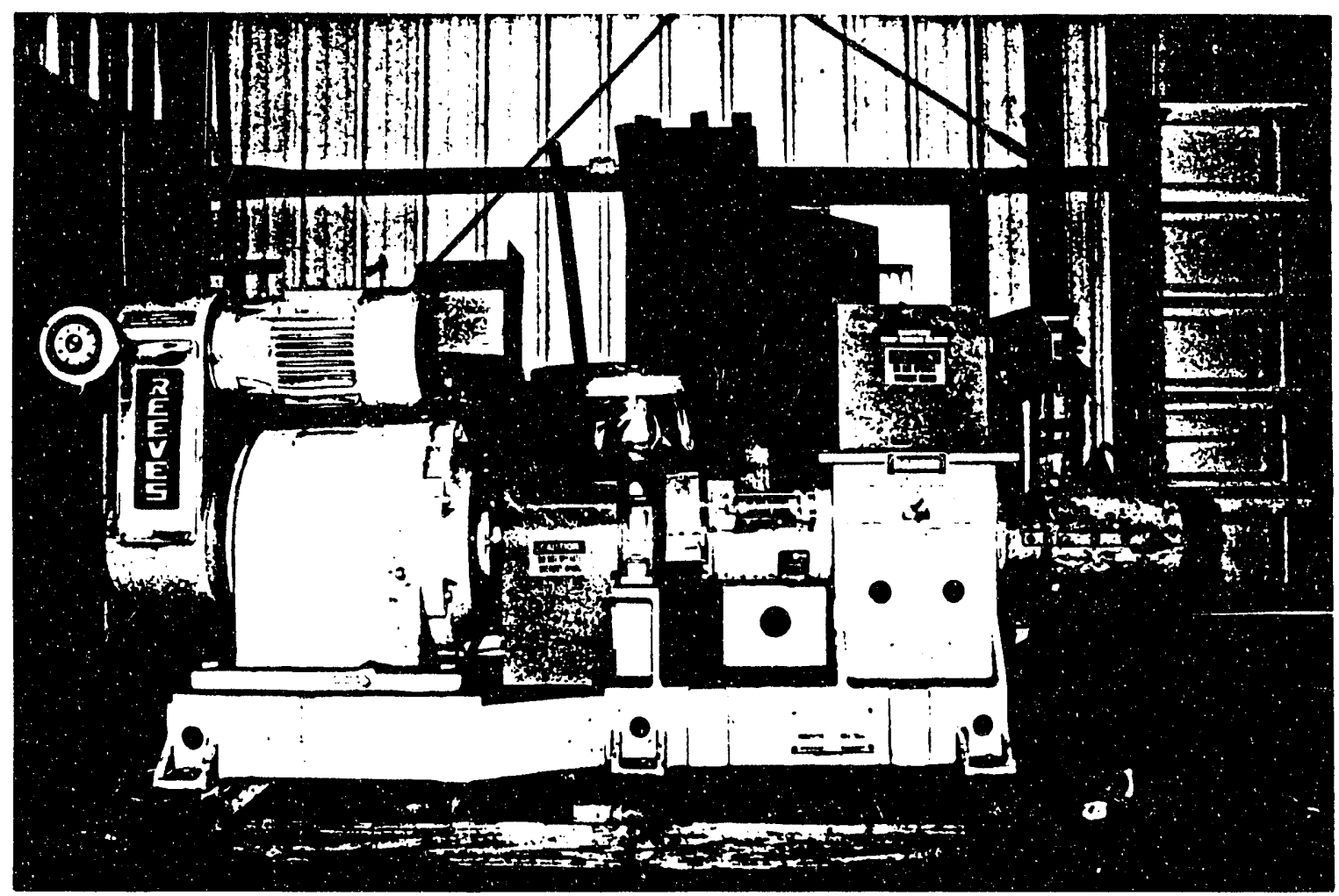

FIGURE 6.8. PILOT SCALE EXTRUSION PELLETIZER

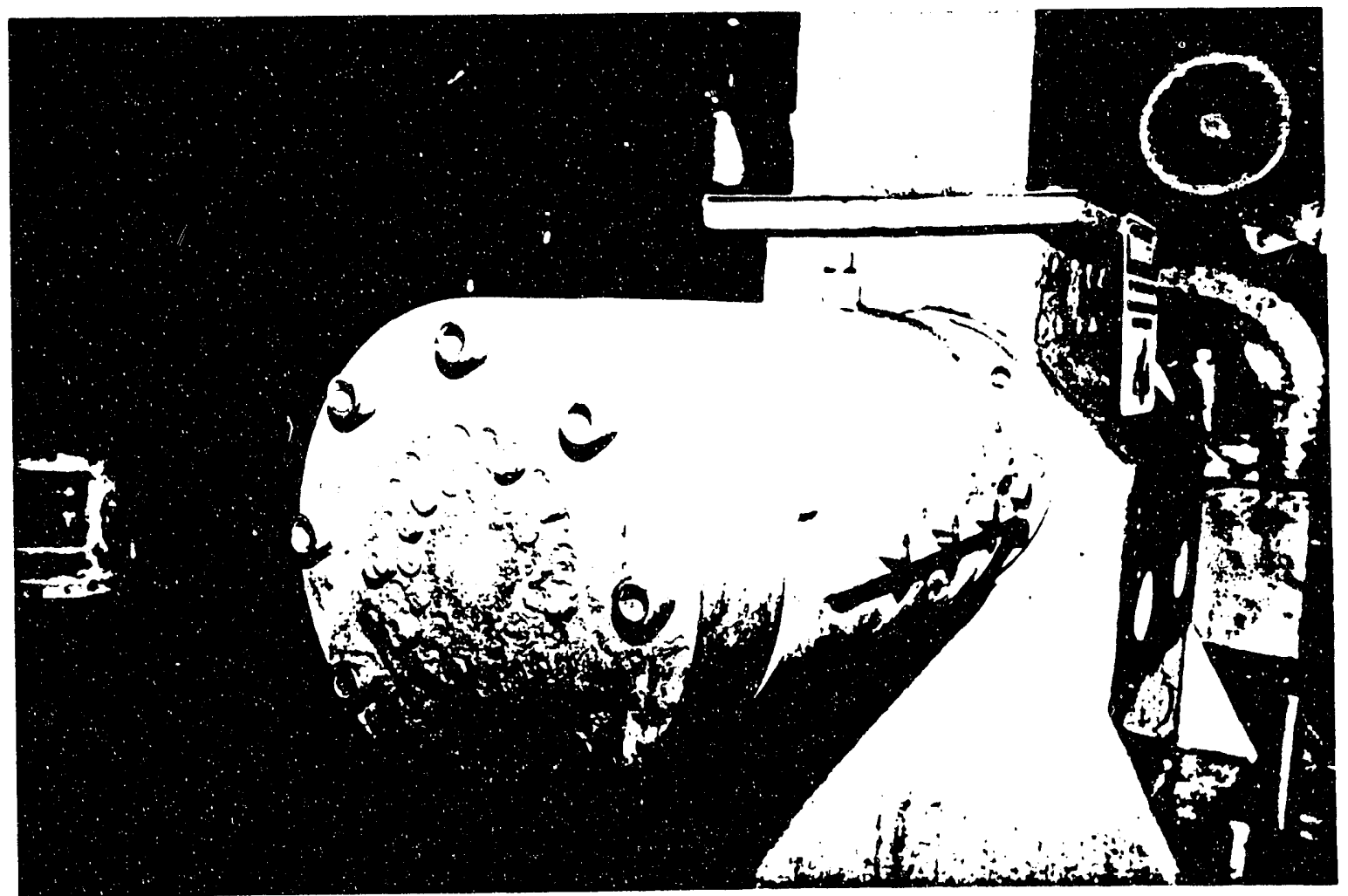

FIGURE 6.9. PILOT SCALE EXTRUSION DIE 


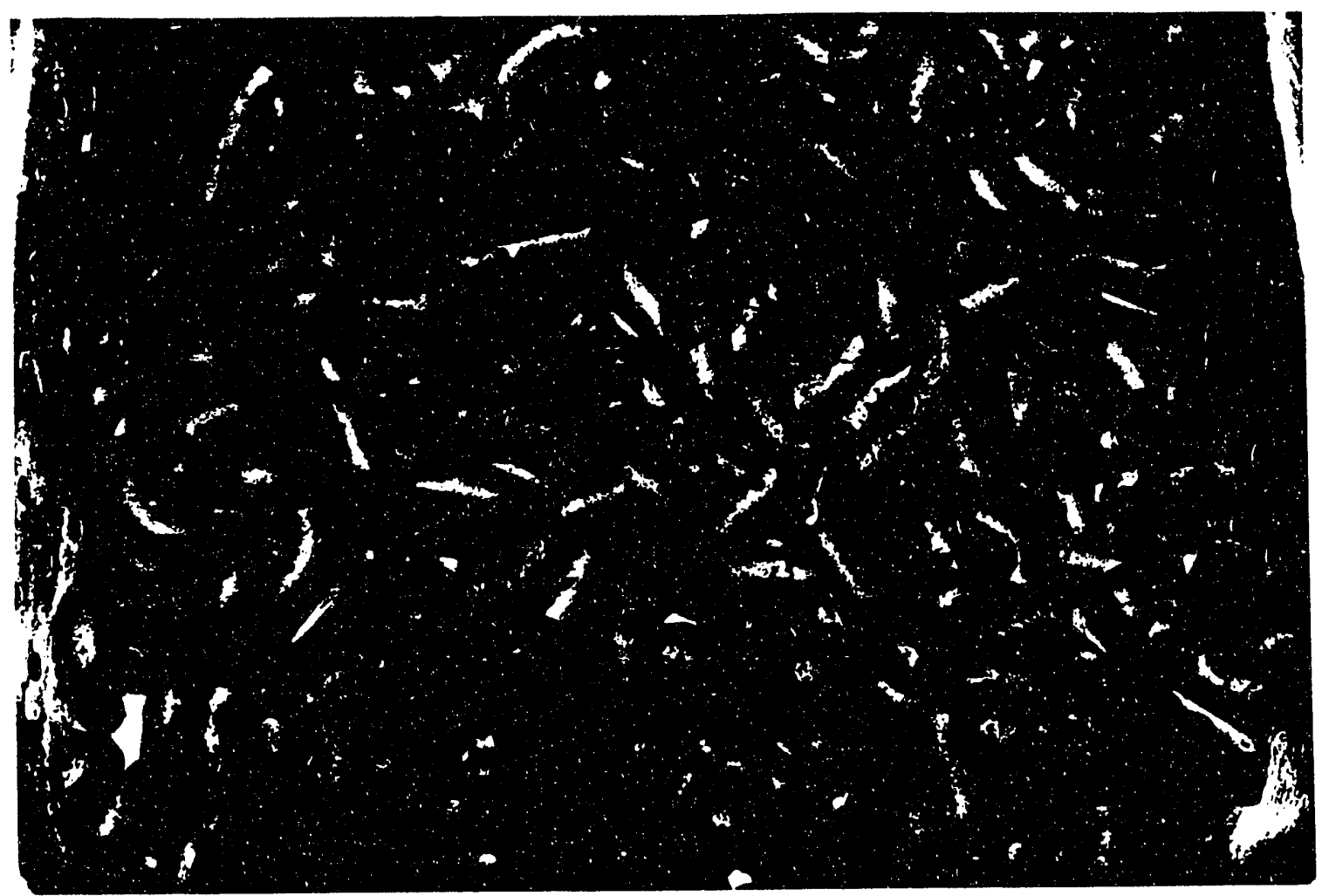

FIGURE 6.10 UTAH COAL PILOT SCALE EXTRUSION PELLET PRODUCTION 


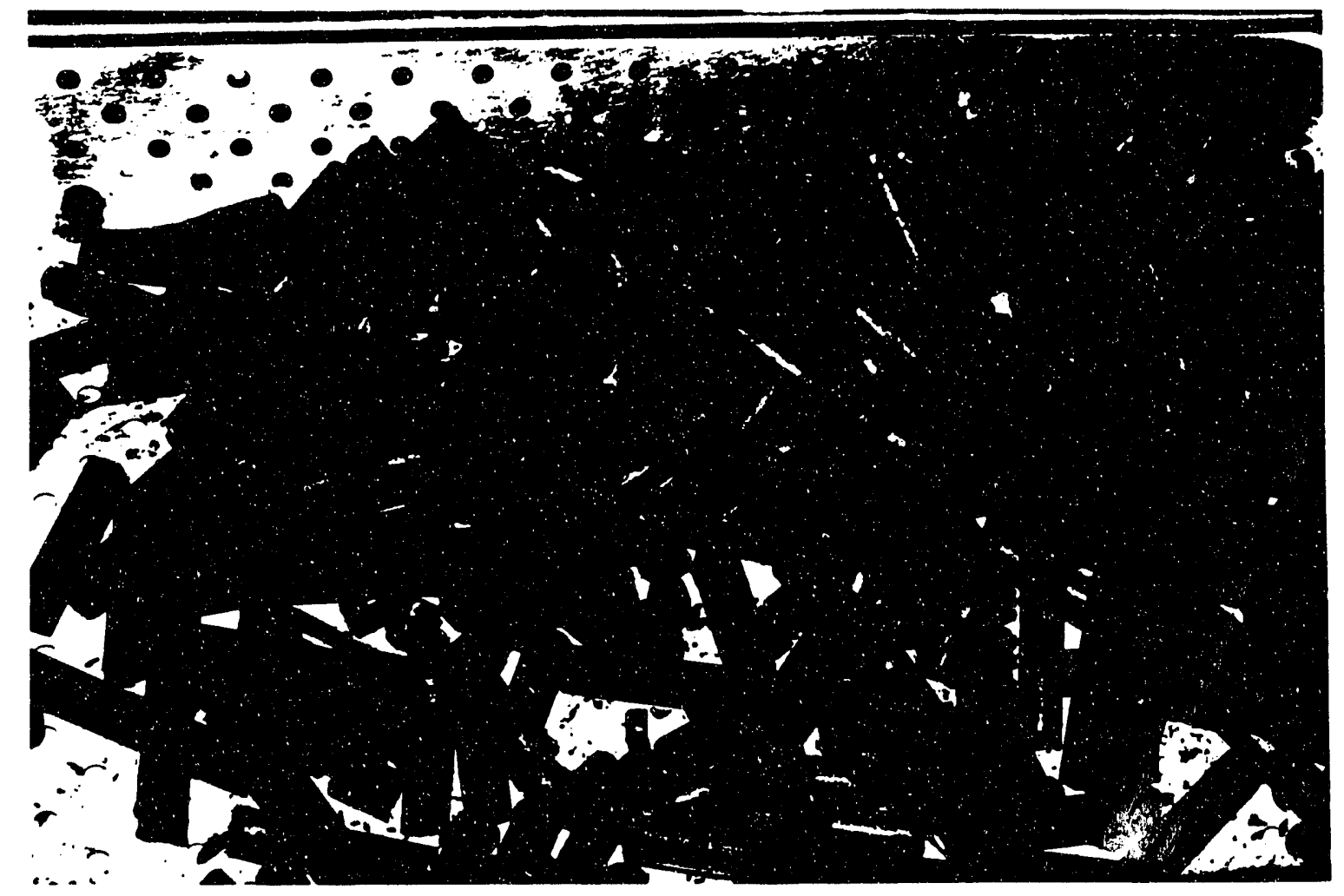

FIGURE 6.11 PHOTOGRAPH OF THE LIGNIN SULFONATE BOUND UTAH COAL EXTRUSION PELLETS 
6.2.4.2 Pellet Uniformity. Variables that control the quality of extrusion pellets are listed below.

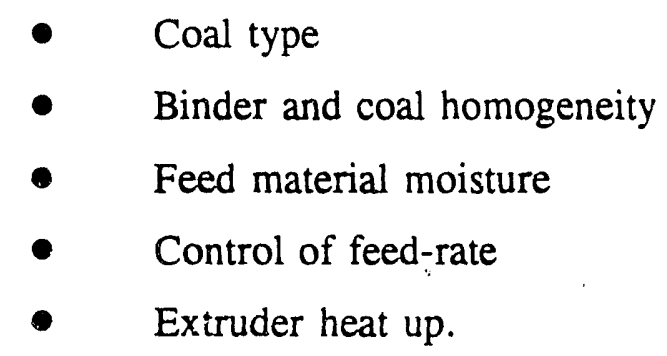

Unlike the roller-and-die and disk pelletization technique, extrusion pelletization was extremely simple and could easily accommodate fluctuations in feed material moisture levels. Extrusion pellet uniformity was evaluated similar to the procedure outlined earlier. Figure 6.12 presents the cured pellet compressive strength during production. Uniform pellets were produced showing very little start-up time. Among the three binders tested, corn starchbound pellets were considerably stronger and easily meet the pellet acceptance criteria.

\subsection{Reslurrying Evaluation}

The objective of this effort was to demonstrate that the pilot-scale pellets produced via roller-and-die-, disk- and extrusion-techniques could be converted into good quality CWF. This effort was undertaken by Amax R\&D. A summary of the final pellet-to-slurry amenability test procedure, developed by Amax $R \& D$, is presented as Appendix $B$. Basically, the procedure involves disintegrating the pellets in a Cowles Dissolver with the appropriate amount of water and dispersant and sampling the slurry periodically to determine its viscosity and the amount of plus 48 mesh $(300 \mu \mathrm{m})$ pellet fragments remaining in the mixture. The amount of moisture in each lot of pellets was determined first in order to calculate the water addition needed to provide a 55-percent coal slurry. The amount of dispersant added was based on previous bench-scale tests and was selected to provide a target viscosity of 500 centipoise (cP) at $100 \mathrm{sec}^{-1}$ shear rate. 


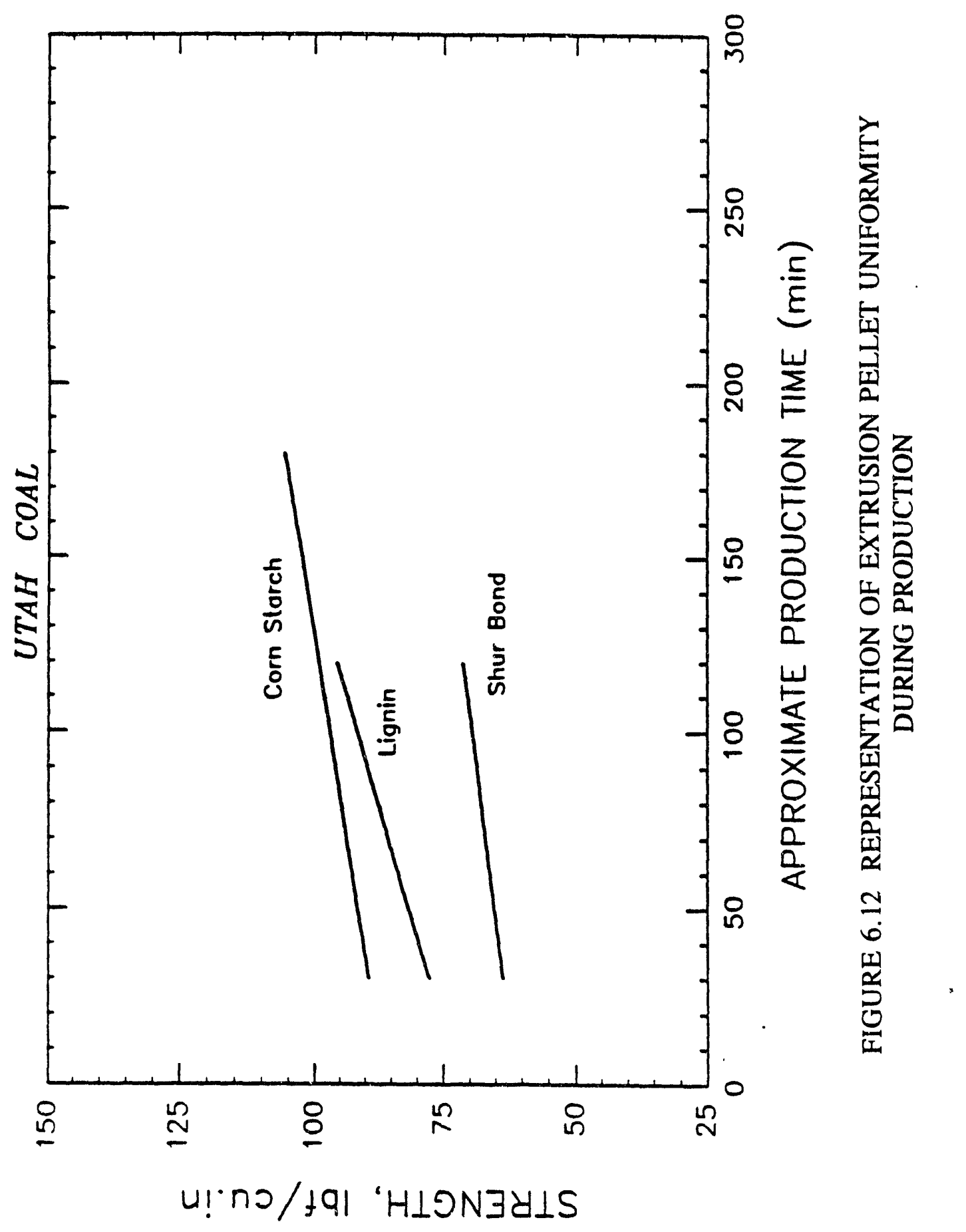


Based on the amenability test data, a pilot-scale continuous pellet-to-slurry formulation unit was built and Pellet-CWF production demonstrated. The task was executed as follows:

- Obtain slurry formulation feasibility data through amenability tests with pilotscale roller-and-die, disk, and extrusion pellets.

- Demonstrated CWF production with pellets from the three production processes in a "pellet-to-slurry" system designed and fabricated in this project.

\subsubsection{Slurry Formulation Amenability Tests}

Tables 6.2 to 6.4 present the reformulation data of production pellets with Illinois No. 6, Utah, and Elkhorn coals. The tables present data on A-23 dispersant dosage, viscosity, coal loading, and the relative ease of disintegration (described by the amount of +48 mesh particles remaining after 8 minutes of formulation time). All three coal pelletstypes were formulated into CWF and showed good rheological characteristics. The +48 mesh fragments present in the slurry is compared and is presented in Table 6.5.

One can see from these averages that the disk and extrusion pellets were more easily disintegrated than the pellets from the roll-and-die machine. Similarly, the pellets made with lignin sulfonate binder were more easily disintegrated than the pellets made with either coin starch or Shur Bond binders. It was difficult to tell whether there is any significant difference in reslurryability among pellets made from Illinois No. 6, Utah, and Elkhorn coals or between pellets made with corn starch and Shur Bond binders. 


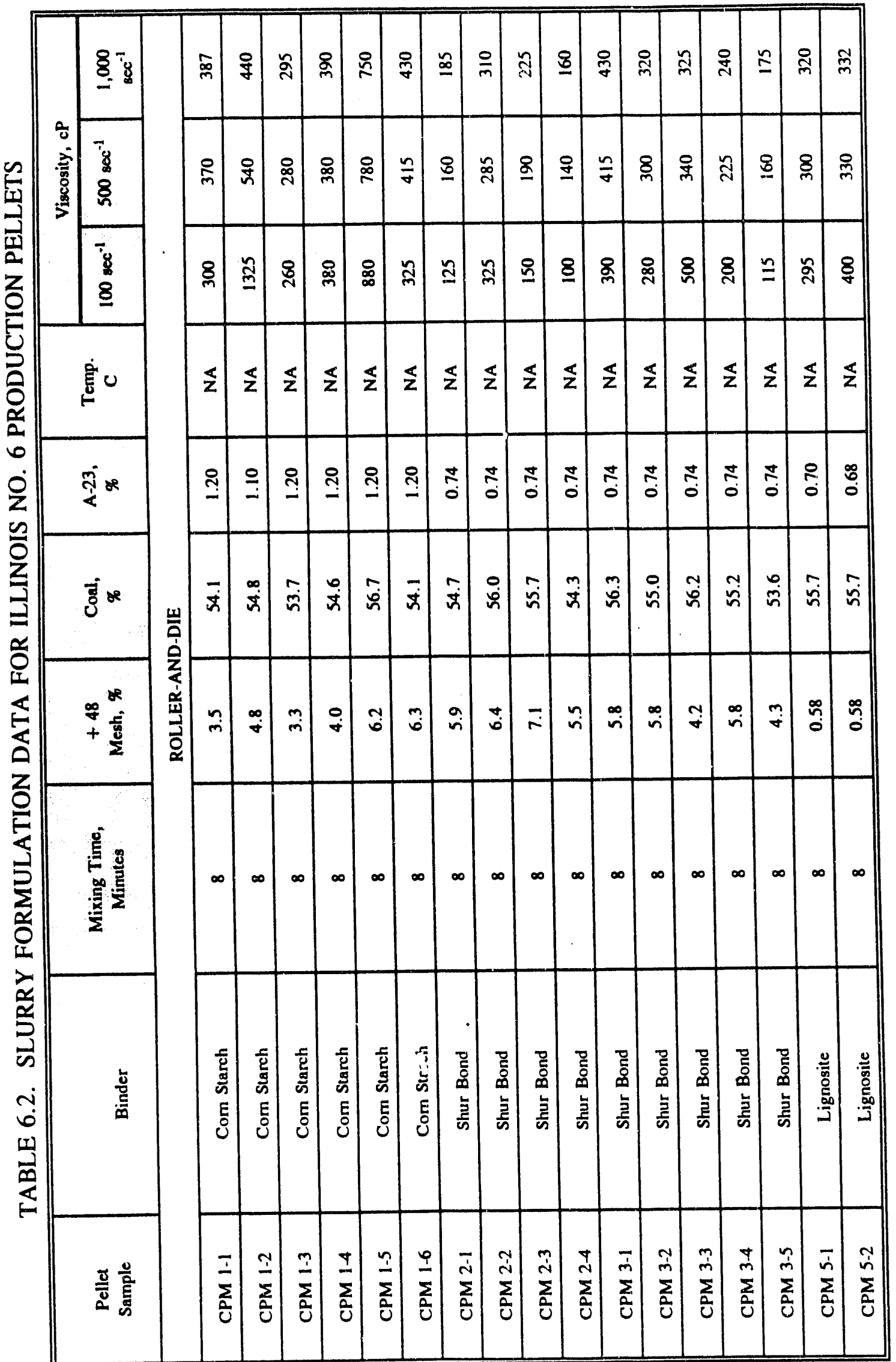




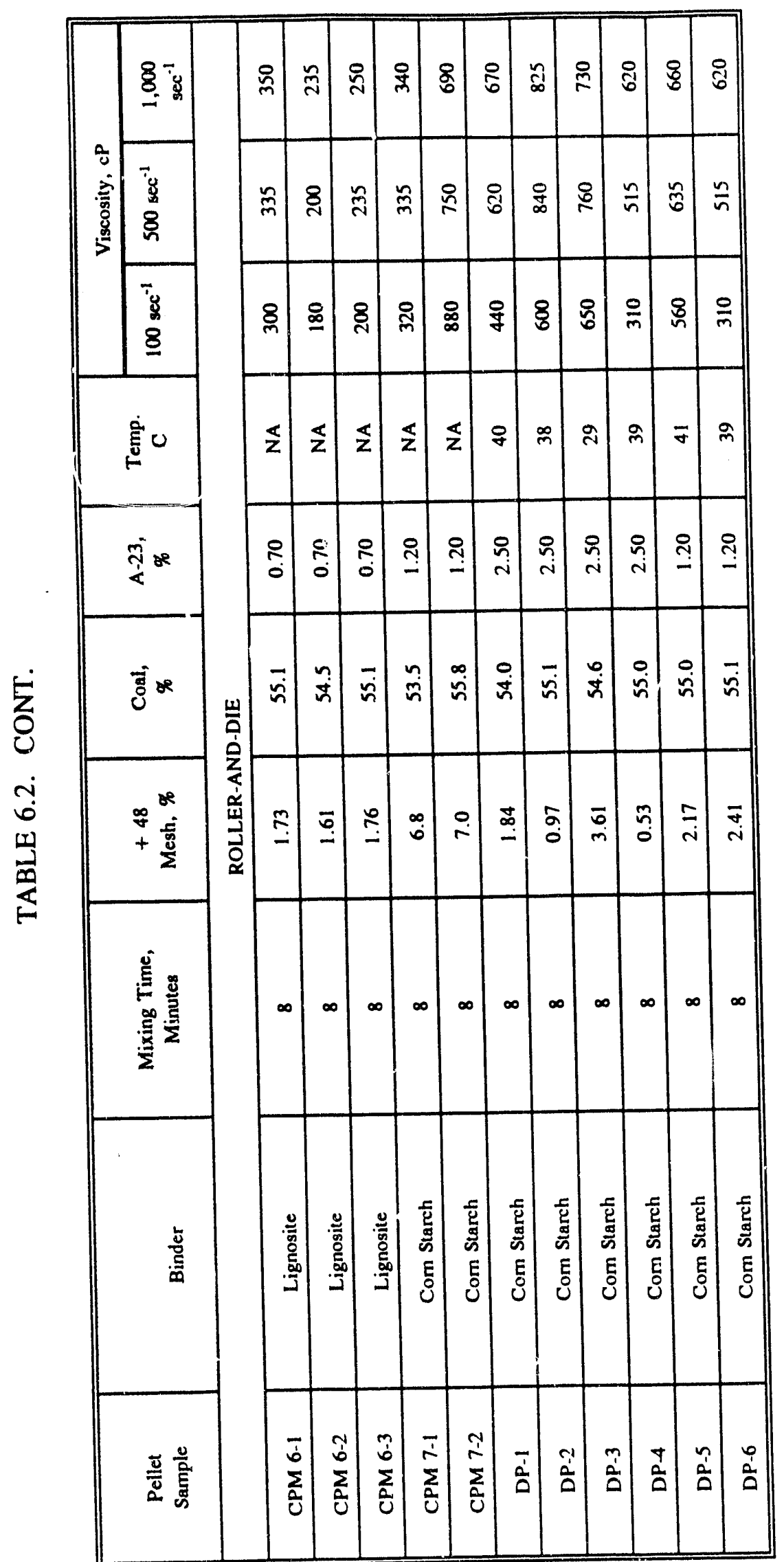




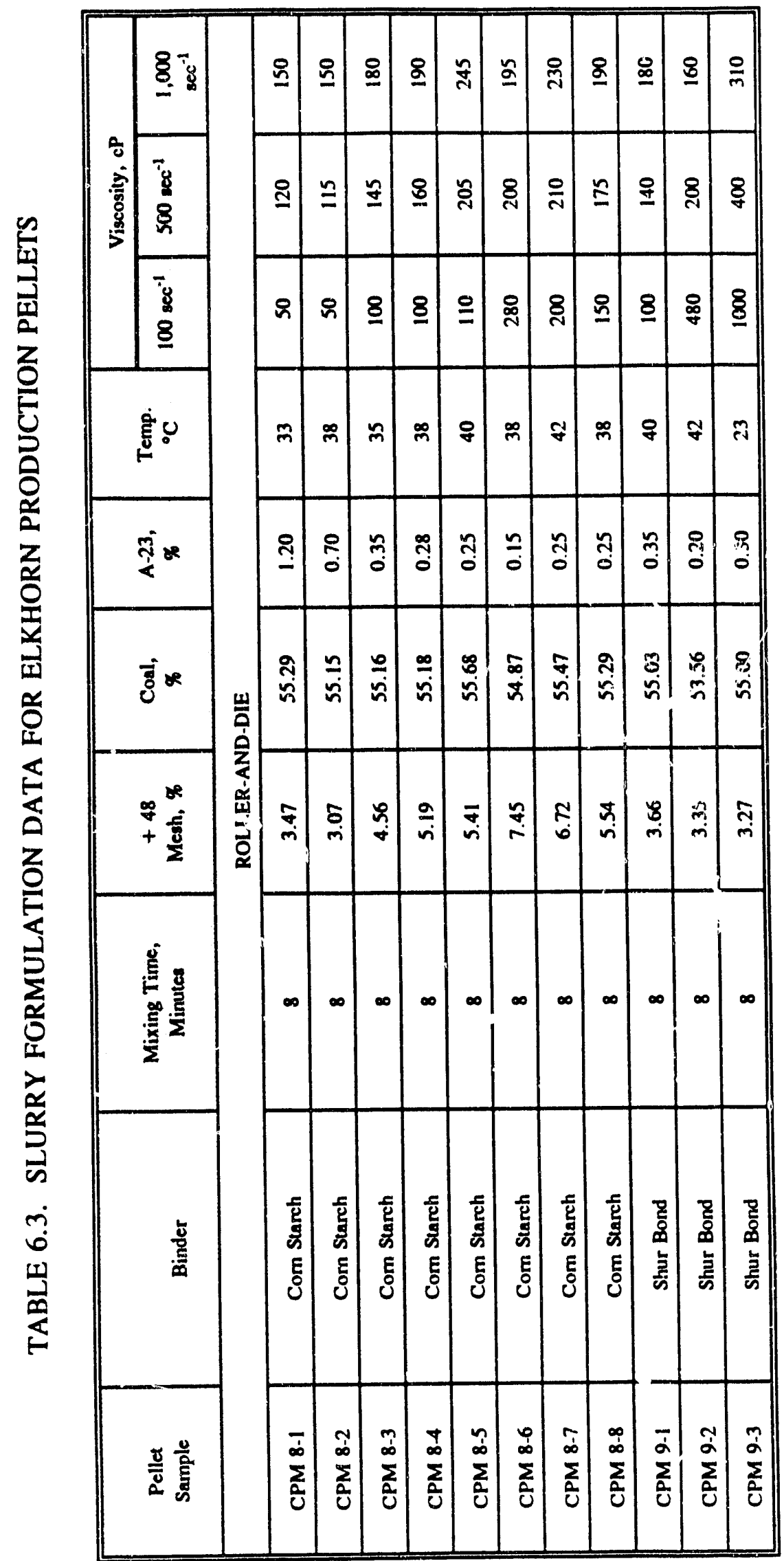




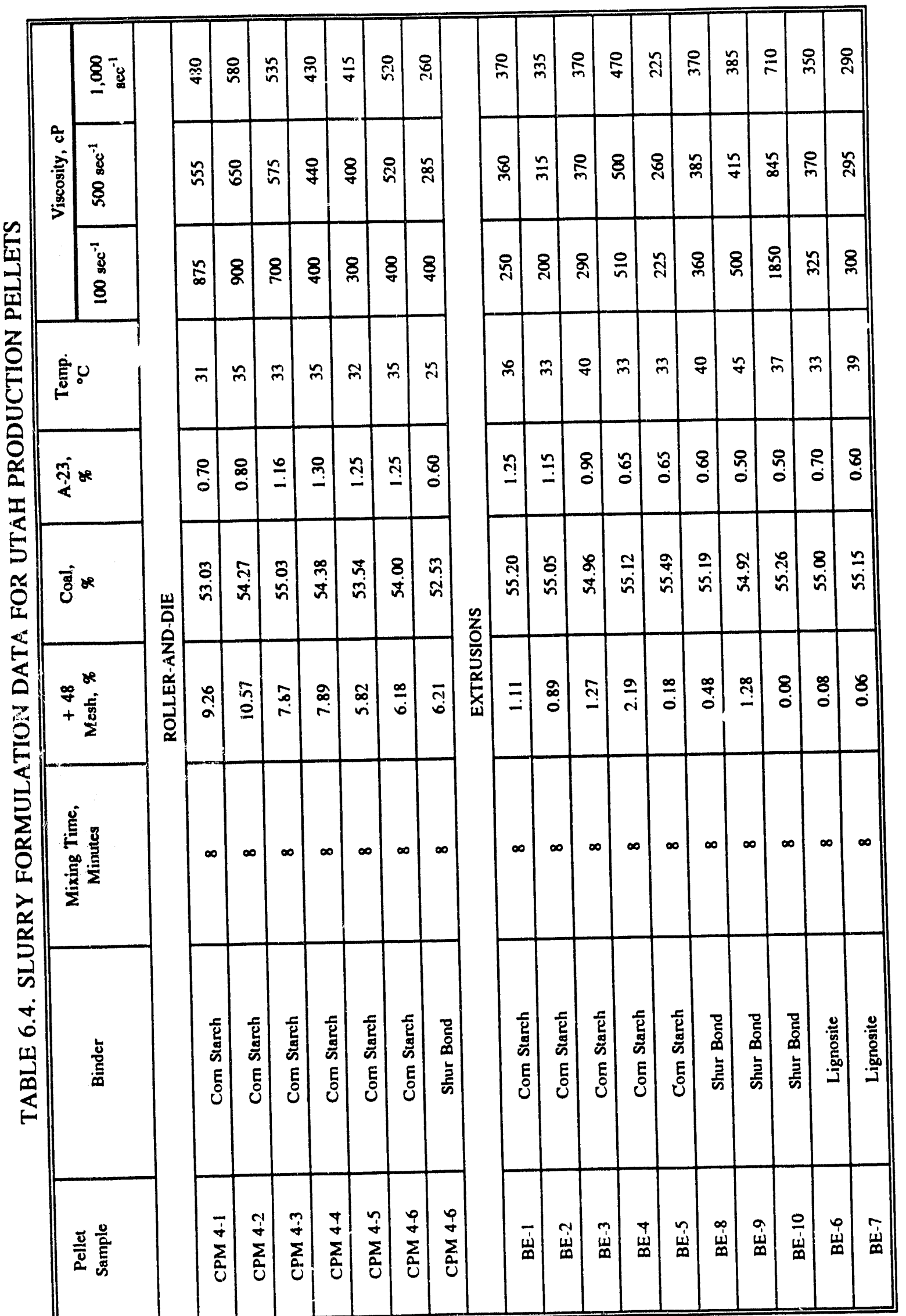


TABLE 6.5. +48 MESH FRAGMENT PERCENTAGE REMAINING AFTER PELLET CONVERSION INTO CWF

\begin{tabular}{|l|c|c|c|c|c|c|c||}
\hline \multirow{2}{*}{} & \multicolumn{3}{|c|}{ Roll-and-Die } & Disk & \multicolumn{3}{c|}{ Extrusion } \\
\cline { 2 - 9 } & Starch & $\begin{array}{c}\text { Shur } \\
\text { Bond }\end{array}$ & $\begin{array}{c}\text { Lignin } \\
\text { Sulfonate }\end{array}$ & Starch & Starch & $\begin{array}{c}\text { Shur } \\
\text { Bond }\end{array}$ & $\begin{array}{c}\text { Lignin } \\
\text { Sulfonate }\end{array}$ \\
\hline Illinois & 5.5 & 5.8 & 1.4 & 1.9 & NT & NT & \\
\hline Utah & 7.8 & 6.2 & NT $^{(\mathbf{a})}$ & NT & 2.1 & 0.6 & 0.1 \\
\hline Elkhorn & 5.4 & 3.4 & NT & 0.5 & NT & NT & \\
\hline
\end{tabular}

(a) NT: Not Tested

Similar comparisons may be made concerning the amount of A-23 dispersant (as percent of dry coal) required to prepare slurries with viscosities under $500 \mathrm{cP}$ at $100 \mathrm{sec}^{-1}$ shear rates, see Table 6.6.

TABLE 6.6. AMOUNT OF A-23 DISPERSANT REQUIRED TO PREPARED QUALITY SLURRIES AS A FUNCTION OF PELLETIZATION METHOD AND BINDER

\begin{tabular}{|c|c|c|c|c|c|c|c|}
\hline & \multicolumn{3}{|c|}{ Roll-and-Die } & \multirow{2}{*}{$\begin{array}{l}\text { Disk } \\
\text { Starch }\end{array}$} & \multicolumn{3}{|c|}{ Extrusion } \\
\hline & Starch & $\begin{array}{l}\text { Shur } \\
\text { Bond }\end{array}$ & $\begin{array}{c}\text { Lignin } \\
\text { Sulfonate }\end{array}$ & & Starch & $\begin{array}{l}\text { Shur } \\
\text { Bond }\end{array}$ & $\begin{array}{c}\text { Lignin } \\
\text { Sulfonate }\end{array}$ \\
\hline Illinois & 1.19 & 0.70 & 0.66 & 2.55 & NT & NT & • \\
\hline Utah & 1.14 & 0.60 & $\mathrm{NT}^{(\mathrm{a})}$ & NT & 0.75 & 0.53 & 0.65 \\
\hline Elkhorn & 0.34 & 0.28 & NT & 0.15 & NT & NT & \\
\hline
\end{tabular}

NT: Not Tested

In this comparison, it appears that pellets made from Illinois No. 6 and Utah coals require larger amounts of dispersant than pellets made from Elkhorn coal. Also, pellets made with corn starch binder require more dispersant than pellets made with either Shur 
Bond or lignin sulfonate binder. It is not clear how the method of pelletization affects dispersant requirements. In the case of Illinois No. 6 coal, disk pellets required considerably more dispersant than roll-and-die pellets, while the opposite was true of pellets made from Elkhorn coal.

\subsubsection{Continuous "Pellet-to-Slurry" Demonstration}

Development of a continuous "pellet-to-slurry" system was also conducted at Amax R\&D. Design of the system included consideration of the scale and slurry specifications of some of the existing DOE combustion programs. For this purpose, the following DOE contractors were contacted to determine their fuel consumptions and specifications:

- Bruce Miller, Pennsylvania State University

- John Balsavich and Tony Litka, Tecogen

- David Arnold, University of Alabama.

Based on the conversations with the above individuals it was decided that a pellet reslurrying system of the following specifications would be sufficient to demonstrate the concept:

Capacity Match University of Alabama atomizer rig $=10$ gallons per hour or match 0.5 million Btu/hr combustor at PETC $=36$ pounds dry coal per hour $=7$ gallons per hour

Particle Size Boiler grind - 100 percent passing $1 \mathrm{~mm}$ (about 14 mesh), 98 percent passing $0.3 \mathrm{~mm}$ (48 mesh)

Loading 54 to 55 percent coal

Viscosity 200 to $800 \mathrm{cP}$ at $100 \mathrm{sec}-1$

Time 8 Minutes.

6.3.2.1 Pellet-to-Slurry System. A "Pellet-to-Slurry" system that matched the above specification was designed and fabricated for demonstrating the concept of continuous slurry production with pellets. A schematic diagram of the system is shown in Figure 6.13. The main components of the module were 1) a hopper for holding the pellets with a belt 
107

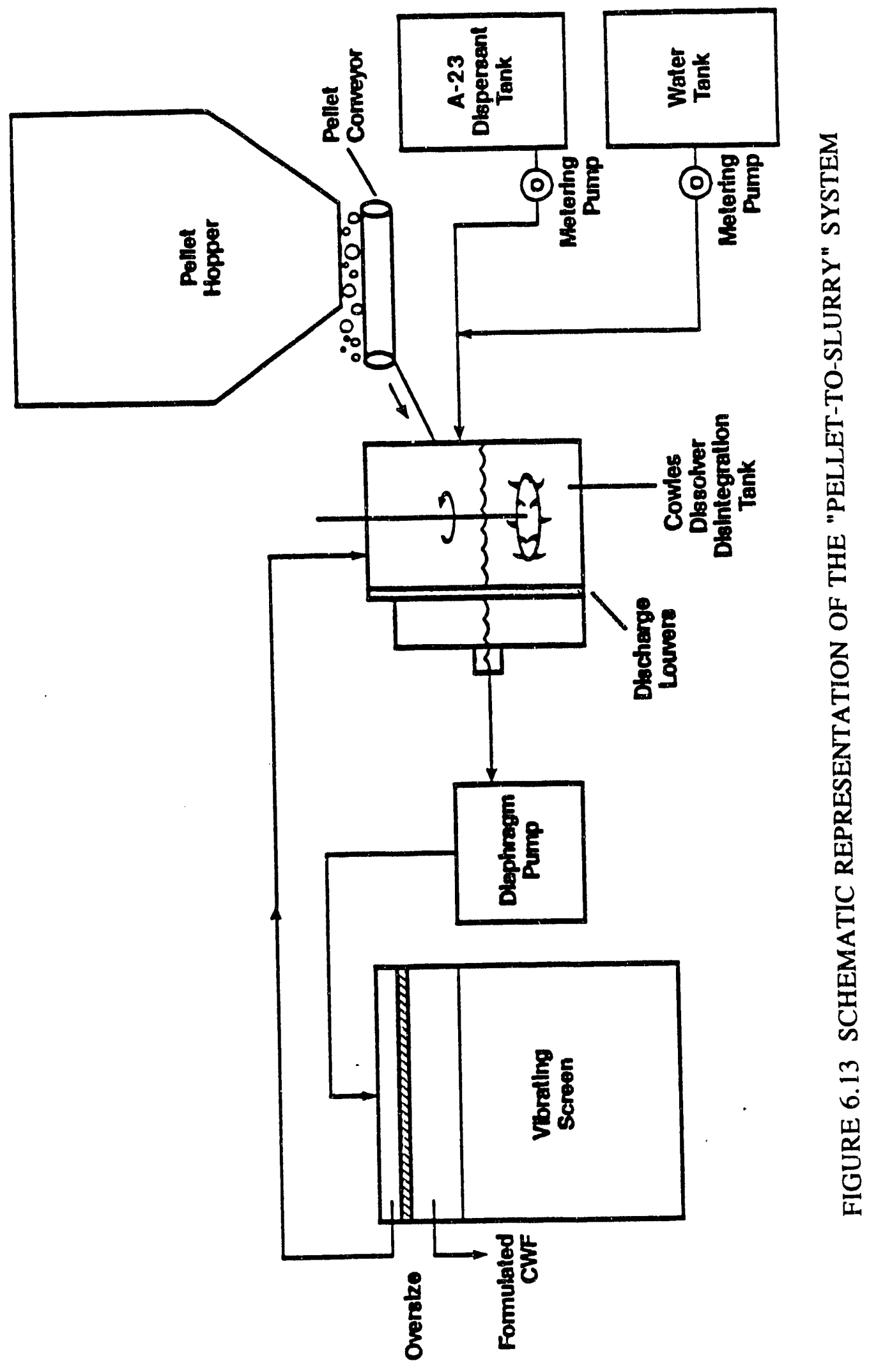


feeder underneath for discharging the pellets at a steady rate, 2) a Cowles Dissolver with a tank especially designed for resiurrying pellets, 3) two positive displacement pumps for metering water and dispersant into the dissolver tank, 4) a slurry transfer gear pump, 5) an 18-in. diameter, 35-mesh Sweco horizontal screen to guard against any oversize entering the atomization system, and 6) an air-operated diaphragm pump for transferring the slurry to the atomization system feed tank. The module also included a 30 -gallon holding tank for temporary storage of slurry if needed. The mixer was designed to control the release of over-sized particle, and yet provide adequate retention time for slurry formulation. The system had an operating capacity of 8 gallons per hour. The slurry left the dissolver tank through louvers cut into the sidewall of the Cowles Dissolver.

A photograph of the reslurrying system is shown in Figure 6.14. The system operated very well during shakedown runs conducted with pellets from disk pelletization. The belt feeder for metering pellets from the hopper had a very limited range of adjustment. The gate was 3 -in. wide and opened to about 2.5 -in. high. The nominal discharge rate was about 290 grams of dry coal per minute, but the actual rate varied according to the size and flow properties of the pellets. The 290-gram-per-minute nominal feed rate was used for design of the dissolver tank.

The dissolver tank was sized to provide 8 minutes of retention for disintegrating the whole pellets as they fed into the dissolver, along with the requisite amounts of water and dispẽrsant. The tank had two compartments. The feed entered the main compartment of the dissolver tank. The tank was 12 -in. deep and the main compartment contained four equally spaced 1-in. vertical removable baffles. The system was usually operated with approximately 6 in. of slurry in the main compartment and with the impeller set 3-in. above the bottom of the tank. The slurry flowed from the main compartment into a side compartment which had an overflow outlet set at mid-level to maintain the slurry depth at 6 in. in both compartments. The two compartments were separated by a removable panel containing vertical louvers. The louvers retained large pellet fragments in the main compartment while allowing finished slurry to flow into the side compartment and out through the overflow. 


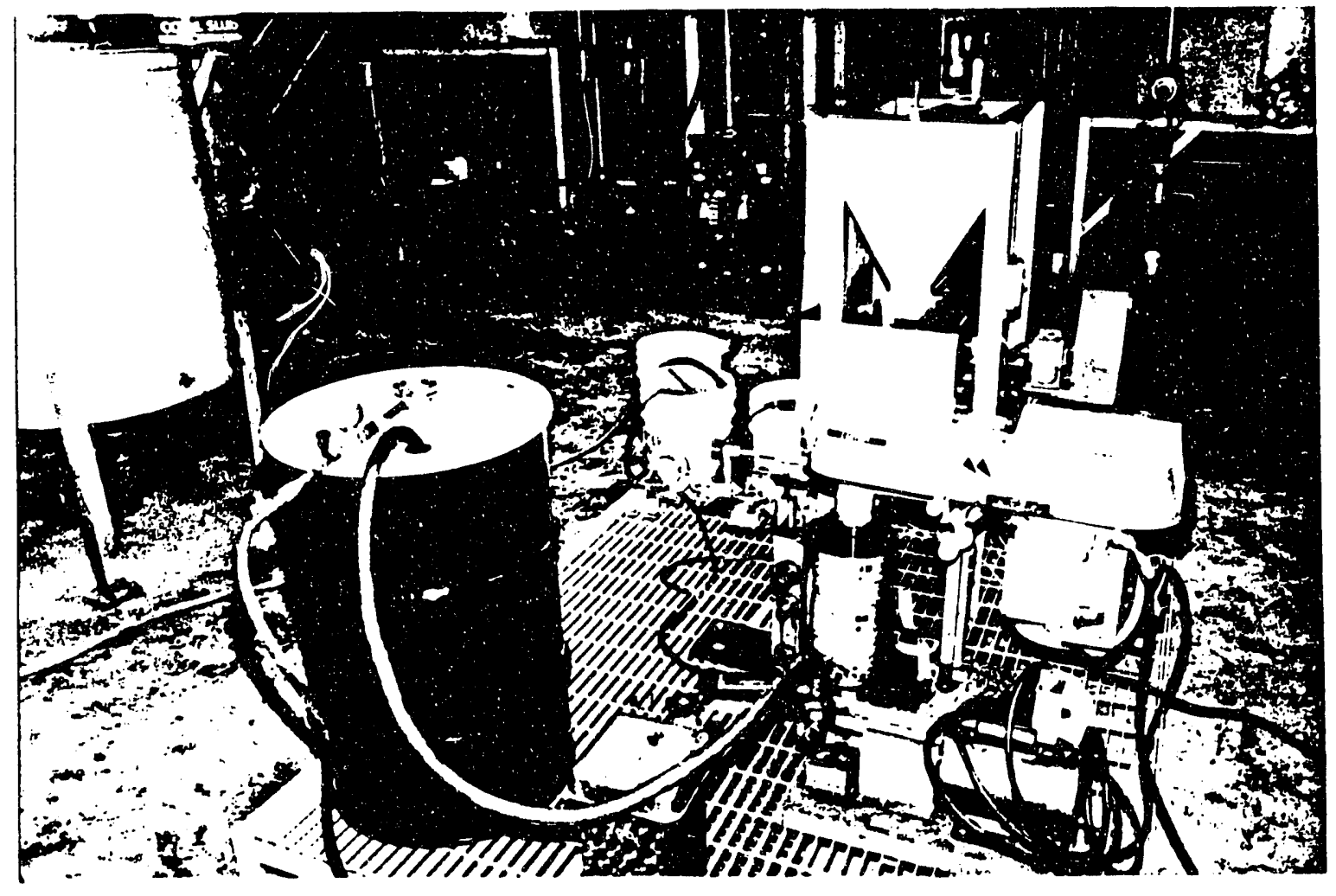

FIGURE 6.14. PHOTOGRAPH OF THE 8-GALLON/HR PELLET-TO-SLURRY SYSTEM 
6.3.2.2 Pilot-Scale Continuous Pellet-to-Slurry Formulation. Pilot-Scale slurry production demonstration was conducted at Jim Walter Resources. The "pellet-to-slurry" system was put in service by Amax R\&D personnel to produce the following slurries:

\begin{tabular}{|c|c|c|c|}
\hline Test & Parent Coal & Pelletization & inder \\
\hline 1 & Utah & Extrusion & Corn Starch \\
\hline 2 & Illinois No. 6 & Disk & Corn Starch \\
\hline 3 & Illinois No. 6 & Roller-and-Die & Shur Bond \\
\hline 4 & Elkhorn & Roller-and-Die & Corn Starch \\
\hline
\end{tabular}

Between 25 and 30 gallons of slurry were produced from each of the four lots of pellets. In each case, moisture determinations and calibration runs were made first. Initial water and dispersant metering pump settings were calculated from these rates using dispersant dosages selected from past amenability tests on similar pellets. The solids loading and viscosity of the product slurries were checked after 20 or 30 minutes of operation and the metering pumps re-adjusted as necessary to meet target specifications of 55 percent coal and $500 \mathrm{cP}$ viscosity. The first 10 or 15 minutes of slurry production from each test was discarded. Each test run required about 4 hours of continuous operation, and a sample of the combined production was taken at the end of each run for viscosity, loading, and particle size distribution determinations. The operating and product quality data for each test run are summarized in Table 6.7. Figures 6.15 through 6.18 show the particle size distributions for the slurries. In each case, the particle size distributions indicate a larger amount of plus 200 -mesh $(75-\mu \mathrm{m})$ material than usually seen when grinding coal this fine.

\section{Test 1 - Utah Coal Extrusion Pellets}

For the most part, the Utah extrusion pellets were 1/2-in. diameter cylinders of various lengths up to about 2 inches. They discharged from the hopper quite evenly and disintegrated very well. Only 0.26 percent of the coal in the finished sluriy was larger than 


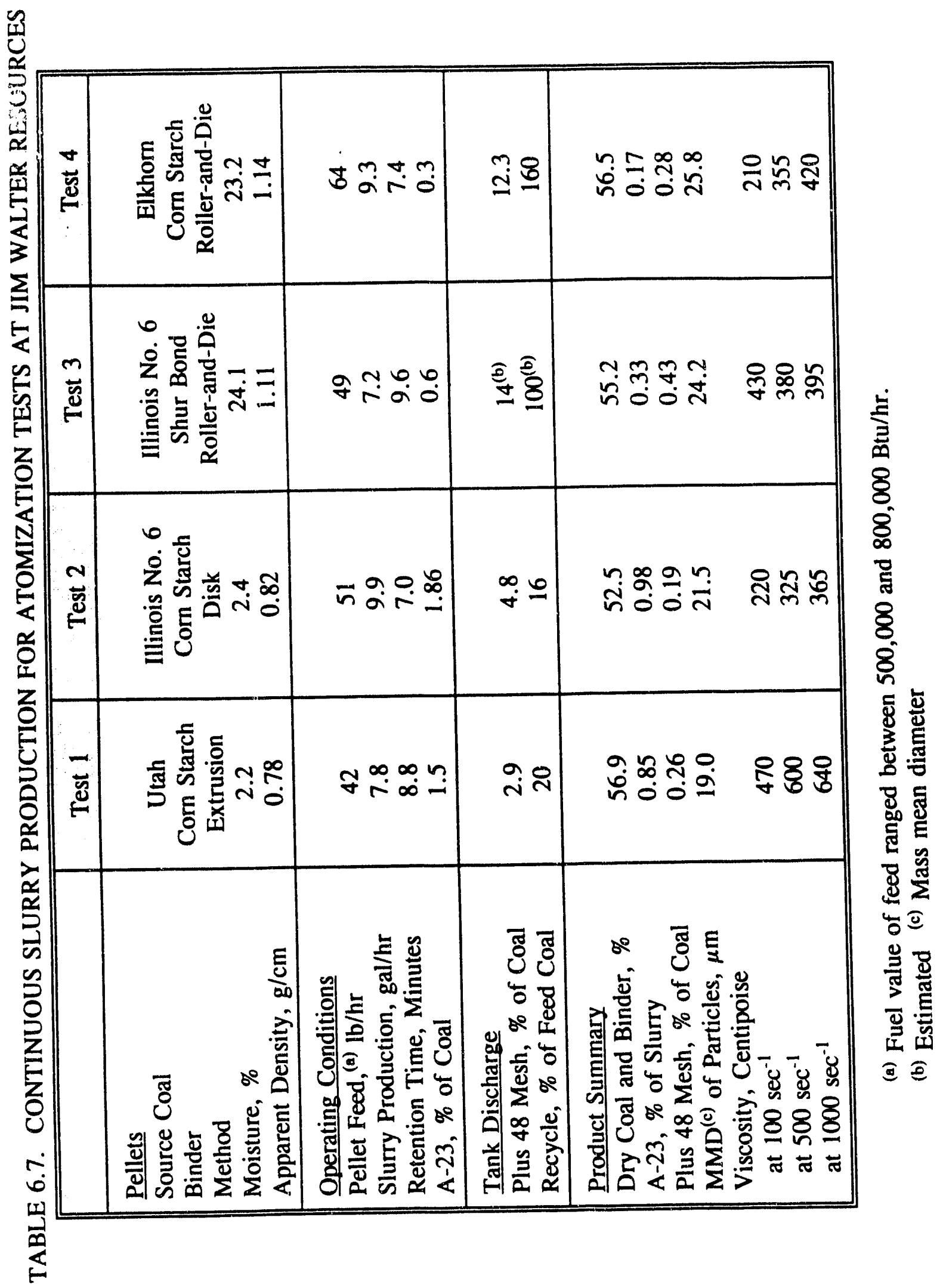




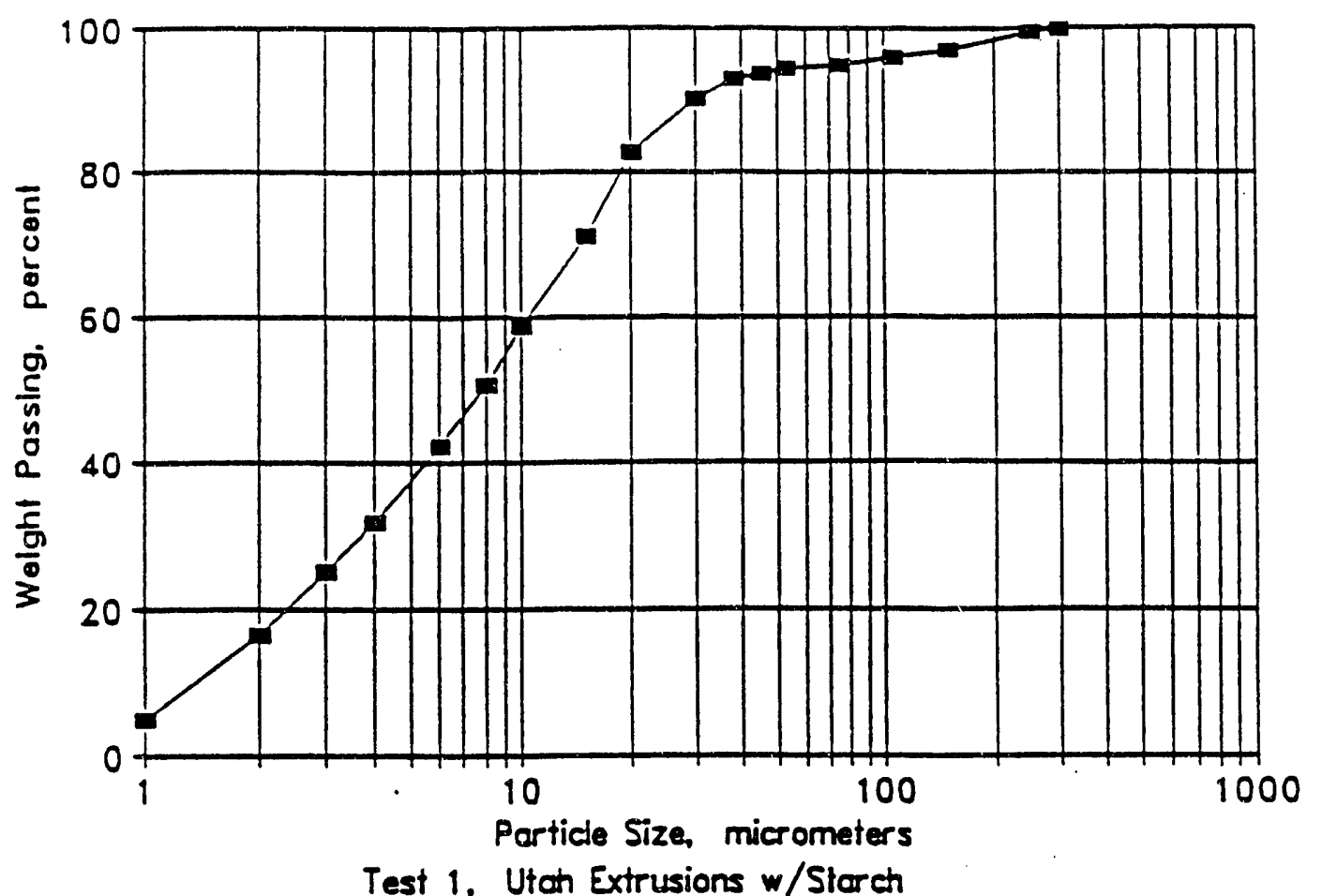

FIGURE 6.15 PARTICLE SIZE DISTRIBUTION OF TEST 1 SLURRY

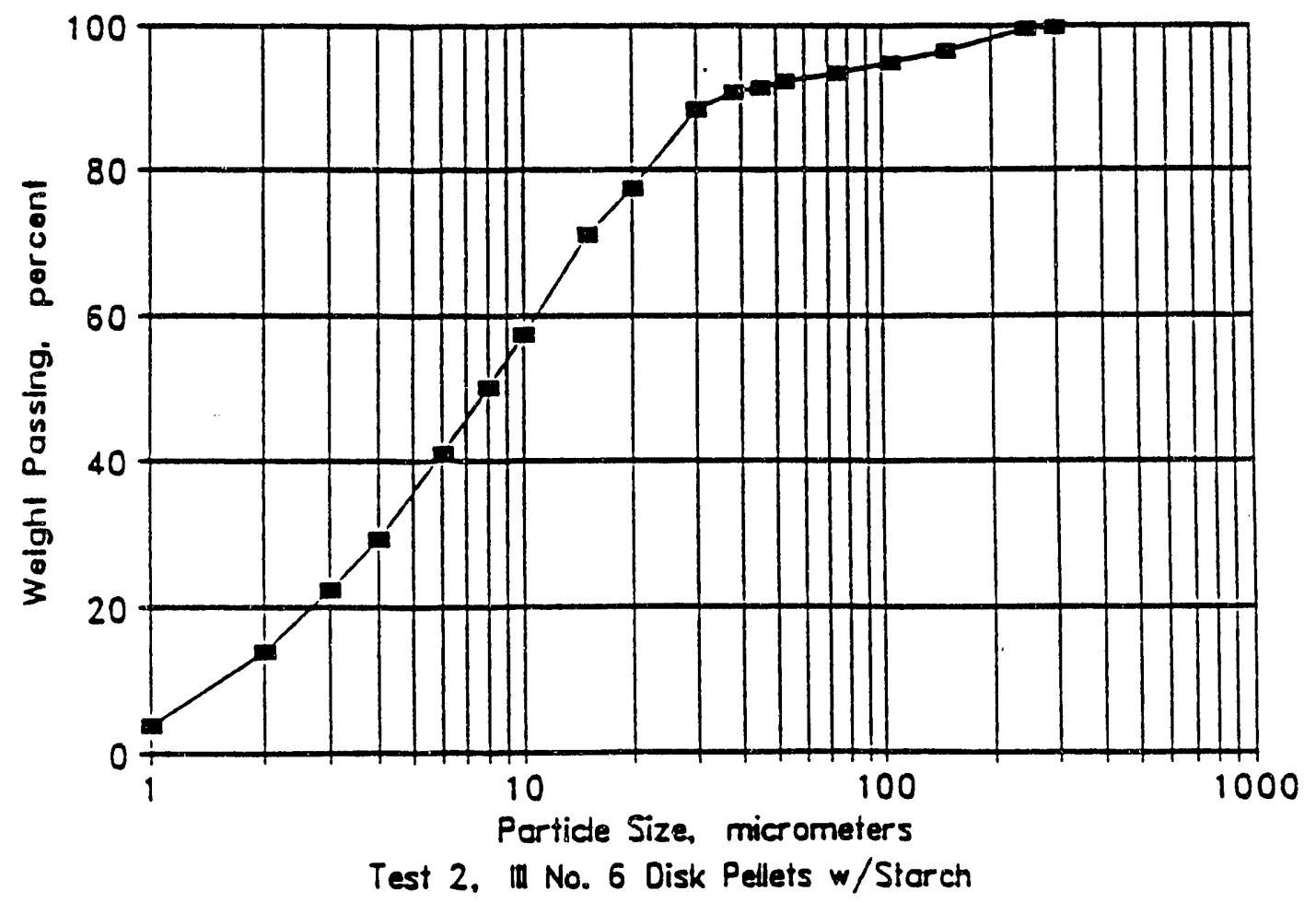

FIGURE 6.16 PARTICLE SIZE DISTRIBUTION OF TEST 2 SLURRY 


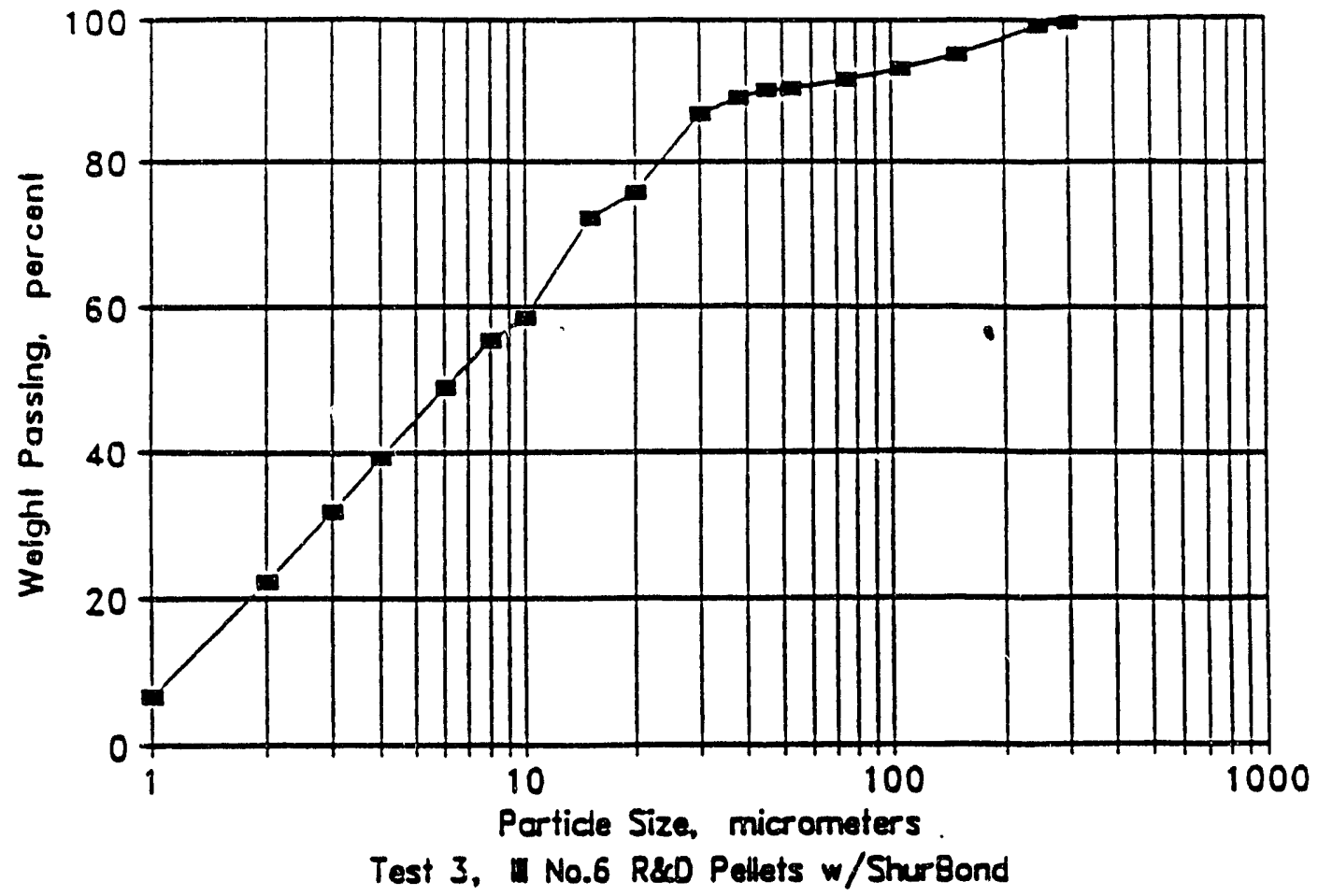

FIGURE 6.17 PARTICLE SIZE DISTRIBUTION OF TEST 3 SLURRY

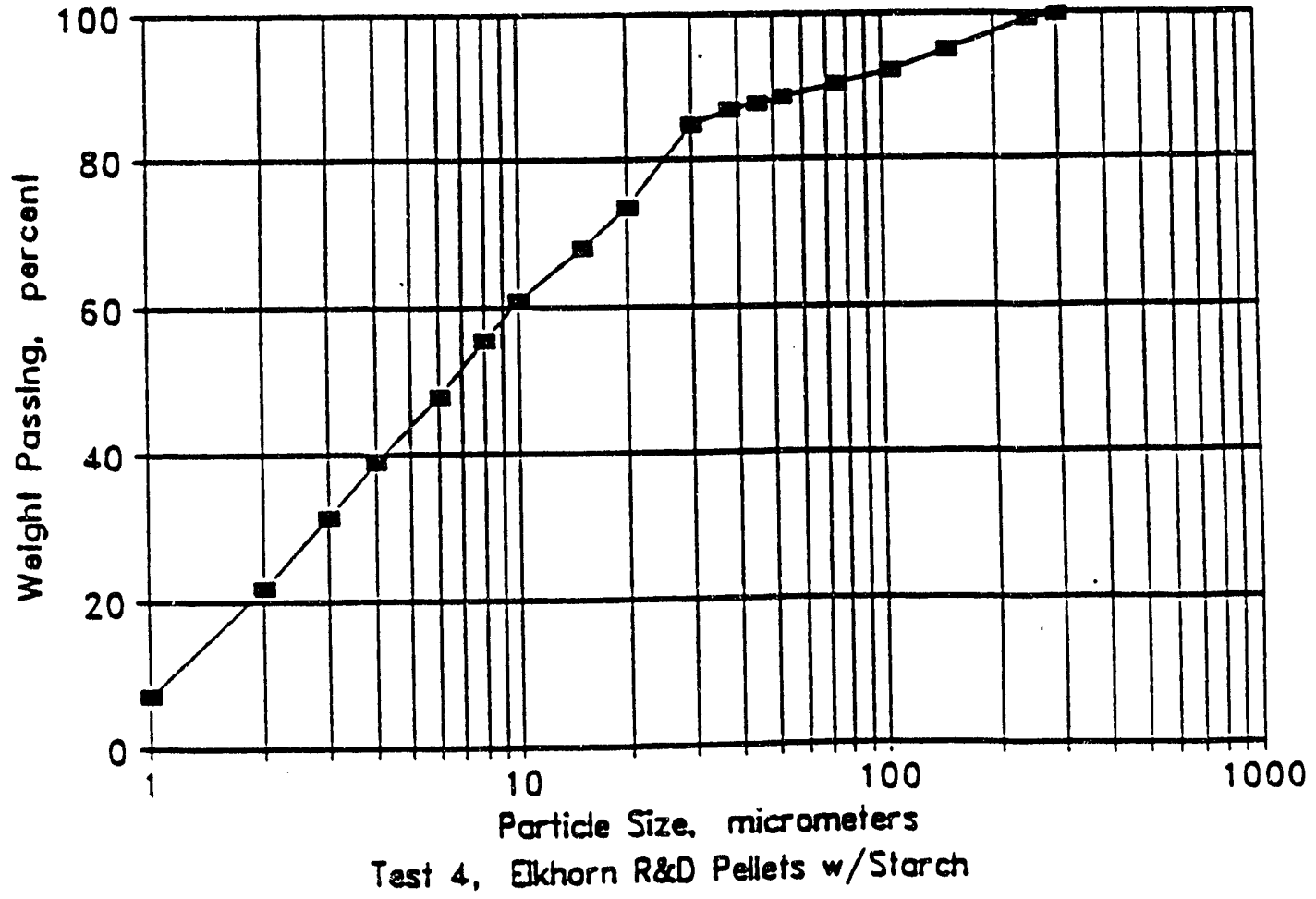

FIGURE 6.18 PARTICLE SIZE DISTRIBUTION OF TEST 4 SLURRY 
48 mesh. Even the direct unscreened discharge from the dissolver had only 2.9 percent of the coal coarser than 48 mesh. The finished slurry was thixotropic and sightly dilatant. Considerably more A-23 dispersant was used than that determined from the amenability tests. The extra A-23 did allow formulation of slurry with a higher loading than usual for Utah pellets.

\section{Test 2 - Illinois No. 6 Coal Disk Pellets}

The Illinois No. 6 disk pellets were mostly spheres ranging in size between 0.5 and 1.0-in. diameter. There were a few larger clusters of fused pellets. If noticed, these clusters were removed or broken by hand. Most of the time the disk pellets discharged from the hopper evenly and disintegrated quite well. The direct unscreened discharge from the dissolver had only 4.7 percent of the coal larger than 48 mesh. The finished slurry was thixotropic and dilatant. More A-23 was needed for slurrying these pellets than was needed for the other three lots of pellets, but the total amount added was still 27 percent less than the amount commonly added during amenability tests on similar pellets.

\section{Test 3 - Illinois No. 6 Roller-and-Die Pellets}

The Illinois No. 6 roller-and-die pellets made with Shur Bond binder, consisted of broken and intact cylinders about 0.75 -in. diameter and up to 1-in. long. They appeared to be moist and quite easily broken and did not discharge from the hopper as well as the Test 1 and Test 2 pellets. Neither did they disintegrate as well. The direct discharge from the tank contained more plus 48-mesh fragments than the direct discharge from the previous tests, and the Sweco screen occasionally became over-loaded as the amount of recycle oversize was high. The difficult disintegration was also indicated by an increase in the mass mean diameter of the particles in the product slurry. It is not clear whether the poorer disintegration was due to the pellets being tougher than the two previous lots of pellets or due to the pellets just being larger in size. The amount of A-23 added while slurrying these pellets was 
comparable to the amount added during amenability tests on similar pellets. The resulting slurry was thixotropic and the only one of the four to be pseudoplastic.

\section{Test 4 - Elkhorn Coal, Roller-and-Die Pellets}

The roller-and-die pellets for this test were prepared from Elkhorn coal and were also about 0.75 in. wi: diameter, out were somewhat longer than the Test 3 roller-and-die pellets. They did not discharge well from the hopper, and the feeder required constant attention. They behaved very similar to the Test 3 pellets during disintegration and a large amount of recycle material collected on the Sweco screen. The mass mean diameter of the particles in the product slurry was slightly larger than the mass mean diameter of the particles in the slurry from Test 3 and significantly larger than the mass mean diameter of the particles in the slurries from Tests 1 and 2. At 0.3 percent on a dry weight basis, the A-23 addition during this run was less than the other three runs, but the amount was comparable to the amount of A-23 used during amenability tests on pellets made from Elkhorn coal. The resulting Test 4 slurry was thixotropic and dilatant.

In conclusion, the performance of the continuous reslurrying module was consistent with the results of the bench-scale and pilot-scale amenability tests. There were more plus 48-mesh fragments in the overflow from the dissolver tank than in the amenability test slurries after comparable retention times, but that did not cause any problems during the production runs because the oversize fragments were recycled. With the recycle in operation, slurry production rates met expectations, and the amount of plus 48-mesh materials in the slurry was well below the specification. The roller-and-die pellets were compacted to significantly higher density than were the extrusion and disk pellets. This difference in compaction may account for the greater difficulty noted when disintegrating the roller-and-die pellets during Tests 3 and 4 than when disintegrating the extrusion and disk pellets during Tests 1 and 2. During reslurrying the roller-and-die pellets, retention times in the dissolver would had to have been increased if the recycle system had not been in place. 


\subsection{Atomization Evaluation}

The four slurry samples prepared continuously in the "Pellet-to-Slurry" system were atomized in the joint University of Alabama/Jim Walter Resources, Inc (JWRI) Atomization Spray Test Facility (ASTF). Details on the atomization test facility and the operational procedure were provided earlier in Section 5.4.

\subsubsection{Pilot-Scale Slurry Atomization}

Atomization characteristics of the coal-water slurries can be characterized by the Sauter Mean Diameter (SMD) of the spray at a Air-Fuel Ratio (AFR). For the four slurries, at the low end of atomization AFR, the mean SMD were between 120 and 160 microns and at the high end of AFR, the mean SMD were between 20 and 55 microns. All the coalwater slurries tested were successfully sprayed without problems, i.e., there were no slurry transfer line or nozzle plugging. The nozzle used for the atomization test was the same AGT research nozzle used earlier in the bench-scale slurry atomization tests.

Figure 6.19, shows the SMD's for the four test fuels plotted against the AFR. The profiles are typical of normal slurries. CWF from Illinois No. 6 coal with corn starch binder, prepared via disk pelletization, show better atomization as reflected by the SMD's of 20 to 30 microns lower than the other three CWF. Within the accuracy of this method, there is no difference among the three other CWFs. The Malvern system used to obtain the droplet size distribution can obtain measurements between 5.80 and 564 microns with one focal length. Accuracy of this instrument is at its maximum at the center of this range. Atomization of the CWF tested showed droplets larger than 564 microns and smaller than 5.80 microns, which could not be measured using this system. However, the data obtained from this study are good indicators of relative atomization quality of the CWFs. 


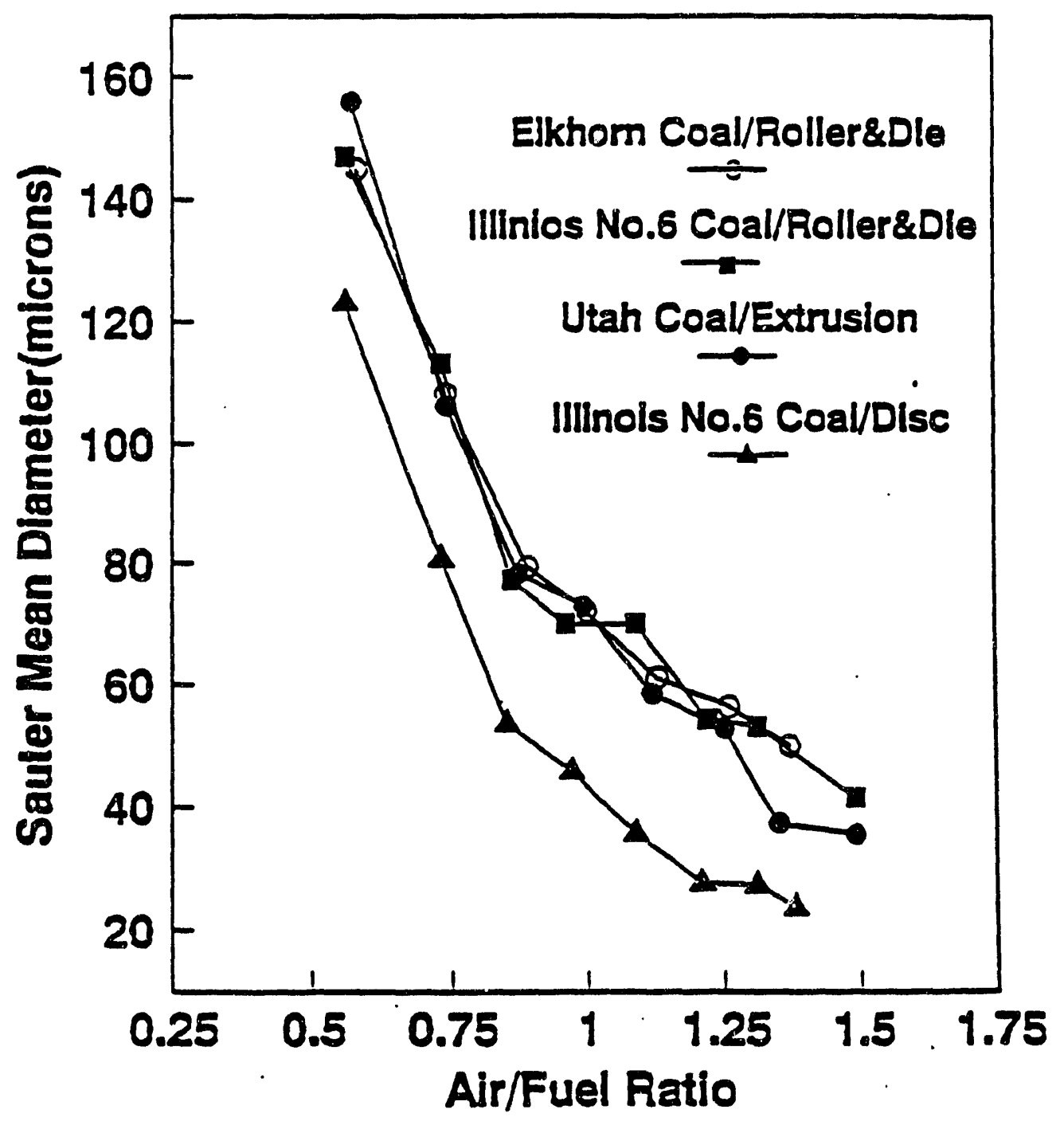

FIGURE 6.19. SMD VARIATION WITH AFR FOR THE FOUR SLURRIES 
In conclusion, atomization evaluations conducted on the slurries indicate:

- All pellets, irrespective of their production method, were successfully formulated into a good quality CWF on a continuous basis and were readily atomized.

- These slurries at 55 percent solid loading, can be sprayed at AFR between 0.55 and 1.5, without problems of plugging (common with most CWFs).

- The atomization spray's SMD are within the acceptable range for good combustion at AFR greater than 1.10

- In terms of operational difficulty no one slurry posed any serious problems to atomize. But, among the four CWF tests, atomization of slurries from Utah and Elkhorn coal were easier than the slurry from the Illinois No. 6 coal.

- The effect of binder type on slurry atomization could not be deduced from the limited number of tests conducted.

\subsection{Section 6 References}

1. Conkle, H. N., Raghavan, J. K., Jha, M. C., and Smit, F. J., "Pelletizing/Reslurrying as a Means of Distributing and Firing Clean Coal," Sixth Quarterly Progress Report prepared by Battelle Memorial Institute for the U. S. Department of Energy under Contract No. DE-AC22-90PC90166, March 17, 1992. 


\subsection{TRANSPORTATION, HANDLING AND STORAGE}

This section describes Tasks 4, 5, and 6 covering the evaluation of the transportation, handling, and storage characteristics of the pelletized coal. Evaluation of pellets included simulation (e.g., crushing strength, durability, etc.) and actual truck transportation tests. Extensive, multi-week storage tests were carried out on each of selected pilot-scale coal/ pelletization techniques/binder combinations.

The primary objective of the task was to assess the acceptability of the pilot-scale pellets for transportation, handling, and storage. A secondary objective was to assess the adequacy of the criterion values in the acceptance criteria as compared with more meaningful transportation and storage tests. Information from the task was used to assess pellet acceptability.

The following subtasks were carried out:

- Subtask 4.1 Measure Strength

- Subtask 4.2 Conduct Freeze/Thaw Tests

- Subtask 4.3 Evaluate Fire/Explosion Hazards

- Subtask 4.4 Conduct other Storage Tests

- Subtask 4.5 Define Storage Requirements

- Subtask 5.1 Drop Tests

- Subtask 5.2 Conduct Tumbling Tests

- Subtask 5.3 Conduct Other Handling Tests

- Subtask 5.4 Define Handling Requirements

- Subtask 6.1 Conduct Vibration Tests

- Subtask 6.2 Conduct Transportation Tests

- Subtask 6.3 Define Transportation Requirements 
Provided in this section are:

- Transportation Evaluation
-
-
Spondling and Storage Evaluation

\subsection{Summary}

Pellets produced in the pilot-scale pellet production processes were studied for survivability during transportation, handling and storage. The pellets were expected to behave similar to lump coal in all of these test modes. Transportation simulation tests were conducted in a test unit designed in this project. The unit controlled the vibration intensities on the pellets. Through the simulated and actual transportation tests, it was found that all the pellets show excellent potential to survive transportation. Typically, less than 5 percent fines ( -48 mesh) were generated.

Storage simulation tests were conducted over 2,4 and 10 week test periods in exposed-outdoor, covered-outdoor, silo, and bag type storage units. All the pellets survived the above modes, except with exposed-outdoor mode, during the 2, 4 and 10 week test periods. In the exposed-outdoor mode, the pellets typically survive easily for first two weeks. Beyond which, extreme structural disintegration occurred, particularly with lignin sulfonate and corn starch bound pellets.

No specific degradation effects were observed when pellets were subjected to the reactivity tests to simulate the effects of spontaneous combustion. Therefore, it is believed that the pellets have a very low potential for spontaneous combustion: 


\subsection{Transportation Evaluation}

\subsubsection{Requirements}

Pilot-scale production pellets were evaluated for their transportation characteristics. The basic criteria that the pellets must satisfy in order to be acceptable for transporting like mined lump coal were:

- The pellets should first meet the pellet acceptance criteria, established in this program. The cured pellet strength should exceed $100 \mathrm{lbf} / \mathrm{in}^{3}$ and durability indices should exceed 28 for DI and 90 for RDI, and for freeze/thaw resistance the WI should exceed 60. (See Section 4.3 for details on the DI, RDI, and WI procedures as well as more information on the acceptance criteria.)

- Fines (-48 mesh) generated during pellet transportation should not exceed 5 percent. This criterion was established based on data obtained from actual pellet transportation in trucks.

\subsubsection{Test Program}

The cured strength, durability and weatherability index data for the pilot-scale pellets were reported in the Seventh Quarteriy Report. ${ }^{(1)}$ Based on these data it was concluded that the corn starch- and lignin sulfonate-bound pellets far exceeded all the three pellet acceptance criteria for pellet transportation. Shur Bond pellets were also found to satisfy the durability and weatherability requirements, but strength was at the bottom end of the acceptable range. Lignin sulfonate-bound pellets could meet the less stringent requirements established for coal capsules.

To evaluate these pilot-scale production pellets for transportation survivability, a transportation simulation device was designed and fabricated in this project. A series of tests were conducted to simulate the effects of transportation of pellets in trucks, rail, etc. Tests 
were designed to obtain baseline data on fines that were generated when pellets were subjected to:

- Medium and high vibration intensity simulating light to heavy forces of transportation, and

- Transportation simulation for test periods ranging between 30 minutes to 5 hours.

A photograph of this unit is shown in Figure 7.1. The device simulated the forces the pellets experienced during transportation. Several simulation tests were conducted to validate the unit. The unit had electrical vibrators attached at its walls. The vibration intensities were controlled by adjusting the input voltage to the vibrators. Manual gates located at the bottom of the unit were used to discharge the pellets after testing. Figure 7.2 presents the simulated profile of fines thai are generated over several hours of vibration/transportation simulation of coal pellets. Data from actual transportation tests, conducted with coal pellets loaded in trucks are also presented and compared. Transportation simulation at medium vibration intensity appeared to reasonably simulate the forces and movements the pellets experience during transportation. Based on this evaluation, the following test conditions were chosen to conduct transportation simulation on pilot-scale production pellets:

- Quantity of pellets for testing - approximately $100 \mathrm{lbs}$

- Vibration intensity - medium

- Vibration duration - 1 and 4 hour time periods.

Selected pilot-scale production samples of roller-and-die, disk, and extrusion pilotscale pellets were tested under these test conditions. Figures 7.3 and 7.4 show the amount of fines that were generated after 1 and 4 hours of vibration, respectively. In the 1 hour simulation test, see Figure 7.3 noted above, all of the samples showed about 10-20 percent higher fines generation cumpared with the results of truck transportation. However, the results are within acceptabie levels ( $<4$ percent) of fines generation, and the method appeared to adequately simulate actual transportation of pellets. 


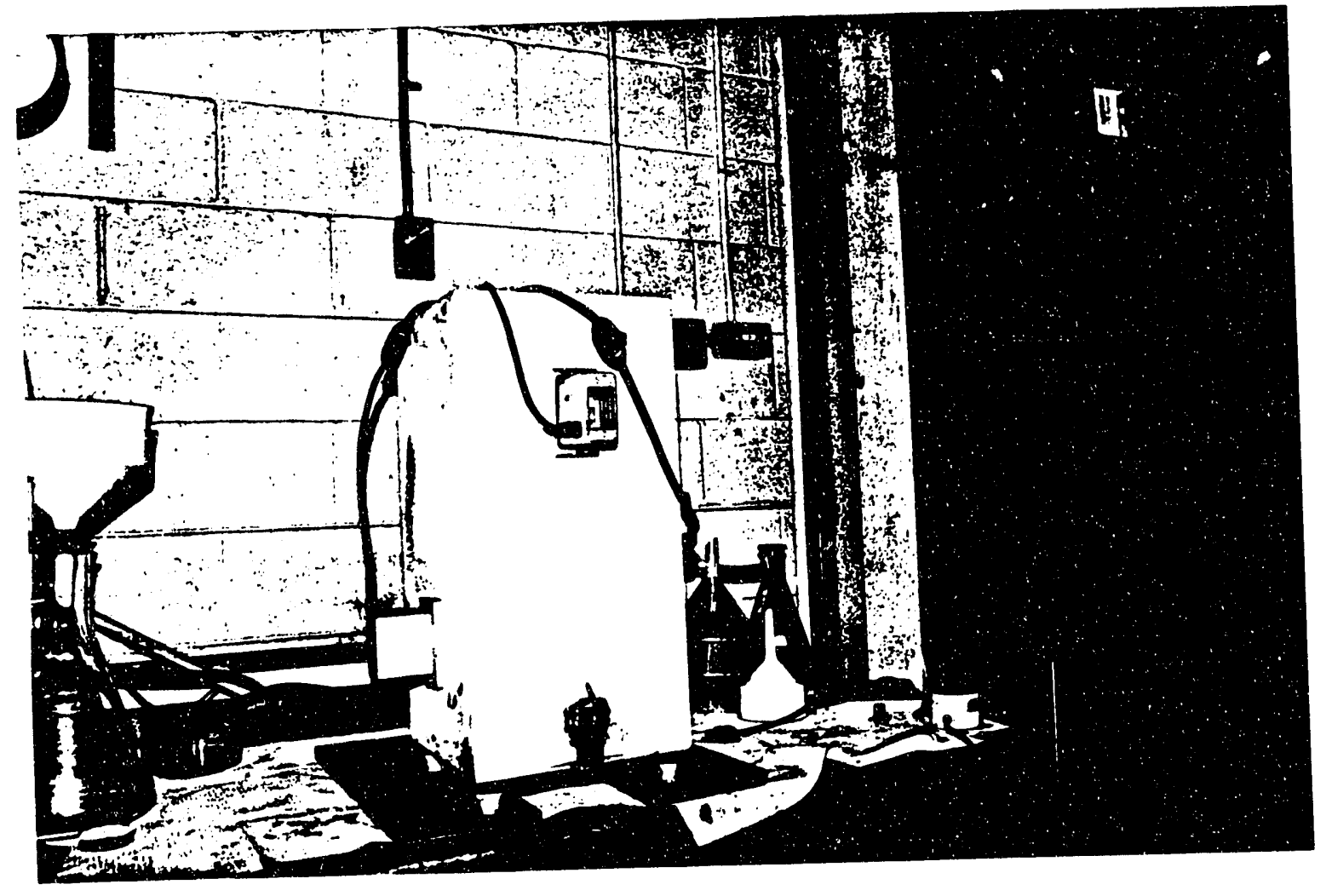

FIGURE 7.1. PHOTOGRAPH OF THE TRANSPORTATION SIMULATION DEVICE 


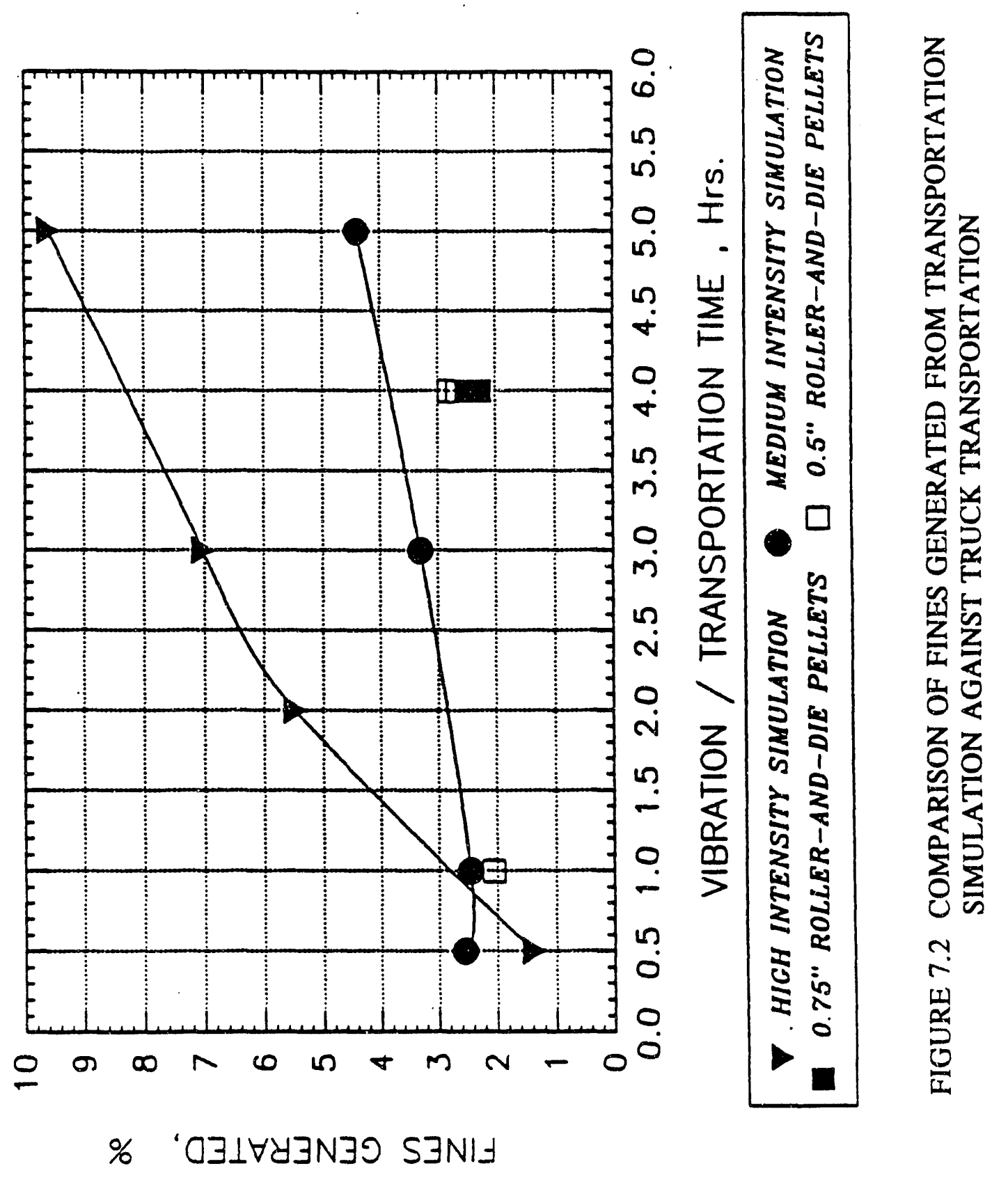




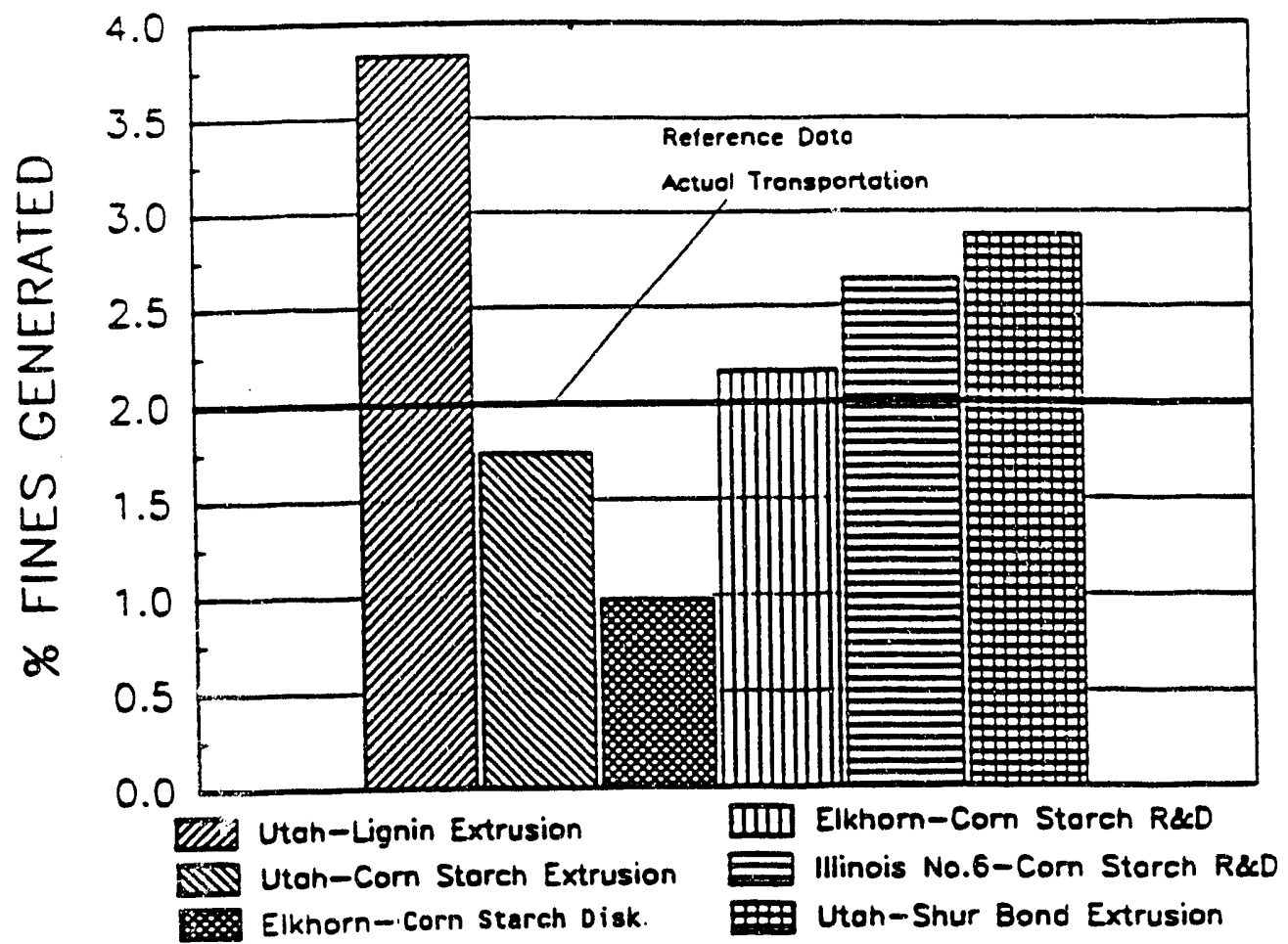

FIGURE 7.3 ONE HOUR TRANSPORTATION SIMULATION

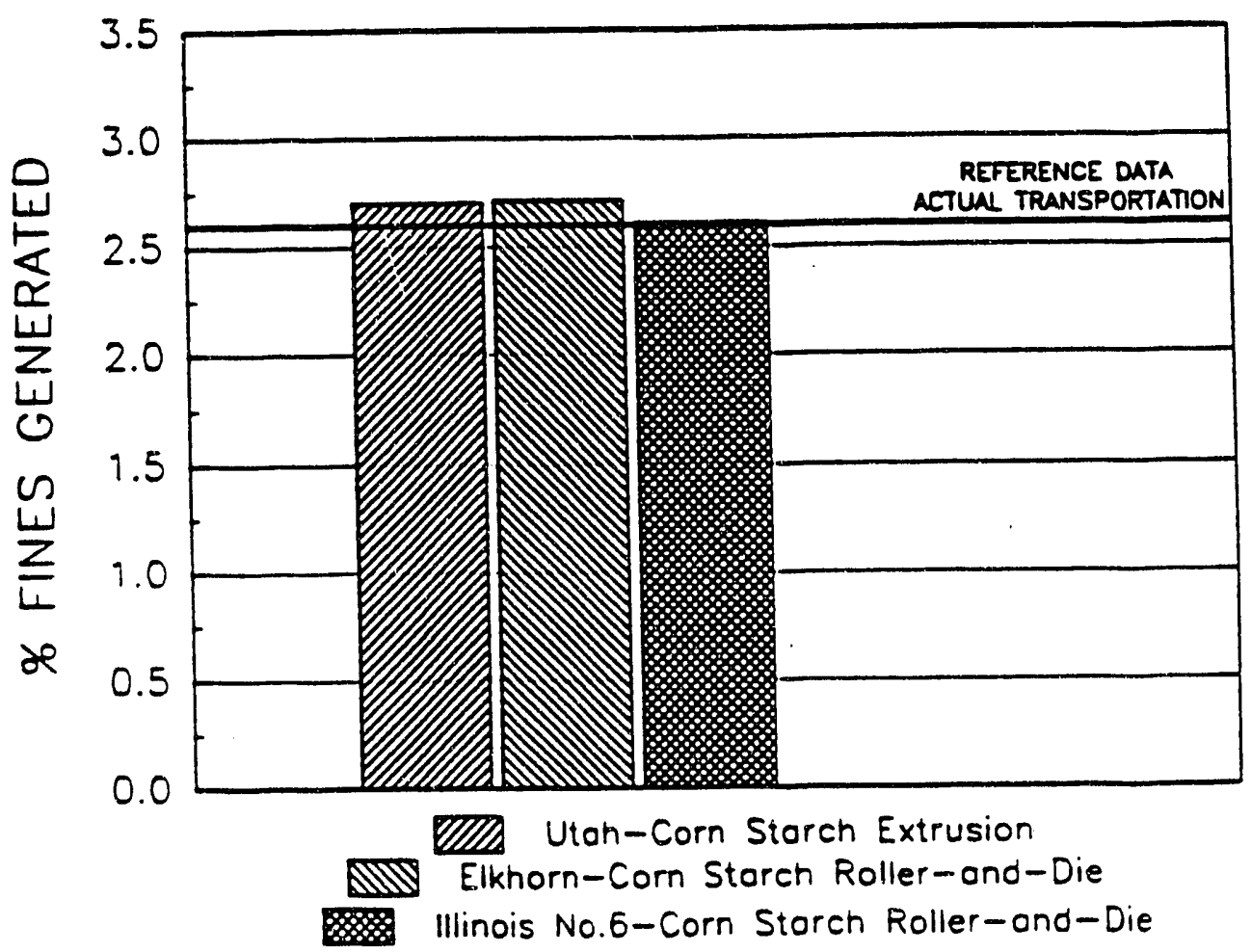

FIGURE 7.4 FOUR HOUR TRANSPORTATION SIMULATION 
The data in Figure 7.4 noted above suggest that the pellets after 4 hours of vibration did not continue to deteriorate with time. The fines that were generated were about the same level recorded after 1 hour. The fines recorded were also of the same level measured from the actual 4 hour truck transportation test.

\subsubsection{Specifications}

Based on the transportation evaluation, it can be concluded that all pilot-scale pellets:

- Meet the pellet acceptance criteria, and

- Produce less than 5 percent fines during transportation.

The severity of fines generation could be higher when handling effects are also incorporated. From the limited results of this study it can also be concluded that corn starch-bound pellets showed the lowest fines generation rate during transportation, followed by Shur Bond- and lignin sulfonate-bound pellets.

\subsection{Handling and Storage Evaluation}

\subsubsection{Requirements}

Handling and storage requirements depend on several variables. The basic criteria that the pellets must satisfy in order to be acceptable as lump coal are:

- The handling equipments used in pellet processing in the production stage should not differ from that of mined lump coal. If the cured pellet strength and durability data exceed the acceptable levels, then the pellets were declared acceptable.

- Pellets should not require special storage requirements and should be able to be stored like mined lump coal.

- Pellets should not pose problems related to spontaneous combustion during handling and storage operations. 


\subsubsection{Test Program}

All the above requirements were verified through a series of tests. The pellet handling requirements were evaluated based on the strength and durability measurements obtined from the pilot-scale samples. All the pellets, prepared by the three production techniques met the pellet acceptance criteria and were therefore found suitable for handling as lump coal.

Storage characteristics of the pellets were evaluated for the following storage modes after 2,4 , and 10 weeks of storage:

- $\quad$ Exposed-outdoor storage

- Covered-outdoor storage

- $\quad$ Silo storage

- $\quad$ Bag storage

7.3.2.1 Exposed-Outdoor Storage Test. The pilot-scale production pellets were stored in cubicles and exposed to outdoor weather and temperature conditions. A photograph of the cubicles with pellets is shown in Figure 7.5. At the end of the 2, 4 and 10 weeks of pellet storage, 20 pounds of pellets were sampled from the cubicles for pellet survivability and reslurryability evaluations.

Visually, all the pellet samples showed excellent physical integrity up to 2 weeks of storage. However, if the pellets are exposed to extreme conditions of rain, as in the case of Elkhorn coal with corn starch binder prepared via roller-and-die, considerable destruction of the pellets was evident. This is shown in Figure 7.6. After two weeks, some of the pellets, especially the roller-and-die pellets prepared with lignin sulfonate binder, showed evidence of deterioration around the edges and at pellet's outer surface.

The physical integrity of the pellets after storage were determined by measuring the compressive strength and the Ro-Tap durability of the pellets. These data were presented in 


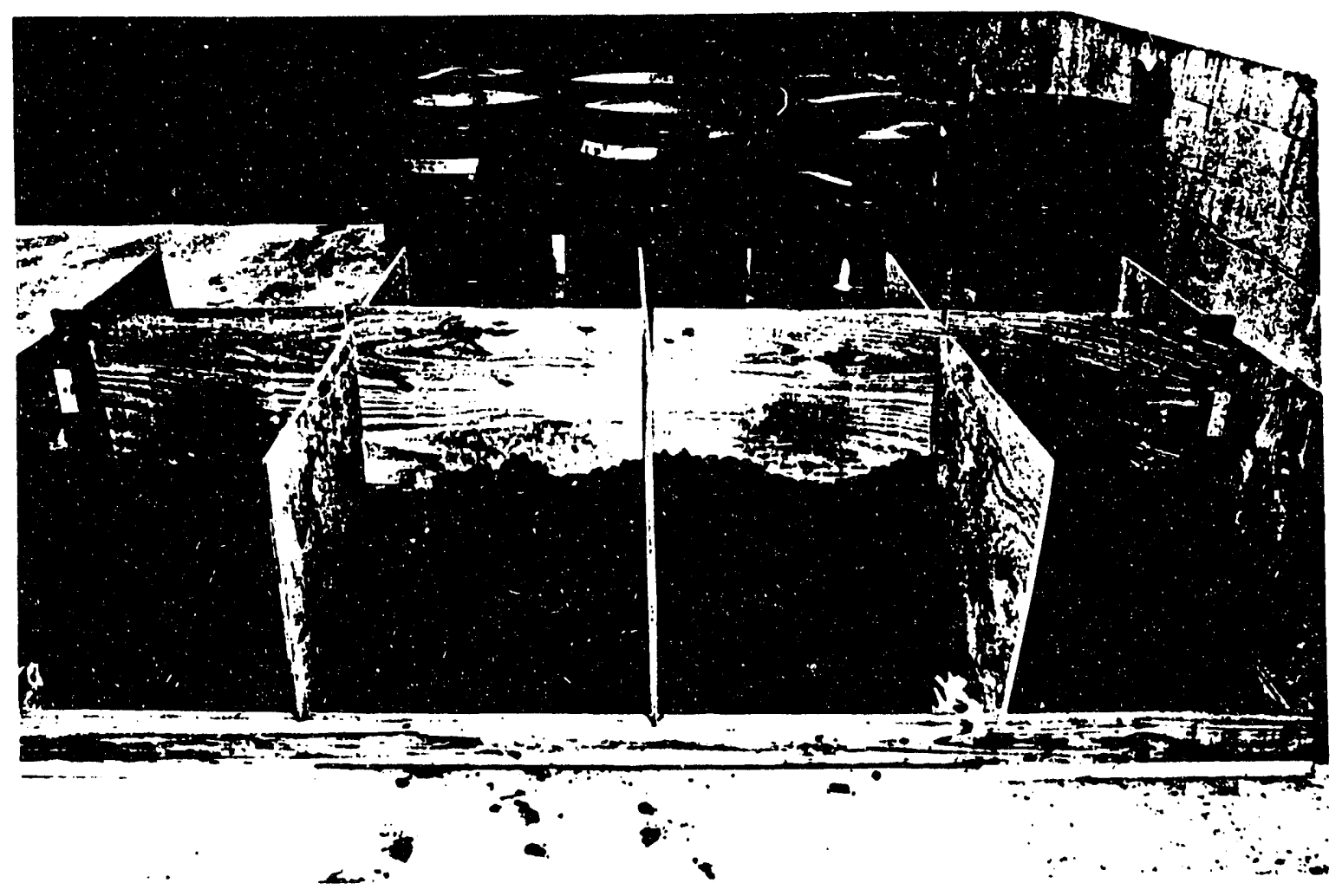

FIGURE 7.5 EXPOSED-OUTDOOR STORAGE TEST-SITE 


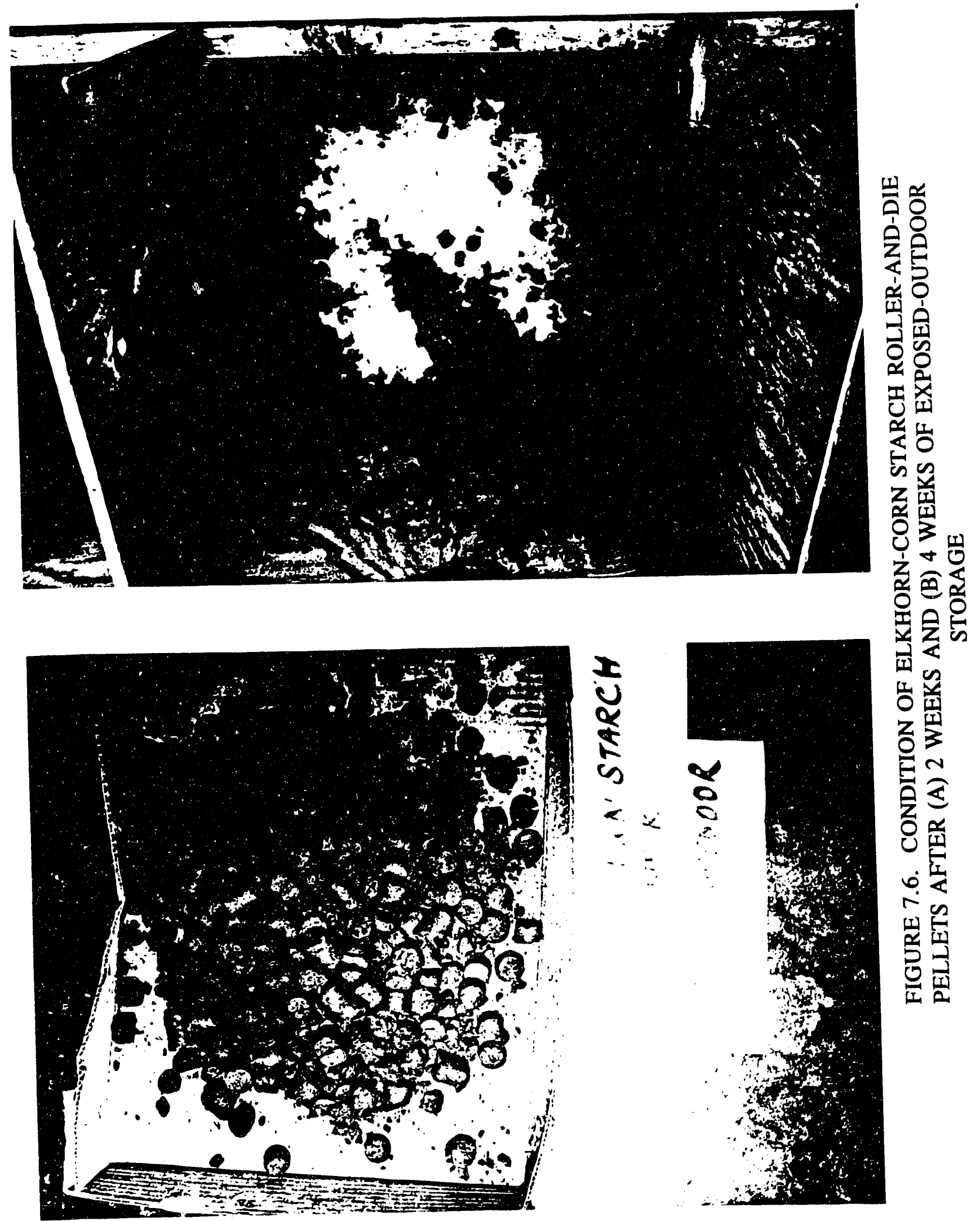


the Seventh Quarterly Report. ${ }^{(1)}$ The compressive strength of the pellets from 2-week storage, showed an increase due to aging, with the exception of the roller-and-die pellets of Utah and Elkhorn coal made with corn starch binder. In both cases, the pellets were exposed to high level of rain during the period of storage. The moisture level measured from these pellets was $>15$ percent, thereby failing the pellet acceptance criteria. Therefore, the survivability of the pellets stored in the exposed-outdoor mode depends on the level of rain experienced. Roller-and-die pellets $;$ rotected from extreme rain conditions were observed to survive the exposed-outdoor storage. In additions, all thermally dried pellets from disk and extrusion pelletization, showed excellent storage characteristics during the first two weeks of exposed storage. Photographs of disk pellet pellets from two week storage are shown in Figure 7.7.

Data on pellets from fourth week onward showed signs of wear on the outer surface. Again disk pellets with corn starch binder showed better survivability -- the strength of these pellets actually increased about 15-25 percent. The high concentration of corn starch binder used in the disk pelletization may explain the increase in strength seen with aging. After 10 weeks of pellet storage, most pellets showed extremely high level of deterioration and had lost the pellet's structural integrity. Based on this evaluations, the following general conclusions were drawn based on the exposed-outdoor storage data:

- Since most of the corn starch- and Shur Bond-bound pellets either showed no change or increased in strength, it can be concluded that these pellets can survive the effects of exposed-outdoor storage for up to four weeks.

- Lignin sulfonate bound pellers were found to deteriorate rapidly after 2 weeks of storage in this mode.

- After 4 weeks storage, disk and extrusion pellets made with corn starch showed bettar potential for survival than roller-and-die pellets.

- Shur Bond pellets showed excellent resistance to water penetration. This was evident by the low levels of moisture intake recorded. 


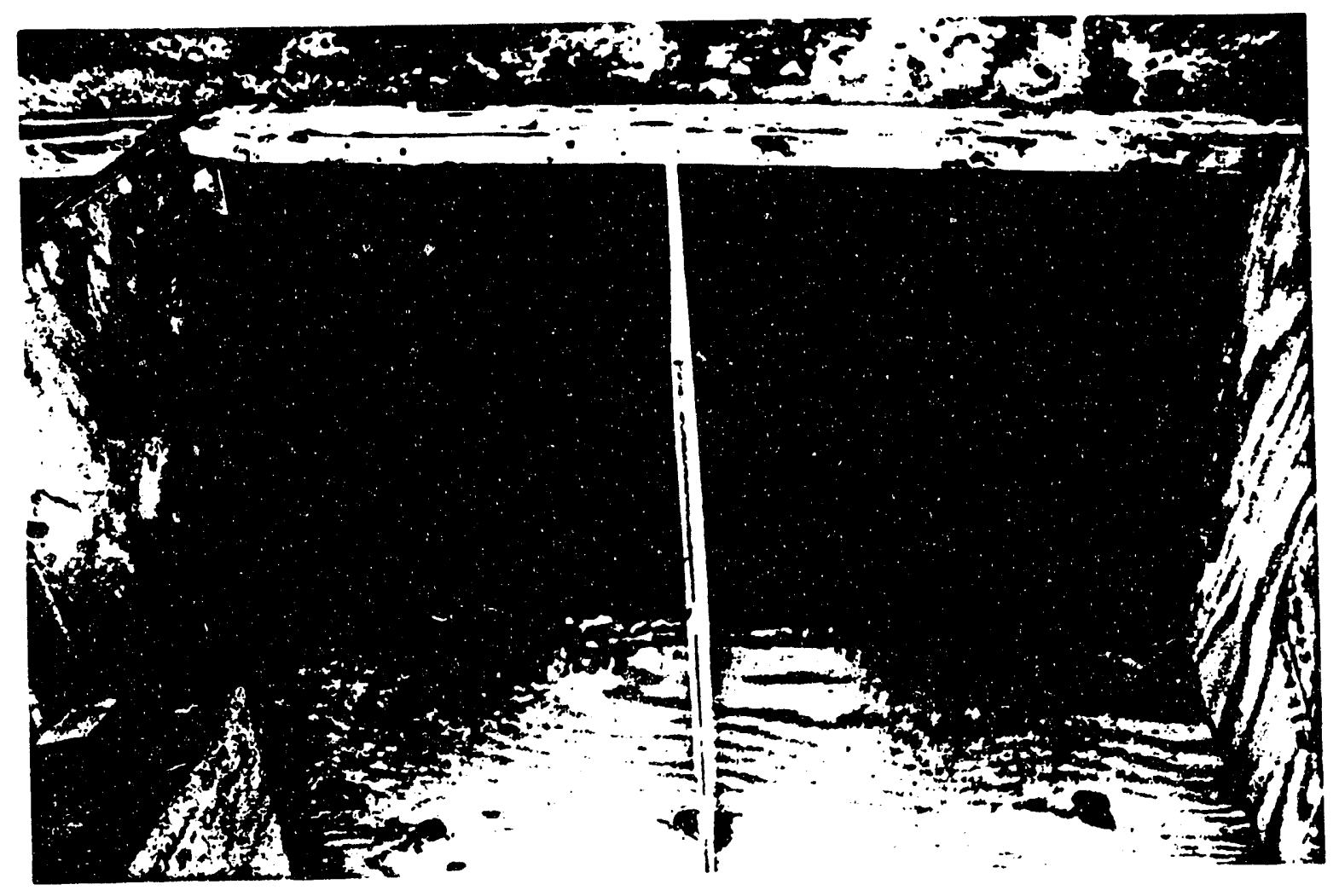

FIGURE 7.7 PHOTOGRAPH OF ELKHORN COAL DISK PELLET AFTER TWO WEEKS OF STORAGE. 
- Roller-and-die pellets subjected to extreme exposure to rain deteriorated, even if corn starch or Shur Bond was used as a binder. However, if these pellets were aged or cured 1 to 5 days before outdoor-exposure storage, the pellets could be expected to survive.

- All pellets stored exposed-outdoor failed to survive for period greater than ten weeks.

- Coal type did not strongly affect pellet-storage survivability.

7.3.2.2 Covered-Outdoor Storage Tests. Pellets were also stored in cubicles, exposed to outdoor temperature conditions but protected from effects of rain, snow, or sun. Photographs of the covered-outdoor storage cubicles are shown in Figure 7.8. One hundred pounds each of eleven production samples, listed earlier, were tested under this storage mode. At the end of 2-, 4-, and 10-week periods of storage testing, 15 to $20 \mathrm{lbs}$ of pellets were sampled for pellet and reslurryability evaluation. Unlike the pellets subjected to exposed-outdoor conditions, all these pellets showed good structural integrity even after ten weeks. Photographs of the Elkhom coal pellet with com starch binder, stored for 2 weeks is . shown in Figure 7.9. The pellet samples from 2-, 4-, and 10-week storage were measured for compressive and Ro-Tap durability measurements and were reported in the Seventh Quarterly Report. ${ }^{(1)}$ The compressive strength of all the storage pellets had increased since production; corn starch bound pellets show the maximum increase. Between the 2- and 4week storage period, in almost all cases, the strength show a continued increasing trend, but at a relatively low level. At the end of 10 weeks of continued pellet stnrage the pellets showed excellent structural integrity. The major conclusions that can be reached from this evaluation are as follows:

- This mode of pellet storage showed excellent degree of success for all coal pellets prepared by the three techniques even after ten weeks exposure.

- Lignin sulfonate bound pellets survived better in this mode than under exposed-outdoor mode. They showed good properties even after ten weeks exposure. 

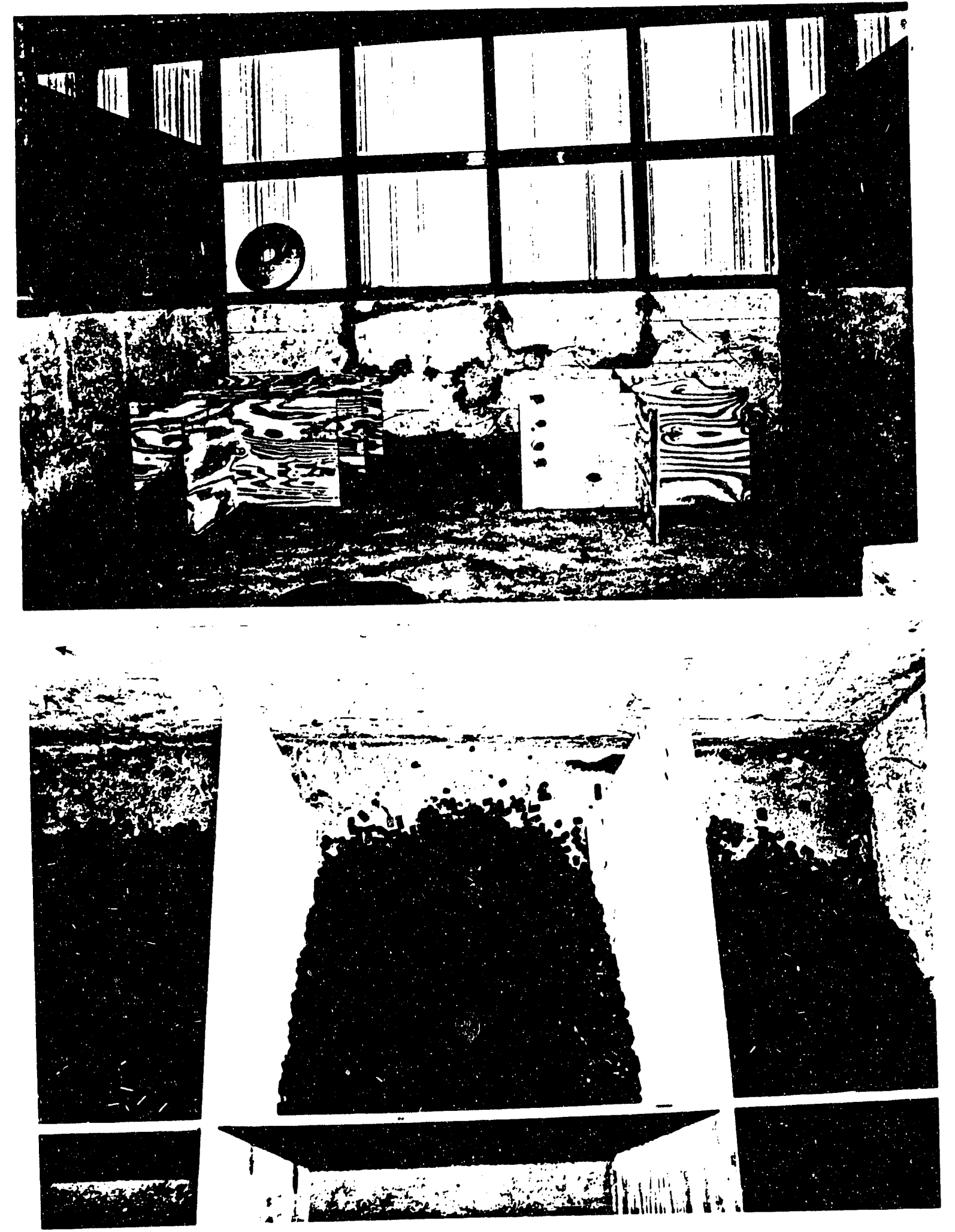

FIGURE 7.8 PHOTOGRAPHS OF THE CUBICALS FOR COVERED-OUTDOOR PELLET STORAGE 


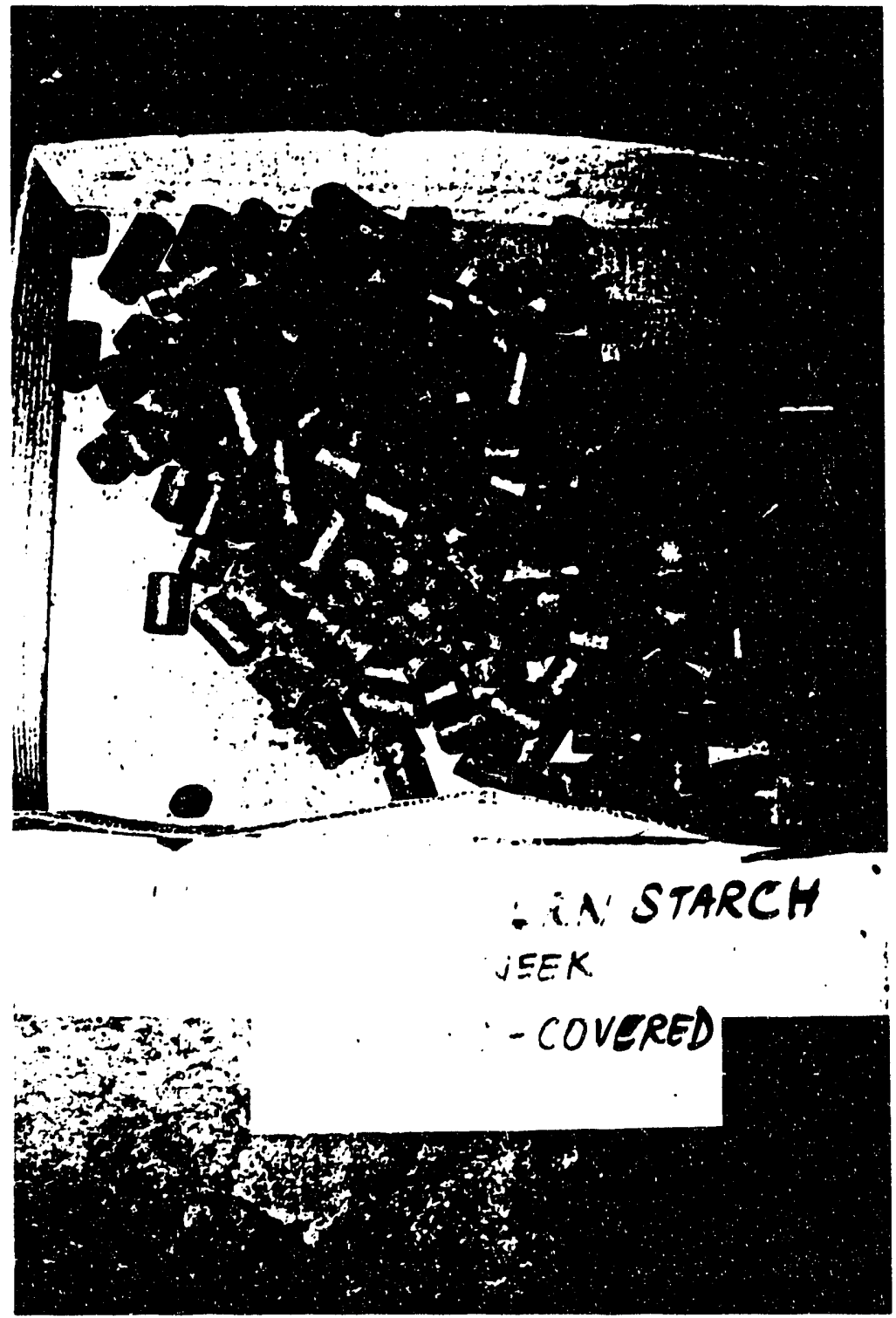

FIGURE 7.9 PHOTOGRAPH OF ELKHORN ROLLER-AND-DIE PELLETS AFTER TWO WEEKS OF STORAGE 
- Roller-and-die pellets, which require immediate protection from rain/snow after production, can be stored in this covered-outdoor mode.

7.3.2.3 Silo Storage Tests. All the pilot-scale production pellets listed earlier were also investigated for storage effects in silos. This was conducted in simulated silo-columns ( 8 in. diameter $\times 10$ feet high), shown in Figure 7.10. The pellets were stored in these columns, completely protected from rain/snow and air movement. The columrs were however constructed in an open-environment subjected to the daily temperature variations. Samples of pellets from the column were drawn out after 2,4 and 10 weeks of storage for pellet and reslurrying evaluation. The pellets stored in the silo were observed visually to survive the effects of loading and abrasion in silo columns. Figure 7.11 shows the Elkhorn roller-and-die pellet samples, drawn from the silo after 2 weeks of storage. The pellets continued to show an increased compressive strength and Ro-Tap durability after two weeks. Complete pellet evaluation data, i.e., strength and durability from 2- and 4 week storage are presented in the Seventh Quarterly Report. ${ }^{(1)}$ Similar to the covered-outdoor storage mode, the pellets' compressive strength measured from the silo samples, showed a significant increase from the production pellet data. However, the average increase seen with the pellets stored in the silo over the 2 and 4 week storage period were less than that observed with covered-outdoor storage mode, suggesting that the pellets are cured more effectively in the covered-outdoor mode, where there is considerable movement of air. The silo storage mode, while technically feasible, is expected to be considerably more expensive.

The major conclusions that can be reached from this investigation in silo storage are: - All coal-pellets, prepared by the three techniques from the three coals, can be stored successfully in silos even after ten weeks of exposure.

- Pellet evaluation conducted with 2- and 4-week storage samples suggest that the quality of pellets stored in silo are superior to exposed-outdoor mode, but are inferior to covered-outdoor mode.

- Higher storage costs were the main disadvantage in șilo storage. 


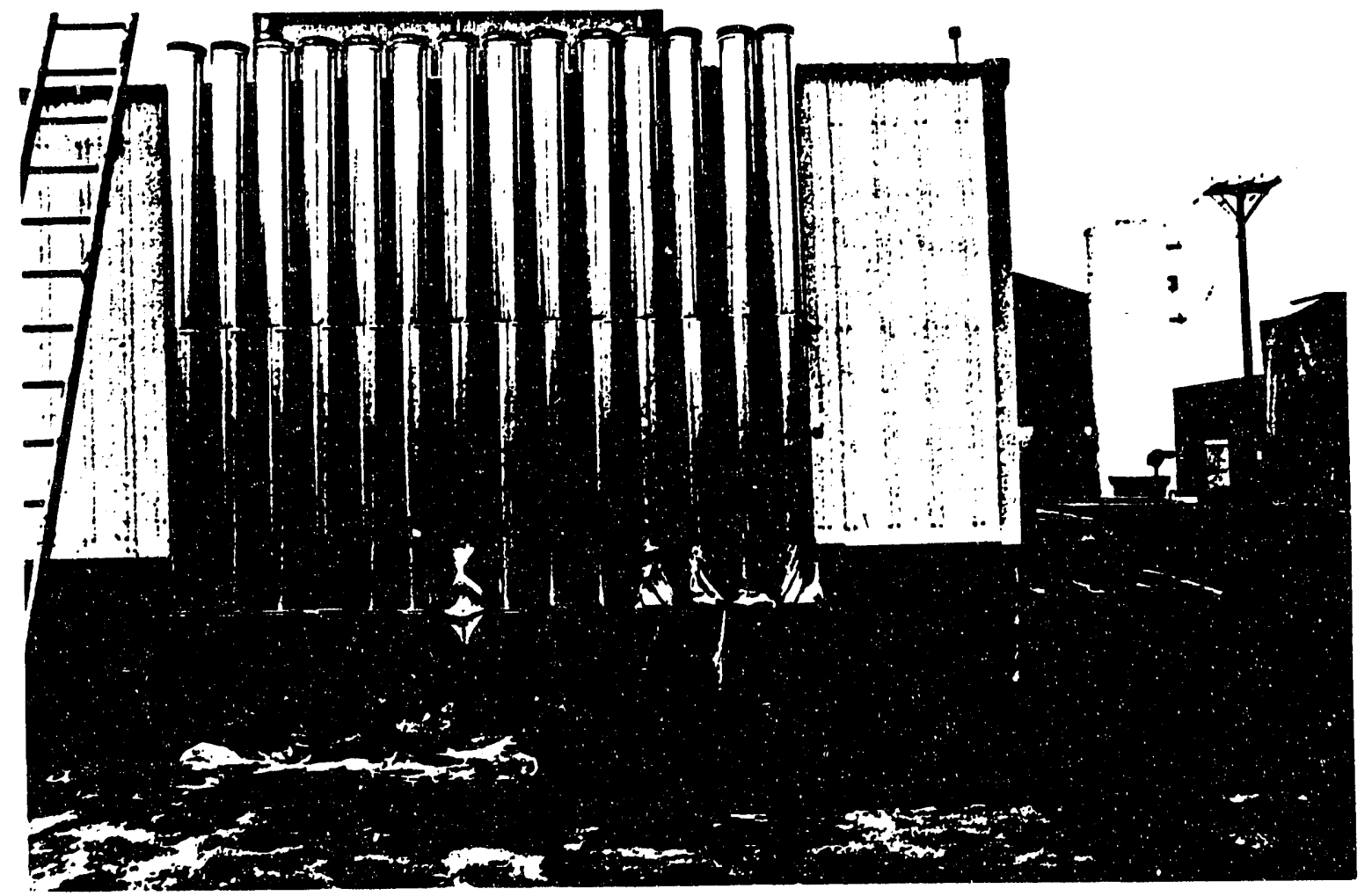

FIGURE 7.10 SIMULATED SILO COLUMNS FOR PELLET STORAGE EVALUATION 


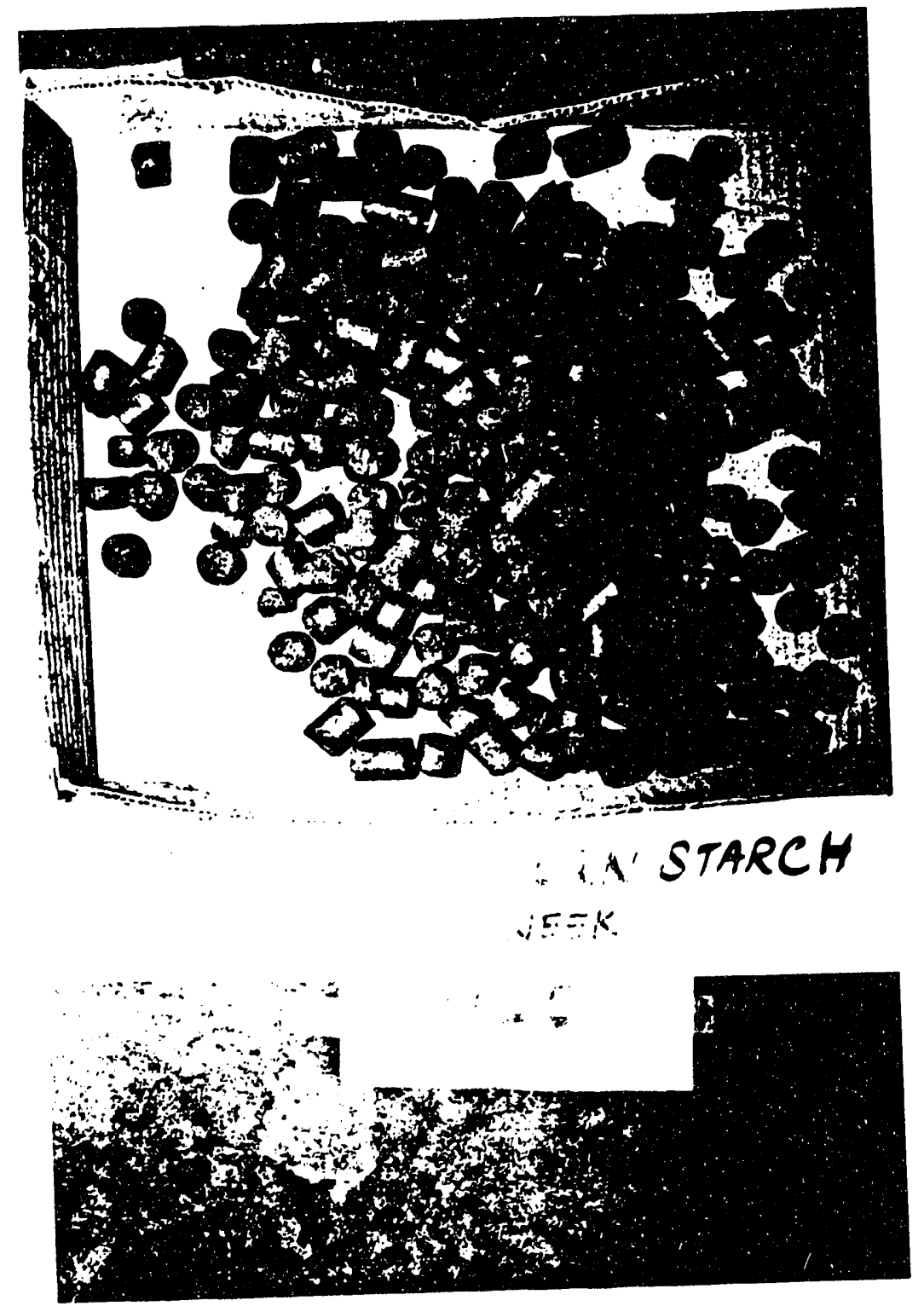

FIGURE 7.11 ELKHORN ROLLER-AND-DIE PELLETS AFTER TWO WEEKS OF STORAGE IN SILOS. 
7.3.2.4 Bag Storage Tests. Storing of pellets in super-sack "nylon" bags were evaluated for pellet handling and storage. About 100 pounds of each pilot-scale production pellets were stored in bags, shown in Figure 7.12. The bags were completely closed and were exposed to the 1 ,utdoor environment and subjected to daily temperature effects, rain, snow, etc. Pellet samples were sampled out from the bag after 2- 4- and 10 week time periods. Figure 7.13 shows the Elkhorn coal roller-and-die pellets after 2 weeks storage. Similar to the Elkhorn coal pellet seen in Figure 7.13, all other pellets stored in bags stayed structurally intact. After 4 weeks, lignin sulfonate bound coal pellets showed evidence of fragmentation. Although the super-sack "nylon" bags were water-repellent, they were not waterproof. It is suspected, that water from rain/snow could have penetrated into the bag, causing pellets at the vicinity of the bag-wall to deteriorate. This was more serious with lignin sulfonate-bound pellets than corn starch- or Shur Bond-bound pellets.

Compressive strength and Ro-Tap durability measurements were also obtained with the pellets from bags and were reported in the Seventh Quarterly Report. Both the 2- and 4week storage pellets showed an average increase in compressive strength and durability from production pellets. Between the 2- and 4-week storage pellets, lignin sulfonate bound pellets showed a decrease in their compressive strength. However, corn starch- and Shur Bondbound pellets after 4 weeks showed maximum and moderate increase over the 2-week storage pellet, respectively. The overall conclusions hat can be derived from this study are:

- Pellet storage in "nylon" bags can be considered as an effective mode of pellet handling and storage.

- If the pellet bags are exposed to rain/snow, lignin sulfonate bound pellets may deteriorate to a moderate amount after 4-weeks of storage.

\subsubsection{Storage Mode Selection}

Pilot-scale coal pellets storage tests conducted over the 10-week period show distinct effects of binder type and storage mode on pellet survival. Figure 7.14 presents the compressive strength of all Illinois No. 6 coal pellets stored for 4 weeks. The figure also compares the effect of storage mode on pellet strength. All corn starch bound-pellets, 


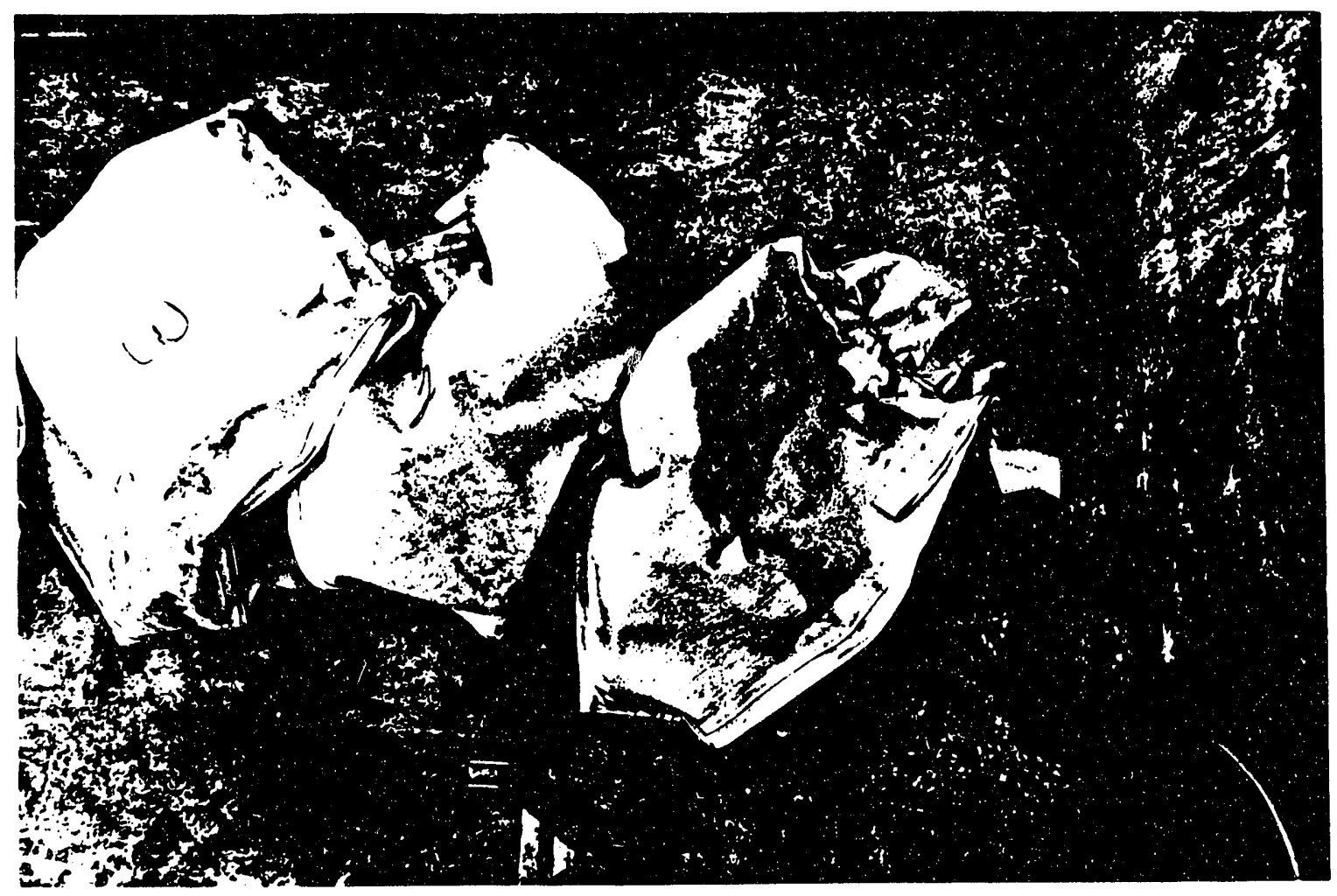

FIGURE 7.12. PELLET STORAGE IN SUPER-SACK "NYLON" BAGS 

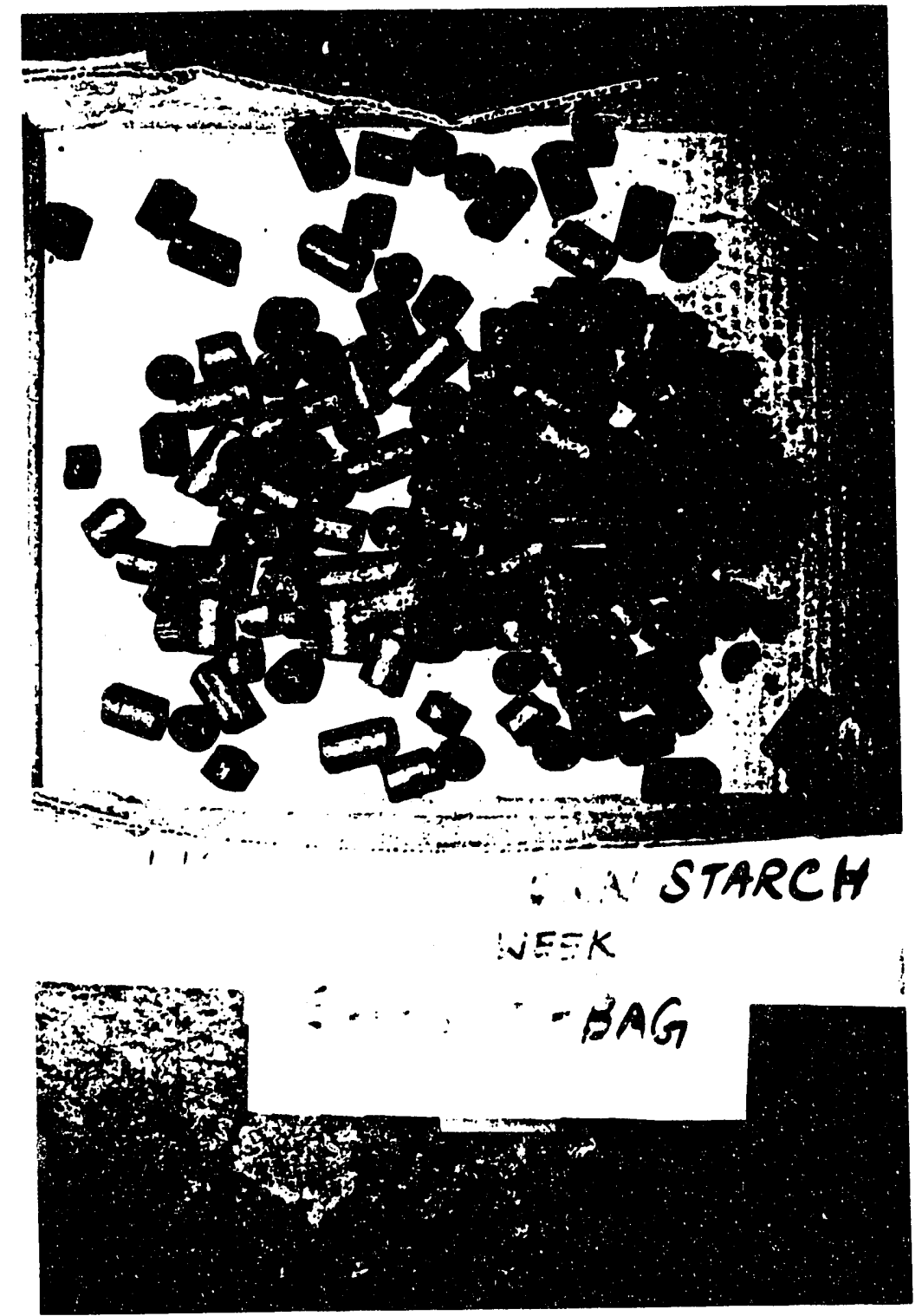

FIGURE 7.13 CONDITION OF ELKHORN-CORN STARCH ROLLER-AND-DIE PELLETS AFTER 2 WEEKS OF BAG STORAGE 


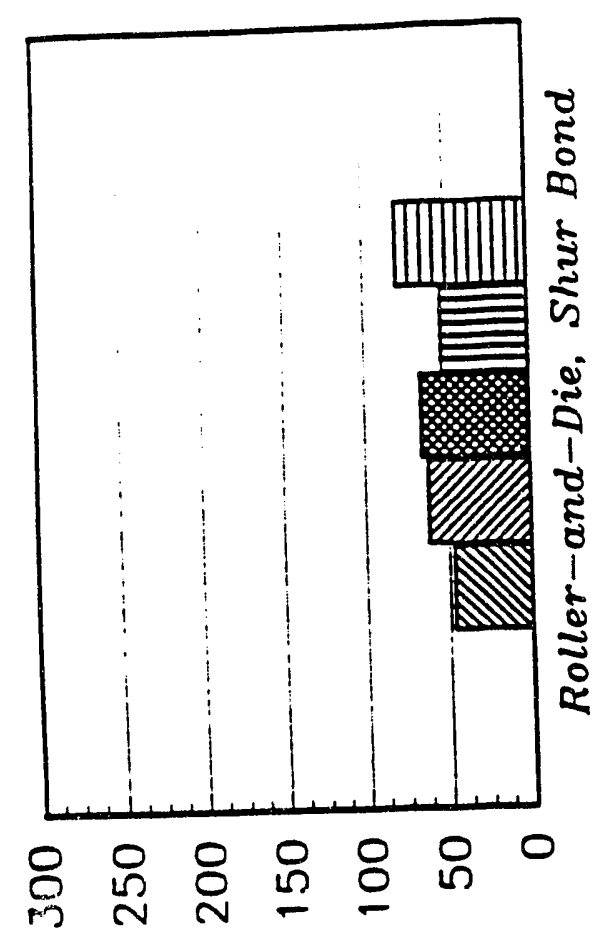

u!no/tal 'HLONJyls

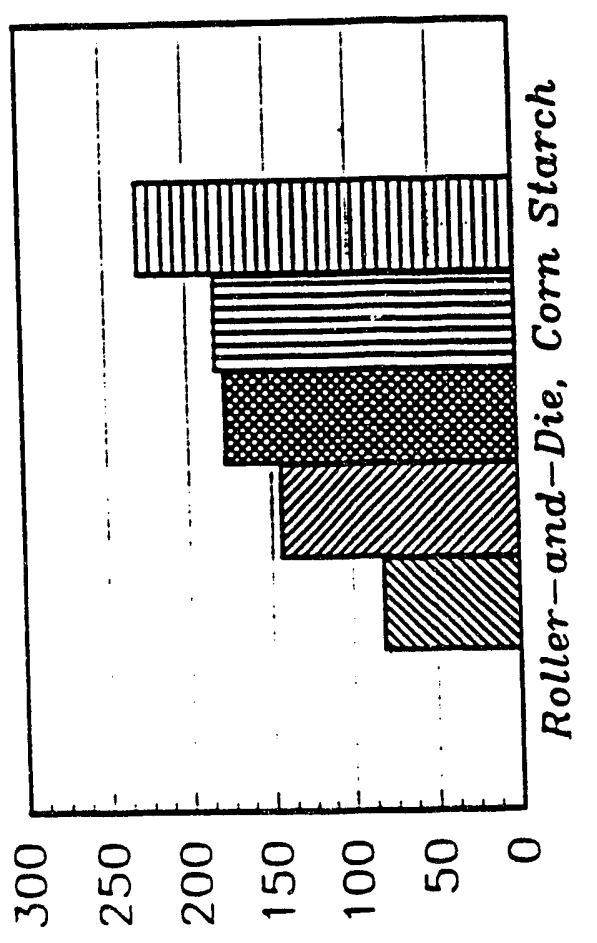

U!no/fal "H1ONJU1S
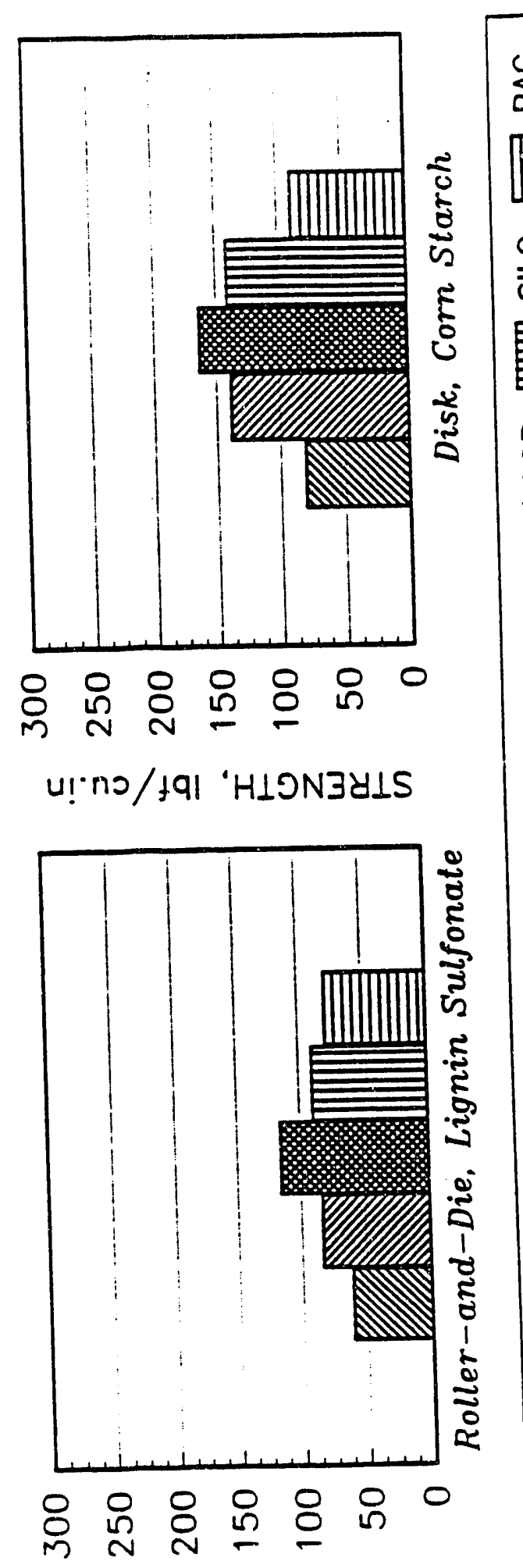

u!'no/tal "HLONJUdS

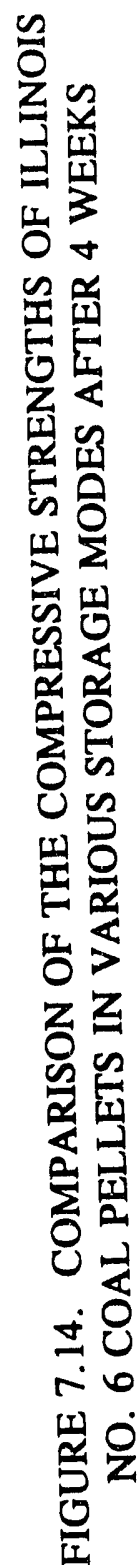


irrespective of their storage mode showed a gradual increase in strength from the production pellets, with the exception of pellets from exposed-outdoor storage. Pellets from coveredoutdoor storage appears to have the greatest strength. Pellets prepared with Shur Bond binder show little or no increase from production pellet strength. With lignin sulfonate bound pellets, although there was a small increase in strength in all storage modes, covered outdoor storage appeared to be the most effective mode for protecting the pellets.

Similar comparisons with Elkhorn and Utah coals stored over the 4 week period are presented in Figures 7.15 and 7.16. Again with these coals, corn starch-bound pellets showed excellent strength characteristics. Shur Bond and lignin sulfonate pellets showed small increases in pellet strength. However, no conclusive assessment could be derived on the effect of coal type or pelletization technique from these figures.

Since pelletization via roller-and-die with all the coals was conducted with a 2-percent corn starch dosage, storage evaluation of these pellets can be used to assess the effect of coal type. Figure 7.17 and 7.18 presents the strengths of corn starch bound roller-and-die pellets after 2- and 4-weeks of storage, respectively. Notice all three coals have production pellet strength of about 75-90 lbf/in ${ }^{3}$. Two week storage pellets showed maximum pellet strength increase with Illinois No. 6 coal in Figure 7.17 noted above. A similar effect is seen even with the four week storage pellets in Figure 7.18 noted above. However, all three coals showed that covered-outdoor or bag type of storage to be the most effective modes for roller-and-die pellet storage during the 10 week storage period. Analysis of these figures also suggests that survival of Illinois No. 6 pellets would be easier than with Utah or Elkhorn coals.

Figure 7.19 presents the effect of pelletization technique on pellet storage with Illinois No. 6 and Elkhorn coals. This figure shows that for a similar production pellet strength, Illinois No. 6 coal pellets have better strength than Elkhorn coal after storage. 

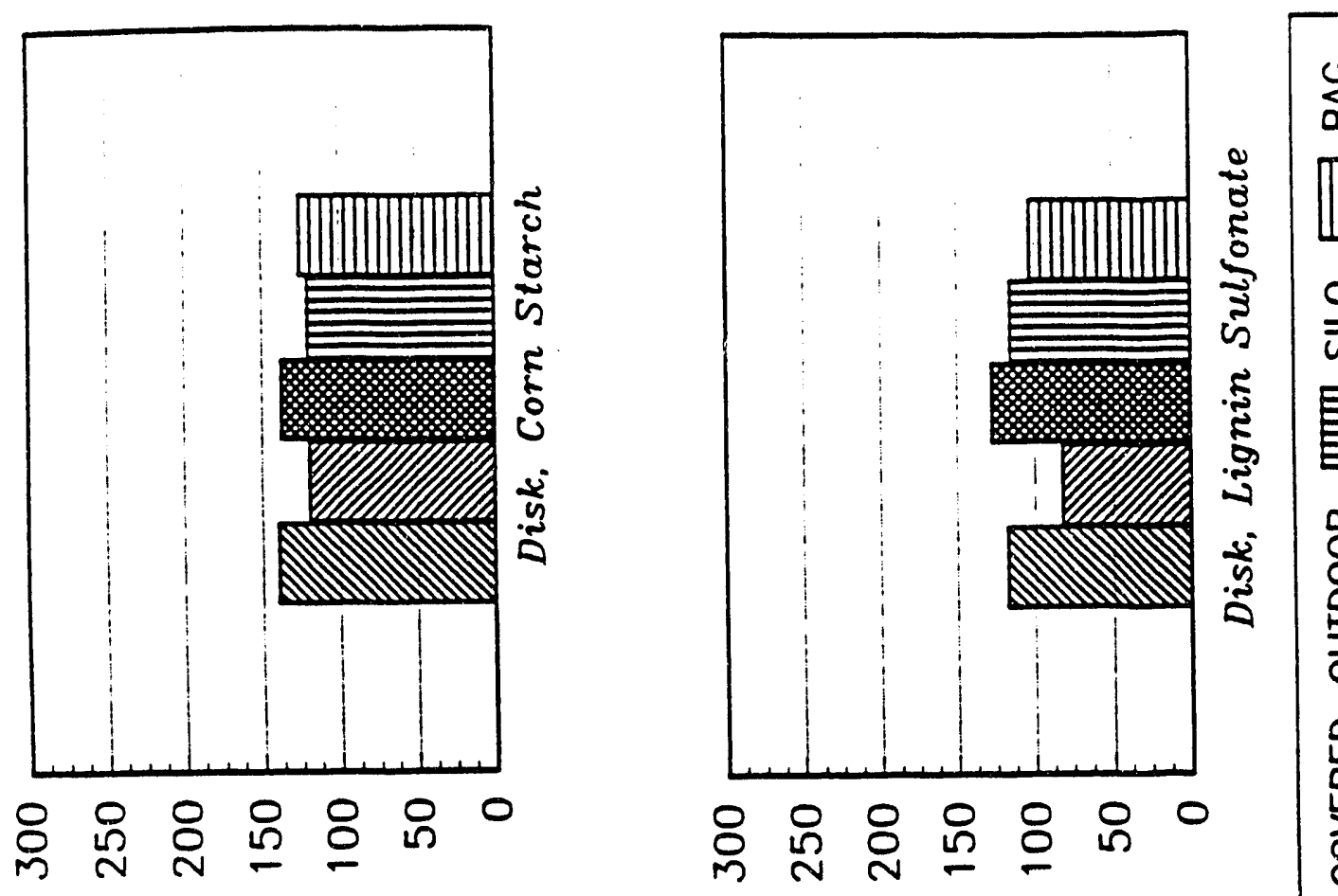

U!no/tql 'HLON3y1S
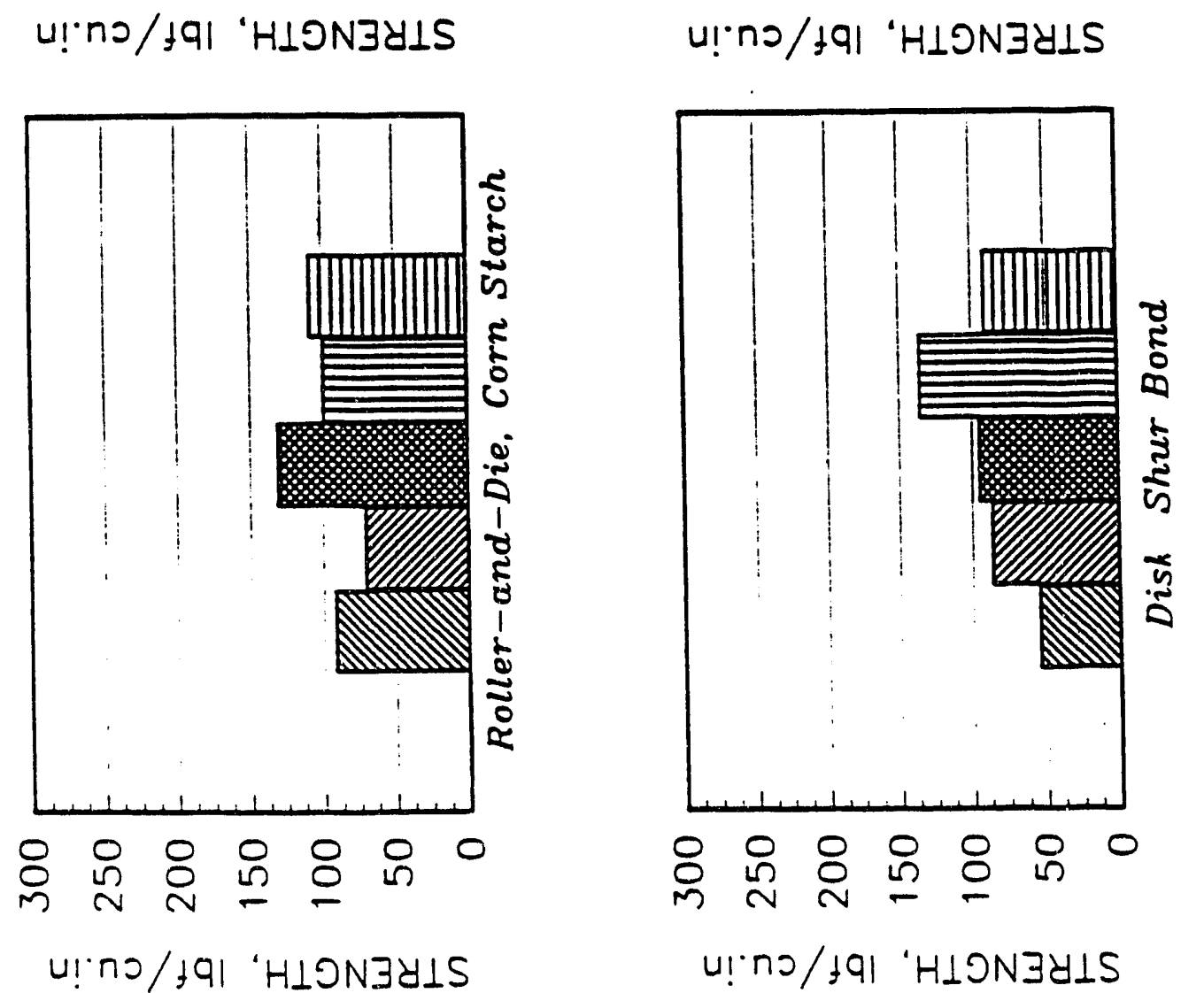

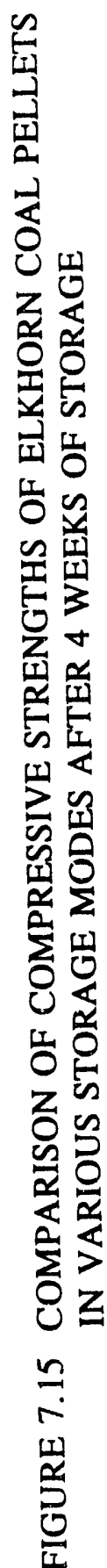
U!'กJ/\&QI 'HLONJVIS 


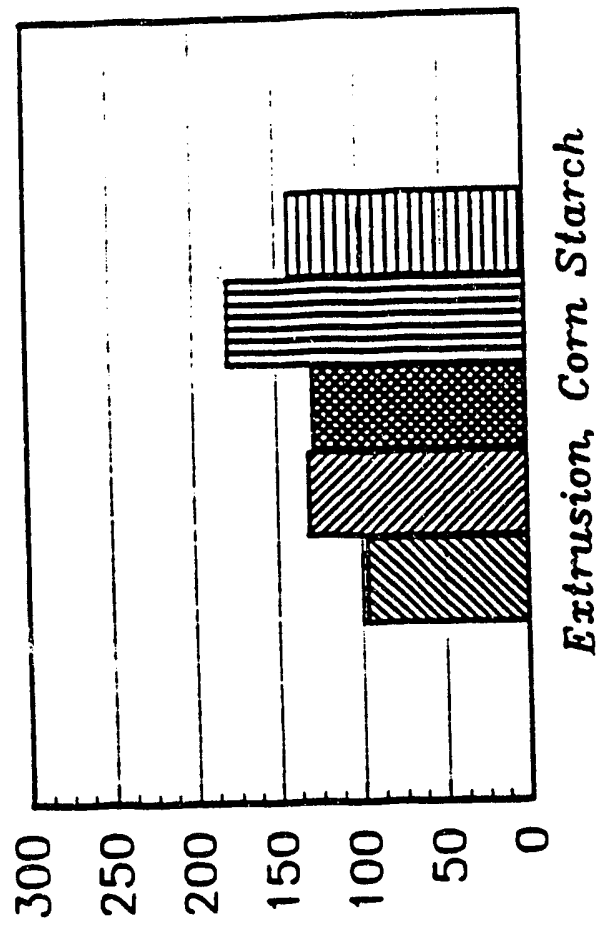

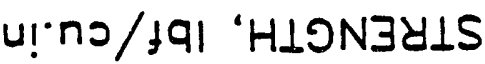

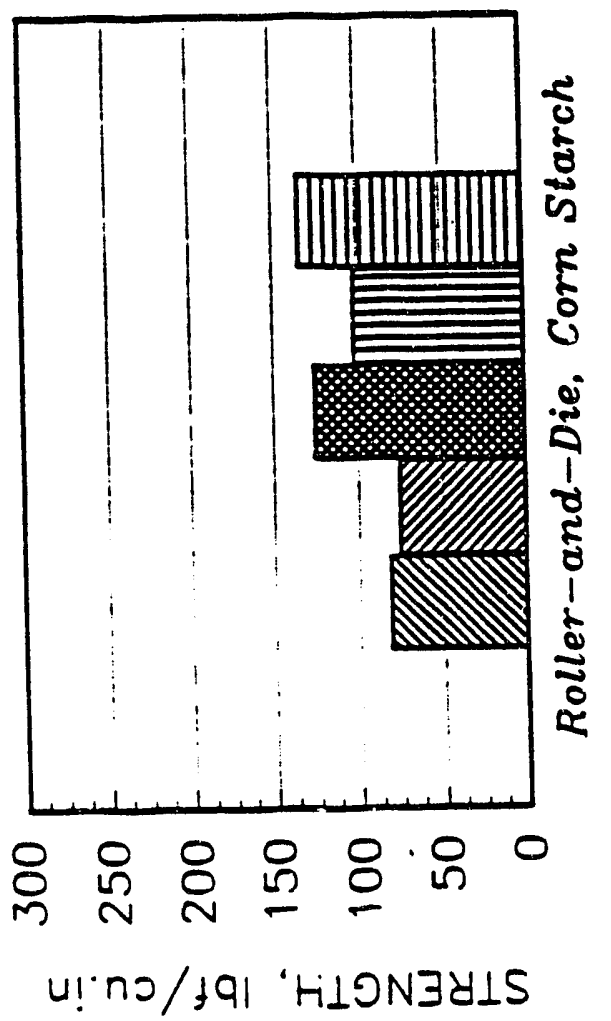

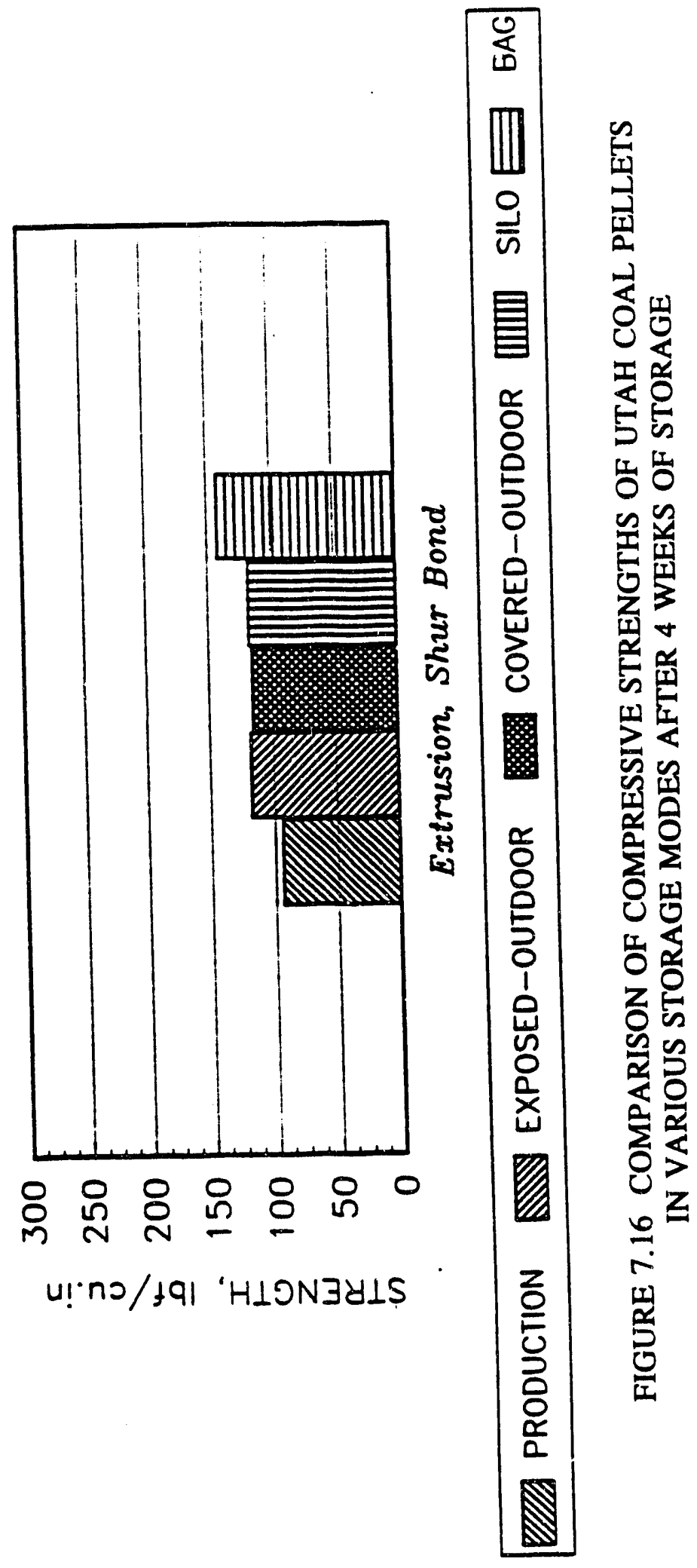



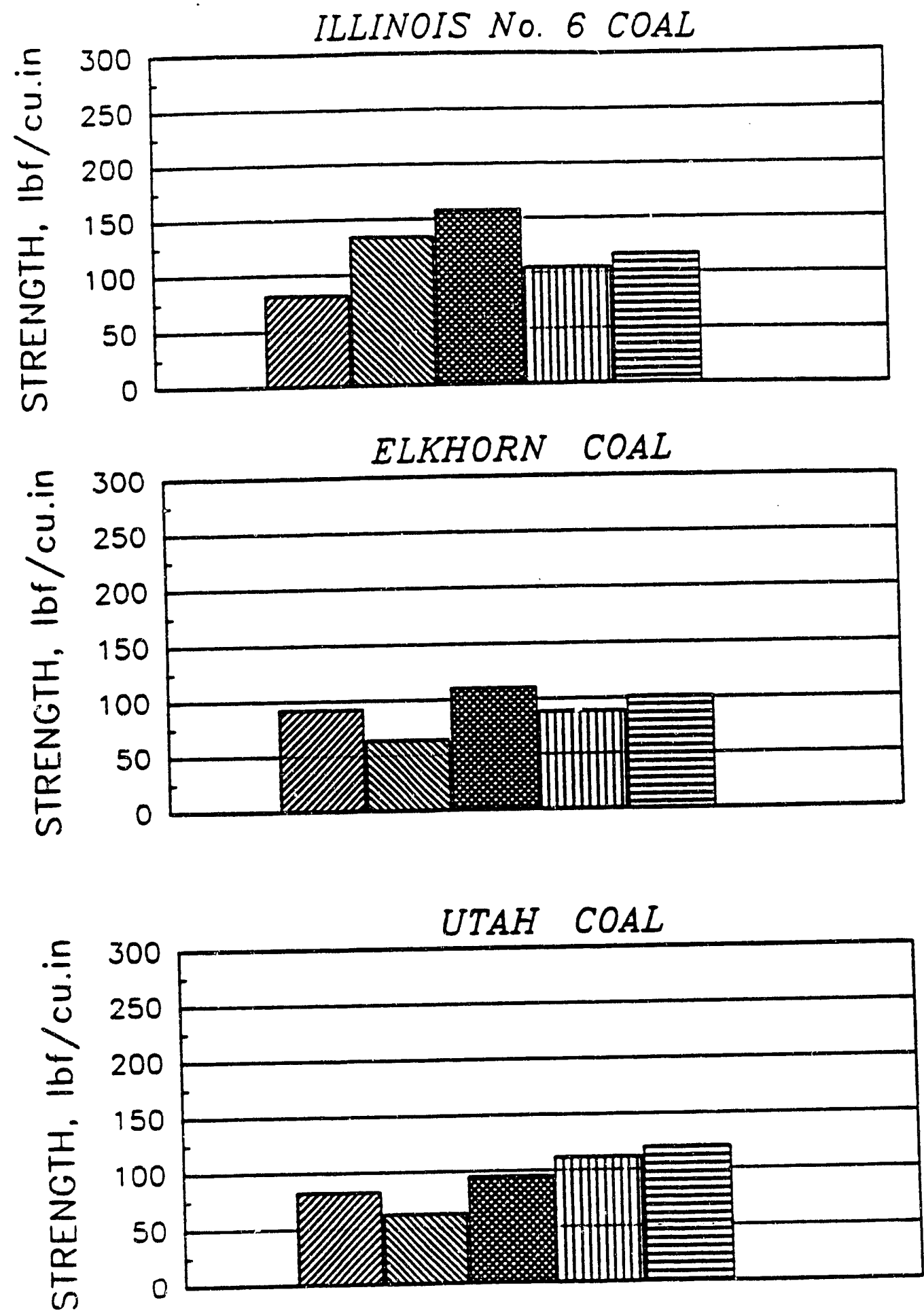

OIIA PRODUCTION EXPOSED-OUTDOOR
COVERED-OUTDOOR IIIIII SILO E BAG

FIGURE 7.17. TWO WEEKS STORAGE EVALUATION OF ROLLER-AND-DIE PELLETS PREPARED WITH CORN STARCH 
146
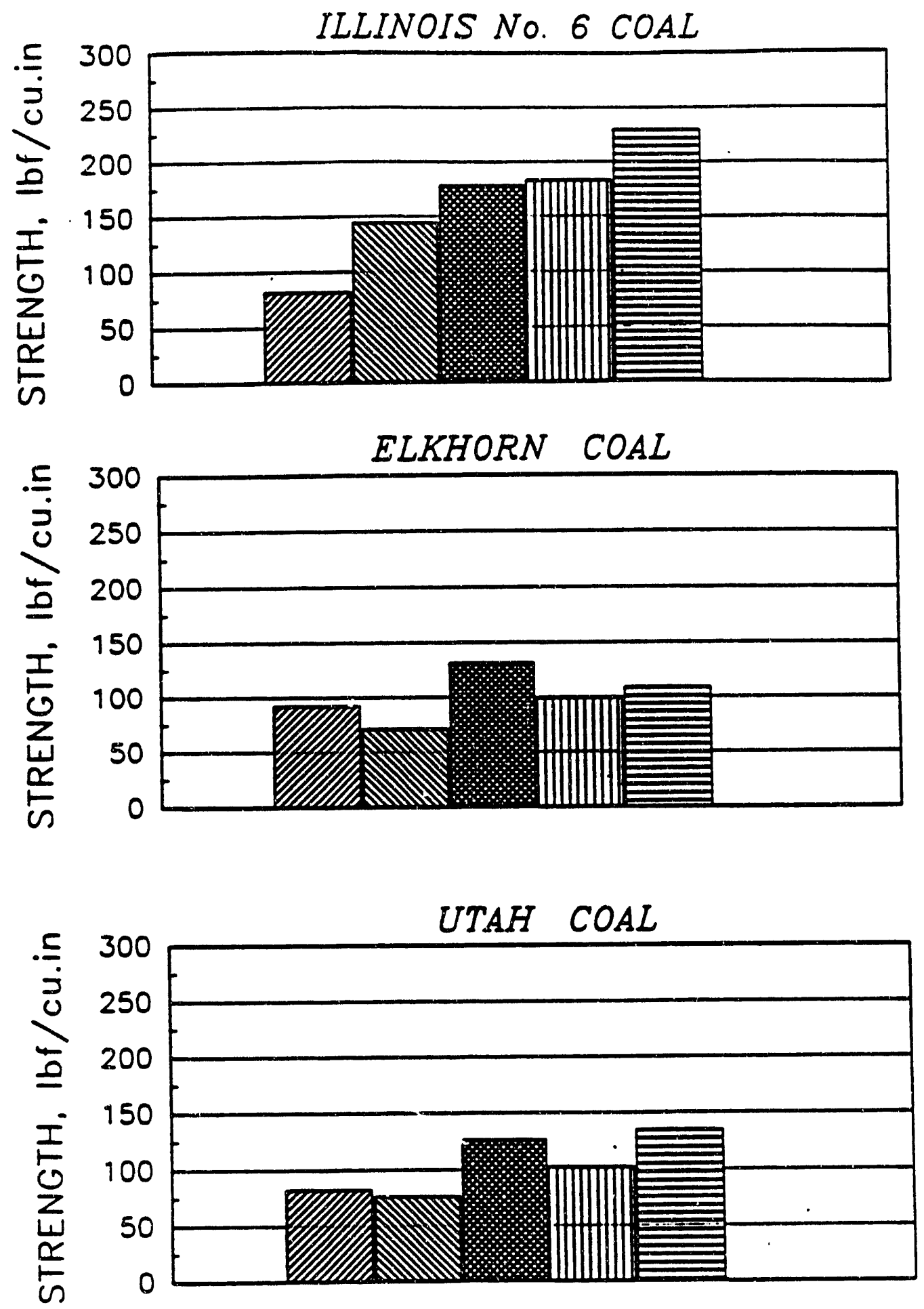

\begin{tabular}{|c|c|}
\hline PRODUCTION & EXPOSED-OUTDOOR \\
\hline COVERED-OUTDOOR & mIm!n SILO \\
\hline
\end{tabular}

FIGURE 7.18. FOUR WEEK STORAGE EVALUATION OF ROLLER-AND-DIE PELLETS PREPARED WITH CORN STARCH 

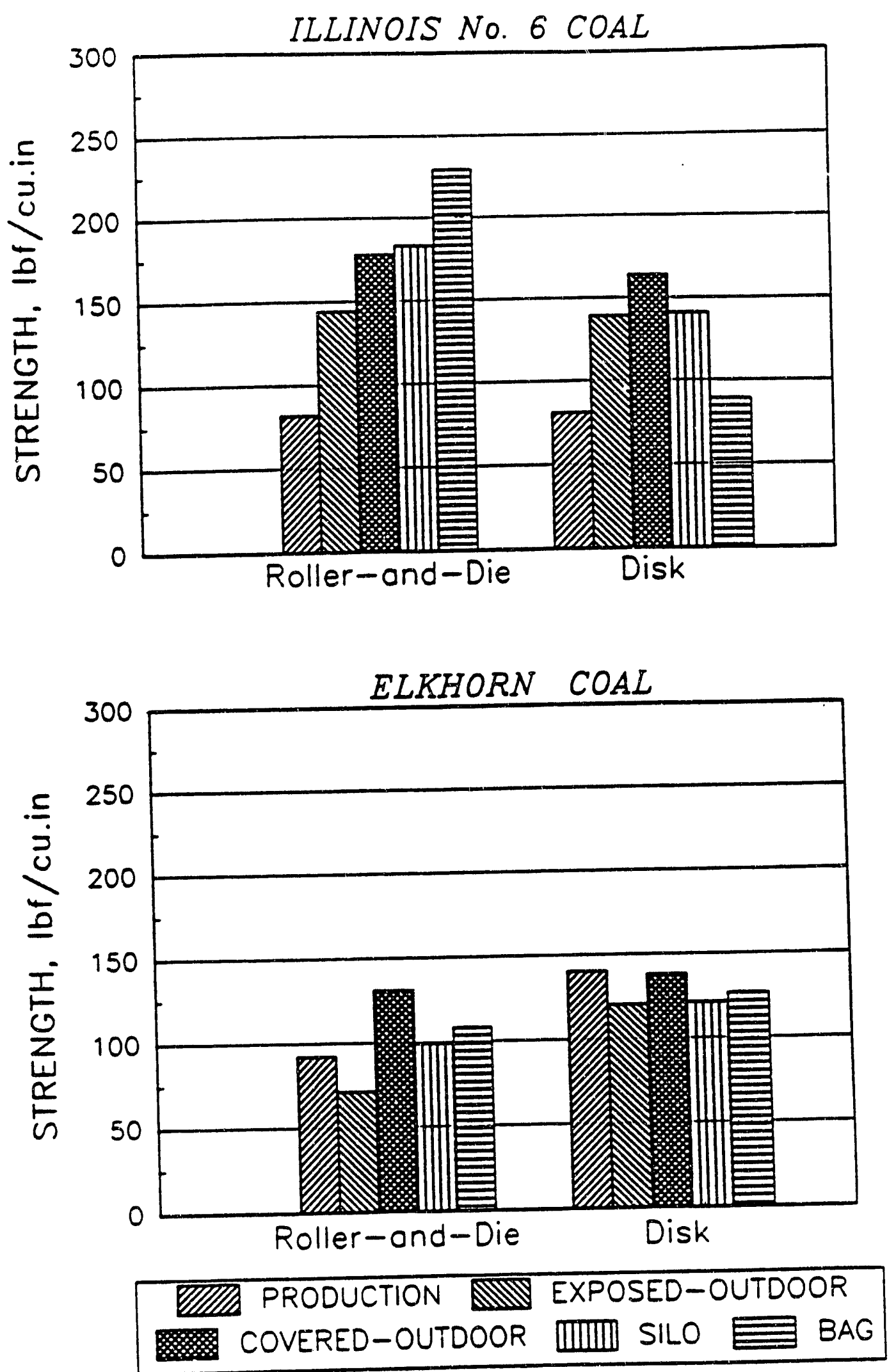

FIGURE 7.19 ILLUSTRATION ON THE EFFECT OF PELLETIZATION TECHNIQUE ON PELLET STORAGE 
From the evaluation conducted for pellets stored over a 4 week period, we observed a distinct effect of binder type and storage mode on pellet survival. Specifically the following conclusions were reached:

- Covered-outdoor mode is recommended to be the most appropriate mode for storage for pellets of all types.

- Shur Bond bound pellets with all three coals, irrespective of the production technique, can survive short-term exposed-outdoor mode of pellet storage. Other binder types do not show the same promise.

- Corn starch was the recommended binder from the perspective of pellet strength.

- Roller-and-die pellets should be cured in covered-outdoor storage for a period of 24 hours before any handling or exposed-outdoor type of storage. Disk and extrusion pellets with corn starch or Shur Bond binders can, after thermal curing, be stored in any type of storage mode.

\subsection{Spontaneous Combustion Characteristics}

Pellets subject to adverse storage/handling/transportation conditions could undergo spontaneous combustion. A heat-cycle test was designed to simulate this environment, and measure the temperature at which spontaneous combustion would occur. The following coal pellet samples were tested:

- Illinois No. 6 coal pelletized with corn starch via roller-and-die pelletization

- Utah coal pelletized with lignin sulfonate via extrusion pelletization

- Illinois No. 6 coal pelletized with Shur Bond via disk pelletization.

Schematic of the experimental set-up for the reactivity tests is shown in Figure 7.20. Pellets at $161 \mathrm{~F}(72 \mathrm{C})$ were introduced into the heat-test reactor. Humidified oxygen was then passed through the pellets, while monitoring the temperature. None of the pellet samples tested showed any surge in temperature over 4-5 hour test period. Therefore, there is little likelihood of pellet spontaneous combustion. The maximum temperature recorded was about 


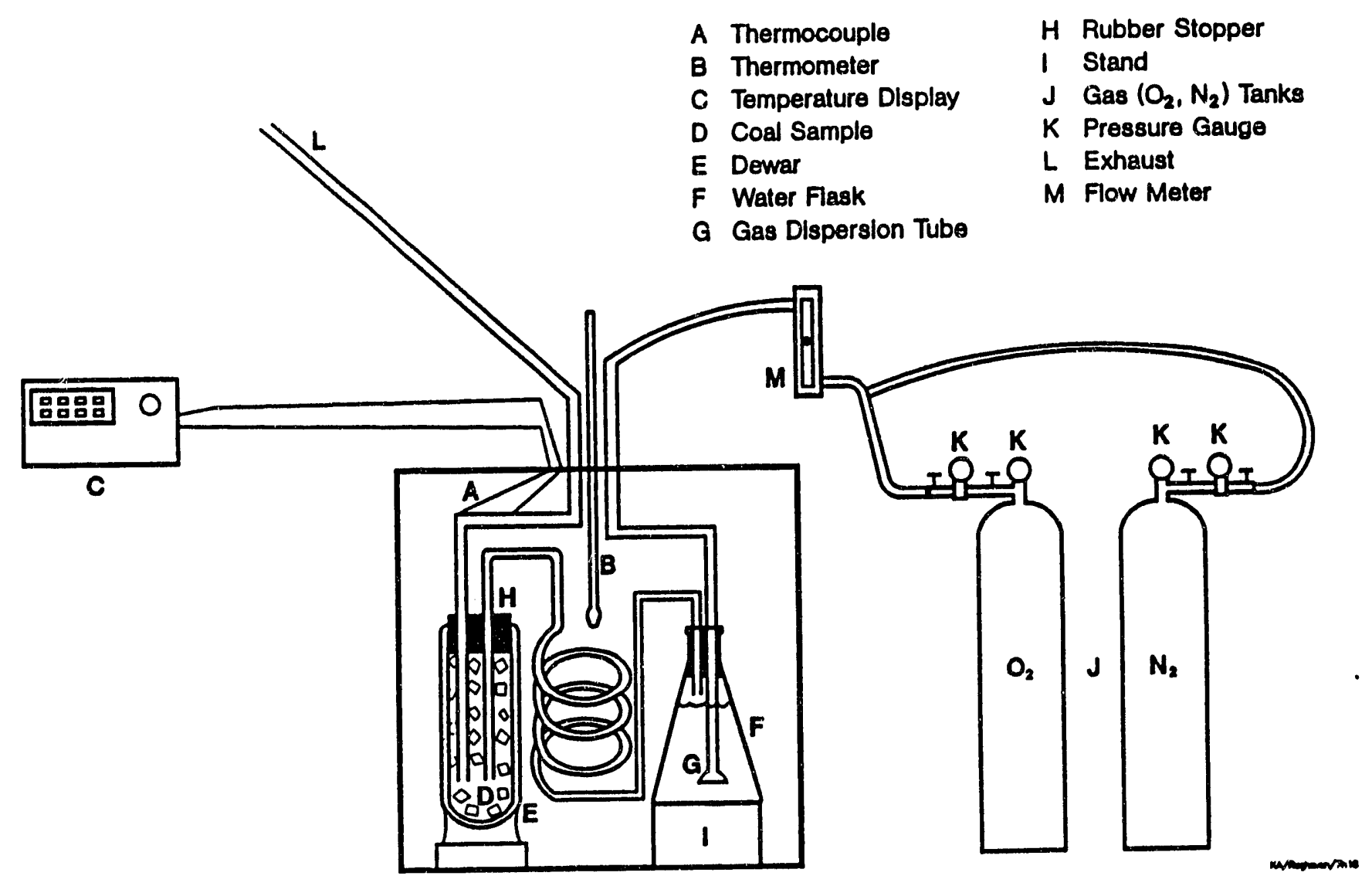

FIGURE 7.20 SCHEMATIC OF THE PELLET REACTIVITY TEST SET-UP 
$194 \mathrm{~F}(90 \mathrm{C})$ which is not adequate for any combustion reactions. Based on tests conducted in this task, we concluded:

- The three test coals in their pelletized form have little potential to spontaneously combust.

- There was no effect of binder or binder type on the pellets' potential for spontaneous combustion.

\subsection{Section 7 References}

1. Conkle, H. N., Raghavan, J. K., Jha, M. C., and Smit, F. J., "Pelletizing/Reslurrying as a Means of Distributing and Firing Clean Coal," Seventh Quarterly Progress Report prepared by Battelle Memorial Institute for the U. S. Department of Energy under Contract No. DE-AC22-90PC90166, June 9, 1992. 


\subsection{UTILIZATION AND COMMERCIALIZATION}

This section describes work on Task 8 , the utilization and commercialization assessment of the Pellet-CWF process. Costs for the basic pelletization processes, CWF formulation, transportation, handling and storage were assessed. The total system costs were compared with the direct filter cake-to-CWF approach. Sensitivity analyses on the effect of pelletization technique, bincer selection, plant size, and transportation distance were carried out for each of the three coals.

The primary objective of the task was to determine if the Pellet-CWF approach had technical and/or economic advantages over the direct CWF approach. A secondary objective was to quantify the advantages and the sensitivity of the results to variations in the processing/transportation/storage parameters. Information from the task was used to assess the commercial potential of the Pellet-CWF approach.

The following subtasks were carried out:

- Subtask 8.1 Develop Process Flowsheets

- Subtask 8.2 Estimate Pellet Production Costs

- Subtask 8.3 Estimate Transportation, Handling and Storage Costs.

Provided in this section are:

- Pelletization Cost Assessment

- Reslurrying Cost Assessment

- Transportation, Handling and Storage Cost Assessment

- Comparison with Direct CWF Approach. 


\subsection{Summary}

The overall production costs for preparing CWF by the Pellet-CWF and Direct-CWF approaches were compared. Briefly, in the pellet-CWF approach, the clean coal filter-cake was pelletized, transported to the user-site, stored and slurried a few hours prior to use. In contrast, in the direct-CWF approach, the filter-cake was converted into slurry at the beneficiation site, transported to the end-user, where the slurry was stored and used. In the following sub-sections, operating costs for the various process areas are compared for the two approaches.

\subsubsection{Pelletization Costs}

In the Pellet-CWF approach, pelletization cost is a significant variable. Operating cost estimates for a 1,000 dry ton/day coal pelletization facility are presented below. Data for two binders (corn starch and Shur Bond), and one coal (Elkhorn) are summarized. Complete details for the other coals and binders are presented later in the text.

Table 8.1 presents the annual operating cost estimates for each pelletization trinnique producing 1,000 dry ton/day of coal pellets. Pelletizing via the roller-and-die techniricie is clearly seen as the most cost effective method; Elkhorn coal mixed with Shur Bond binder could be pelletized for about $\$ 7.58 / \mathrm{dry}$ ton equivalent $(\$ 0.25 / \mathrm{MM}$ Btu). The pellets prepared by this technique also required low binder dosage levels to produce pellets with acceptable pellet strength and durability, etc. Other pelletization methods require slightly more binders and/or require more processing, resulting in higher annual.operating costs.

Figure 8.1 presents a breakdown of the operating cost components for pelletizing Elkhorn coal with Shur Bond binder as a function of plant size. The three pelletization techniques are also compared in this figure. Clearly, as plant size increases, cost per ton drops rapidly for the roller-and-die technique; major cost elements are labor (30 percent) and 
TABLE 8.1. ANNUAL OPERATING COST ESTIMATE FOR PROCESSING ELKHORN COAL AT 1,000 DRY TON/DAY CAPACITY

\begin{tabular}{||c|c|c|c|c|c|c||}
\hline & \multicolumn{5}{|c|}{ Operating Cost Estimate, \$/dry ton (4th Qtr 1991) } \\
\cline { 2 - 7 } & \multicolumn{2}{|c|}{ Roller-and-Die } & \multicolumn{2}{|c|}{ Disk } & \multicolumn{2}{c||}{ Extrusion } \\
\hline $\begin{array}{c}\text { Binder } \\
\text { and Concentration }\end{array}$ & $\begin{array}{c}\text { Corn } \\
\text { Starch } \\
(2.0 \%)\end{array}$ & $\begin{array}{c}\text { Shur } \\
\text { Bond } \\
(4.5 \%)\end{array}$ & $\begin{array}{c}\text { Corn } \\
\text { Starch } \\
(4.0 \%)\end{array}$ & $\begin{array}{c}\text { Shur Bond } \\
(4.5 \%)^{(a)}\end{array}$ & $\begin{array}{c}\text { Corn } \\
\text { Starch } \\
(2.0 \%)\end{array}$ & $\begin{array}{c}\text { Shur } \\
\text { Bond } \\
(4.5 \%)^{(\mathbf{a})}\end{array}$ \\
\hline Pelletizing & 8.42 & 7.58 & 12.66 & 11.24 & 12.10 & 11.35 \\
\hline $\begin{array}{c}\text { Transportation (100 } \\
\text { miles), Storage and } \\
\text { Handling }\end{array}$ & 7.97 & 7.91 & 7.97 & 7.91 & 7.97 & 7.91 \\
\hline $\begin{array}{c}\text { CWF Formulation } \\
\text { (20 @50 ton/day } \\
\text { plants), (\$/MM Btu) }\end{array}$ & 9.78 & 7.80 & 12.48 & 8.45 & 10.59 & 9.14 \\
\hline Total & 26.17 & 23.29 & 33.11 & 27.60 & 30.66 & 28.40 \\
\hline (\$/MM Btu) & 0.88 & 0.79 & 1.19 & 0.93 & 1.04 & 0.96 \\
\hline \hline
\end{tabular}

(a) Includes 0.5 percent corn starch used as secondary binder

maintenance ( 25 percent). Much of the cost associated with maintenance was for rollers and dies replacement or resurfacing. A die life of 16,000 tons and a roller life of 8,000 tons were assumed for this purpose. For the disk and extrusion techniques, the major cost elements included utilities $(-30$ percent) and labor $(\sim 28$ percent). The cost of thermal drying the pellets directly influenced the utilities cost. Among the three pelletization techniques, it was quite clear that the roller-and-die technique was the most attractive.

The cost estimates presented above were based on an optimized binder requirement. For roller-and-die pelletization, 4.5 weight percent of binder solution made up of 5 parts water and 1 part Shur Bond was determined to be adequate. However, with extrusion and disk pelletization, abc'st 0.5 percent corn starch was always required as a secondary binder. This directly increased the raw material cost for these two techniques. Cost elements such as depreciation, taxes, and maintenance, which are functions of capital cost, were estimated to 

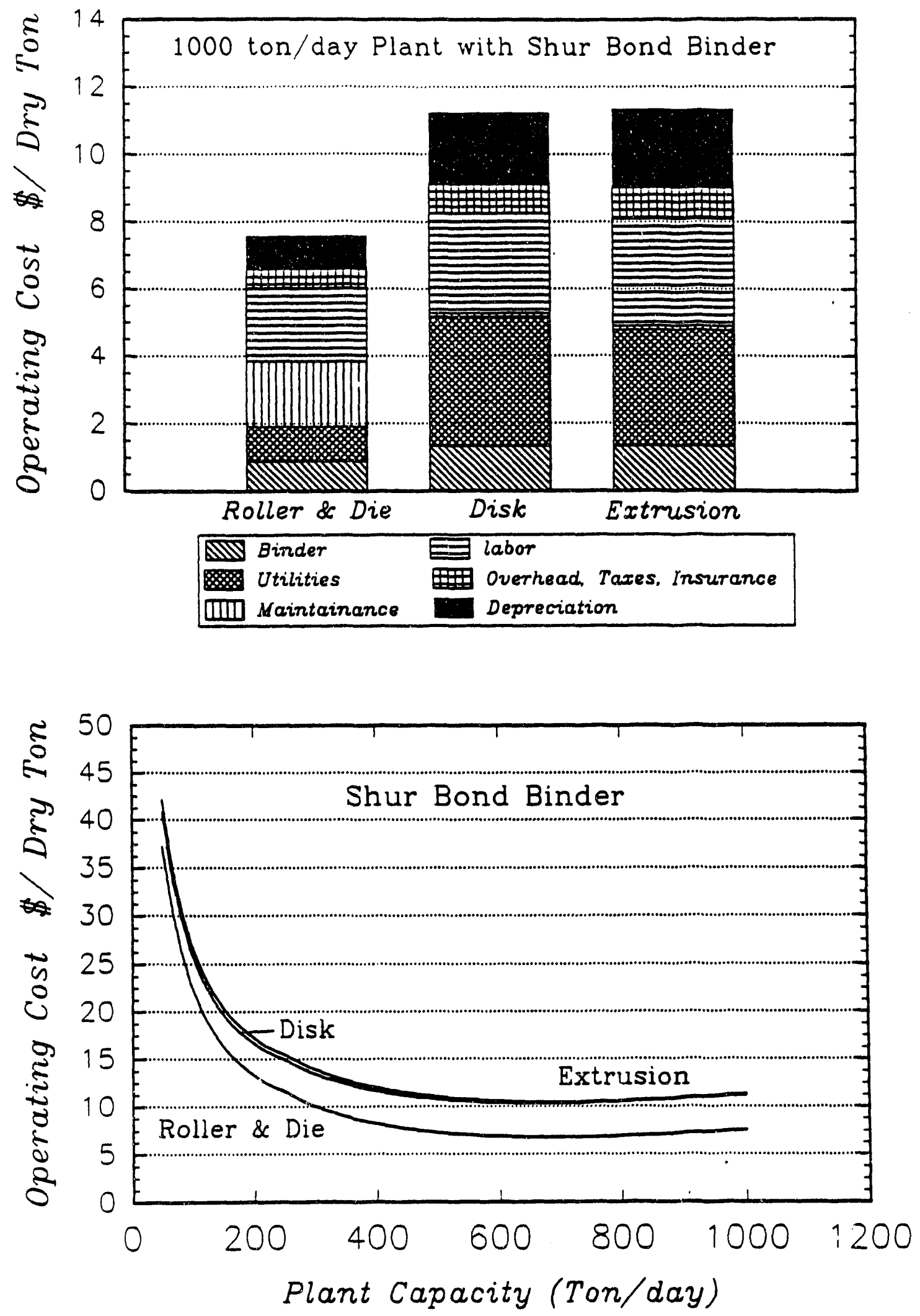

FIGURE 8.1 PELLETIZATION OPERATING COST BY TECHNIQUE AND PLANT CAPACITY 
be higher with disk and extrusion than with roller-and-die pelletization due primarily to the requirement for thermal drying before use.

\subsubsection{Coal Water Fuel Formulation Costs}

Comparison of reslurrying costs for Pellet-CWF and the direct-CWF approaches is summarized in this section. It was assumed in the Pellet-CWF approach, pellet reslurrying would be done at one of 20 localized reslurrying plants whereas for the direct-CWF approach, all the filter cake-to-slurry conversion would be performed at a centralized facility located at the cleaning plant. Conversion of pellets to CWF involved moving pellets from the storage area where they were mixed with water and a minimum of dispersant in a special agitated tank, then pumped to the boiler or furnace. For a 50 ton coal/day, Elkhorn coal, Shur Bond bound, roller-and-die pellet conversion to CWF facility, the reslurrying costs were approximately $\$ 7.80 /$ dry ton fed $(\$ 0.26 / \mathrm{MM}$ Btu). A summary of similar reslurrying cost estimates for disk and extrusion pellets was shown in Table 8.1 presented earlier. The major cost elements were dispersant ( 34 percent) and labor (45 percent).

For the direct-CWF approach the CWF formulation costs were estimated to be $\$ 23.09 /$ dry ton fed $(\$ 0.78 / \mathrm{MM} \mathrm{Btu})$. The major elements were similar to the Pellet-CWF approach. But costs were greater because more dispersant was required and a stabilization chemical (Flocon) was needed to prevent the coal particles in the slurry from settling into an un-pumpable cake during extended, un-agitated storage.

The cost of CWF formulation by the two approaches is shown in Figure 8.2. Clearly the costs for converting Elkhorn coal pellets into slurry at multiple small facilities were significantly less than preparing slurry at a centralized facility. Lower chemical requirements for pellets conversion of this coal and binder outweighed the economies of scale achieved at the centralized CWF plant. 


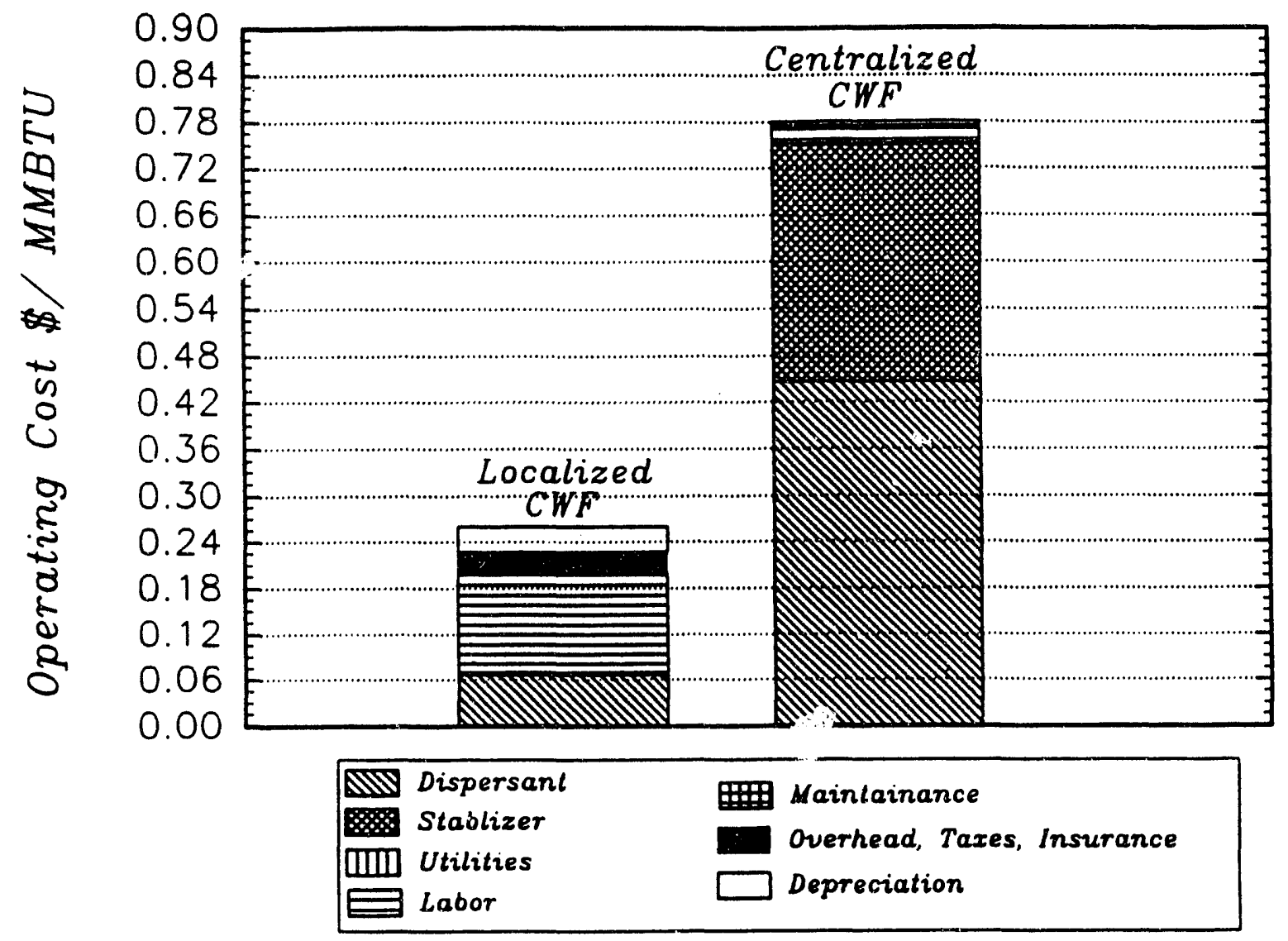

FIGURE 8.2. RESLURRYING OPERATING COSTS FOR PELLETS AND FILTERCAKE BY COST COMPONENT 


\subsubsection{Transportation Costs}

The transportation of coal pellets is compared with CWF. It was assumed that the 1,000 dry ton/day of clean coal filter cake would be either converted into pellets or CWF. As a design basis, we assumed 20 users each consuming approximately 50 dry tons of clean coal each day. A transportation distance of 100 miles was chosen as reasonable. The pellets after curing were loaded into 30-ton capacity trucks and transported to the various end users. A 1991 transportation cost of $\$ 0.078 /$ dry ton-mile ${ }^{(2)}$ was used; thus, the pellet transportation cost was \$7.80/ton (\$0.27/MM Btu).

In the direct coal-to-CWF approach, the CWF was transferred into 4,500 gal capacity tanker trucks and transported to the users. A 1991 transportation cost of $\$ 0.304 /$ dry tonmile $^{(3)}$ was used. Slurry transportation costs were greater due to the need to transport more water (10 percent moisture coal pellets versus 45 percent moisture CWF) plus the need to use specialized tanker cars rather than conventional coal trucks. The CWF transportation cost was $\$ 30.4 / \mathrm{dry}$ ton (\$1.04/MM Btu) for 100 miles. Savings in transportation costs between pellets and slurry was very significant. As transportation distances increases, the savings would become even more pronounced.

\subsubsection{Storage and Handling Costs}

The costs of storage and handling of the fuel once it reached the 20 users site was estimated for both the pellets and the CWF. Pellet handling and storage included a concrete pad for unloading the pellets received each day, and a front-end loader to move the pellets to the feed conveyor of the conversion facility. No labor was included (front-end loader labor costs were included with the reslurrying costs) and the only operating costs were related to the depreciation of the handling and storage facilities. Costs were estimated at $\$ 0.17 /$ dry ton (\$0.006/MM Btu) for closed barn type and $\$ 0.11 /$ dry ton for open concrete pad type of storage. Estimated operating costs for the pellet transportation, handling, and storage were also presented in Table 8.1. 
In the case of the direct-CWF approach, CWF storage and handling included facilities to unload the tanker trucks each day, pumps to move the slurry to a 5-day, unheated, unagitated storage tank, and pumps to transfer the stored CWF to the boiler or furnace feed tank. Again no labor was assumed. Operating costs were estimated to be $\$ 0.84 /$ dry ton (\$0.030/MM Btu). The savings for the pellet approach were still significant.

\subsubsection{Total Cost}

A comparison of the estimated operating costs for the Pellet-CWF and direct-CWF approach is shown in Figure 8.3. Costs did not include the cleaned coal cost, nor the cost of beneficiation. The cost basis included facilities for 1,000 dry tons of Elkhorn coal/day of froth-flotation cleaned coal converted into CWF. The CWF was used at 20 separate sites each utilizing approximately 50 dry tons equivalent of slurry. The Pellet-CWF approach included:

- Roller-and-die pelletization with Shur Bond binder

- Transportation by 30 -ton coal trucks for 100 miles to 20 sites

- Storage on an outdoor, exposed concrete pad (5 day)

- Handling by front-end loader

- Reslurrying in a specialized pellet-to-slurry machine with A-23 dispersant

(including holding tank and slurry-to-boiler delivery pumps).

The Pellet-CWF costs are compared with the direct coal-to-CWF approach which included:

- CWF formulation (1,000 dry ton/day) with A-23 dispersant and Flocon stabilizer

- Transportation in 4,500 gal tanker trucks for 100 miles to 20 sites

- Storage in a 100,000 gal un-agitated, unheated storage tank

- Handling by centrifugal pumps.

The total operating cost for Pellet-CWF approach was estimated at \$0.79/MM Btu, and $\$ 1.83$ for the direct-CWF approach. The cost of dispersant and stabilizer required for preparing the Elkhorn-coal CWF directly without pelletizing was estimated to be significantly 


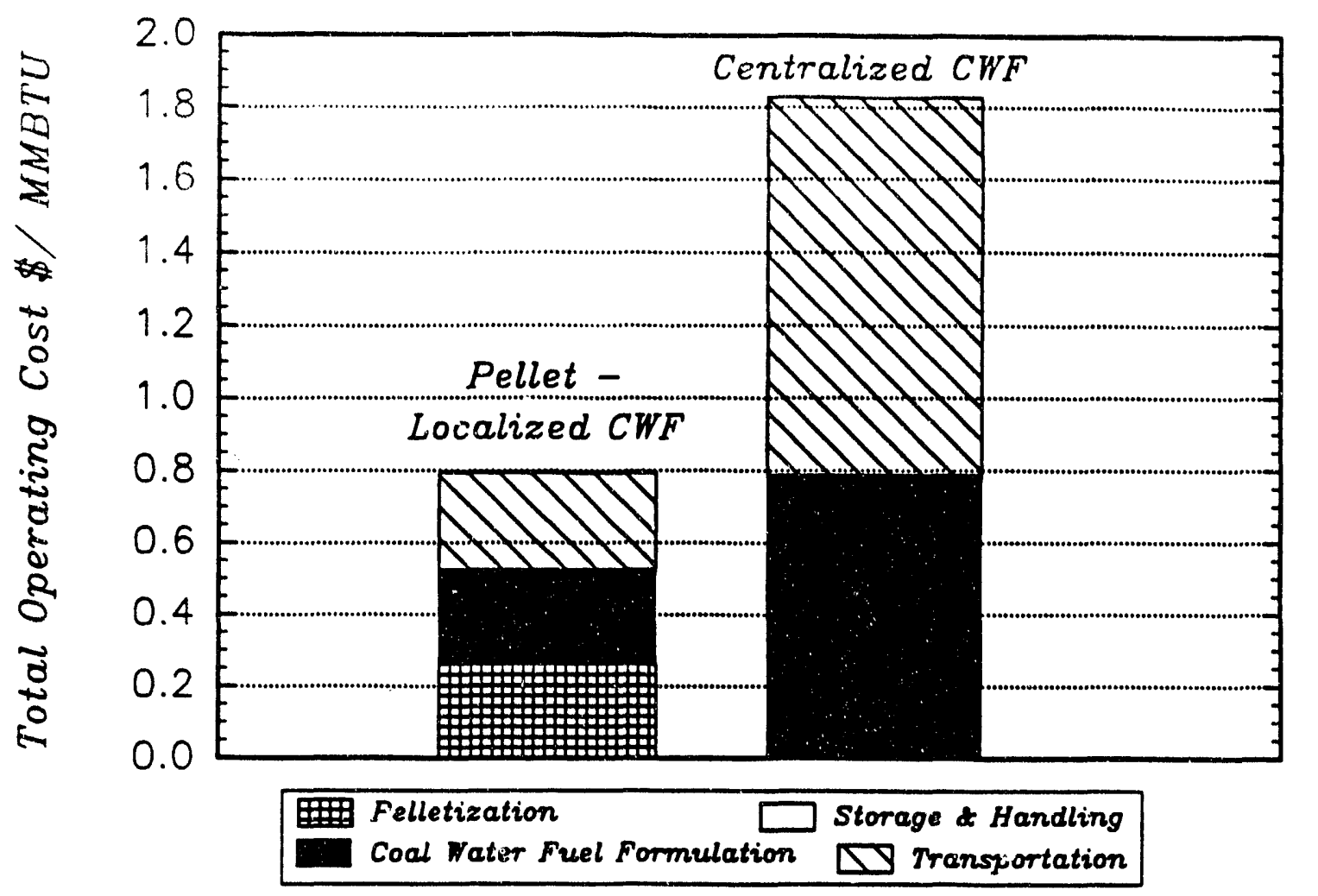

FIGURE 8.3 COAL PELLETIZATION, TRANSPORTATION, STORAGE, HANDLING AND CWF CONVERSION OPERATING COSTS COMPARISON FOR THE TWO APPROACHES 
greater than preparing CWF at the user site after pelletizing. This combined with the lower transportation costs and lower storage and handling costs showed the pelletization approach to offer good incentives for development. Cost estimates for the three coals, processed by the Pellet-CWF and the direct-CWF approaches, are presented in the following sections.

\subsection{Pelletization Cost Assessment}

Pelletization cost estimation to convert the beneficiated clean coal filter cake into a reconstituted pellet product was computed for the Elkhorn, Utah, and Illinois No. 6 coals. Estimates were also obtained for the three pelletization processes. All of the cost estimates were obtained using a cost-model. The cost-model incorporated design information and experimental data to make material balance, equipment selection and sizing, fixed capital, and operating cost estimates. This task was executed as follows:

- Obtain pelletization process experience from one or more commercial operating facilities.

- Prepare flowsheets for process areas such as pelletization, binder preparation, reslurrying process, etc.

- Verify that assumptions for the cost-model are realistic.

Flow sheet development to allow equipment selection and sizing for various plant sizes was provided in detail in the Seventh Quarterly Report. ${ }^{(1)}$ Typical flowsheet and equipment selection output from the cost-model are shown for the purpose of illustration in Figures 8.4 and 8.5. Table 8. 2 lists typical process assumptions used in the cost model.

Cost estimates for pellet production from clean coal filter-cake of. Elkhorn, Illinois No. 6, and Utah coals using Shur Bond, corn starch, and lignin sulfonate binders were evaluated. Estimates were also prepared for the following reconstitution techniques.

- Roller-and-die pelletization

- Disk pelletization

- Extrusion pelletization.

Plant capacities of 50, 250, and 1000 ton/day were chosen for obtaining the cost estimates. 


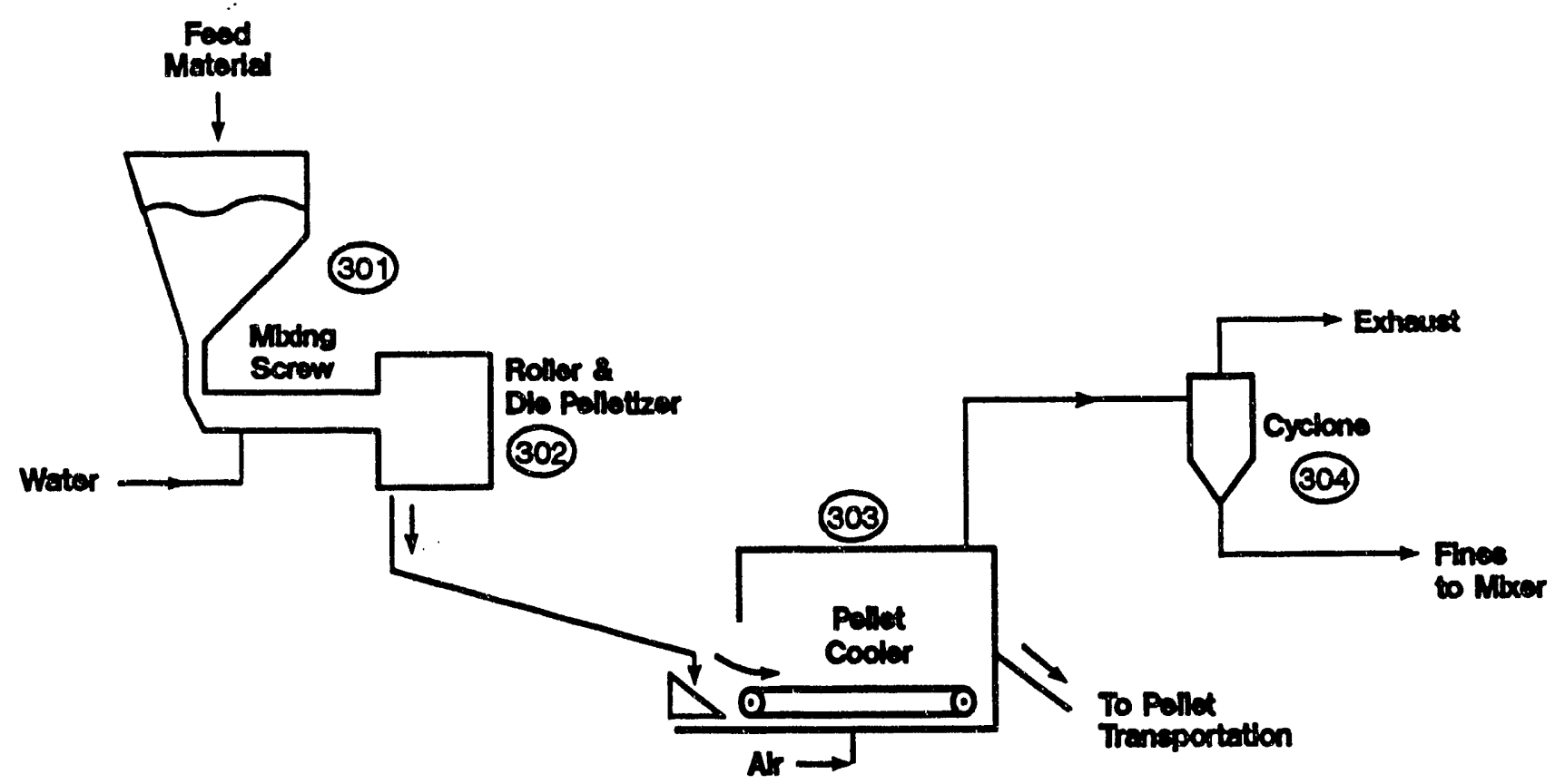

FIGURE 8.4 TYPICAL FLOWSHEET PREPARED FOR PROCESS COST ESTIMATION (FLOWSHEET FOR ROLLER-AND-DIE PELLETIZATION PROCESS) 


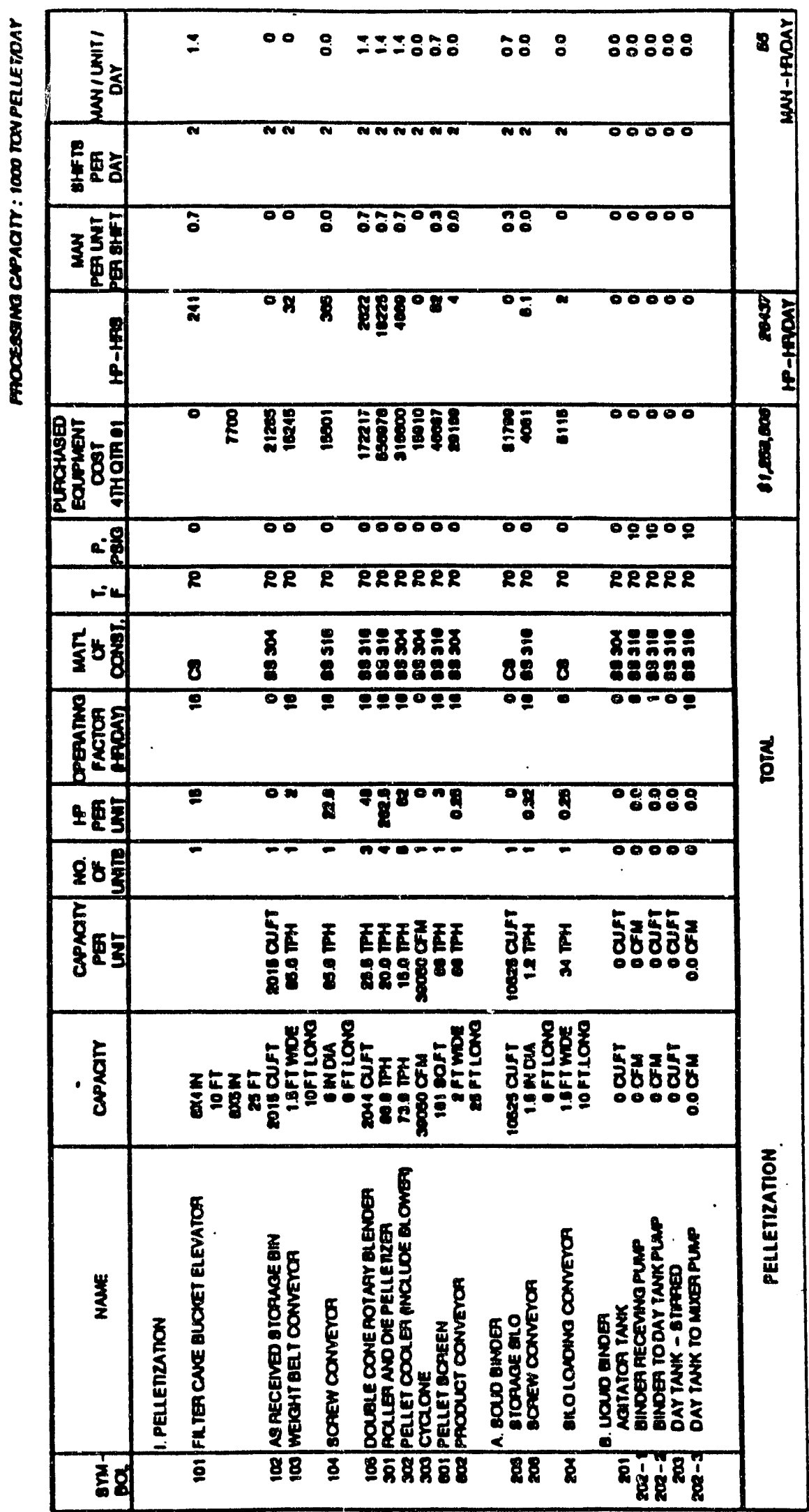

2 
TABLE 8.2 PROCESS ASSUMPTIONS USED IN THE COST-MODEL

\begin{tabular}{|c|c|c|c|}
\hline \multicolumn{4}{|c|}{ Cost Estimate Model Assumpt ion } \\
\hline \multicolumn{2}{|c|}{ Operating Cost Estimation } & \multicolumn{2}{|c|}{$\begin{array}{l}\text { Capital Cost Estimation } \\
\text { ractors }\end{array}$} \\
\hline $\begin{array}{l}\text { Raw Material } \\
\text { Corn Starch: } \\
\text { Shur Bond } \\
\text { (diluted): } \\
\text { Dispersant } \\
\text { (A23): } \\
\text { Stabilizer } \\
\text { (FLOCON): }\end{array}$ & $\begin{array}{l}\$ 0.045 / 1 b \\
\text { s0.010/1b } \\
\text { (diluted) } \\
\$ 0.330 / 1 \mathrm{~b} \\
\$ 1.000 / 1 \mathrm{~b}\end{array}$ & $\begin{array}{l}\text { Direct Cost Items } \\
\text { Equip. Installa- } \\
\text { tion: } \\
\text { Instrumentation: } \\
\text { Piping: } \\
\text { (pelleting) } \\
\text { (reslurrying) } \\
\text { Electrical: } \\
\text { Building: }\end{array}$ & $\begin{array}{rl}16.5 \% & \mathrm{PE} \\
2.5 \% & \mathrm{PE} \\
& \\
3.0 \% & \mathrm{PE} \\
5.0 \% & \mathrm{PE} \\
6.0 \% & \mathrm{PE} \\
15.0 \% \mathrm{PE}\end{array}$ \\
\hline $\begin{array}{l}\text { Utilities } \\
\text { Electricity: } \\
\text { Steam: } \\
\text { Water: }\end{array}$ & $\begin{array}{l}\$ 0.05 / \mathrm{kWhr} \\
\$ 0.0024 / / 1 \mathrm{~b} \\
\$ 3.6 \times 10^{-5} / 1 \mathrm{~b}\end{array}$ & $\begin{array}{l}\text { Indirect cost } \\
\text { Items } \\
\text { Engineering and } \\
\text { Supervision: } \\
\text { Construction: }\end{array}$ & $\begin{array}{l}12.0 \% \\
12.0 \% \\
\end{array}$ \\
\hline $\begin{array}{l}\text { Labor } \\
\text { Operat ing: } \\
\text { Maintenance: } \\
\text { Supervision: }\end{array}$ & $\begin{array}{l}\$ 30 / \mathrm{man}-\mathrm{hr} \\
3.0 \% \text { of FCI } \\
15 \% \text { of Operating } \\
\text { labor }\end{array}$ & $\begin{array}{l}\frac{\text { Other }}{\text { Contractors Fee: }} \\
\text { Contingency: } \\
\text { Working Capital: }\end{array}$ & $\begin{array}{l}2.0 \% \text { of Dir \& } \\
\text { Indirect Costs } \\
8.0 \% \text { of Dir \& } \\
\text { Indirect Costs } \\
1 \text { month of } \\
\text { annual operat- } \\
\text { ing cost }\end{array}$ \\
\hline $\begin{array}{l}\text { Roller-and-Die } \\
\text { Maintenance } \\
\text { Basis: } \\
\text { Plant Over- } \\
\text { head: } \\
\text { Local Taxes, } \\
\text { Insurance: } \\
\text { Depreciation: }\end{array}$ & $\begin{array}{l}\$ 12,500 / \text { die; } \\
16,000 \text { ton/die } \\
\$ 5,000 / \text { roller; } \\
8,000 \text { ton/roller } \\
20 \% \text { of Operating } \\
\text { \& Maintenance } \\
\text { Labor } \\
1 \% \text { FCI } \\
8 \% \text { FCI }\end{array}$ & & \\
\hline & $\begin{array}{l}\text { PE: Pur } \\
\text { FCI: Fixed }\end{array}$ & $\begin{array}{l}\text { eq Equipment } \\
\text { ital Investment }\end{array}$ & \\
\hline
\end{tabular}




\subsubsection{Fixed Capital Estimate}

Surnmaries of the fixed capital investment estimates for pelletization of the three coals via the three techniques are presented in Tables 8.3, 8.4, and 8.5. The estimate includes direct plant costs such as installation, piping, electrical and building. Indirect cost items like construction, engineering and supervision were also estimated. Fixed capital cost estimates represents the actual dollars required for constructing the plant. For the same plant size, the roller-and-die pelletization process required the lowest investment; disk and extrusion processes were between twice to $2 \frac{1}{2}$ times more. The difference was mostly due to the additional expense required for the thermal drying. There was little difference for the different coals. Binder type affected capital costs by 7 to 20 percent with the dry, free flowing com starch providing the lowest cost.

TABLE 8.3. FIXED CAPITAL INVESTMENT ESTIMATES FOR ROLLER-AND-DIE PELLETIZATION

\begin{tabular}{|l|c|c|c|}
\hline \multirow{2}{*}{} & \multicolumn{3}{|c|}{ Capital Investment, \$ × 1000 \pm 2000 [4th Quarter, 1991] } \\
\cline { 2 - 4 } & \multicolumn{3}{|c|}{ Illinois, Utah and Elkhorn Coals } \\
\cline { 2 - 4 } & 50 TPD & 250 TPD & 1000 TPD \\
\hline Corn Starch & 333 & 720 & 2,316 \\
\hline Shur Bond & 358 & 811 & 2,540 \\
\hline Lignin Sulfonate & 389 & 866 & 2,631 \\
\hline
\end{tabular}


TABLE 8.4. FIXED CAPITAL INVESTMENT ESTIMATES FOR DISK PELLETIZATION

\begin{tabular}{|c|c|c|c|}
\hline & \multicolumn{3}{|c|}{$\begin{array}{c}\text { Capital Investment, } \$ \times 1000 \pm 2000 \text { [4th } \\
\text { Quarter, 1991] }\end{array}$} \\
\hline & \multicolumn{3}{|c|}{ Illinois, Utah and Elkhorn Coals } \\
\hline & $50 \mathrm{TPD}$ & 250 TPD & 1000 TPD \\
\hline Corn Starch & 549 & 1,553 & 5,070 \\
\hline Shur Bond & 594 & 1,667 & 5,344 \\
\hline Lignin Sulfonate & 623 & 1,719 & 5,403 \\
\hline
\end{tabular}

TABLE 8.5. FIXED CAPITAL INVESTMENT ESTIMATES FOR EXTRUSION PELLETIZATION

\begin{tabular}{|l|c|c|c|}
\hline \multirow{2}{*}{} & \multicolumn{3}{|c|}{ Capital Investment, $\$ \times 1000 \pm 2000$ [4th Quarter, 1991] } \\
\cline { 2 - 4 } & \multicolumn{3}{|c|}{ Illinois, Utah and Elkhorn Coals } \\
\cline { 2 - 4 } & 50 TPD & 250 TPD & 1000 TPD \\
\hline Corn Starch & 485 & 1,518 & 5,541 \\
\hline Shur Bond & 534 & 1,640 & 5,830 \\
\hline Lignin Sulfonate & 563 & 1,689 & 5,872 \\
\hline
\end{tabular}

Figure 8.6 presents these variations for the various plant sizes.

\subsubsection{Operating Cost Estimate}

Annual operating cost estimates for pelletization were also estimated via the costmodel. Using estimates of raw materials, utilities, labor, maintenance, depreciation costs, etc., the model estimated the total operating cost. 
166
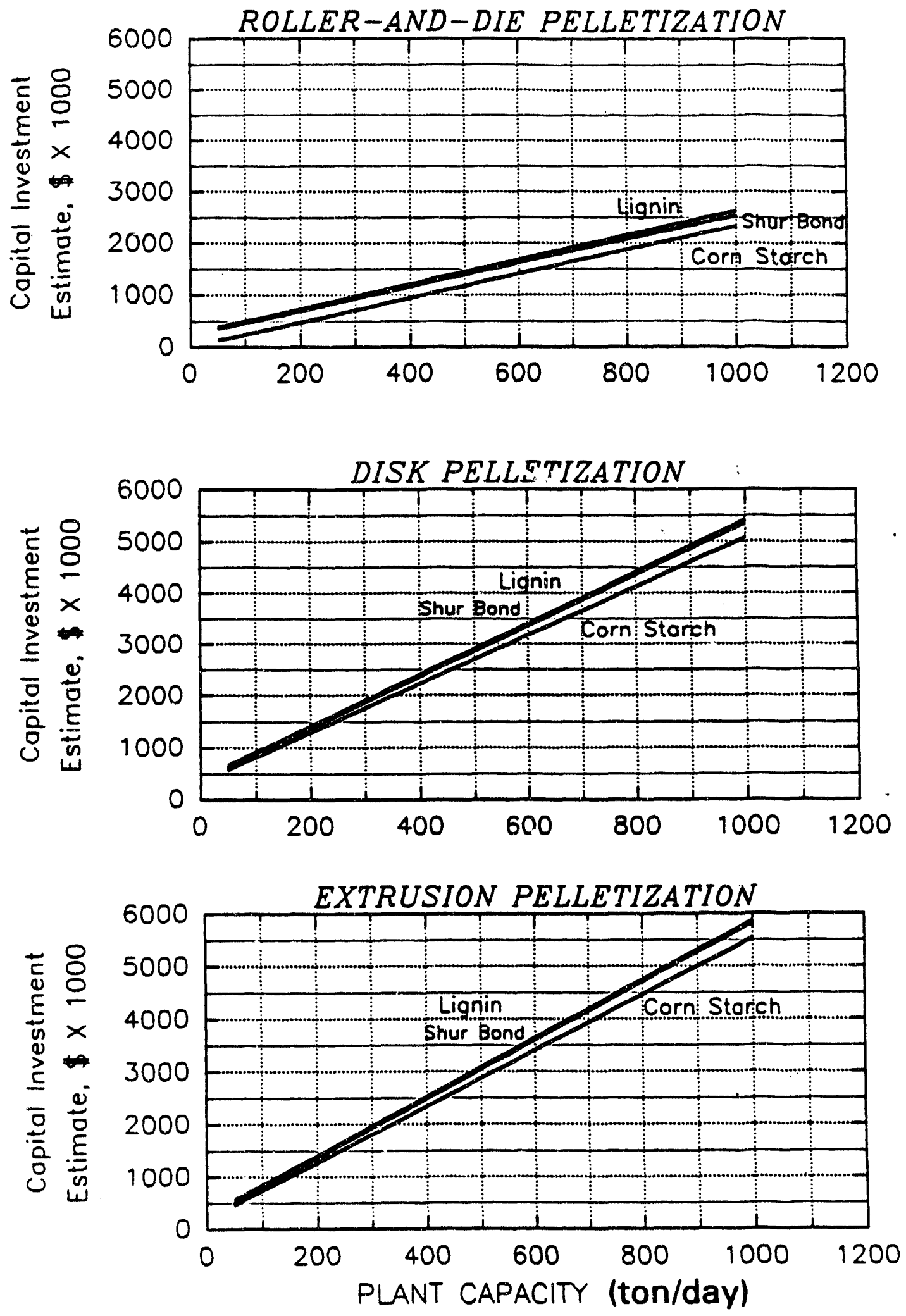

FIGURE 8.6 FIXED CAPITAL INVESTMENT PROFILE FOR PELLETIZATION OF ELKHORN COAL 
Figure 8.7 presents the sensitivity of the operating cost estimates with plant size, for the three pelletization techniques and for the three binders. Shur Bond-bound pellets were observed to be consistently less expensive to produce than corn starch- or lignin sulfonatebound pellets. The figure also indicates that for plant at capacities less than 500 ton (dry)/day the operating cost is less economically attractive. Figures 8.8 through 8.10 present the distribution of the operating costs for the three plant sizes, i.e, 50, 250, and 1000 ton (dry)/day and for the three pelletization techniques. At plant capacities between 50 and 250 ton (dry)/day, labor and depreciation costs were high, dominating the over-all cost.

Binder cost added a significant contribution to the overall costs. It was a function of binder type and dosage. Sensitivity analysis indicated that a 0.5 percent increase (i.e., from 2 to 2.5 percent) corn starch dosage could account for a 5 to 10 percent increase in total operating costs. Based on the economic analysis, the following conclusions can be derived on the pelletization process:

- Total roller-and-die pelletization costs (operating and fixed capital investment) were considerably less than disk and extrusion pelletization.

- Binder, utilities and depreciation cost contributions were lowest with rollerand-die, but maintenance (due to high roller-and-die replacement requirements) costs were the highest.

- Disk and extrusion pelletization had low maintenance costs but had high utilities and depreciation costs.

A summary of estimated total annual operating costs are presented in Tables 8.6, 8.7, and 8.8. Clearly, with all the three coals, Shur Bond binder was the most economical binder. Pellet production technique also had a strong effect. Roller-and-die pelletization was consistently the least expensive pelletization method for all three coals. Data from these tables also indicated that for the selected coal-binder combination, operating costs for the roller-and-die pelletization were about 30 to 35 percent lower than for disk and extrusion pelletization. Utilities costs, ranging between $\$ 2.50$ to $\$ 2.95 /$ ton (dry basis) for drying the pellets, were the major cost factor contributing to higher disk and extrusion pelletization costs. Very little coal effect was observed. 

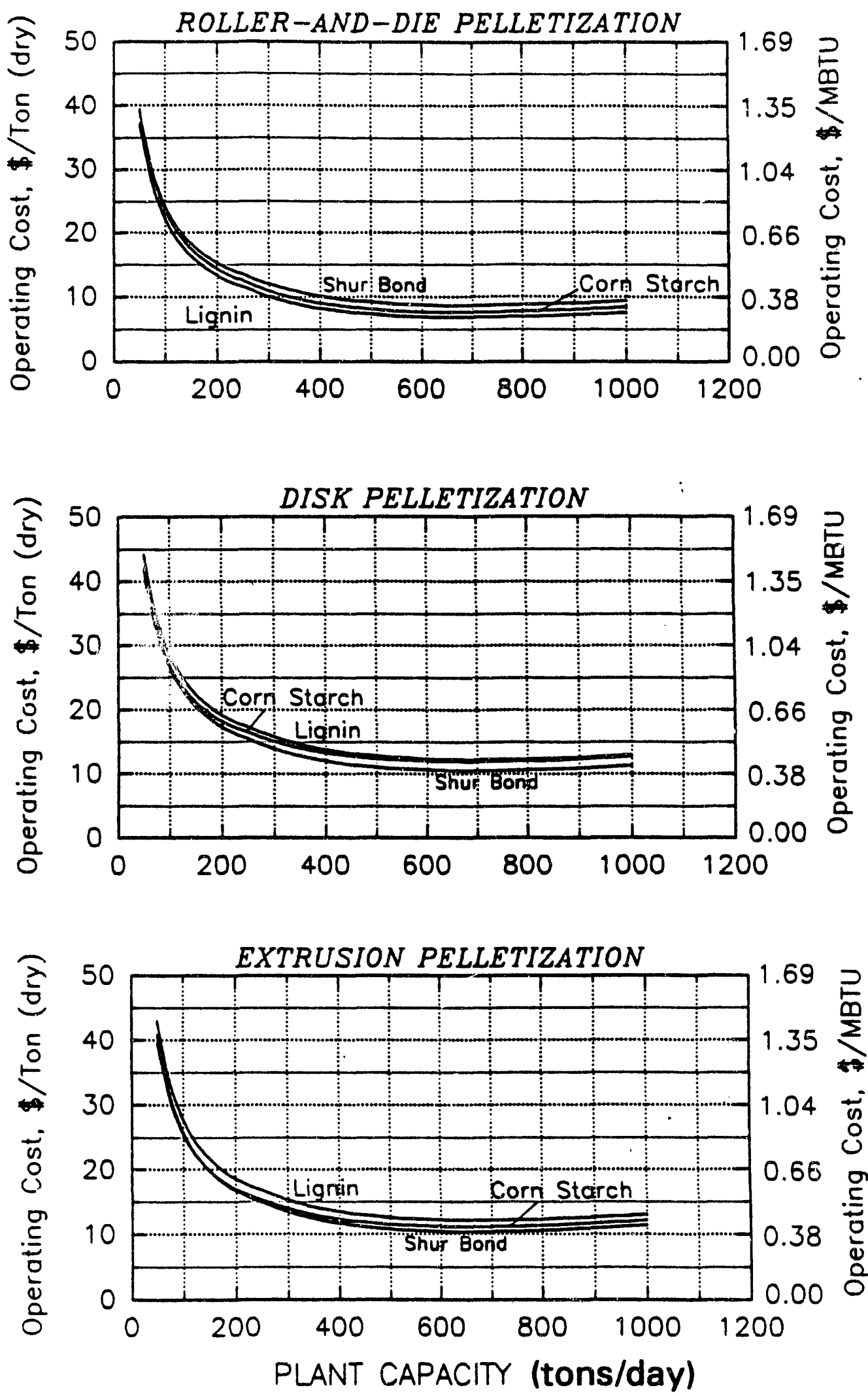

FIGURE 8.7 OPERATING COST ESTIMATES SENSITIVITY WITH PLANT SIZE FOR PELLETIZATION OF ELKHORN COAL 

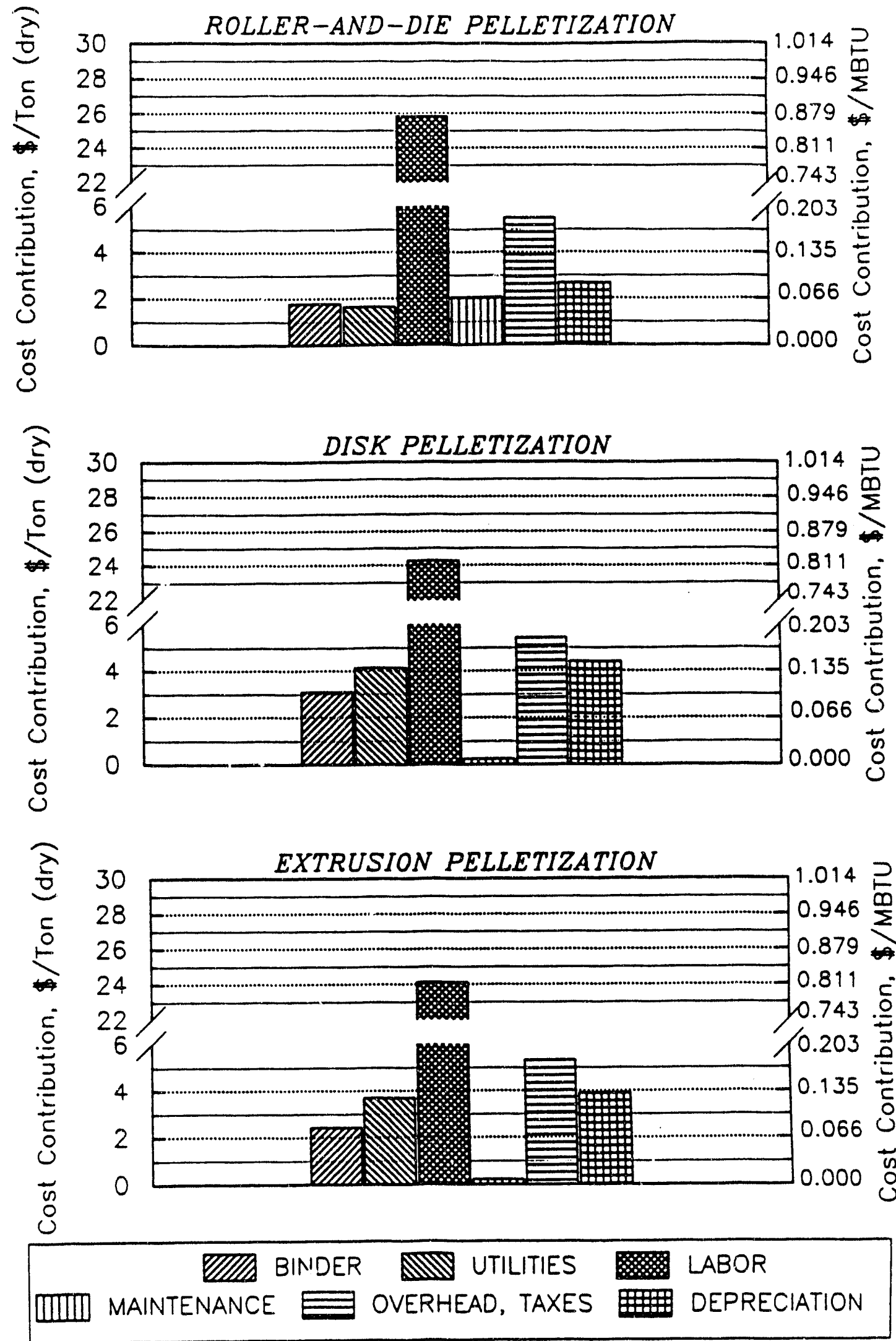

FIGURE 8.8. DISTRIBUTION OF OPERATING COST ELEMENTS FOR PELLETIZATION OF ELKHORN COAL AT 50 TPD CAPACITY 

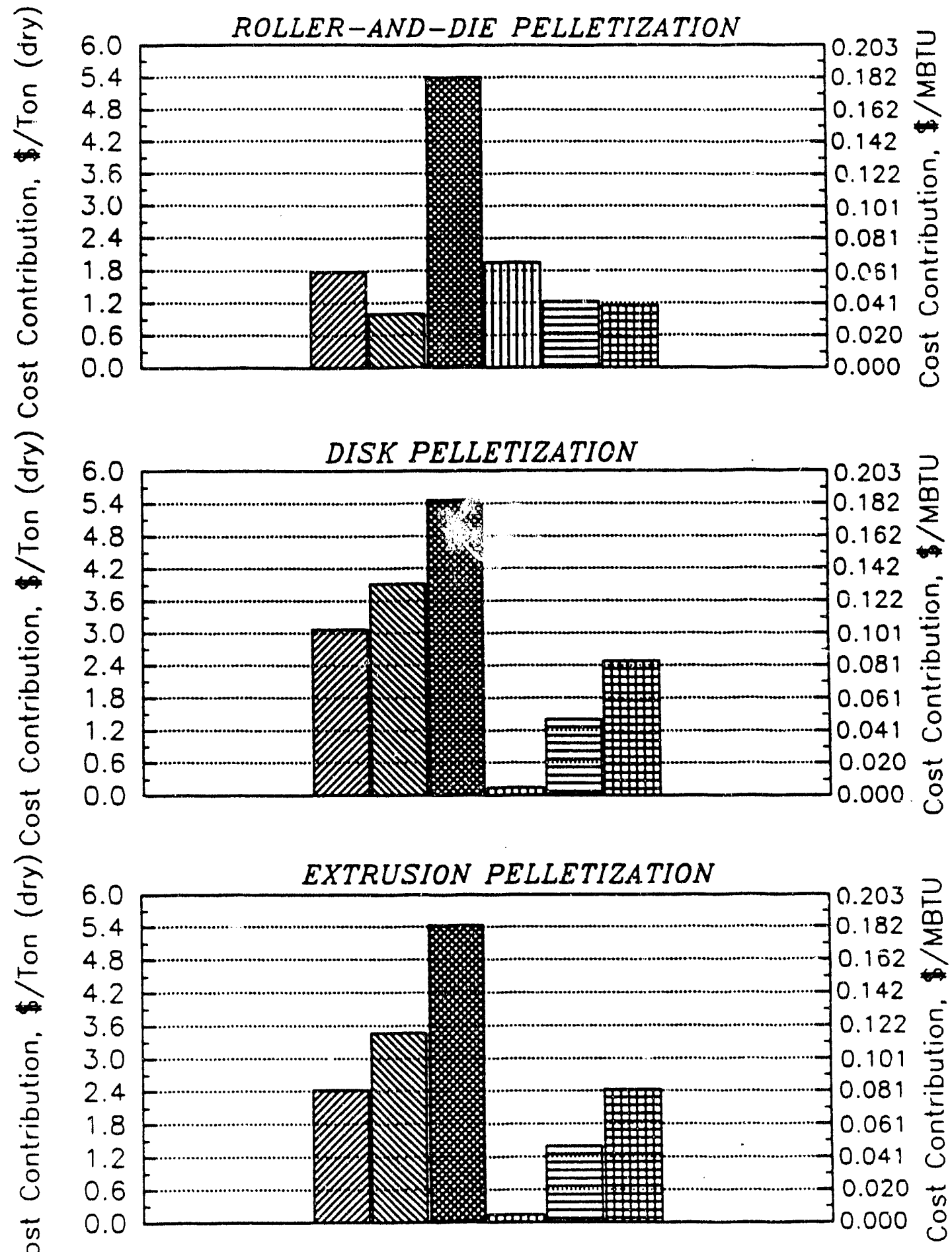

\section{WIIS BINDER UTILITIES LABOR} m MAINTENANCE OVERHEAD, TAXES DEPRECIATION

FIGURE 8.9. DISTRIBUTION OF OPERATING COST ELEMENTS FOR PELLETIZATION OF ELKHORN COAL AT 250 TPD CAPACITY 

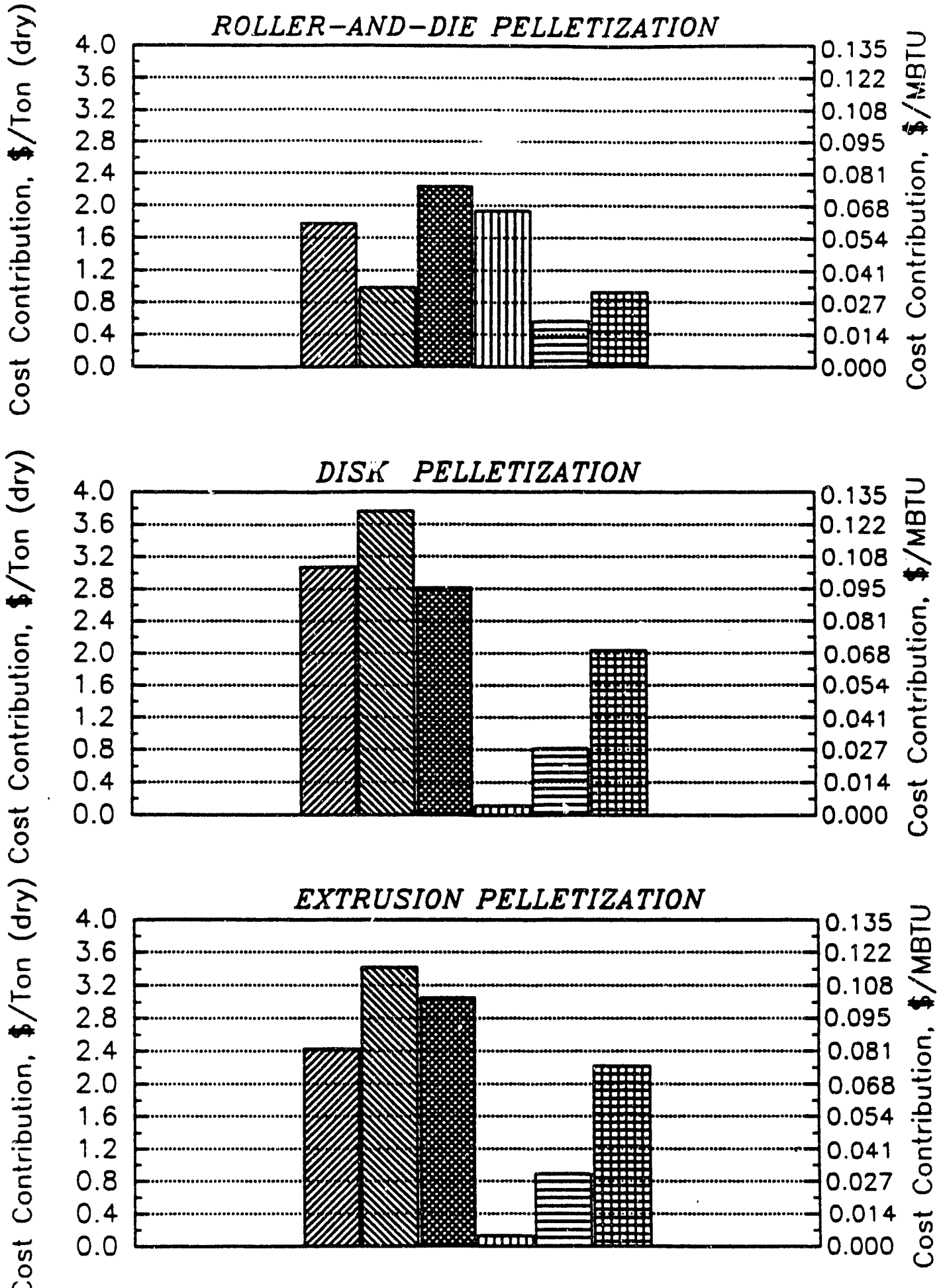

\section{MIIIA BINDER UTILITIES LABOR
DIIIII MAINTENANCE OVERHEAD, TAXES ORECIATION}

FIGURE 8.10. DISTRIBUTION OF OPERATING COST ELEMENTS FOR PELLETIZATION OF ELKHORN COAL AT 1000 TPD CAPACITY 


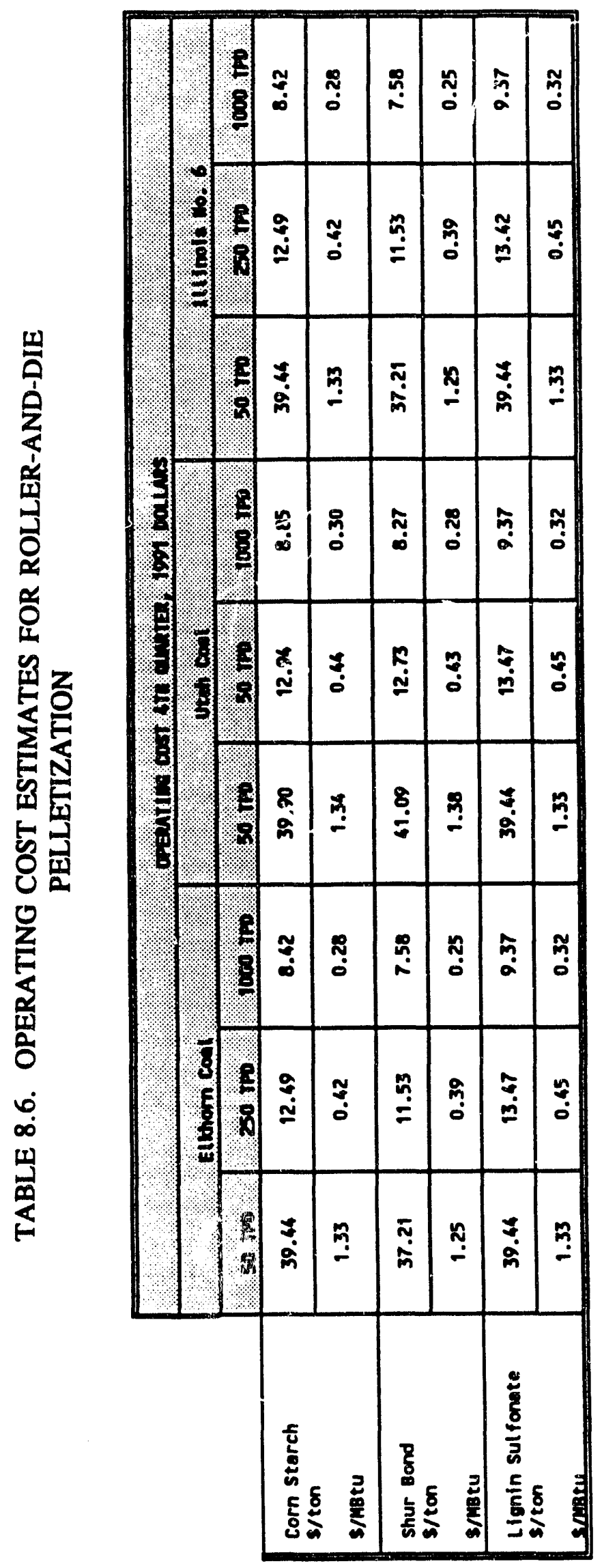




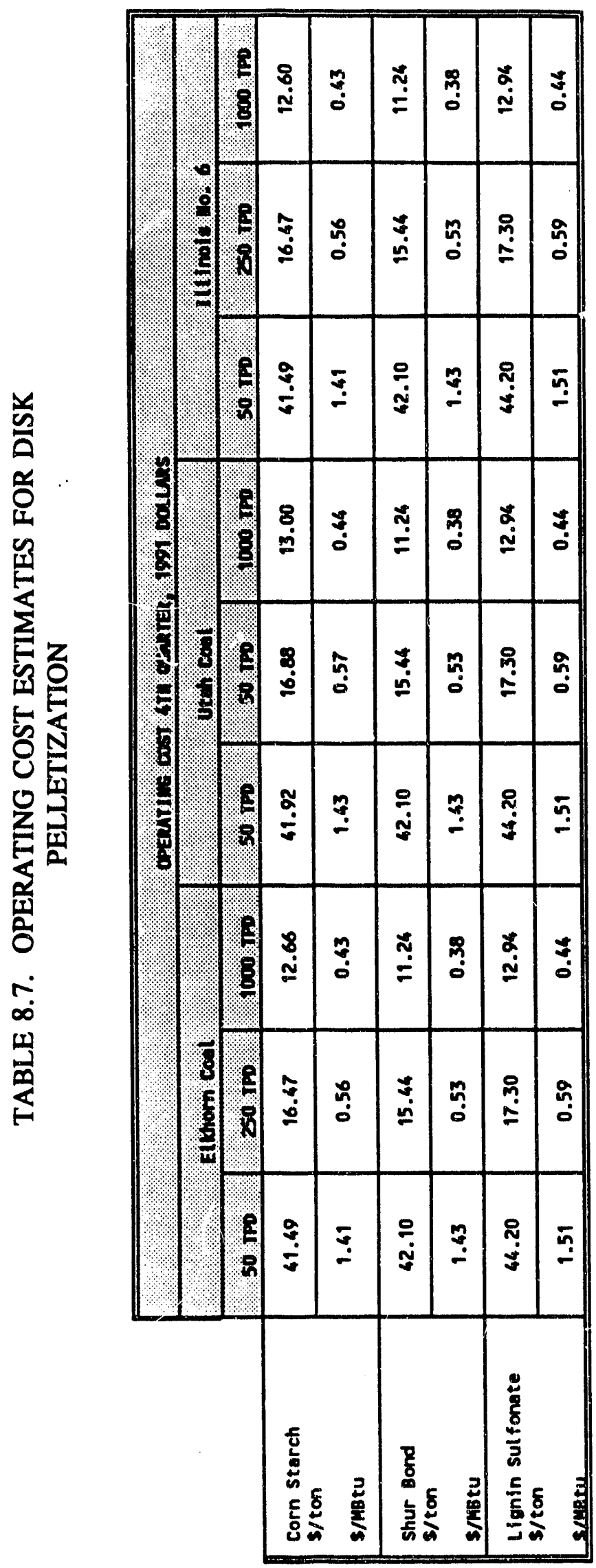




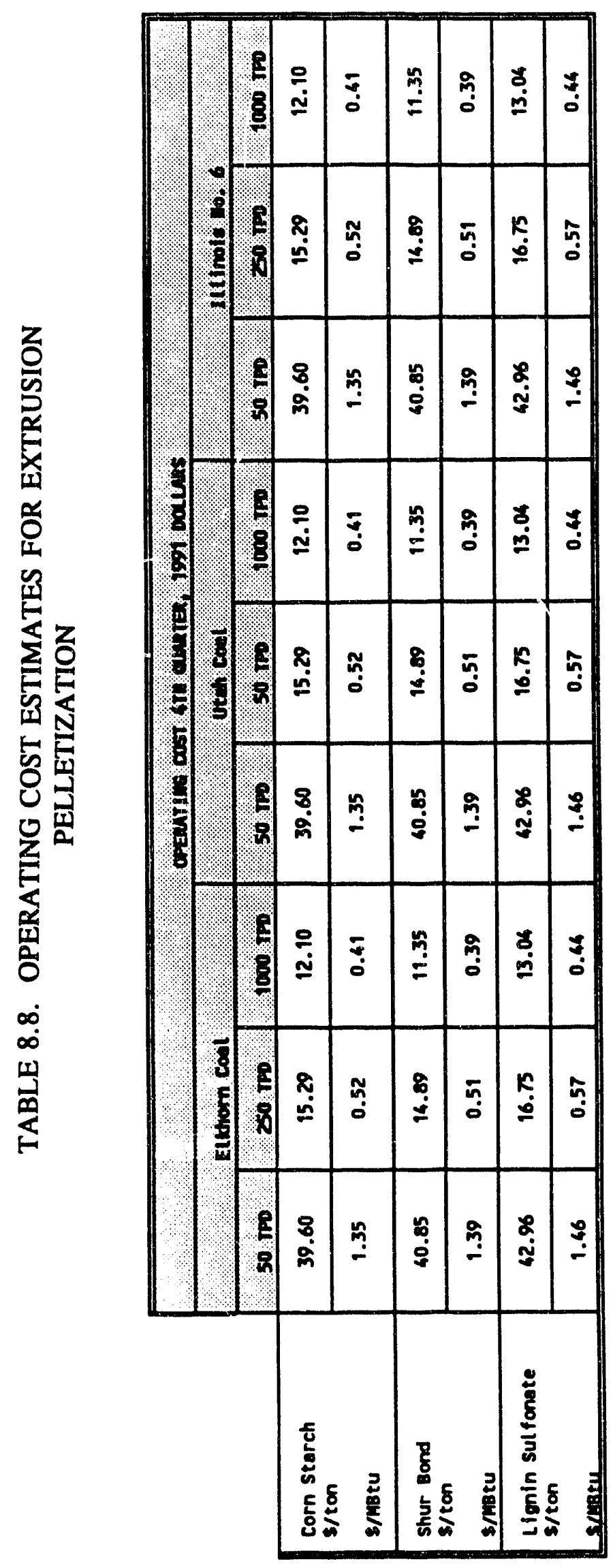




\subsection{Reslurrying Cost Assessment}

The ultra-fine, ultra-clean filter-cake produced at the benefici-ition site could be utilized in either of the two following ways to produce CWF:

- Pellet-CWF Approach: Pelletize the filter-cake, transport, handle and store the coal as pellets, and prepare CWF for use on demand at the user sites

- Direct-CWF Approach: Convert the filter cake into CWF at the beneficiation site, transport, handle and store the coal as CWF at the user's site (i.e., the conventional approach).

These two approaches are schematically presented in Figure 8.11. Bench-scale and pilotscale $\mathrm{CW}_{\mathbf{r}}$ formulation tests conducted in this project identified the additives and their dosage needed for CWF formulation by the two approaches. Based on these data and other process information, the cost of preparing the slurry by the two approaches was estimated using the cost-model. In the folluwing sections, these cost estimates (capital investment, operating cost) are presented.

\subsubsection{Pellet-CWF Formulation}

Pellets from a pellet-production plant would be delivered to the users for slurry production. For the purpose of cost sensitivity analysis, slurry utilization sites have been designed for 2,10 , or 50 ton (dry equivalent)/day of CWF usage. These plant capacities represent typical CWF users targeted in this program. Material balances and equipment selection for the reslurrying operations, etc., were obtained using the cost model. Details were provided in the Seventh Quarterly Report. ${ }^{(1)}$ 


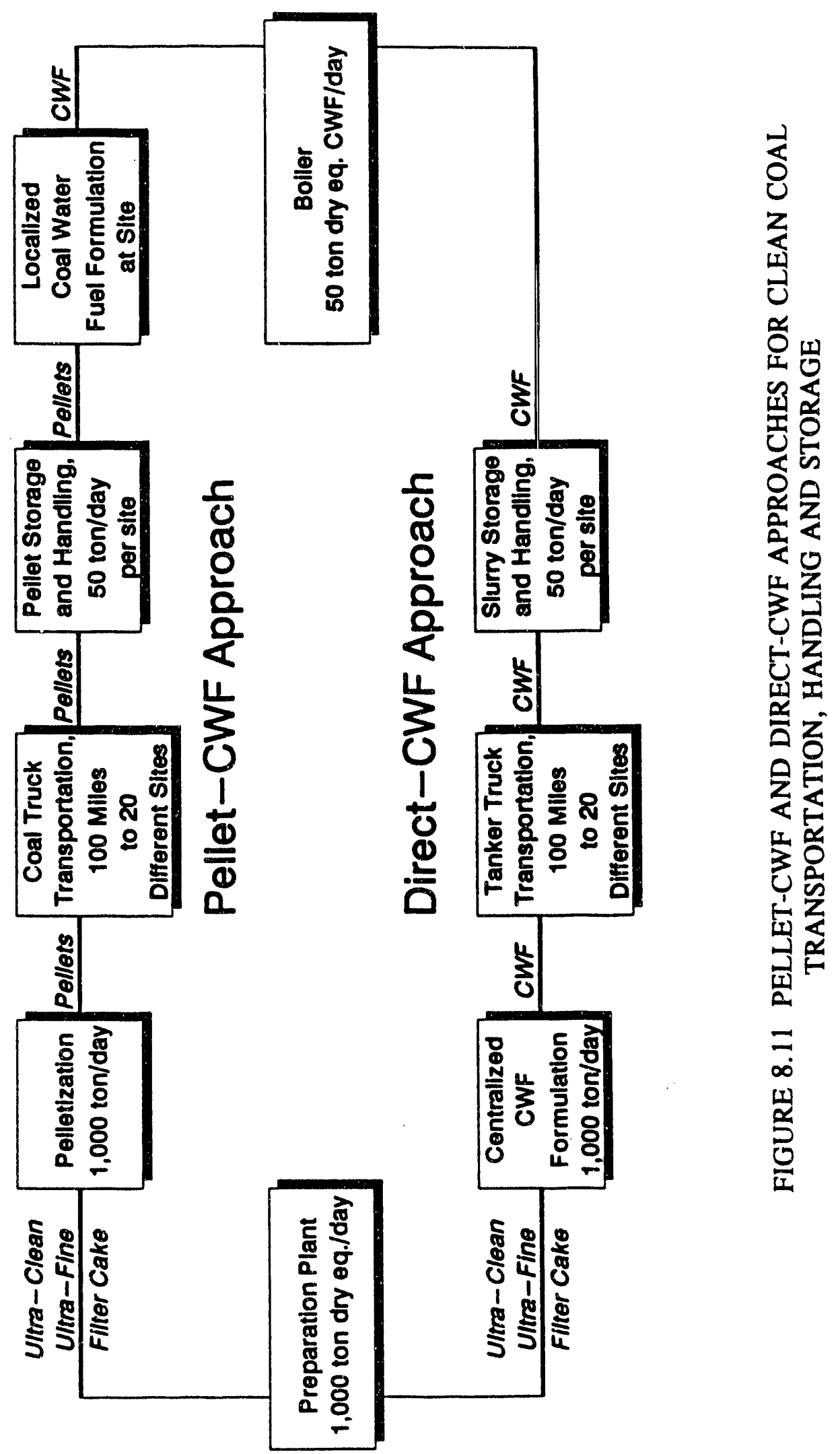




\subsubsection{Capital Cost Estimates}

Summary of the capital cost estimated for the Pellet-CWF approach is given in Table 8.9. Data presented in the table show that slurry formulation plant size is the main variable affecting fixed capital investment. Other variables such as coal type, binder, or pelletization technique had little or no effect. This sensitivity observed with plant size is illustrated in Figure 8.12. Notice that the pellets from the three production techniques have identical fixed investment profile.

\subsubsection{Operating Cost Estimates}

Annual operating costs for 2, 10, and 50 TPD Pellet-CWF formulation plants were estimated. Tables 8.10, 8.11 and 8.12 summarize the operating cost estimates for the CWF formulated by each of the three pelletization techniques for each of three plant sizes.

Figures 8.13, 8.14 and 8.15 present the distributio's of various operating cost elements for the three plant sizes. At 2 TPD, the labor cost element is so high that the process does not appear to be economically attractive. Reslurrying dispersant (A-23) cost was observed to contribute almost 50 percent of the operating cost. This clearly indicates that the A-23 dosage must be minimized. Among the three pellet types, roller-and-die pellets showed the lowest overall operatir costs. This was primarily due to the fact that less A-23 additive was required to formulate the roller-and-die pellets into CWF.

Figure 8.16 presents the sensitivity of operating costs to variations in plant size for Elkhorn coal pellets. The effect of binder type is also presented. Shur Bond-bound pellets required the lowest A-23 dosage and therefore resulted in the lowest pellet reslurrying cost. 
TABLE 8.9. FIXED CAPITAL INVESTMENT ESTIMATES FOR CWF FORMULATION OF PELLETS

\begin{tabular}{||l|c|c|c||}
\hline \multirow{2}{*}{} & \multicolumn{3}{|c|}{ Capital Investmerit, \$ X 1000 [4th Quarter, 1991] } \\
\cline { 2 - 4 } & \multicolumn{3}{|c||}{ Ilinois, Utah, and Elkhorn Coals } \\
\cline { 2 - 4 } & 2 TPD & 10 TPD & Soller-and-Die Pellets \\
\hline Corn Starch & 22.5 & 62 & 119 \\
\hline Shur Bond & 22 & 61 & 118.5 \\
\hline Lignin Sulfonate & 22.5 & 62 & 119 \\
\hline & & \multicolumn{3}{|c||}{ Disk Pellets } \\
\hline Corn Starch & 23 & 63 & 121 \\
\hline Shur Bond & 22 & 61 & 119 \\
\hline Lignin Sulfonate & 23 & 62 & 121 \\
\hline & & Extrusion Pellets \\
\hline Corn Starch & 23 & 46.5 & 104 \\
\hline Shur Bond & 23 & 46 & 104 \\
\hline Lignin Sulfonate & 23 & 46 & \multicolumn{3}{|c||}{} \\
\hline
\end{tabular}



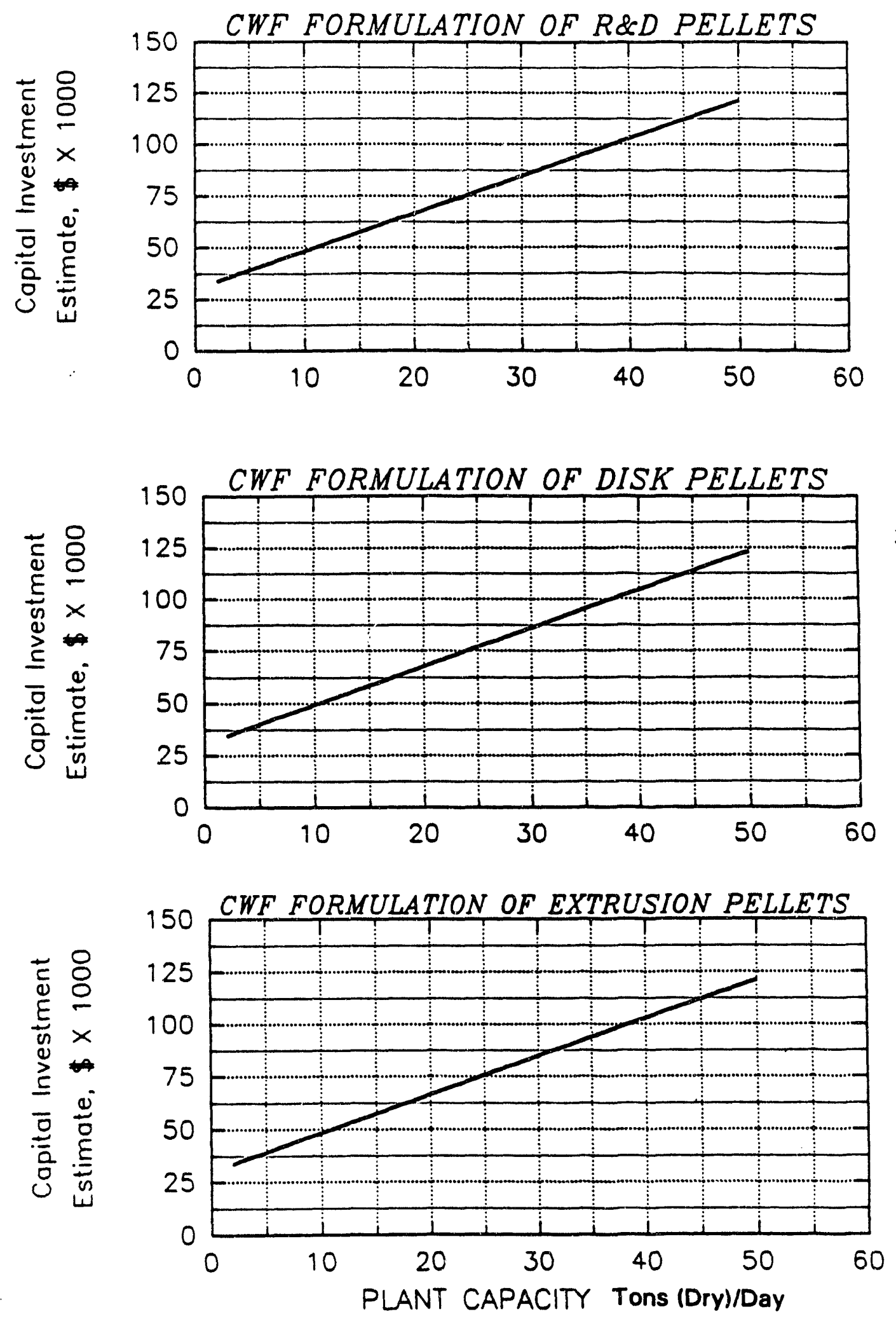

FIGURE 8.12 SENSITIVITY OF FIXED CAPITAL INVESTMENT FOR FORMULATION OF CWF FROM PELLETS WITH PLANT SIZE 


\begin{tabular}{|c|c|c|c|c|c|c|c|c|}
\hline \multirow{9}{*}{ 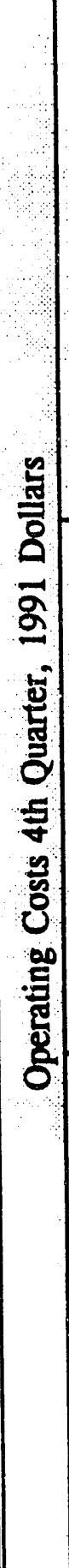 } & \multirow{3}{*}{ o } & $\begin{array}{l}2 \\
\stackrel{2}{5} \\
\stackrel{2}{n}\end{array}$ & 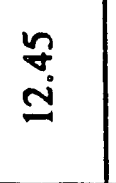 & $\underset{̛}{\mathscr{Y}}$ & $\underset{\infty}{\mathfrak{f}}$ & స్తి & ợ & $\vec{n}$ \\
\hline & & $\begin{array}{l}2 \\
\mathrm{e} \\
=\end{array}$ & बूले & $\begin{array}{l}8 \\
0 \\
0\end{array}$ & 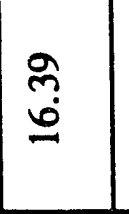 & $\tilde{n}$ & $\stackrel{8}{\stackrel{8}{\Xi}}$ & $\tilde{n}$ \\
\hline & & $\begin{array}{l}\stackrel{Q}{\mathrm{~F}} \\
\sim\end{array}$ & 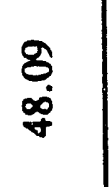 & $\stackrel{\widetilde{\sigma}}{-}$ & $\begin{array}{l}\tilde{O} \\
\dot{j}\end{array}$ & $\stackrel{\infty}{\stackrel{\infty}{:}}$ & $\begin{array}{l}8 \\
\dot{J} \\
\dot{J}\end{array}$ & $\stackrel{\mathscr{n}}{-}$ \\
\hline & & $\begin{array}{l}2 \\
\text { है } \\
0\end{array}$ & $\begin{array}{l}\infty \\
\stackrel{0}{2}\end{array}$ & $\begin{array}{l}0 \\
\stackrel{0}{0}\end{array}$ & $\begin{array}{l}\infty \\
\infty \\
\sigma\end{array}$ & $\stackrel{\overbrace{}}{\tilde{0}}$ & $\begin{array}{l}\stackrel{9}{\circ} \\
\stackrel{0}{0}\end{array}$ & $\stackrel{n}{3}$ \\
\hline & $\begin{array}{l}7 \\
8 \\
5 \\
5\end{array}$ & $\begin{array}{l}\stackrel{\theta}{\epsilon} \\
\varrho\end{array}$ & $\frac{\vec{i}}{\vec{N}}$ & $\stackrel{?}{\circ}$ & $\stackrel{n}{\stackrel{2}{I}}$ & $\begin{array}{l}8 \\
0 \\
0\end{array}$ & $\underset{\sim}{\tilde{\infty}}$ & $\underset{0}{\sigma}$ \\
\hline & & $\underset{\sim}{\stackrel{f}{\sim}}$ & 守 & $\stackrel{8}{8}$ & $\stackrel{q}{\mathscr{q}}$ & $\tilde{n}$ & $\begin{array}{l}8 \\
6 \\
6\end{array}$ & $\approx$ \\
\hline & & 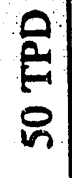 & $\stackrel{\infty}{a}$ & $\stackrel{\tilde{m}}{0}$ & $\stackrel{\infty}{\stackrel{\infty}{r}}$ & ז̊ & ș & $\tilde{\sigma}$ \\
\hline & $\begin{array}{l}0 \\
\vdots \\
\vdots \\
\underline{g}\end{array}$ & $\begin{array}{l}0 \\
\stackrel{2}{0} \\
0\end{array}$ & $\stackrel{\stackrel{5}{5}}{\stackrel{5}{I}}$ & $\begin{array}{l}8 \\
0 \\
0\end{array}$ & $\tilde{\tilde{n}}$ & $\tilde{n}$ & $\underset{8}{8}$ & $\tilde{n}$ \\
\hline & & $\begin{array}{l}a \\
\stackrel{a}{\sim} \\
\sim\end{array}$ & 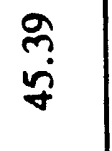 & $\tilde{n}$ & $\stackrel{\sim}{\sim}$ & 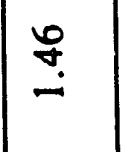 & $\begin{array}{l}8 \\
8 \\
\dot{f}\end{array}$ & $\stackrel{\circ}{\simeq}$ \\
\hline & & & 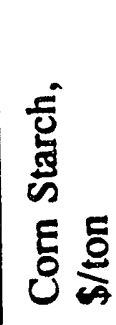 & $\sum_{j}^{\sum}$ & 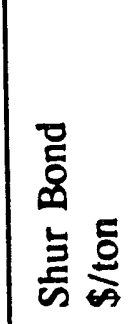 & $\sum_{i=\mid}^{\sum}$ & 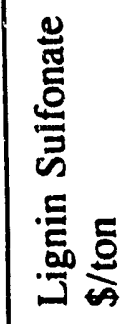 & $\sum_{i}^{\sum}$ \\
\hline
\end{tabular}


181

\begin{tabular}{|c|c|c|c|c|c|c|c|c|}
\hline \multirow{9}{*}{$\begin{array}{l} \\
\\
\\
\end{array}$} & \multirow{3}{*}{$\begin{array}{c} \\
0 \\
0 \\
0 \\
: \\
: \\
=\end{array}$} & $\begin{array}{l}2 \\
0 \\
\text { in }\end{array}$ & $\tilde{n}$ & $\stackrel{\bar{\sigma}}{0}$ & $\begin{array}{l}\stackrel{\infty}{\mathfrak{0}} \\
\stackrel{0}{0}\end{array}$ & ஸై & $\stackrel{\check{n}}{\simeq}$ & ণ̃. \\
\hline & & है & $\underset{\sim}{\stackrel{\infty}{\sim}}$ & $\begin{array}{l}\infty \\
\infty \\
0 \\
0\end{array}$ & $\underset{\infty}{\vec{\infty}}$ & $\stackrel{\Xi}{\leftrightarrows}$ & $\begin{array}{l}\tilde{n} \\
\tilde{i}\end{array}$ & $\begin{array}{l}\stackrel{\circ}{0} \\
0\end{array}$ \\
\hline & & $\begin{array}{l}\text { D } \\
\text { N } \\
N\end{array}$ & $\begin{array}{l}\tilde{n} \\
\tilde{n}\end{array}$ & $\stackrel{\infty}{-}$ & $\begin{array}{l}\stackrel{P}{+} \\
\dot{b}\end{array}$ & $\stackrel{\infty}{\sim}$ & 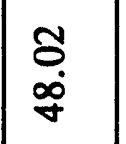 & $\underset{-}{\mathbb{Z}}$ \\
\hline & \multirow{3}{*}{ 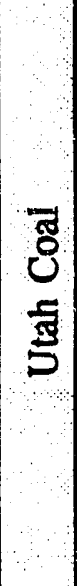 } & $\begin{array}{l}\text { ㄹ } \\
\stackrel{2}{2} \\
8\end{array}$ & $\frac{\infty}{a}$ & $\stackrel{n}{0}$ & $\stackrel{n}{\stackrel{y}{\simeq}}$ & $\stackrel{\sim}{\mathscr{q}}$ & $\begin{array}{l}\bar{\sigma} \\
\dot{\Xi}\end{array}$ & $\stackrel{\infty}{\stackrel{0}{0}}$ \\
\hline & & $\begin{array}{l}2 \\
\hat{b} \\
0\end{array}$ & $\underset{⿱ 亠}{\Delta}$ & ๙ૂ & $\begin{array}{l}\stackrel{\infty}{\dddot{n}} \\
\stackrel{\sim}{\sim}\end{array}$ & $\begin{array}{l}8 \\
0 \\
0\end{array}$ & $\frac{\mathscr{2}}{\text { స̆ }}$ & $\frac{n}{0}$ \\
\hline & & $\begin{array}{l}2 \\
\stackrel{\vec{E}}{\sim}\end{array}$ & $\begin{array}{l}\stackrel{0}{0} \\
\dot{\vec{n}}\end{array}$ & $\stackrel{\infty}{\infty}$ & $\begin{array}{l}\infty \\
0 \\
\infty \\
\infty\end{array}$ & 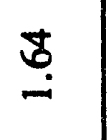 & $\begin{array}{l}\infty \\
: 0 \\
\dot{\sigma}\end{array}$ & $\stackrel{\text { ga }}{\text { - }}$ \\
\hline & \multirow{3}{*}{ 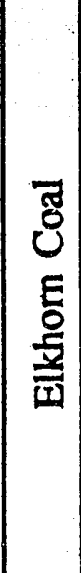 } & $\begin{array}{l}0 \\
\vec{H} \\
0 \\
0\end{array}$ & $\stackrel{\infty}{\stackrel{\infty}{\sim}}$ & $\stackrel{?}{\circ}$ & $\underset{\infty}{\infty}$ & స్రి & $\stackrel{m}{\stackrel{m}{0}}$ & $\stackrel{n}{0}$ \\
\hline & & $\begin{array}{l}0 \\
\vec{B} \\
0\end{array}$ & $\stackrel{\text { ণ }}{\stackrel{\sim}{*}}$ & $\stackrel{R}{\stackrel{2}{0}}$ & कृ & $\stackrel{\mathscr{n}}{0}$ & $\begin{array}{l}0 \\
0 \\
0 \\
\infty\end{array}$ & \begin{tabular}{l}
\multirow{0}{*}{} \\
0
\end{tabular} \\
\hline & & $\begin{array}{l}\stackrel{2}{\mathrm{E}} \\
\text { N }\end{array}$ & $\underset{\substack{\infty \\
\dot{\infty}}}{m}$ & 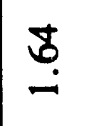 & $\begin{array}{l}\tilde{O} \\
\dot{j}\end{array}$ & $\stackrel{8}{\dddot{2}}$ & 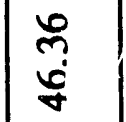 & $\stackrel{\infty}{n}$ \\
\hline & & & 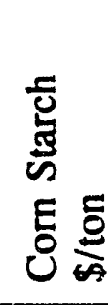 & $\sum_{\infty}^{\sum}$ & 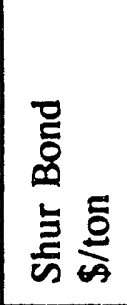 & $\sum_{i}^{D}$ & 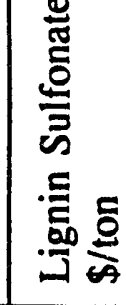 & $\sum_{\infty}^{\sum}$ \\
\hline
\end{tabular}


182

\begin{tabular}{|c|c|c|c|c|c|c|c|c|}
\hline \multirow{9}{*}{$\begin{array}{c} \\
\\
\\
\end{array}$} & \multirow{3}{*}{$\begin{array}{l} \\
0 \\
2 \\
0 \\
0 \\
\\
0\end{array}$} & 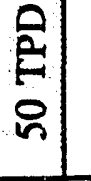 & $\begin{array}{l}8 \\
\stackrel{\square}{0}\end{array}$ & $\tilde{n}$ & 守 & ஸొ & 气̃ & 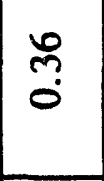 \\
\hline & & 열 & $\begin{array}{l}\ddot{c} \\
\tilde{i}\end{array}$ & $\stackrel{\infty}{\stackrel{\infty}{0}}$ & $\stackrel{8}{5}$ & $\stackrel{\bar{\sigma}}{0}$ & 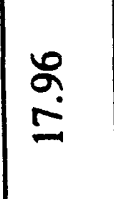 & $\begin{array}{l}\overrightarrow{0} \\
0\end{array}$ \\
\hline & & $\begin{array}{l}\stackrel{Q}{A} \\
\sim\end{array}$ & $\frac{\infty}{\dot{\square}}$ & $\stackrel{r}{=}$ & 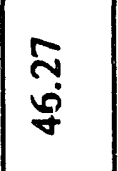 & $\stackrel{\infty}{n}$ & $\begin{array}{l}n \\
\mathscr{b} \\
\dot{q}\end{array}$ & $\stackrel{\infty}{n}$ \\
\hline & \multirow{3}{*}{$\begin{array}{c} \\
\tilde{8} \\
\tilde{8} \\
\tilde{3} \\
5 \\
\end{array}$} & है & $\begin{array}{l}8 \\
\stackrel{0}{0}\end{array}$ & $\tilde{n}$ & $\stackrel{f}{\Xi}$ & ભ్లి & $\stackrel{0}{\simeq}$ & $\overrightarrow{0}$ \\
\hline & & $\stackrel{8}{2}$ & $\begin{array}{l}y \\
\tilde{\nabla} \\
\ddot{v}\end{array}$ & $\stackrel{\infty}{\stackrel{\infty}{0}}$ & $\begin{array}{l}\& \\
\infty \\
\infty\end{array}$ & \begin{tabular}{l}
\multirow{0}{*}{} \\
0 \\
0
\end{tabular} & $\begin{array}{l}\overrightarrow{0} \\
\stackrel{\sigma}{\sigma}\end{array}$ & $\stackrel{5}{6}$ \\
\hline & & $\stackrel{0}{\approx}$ & $\frac{\infty}{\dot{n}}$ & 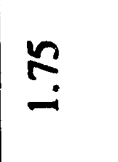 & 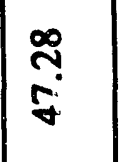 & $\stackrel{\overrightarrow{0}}{-}$ & $\begin{array}{l}\bar{\sigma} \\
\text { o } \\
q\end{array}$ & $\stackrel{3}{-}$ \\
\hline & \multirow{3}{*}{ 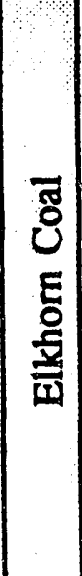 } & $\begin{array}{l}\hat{2} \\
8 \\
8\end{array}$ & $\begin{array}{l}\widehat{\hat{n}} \\
\varrho\end{array}$ & 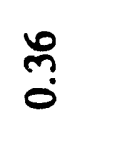 & $\frac{ \pm}{a}$ & ஸే & กั & 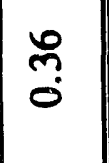 \\
\hline & & $\begin{array}{l}0 \\
\hat{R} \\
0 \\
0\end{array}$ & $\begin{array}{l}\tilde{O} \\
\infty \\
\infty\end{array}$ & $\begin{array}{l}\bar{\sigma} \\
0\end{array}$ & $\begin{array}{l}\mathscr{D} \\
\stackrel{0}{0}\end{array}$ & ڤ̊ & ֻั & $\stackrel{\overline{0}}{0}$ \\
\hline & & $\begin{array}{l}\hat{Q} \\
\hat{H} \\
\mathrm{~N}\end{array}$ & $\begin{array}{l}\text { qu } \\
\dot{\sigma}\end{array}$ & $\stackrel{\infty}{n}$ & $\begin{array}{l}\bar{a} \\
\dot{y}\end{array}$ & $\tilde{n}$ & ఝ̂. & $\stackrel{\infty}{\sim}$ \\
\hline & & & 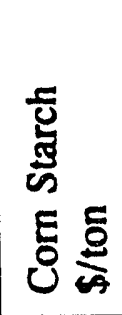 & $\sum_{\sum}^{\sum}$ & 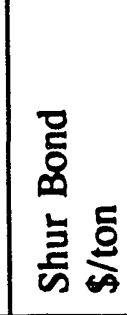 & $\sum_{i=\mid}^{\sum}$ & 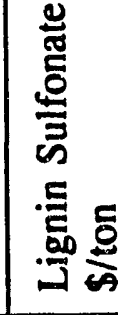 & 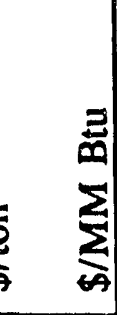 \\
\hline
\end{tabular}


183
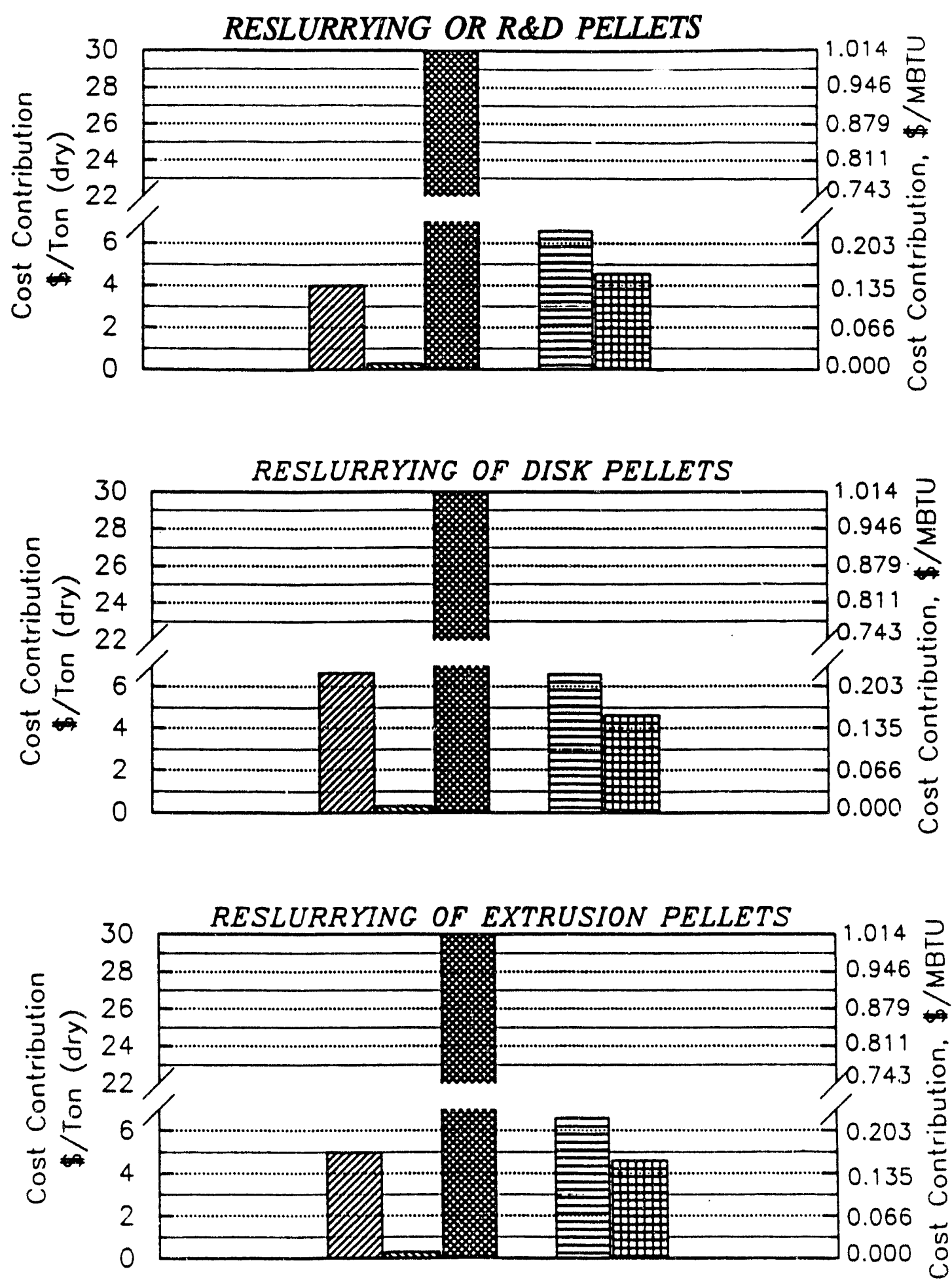

DISPERSANT UISILIES LABOR
DIIIII MAINTENANCE OVERHEAD, TAXES DEPECIATION



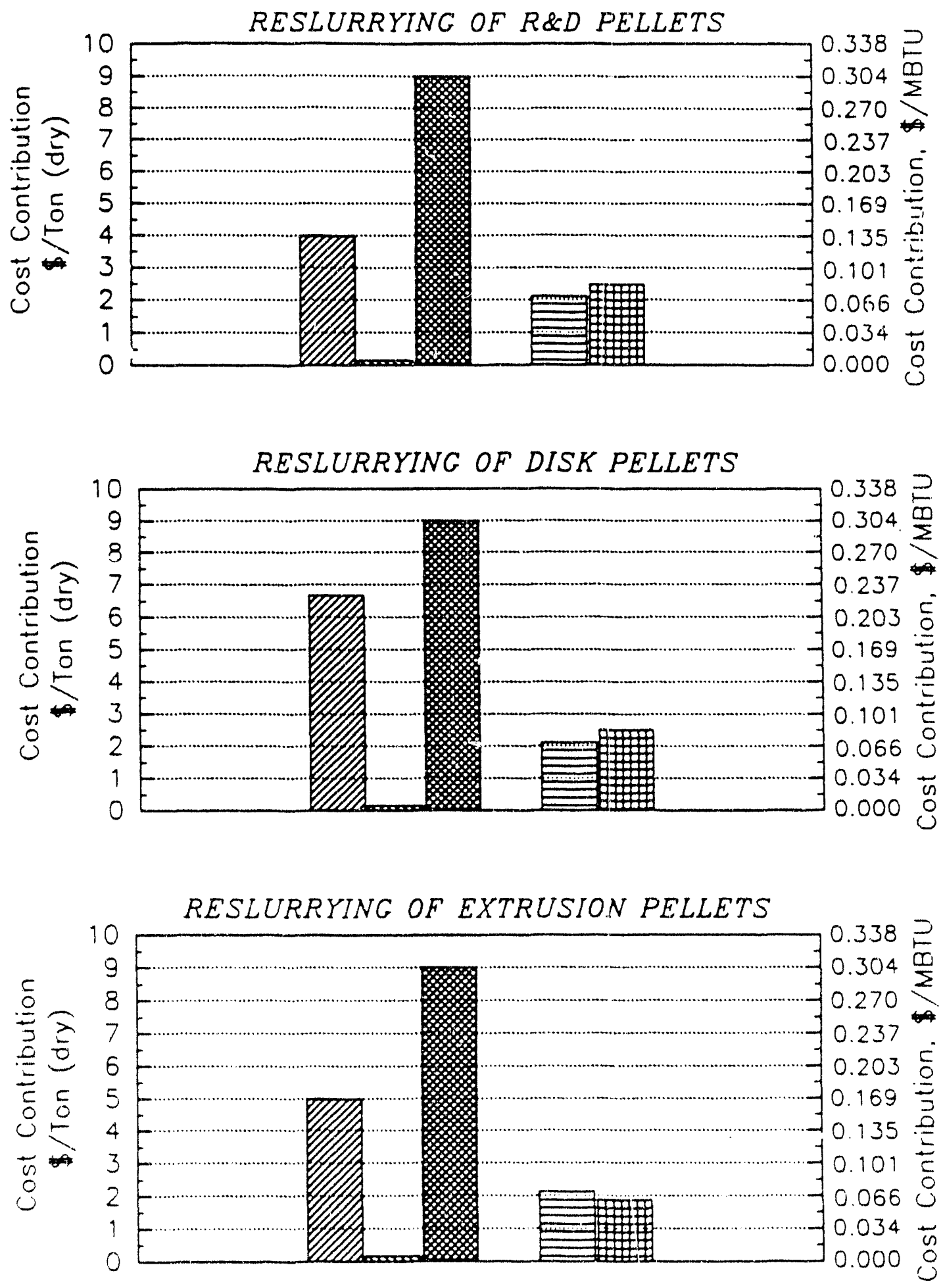

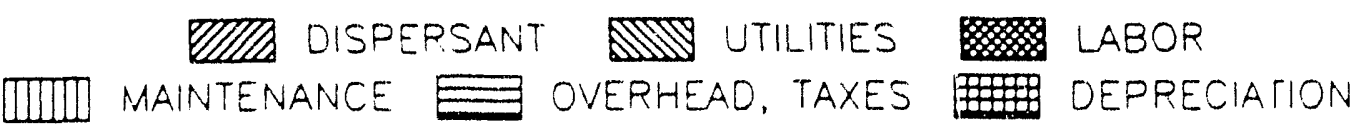

FIGURE 8.14. OPERATING COST DISTRIBUTION FOR PELLET-CWF FORMULATION IN A 10 TPD PLANT 

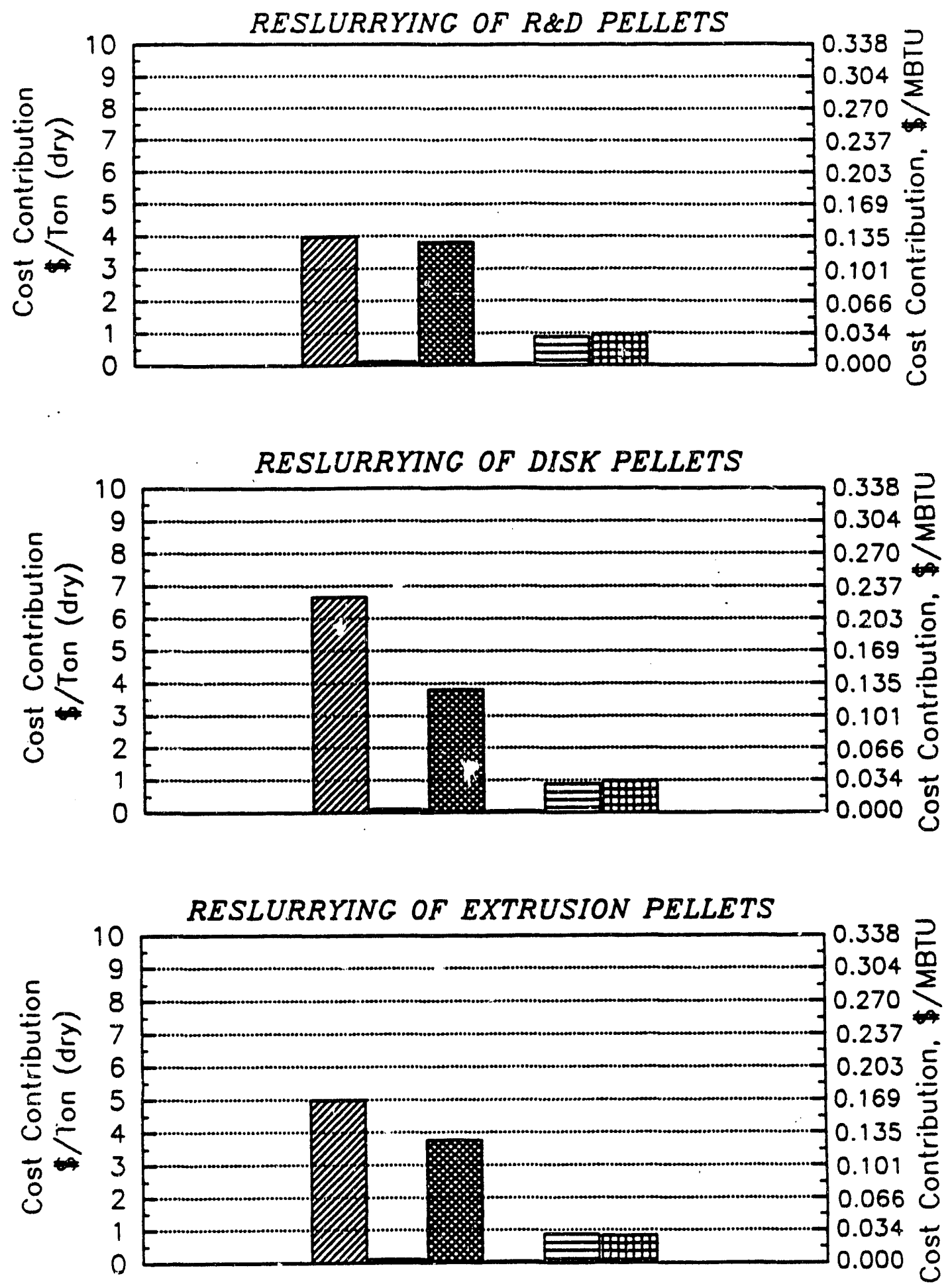

\begin{tabular}{|l}
\hline DISA DISPERSANT UTILITIES LABOR \\
DIIIII MAINTENANCE OVERHEAD, TAXES
\end{tabular}

FIGURE 8.15. OPERATING COST DISTRIBUTION FOR PELLET-CWF FORMULATION IN A 50 TPD PLANT 


\section{6}
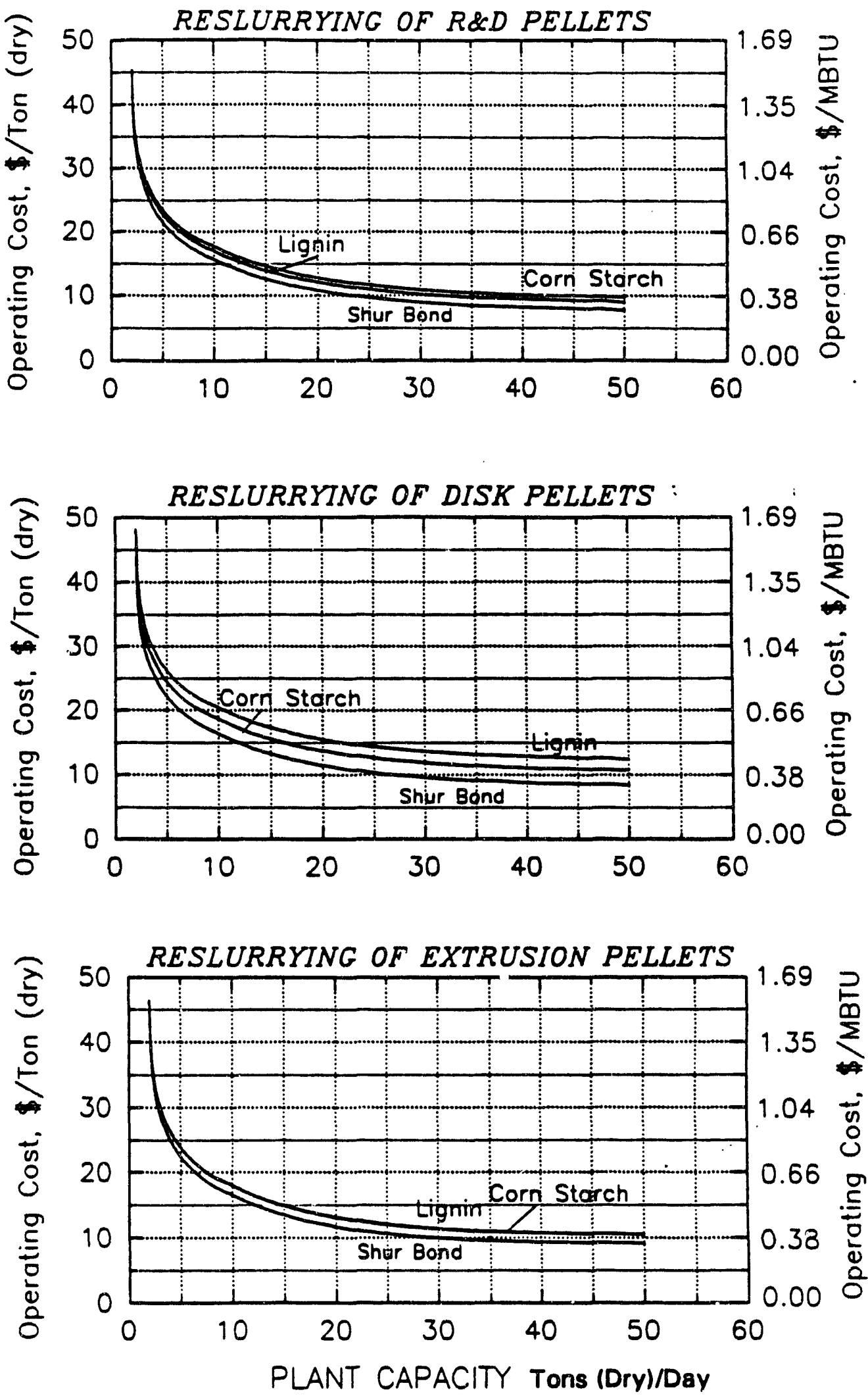

FIGURE 8.16. OPERATING COST FOR PELLET-CWF FORMULATION WITH RESPECT TO PLANT SIZE FOR VARIOUS PELLET TYPES 


\subsubsection{Direct-CWF Formulation}

This approach requires that the filter-cake be converted into CWF at the beneficiation site. Consequently, equipment was selected and sized for 50, 250, 1000 TPD (dry equivalent) plants. Capital investment for the 3 plant sizes (in 4th quarter 1991 dollars) are noted in Table 8.13 below.

\section{TABLE 8.13. DIRECT CWF CAPITAL INVESTMENT COSTS AS A FUNCTION OF PLANT SIZE}

\begin{tabular}{|c|c|}
\hline $\begin{array}{c}\text { CWF Plant Size } \\
\text { TPD (Dry Equivalent) }\end{array}$ & $\begin{array}{c}\text { Capital Investment } \\
\$ \times 1000\end{array}$ \\
\hline 50 & 124.5 \\
\hline 250 & 224.5 \\
\hline 1000 & 389.2 \\
\hline
\end{tabular}

Based on the filter cake dispersant and stabilizer requirements and other cost factors, operating costs for the direct CWF-Approach were estimated for the three coals at three plant sizes. The results are summarized in Table 8.14. The cost to formulate Elkhorn filter cake into CWF was observed to be about 30 percent more expensive than for Illinois No. 6 and Utah coal due to differences in the pelletization properties of these two coals. A comparison of the economic advantages and disadvantages of adopting either of the two approaches is presented later in Section 8.5 "Total Cost Estimate" of this report. 


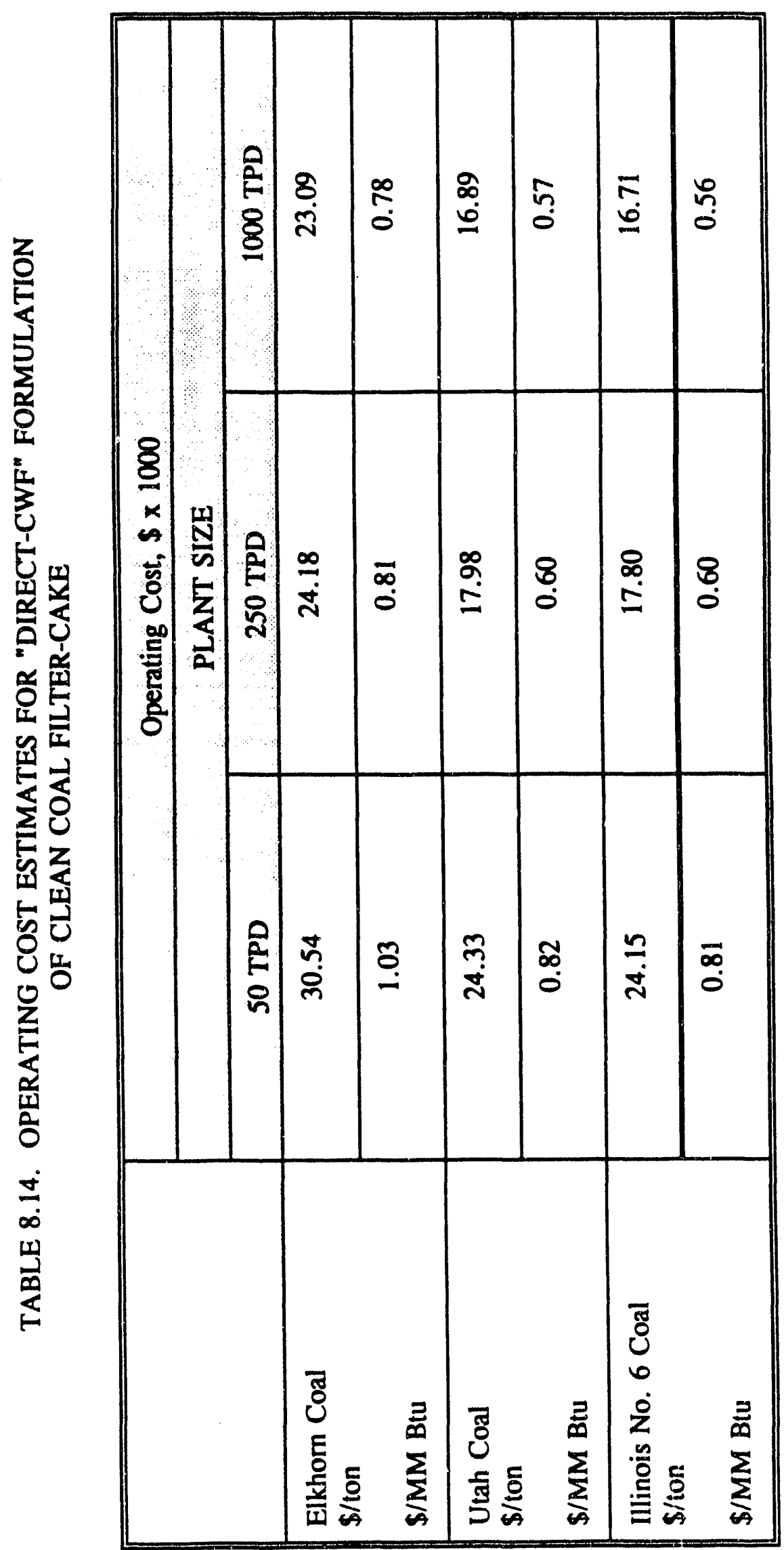




\subsection{Transportation, Handling and Storage Cost Assessment}

Estimates for transporting pellets/coal-water slurries were determined for the two approaches outlined in the last section. Estimates were based on the following guidelines.

Pellet-CWF (a) Pellets from 50 and 250 TPD plants could require 10, 50, or 100 miles of transportation. Transportation via trucks was recommended.

(b) Pellets from 1000 TPD plants could require 50, 100, or 300 miles of transportation. Rail transportation was recommended for distances equal to or greater than 300 miles.

Direct-CWF (a) CWF production from 50 and 250 TPD CWF plants would be distributed via specialized slurry trucks for distances of 10,50 , or 100 miles.

(d) CWF production from 1000 TPD CWF plants would be distributed via special rail-cars for distances equal to or greater than 300 miles. For distances less than 300 miles, the distribution was by special slurry tanker trucks.

\subsubsection{Pellet-CWF Transportation}

8.4.1.1 Truck Transportation. Since pellets produced are expected to be transported like mined lump coal, a transportation cost of $\$ 0.078 /$ ton-mile ${ }^{(2)}$ (in 4th quarter 1991 dollars) was used as a basis to estimate transportation costs. Therefore for the targeted transportation distances, the cost estimates are given in Table 8.15. 
TABLE 8.15. TRUCK TRANSPORTATION COSTS FOR PELLETS

\begin{tabular}{|c|c|}
\hline & $\begin{array}{c}\text { Estimated Cost } \\
\text { \$/dry ton }\end{array}$ \\
\hline Distance & 0.78 \\
\hline 10 mile & 3.90 \\
\hline 50 mile & 7.80 \\
\hline 100 mile & \\
\hline
\end{tabular}

These estimates are not influenced by the type of pellet, coal, or binder -- only moisture level.

8.4.1.2 Rail Transportation. For pellets from a 1000 ton/day pellet plant, rail transportation should be considered for distances greater than 300 miles. A rate of $\$ 0.028 /$ ton-mile ${ }^{(3)}$ (in 4th quarter 1991 dollars) was used as a basis to obtain estimates for transportation via rail. Cost estimates computed on this basis and are given in Table 8.16 below:

TABLE 8.16. RAIL TRANSPORTATION COSTS FOR PELLETS

\begin{tabular}{|c|c|}
\hline Distance & $\begin{array}{c}\text { Estimated Cost } \\
\text { \$/dry ton }\end{array}$ \\
\hline 300 mile & 8.40 \\
\hline 500 mile & 14.00 \\
\hline
\end{tabular}

\subsubsection{Direct-CWF Transportation}

8.4.2.1 Coal-Water Truck Transportation. Transportation of CWF prepared by the Direct-CWF approach required specialized tanker trucks to handle the slurry and protect against freezing. Trucks which are currently used in transporting fuel-oil, were considered 
to be the type suitable for CWF transportation. Based on the fuel oil transportation cost of $\$ 0.304 /$ mile-ton $^{(2)}$ (again in 4th quarter 1991 dollars), estimates for truck transportation of CWF were computed and are given in Table 8.17 below.

TABLE 8.17. TRUCK TRANSPORTATION COSTS FOR CWF

\begin{tabular}{|c|c|}
\hline Distance & $\begin{array}{c}\text { Estimated Cost } \\
\text { \$/ton (dry) }\end{array}$ \\
\hline 10 & 3.04 \\
\hline 50 & 15.20 \\
\hline 100 & 30.40 \\
\hline
\end{tabular}

8.4.2.2 Coal-Water Rail Transportation. For distances greater than 300 miles, transportation via special rail tankers was considered to be more viable than tanker trucks. The estimated transportation costs for slurries in rail tankers was $\$ 0.11 /$ ton-mile ${ }^{(3)}$ (4th quarter 1991 dollars). The estimated costs are presented in Table 8.18 below.

TABLE 8.18. RAIL TRANSPORTATION COSTS FOR CWF

\begin{tabular}{|c|c|}
\hline $\begin{array}{c}\text { Distance } \\
\text { (miles) }\end{array}$ & $\begin{array}{c}\text { Estimated Cost } \\
\text { \$/ton (dry) }\end{array}$ \\
\hline 300 & 33 \\
\hline 500 & 55 \\
\hline
\end{tabular}

Neither the type of coal, binder, or pelletization technique should affect the transportation costs noted above. Therefore, the cost could be used for any coal and pellet type.

Figure 8.17 presents a comparison of transportation cost for the two approaches. In both the rail and truck modes, there was a clear advantage in adopting the Pellet-CWF approach. As distance increased, the Pellet-CWF approach became more attractive. 


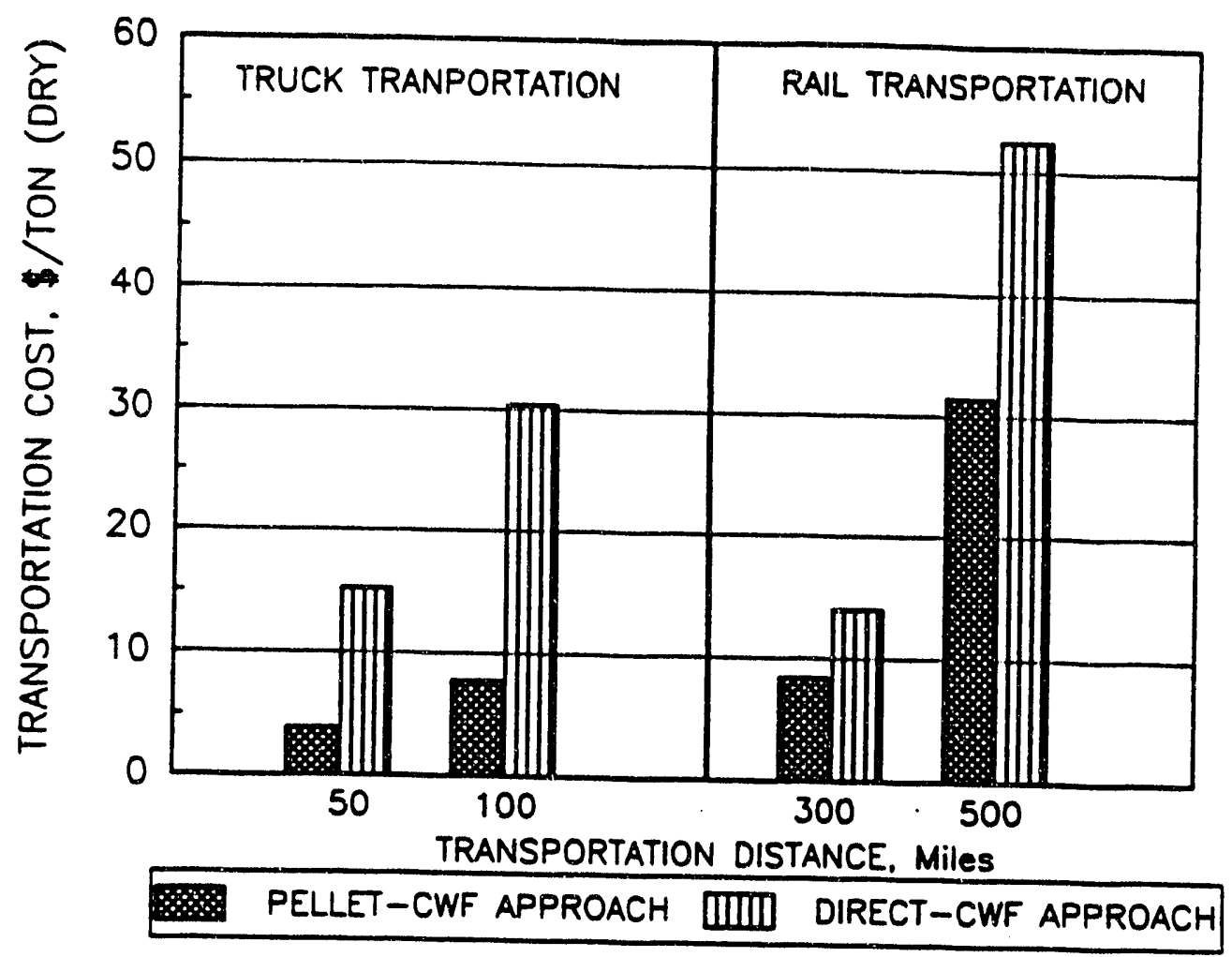

FIGURE 8.17. COMPARISON OF TRANSPORTATION COST FOR PELLETCWF AND DIRECT-CWF APPROACHES 


\subsubsection{Handling and Storage Cost for Pellet-CWF}

In the storage evaluation study conducted in this project various pellet storage modes were examined. The modes studied included:

- $\quad$ Exposed-outdoor

- $\quad$ Covered-outdoor

- Silo, and

- Bag.

The major conclusion of this study was that pellet storage mode was dictated primarily by the binder used. Shur Bond- and corn starch-bound coal pellets survived short-term exposedoutdoor mode, but lignin sulfonate-bound pellets were not suitable for exposed-outdoor storage. All the pellets survived the covered-outdoor, silo and bag type storage. Economics suggests that exposed-outdoor and covered-outdoor modes would be the most cost-effective. Therefore cost estimates for only these storage modes were computed. In the pellet-to-slurry approach, the user's CWF production capacity controls the storage capacity. A 5-day reserve storage was selected for the purpose of design. Thus, for users with 2,10 , or 50 TPD slurries production facility, pellet storage facility of 10,50 , or 250 ton was recommended.

For an exposed-outdoor storage mode, a concrete pad, and for exposed-covered, a covered concrete pad (pole barn) was recommended. In the handling operation, all coal pellets are expected to be moved in and out of storage to utilization with a frontend loader. An estimate of storage and handling cost for coal pellets is provided in Table 8.19.

\subsubsection{Handling and Storage Cost for Direct-CWF}

In the direct-CWF approach, where CWF is prepared at the beneficiation site and delivered to users via trucks, capital cost for a storage facility is considerably higher. Since much of the annual operating cost is dependent on the depreciation cost-element, the storage and handling costs were expected to be higher for the direct-CWF approach. 
TABLE 8.19. HANDLING AND STORAGE COST FOR PELLET-CWF APPROACH

\begin{tabular}{|c|c|c|c|c||}
\hline \multirow{2}{*}{$\begin{array}{c}\text { Slurry User } \\
\text { Capacity }\end{array}$} & \multirow{2}{*}{$\begin{array}{c}\text { Total Storage } \\
\text { Capacity } \\
\text { ton/day) }\end{array}$} & (Dry ton) & \multirow{2}{*}{$\begin{array}{c}\text { Storage Area } \\
\text { sq. ft. }\end{array}$} & \multicolumn{2}{|c|}{$\begin{array}{c}\text { Storage and Handling Cost } \\
\text { \$/ton (dry) }\end{array}$} \\
\cline { 4 - 5 } & & & Exposed-Outdoor & Covered-Outdoor \\
\hline 2 & 10 & 100 & 0.40 & 0.46 \\
\hline 10 & 50 & 500 & 0.17 & 0.23 \\
\hline 50 & 250 & 2,500 & 0.11 & 0.17 \\
\hline
\end{tabular}

Assuming a 5-day reserve is necessary at the user's site, the CWF handling and storage costs were estimated and are presented in Table 8.20.

TAELE 8.20. HANDLING AND STORAGE COST FOR DIRECT-CWF APPROACH

\begin{tabular}{|c|c|c|}
\hline $\begin{array}{c}\text { Utilization Capacity } \\
\text { (dry tons/day) }\end{array}$ & $\begin{array}{c}\text { Storage Capacity } \\
\text { (dry-ton) }\end{array}$ & $\begin{array}{c}\text { Estimated Handling and } \\
\text { Storage Cost } \\
\text { \$/ton dry }\end{array}$ \\
\hline 2 & 10 & 2.08 \\
\hline 10 & 50 & 1.06 \\
\hline 50 & 250 & 0.84 \\
\hline
\end{tabular}

Figure 8.18 presents a comparison of all the estimated handling and storage costs. The Pellet-CWF approach has a clear economic advantage in terms of coal handling and storage costs.

\subsection{Comparison of CWF Production Approaches}

The two approaches can be best compared when the total production cost estimates (i.e., operating cost plus amortization of capital costs) are reviewed. The total annualized costs were estimated for the following two approaches: 


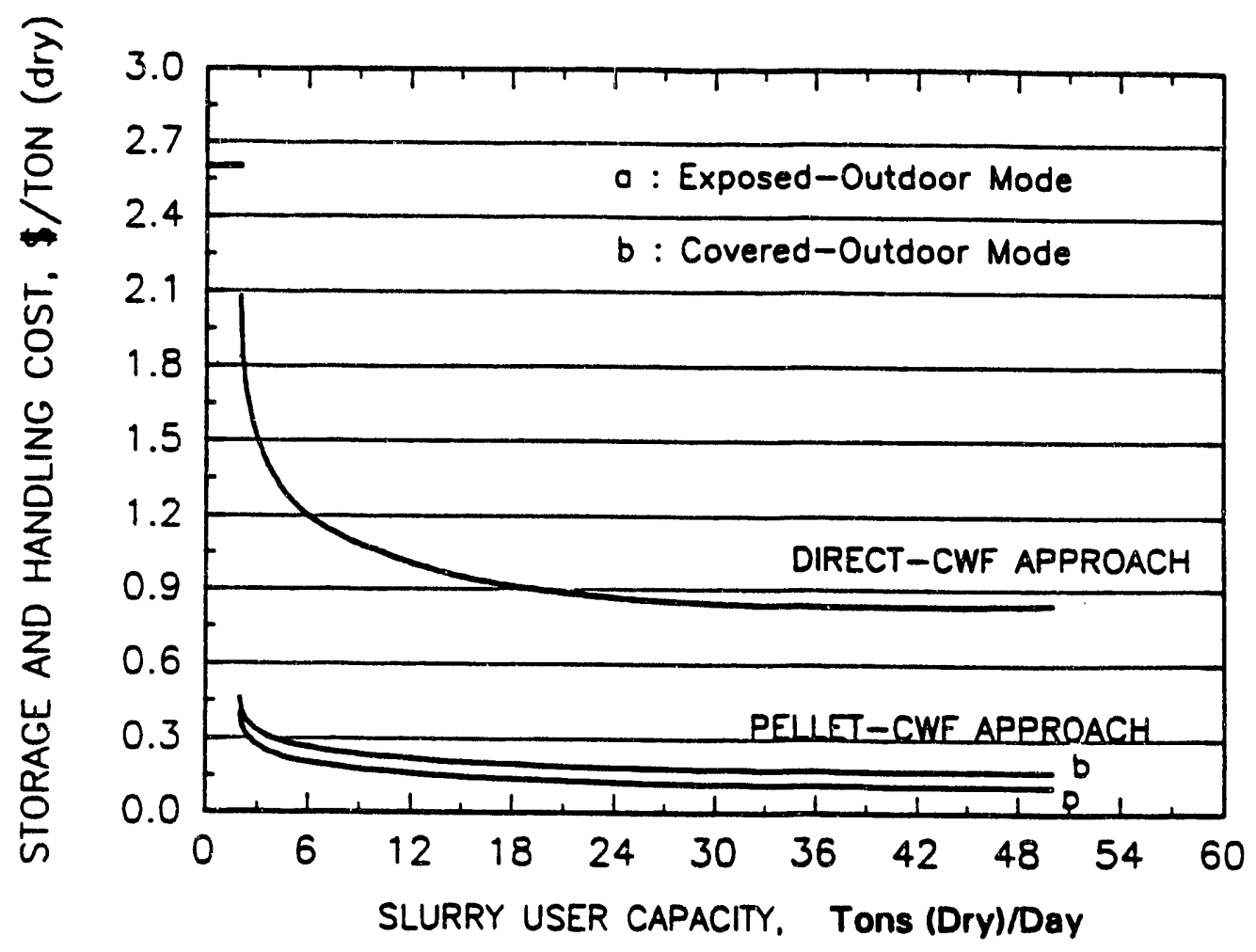

FIGURE 8.18 COMPARISON OF STORAGE AND HANDLING COSTS FOR PELLET-CWF AND DIRECT-CWF APPROACHES 
(1) Pellet-CWF Approach: The total cost incudes the operating cost plus capital amortization for pelletization, transportation, storage and handling, and reslurrying of the pellets.

(2) Direct-CWF Approach: The total cost includes the operating and amortization costs for formulation of filter-cake into slurry, transportation, storage and handling of the CWF.

\subsubsection{Pellet-CWF Approach}

Pelletization and reslurrying cost estimates discussed in previous sections, represent a comprehensive summary of the effect of parameters such as plant size, binder type, coal type, dispersant additives, etc. on the respective operating costs. Similarly, storage and transportation costs were also evaluated as a function of mode and distance. Total production cost estimate computation for all the possible combinations is simpiy a numerical addition, which can be expressed as:

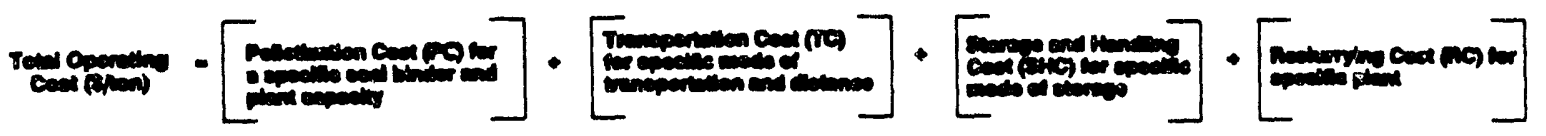

This will invariably present several possible combinations of PC, TC, SHC, and RC factors. In order to present the economics of the Pellet- CWF approach in a concise manner, estimates for only those combinations that have an impact on assessing the viability of the approach are presented. From earlier discussions presented on each of the cost factors, i.e., pelietization, transportation, etc., we were aware of the process conditions that favored economic viability. Thus, for example, in the pelletization process the overall-operating cost is insensitive to plant size for capacities $>500$ ton/day. Based on similar logic, a decision diagram was prepared and is presented in Figure 8.19 This figure was used to select the process conditions which hold promise for future implementation. 


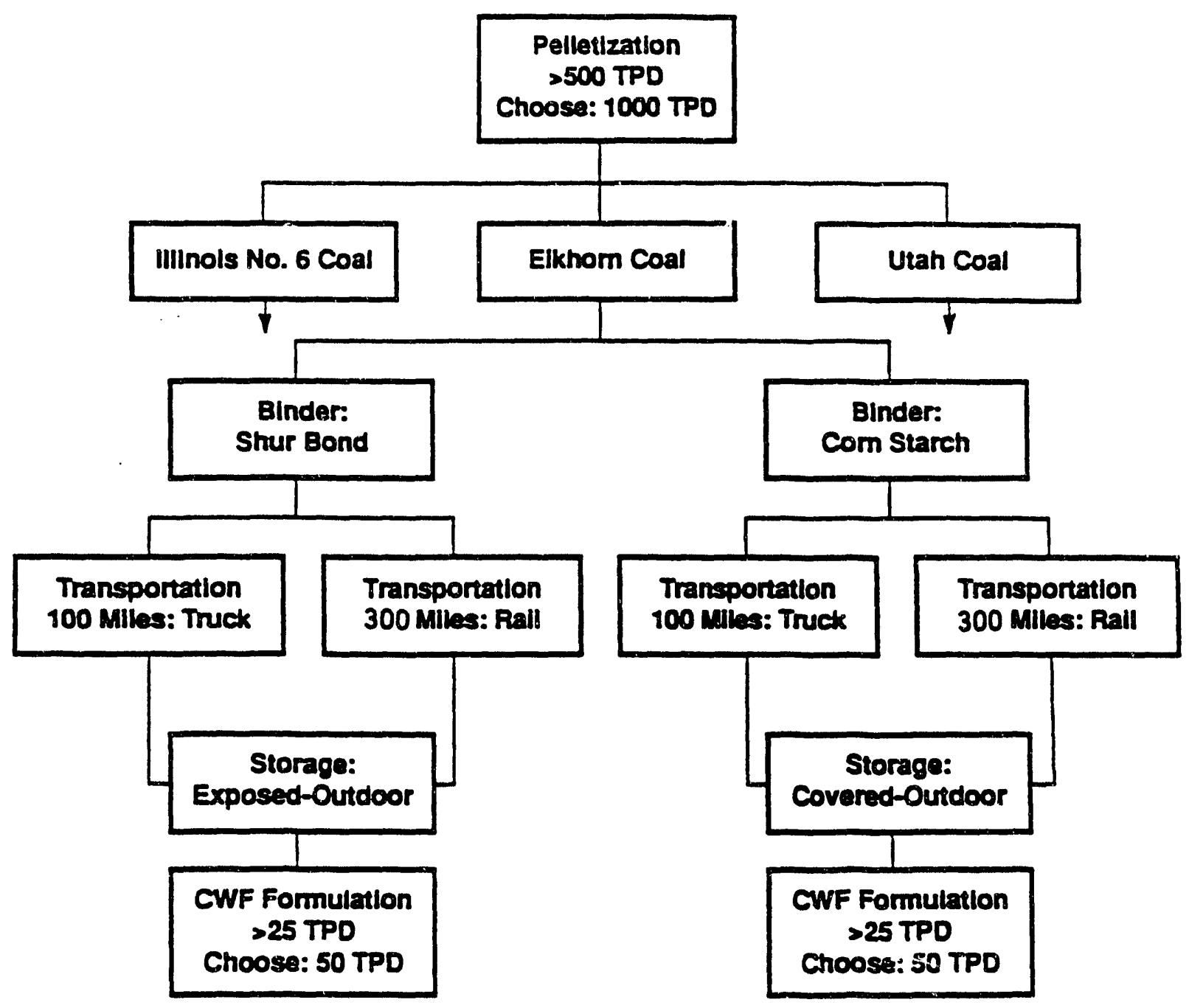

FIGURE 8.19. FLOW DIAGRAM TO ESTIMATE TOTAL OPERATING COST FOR THE PELLET-CWF APPROACH 
Total production cost estimates for the schemes outlined in Figure 8.19 presented above were computed. Tables 8.21 and 8.22 present the data for 100 and 300 miles of pellet transportation, respectively. The data presented in the tables correspond to processing Elkhorn coal. In both the 100 mile and 300 mile cases, a product from roller-and-die pelletization was consistently the lowest cost. Similar data with Illinois No. 6 and Utah coal are presented in Tables 8.23 through $\mathbf{8 . 2 6}$.

\subsubsection{Direct-CWF Approach}

Discussions on econumics of direct-CWF approach presented earlier indicate that CWF formulation at $>500$ TPD is economically attractive. A ciscisior, diagram representing optimized conditions of CWF formulation, transportation and storage/handling was prepared and is presented in Figure 8.20. Cost estimates, based on the flow sheet were computed and are presented for the three coals in Table 8.27 and $\mathbf{8 . 2 8}$ for 100 mile and 300 mile transportation, respectively. Figure 8.21 presents a comparison of the two CWF preparation approaches for Elkhom coal. The Pellet-CWF approach is clearly seen as the most economical route for CWF preparation from the beneficiated Flkhorn coal. Similar analysis with Illinois and Utah coal is presented in Figures 8.22 nd 8.23, respectively.

\subsubsection{Sensitivity Analysis}

Several parameters were identified which impact the estimated annualized cost for the two approaches. However, the parameters that were most critical were plant size and transportation distance. In the previous section, we have seen that as the plant size increased the total cost of CWF production decreased. Even more important, however, was transportation distance. As the distance the coal-water slurry must be transported increased, the total cost increased. The rise in transportation related costs was much more pronounced in the Direct-CWF approach thereby clearly favoring the Pellet-CWF approach. As noted in 


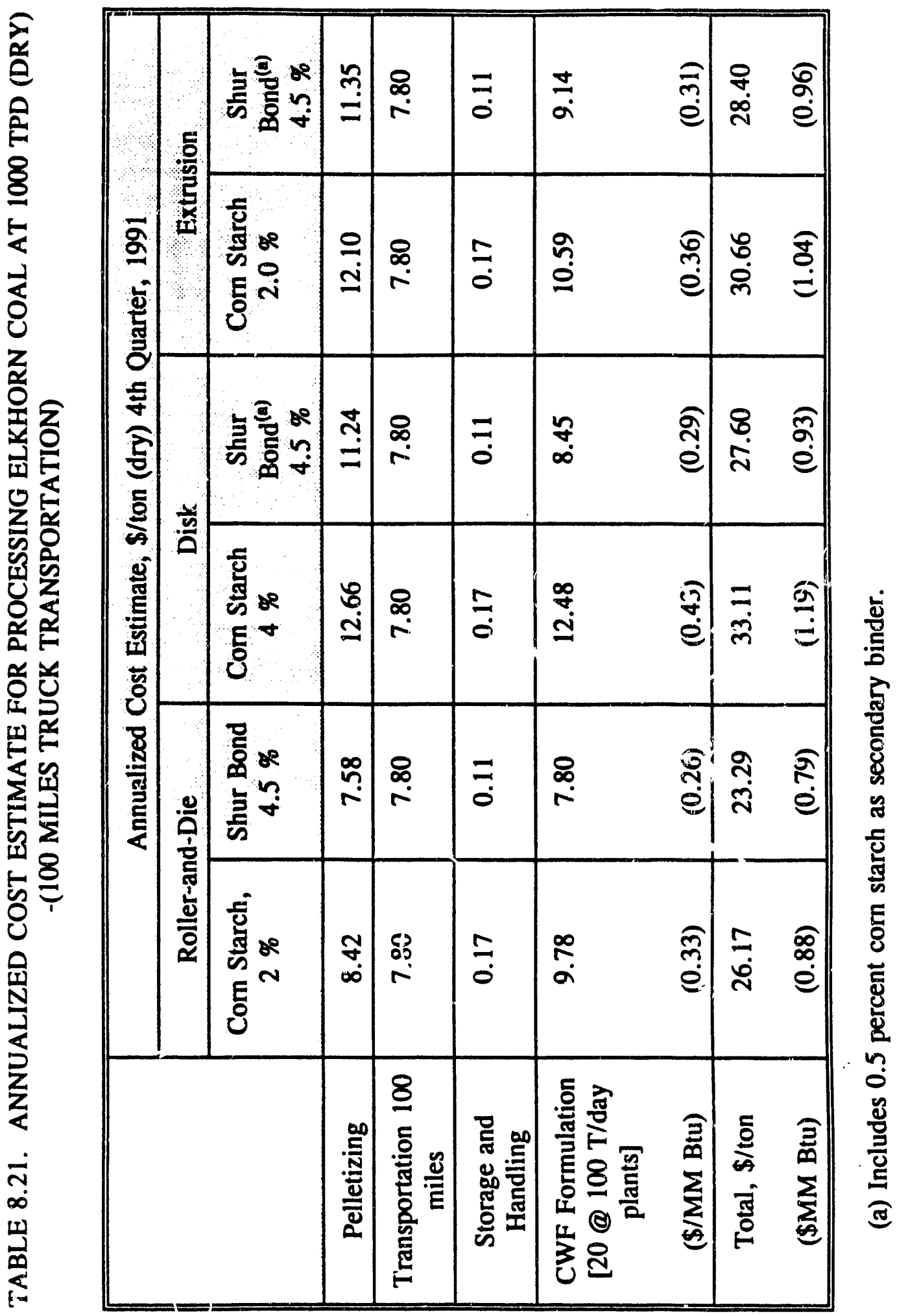




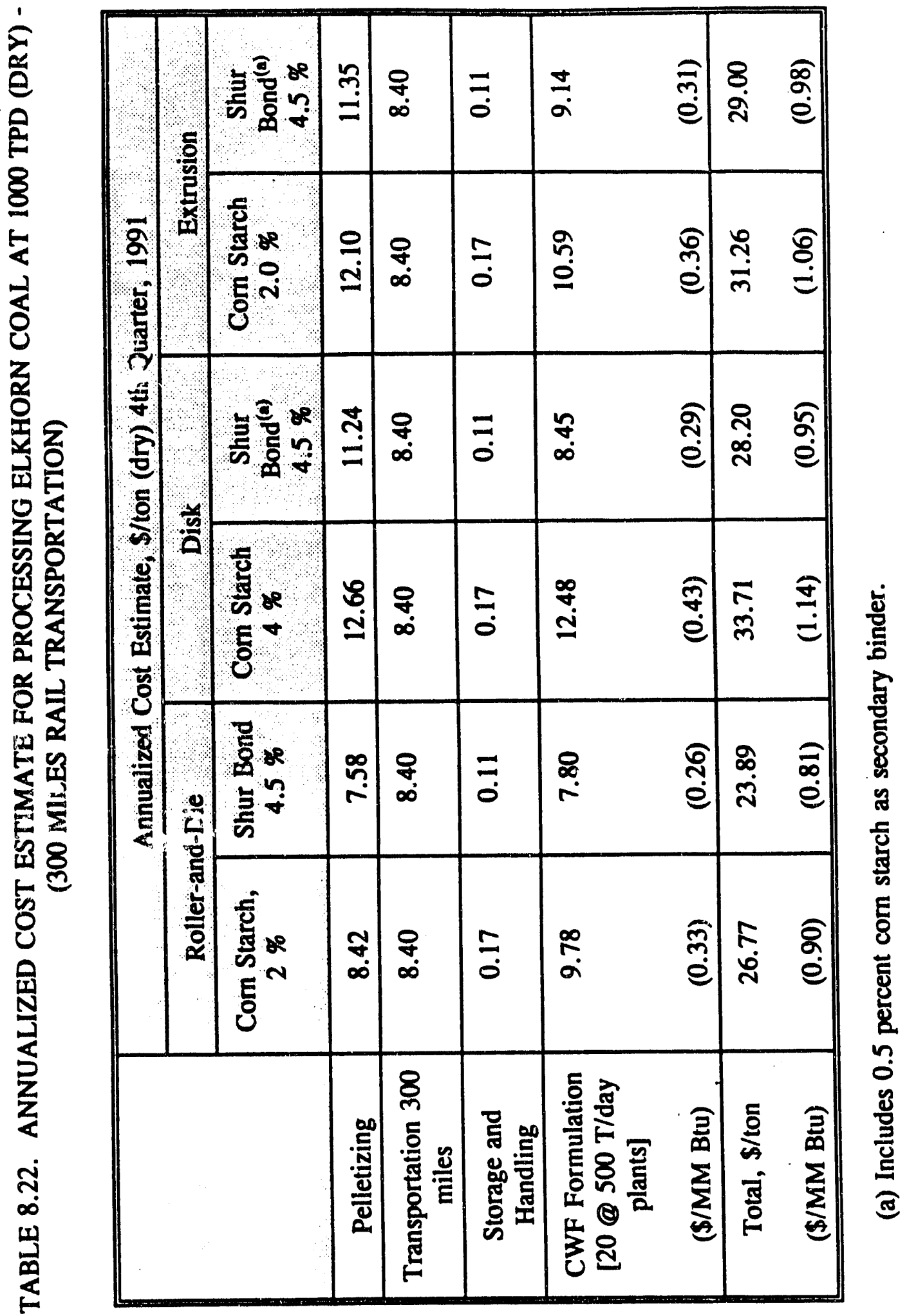




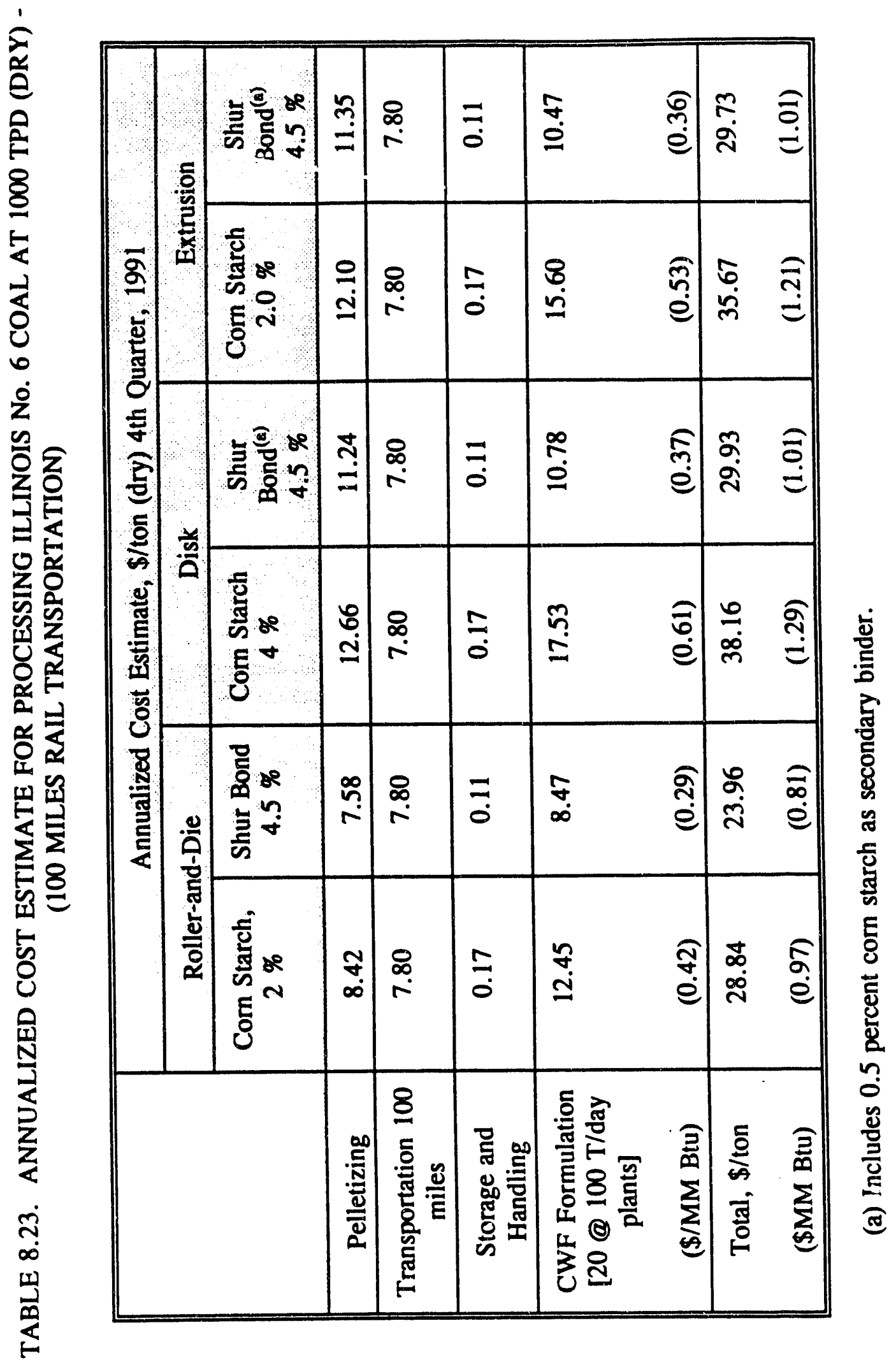


202

8

อิ

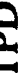

8

4

8

6

¿

ํㅡㄹ

글

苯

\begin{tabular}{|c|c|c|c|c|c|c|c|c|c|}
\hline \multirow{4}{*}{ 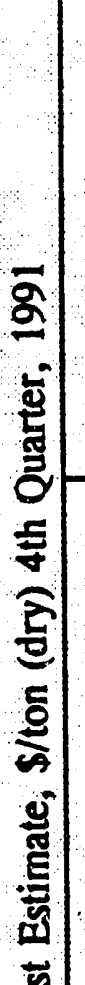 } & \multirow{2}{*}{ ह5 } & 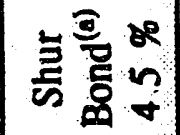 & $\stackrel{\sim}{\stackrel{\Xi}{=}}$ & $\underset{\infty}{\stackrel{P}{\infty}}$ & $\overline{0}$ & $\begin{array}{l}\text { f̊ } \\
\stackrel{0}{0}\end{array}$ & 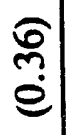 & 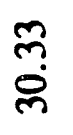 & $\stackrel{\widehat{8}}{=}$ \\
\hline & & $\begin{array}{l}\overline{5} \\
5 \\
5 \\
5 \\
\text { E } \\
\tilde{8}\end{array}$ & $\begin{array}{c}0 \\
\simeq\end{array}$ & $\underset{\infty}{\stackrel{\infty}{+}}$ & $\frac{5}{0}$ & $\begin{array}{l}80 \\
\underline{n} \\
.\end{array}$ & $\begin{array}{l}\tilde{\tilde{n}} \\
\stackrel{e}{0}\end{array}$ & $\begin{array}{c}\text { స్ } \\
\text { D্ }\end{array}$ & $\stackrel{\widetilde{N}}{=}$ \\
\hline & & 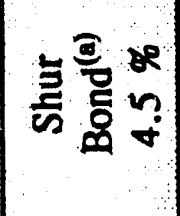 & $\stackrel{\mathbb{N}}{=}$ & $\underset{\infty}{\stackrel{+}{0}}$ & $\overline{0}$ & $\begin{array}{l}\stackrel{\infty}{\leftarrow} \\
\stackrel{0}{0}\end{array}$ & 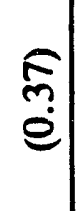 & $\begin{array}{l}\tilde{n} \\
\text { on }\end{array}$ & $\stackrel{\widehat{\delta}}{\Xi}$ \\
\hline & & $\begin{array}{l}\bar{s} \\
\overline{5} \\
\frac{E}{\delta}\end{array}$ & $\begin{array}{l}8 \\
\stackrel{8}{9}\end{array}$ & $\underset{\infty}{q}$ & $\frac{5}{0}$ & $\stackrel{n}{\check{n}}$ & $\begin{array}{l}\hat{\bar{b}} \\
\dot{e}\end{array}$ & $\begin{array}{l}R \\
\infty \\
\infty\end{array}$ & 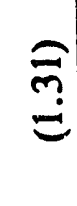 \\
\hline
\end{tabular}

政

颌ฐ

도 도

빈묘

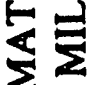

हृ

号

$\frac{1}{2}$

i்

मे

\&

焉

응

紊

$+$

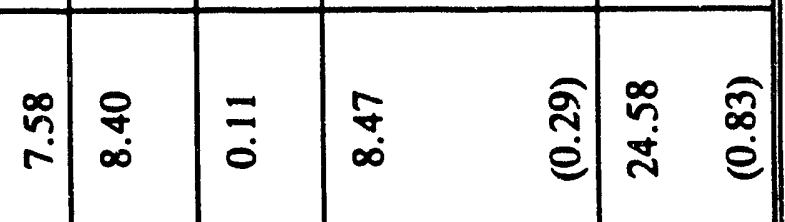

놀

디

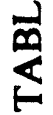

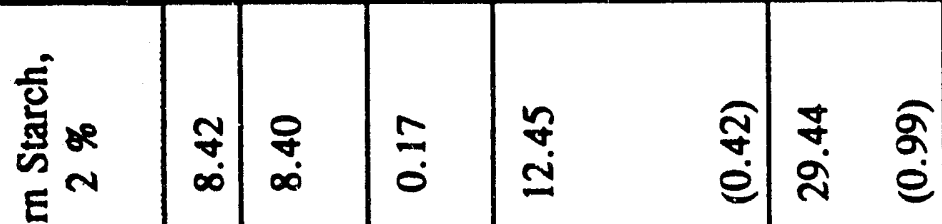

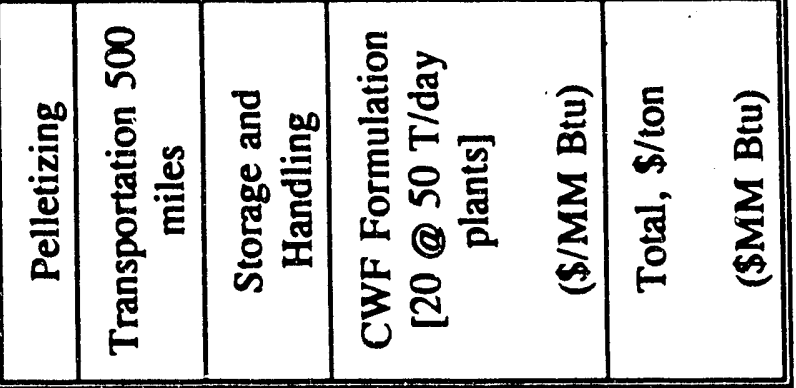

공

ร

氧

E

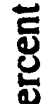

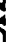

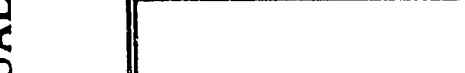




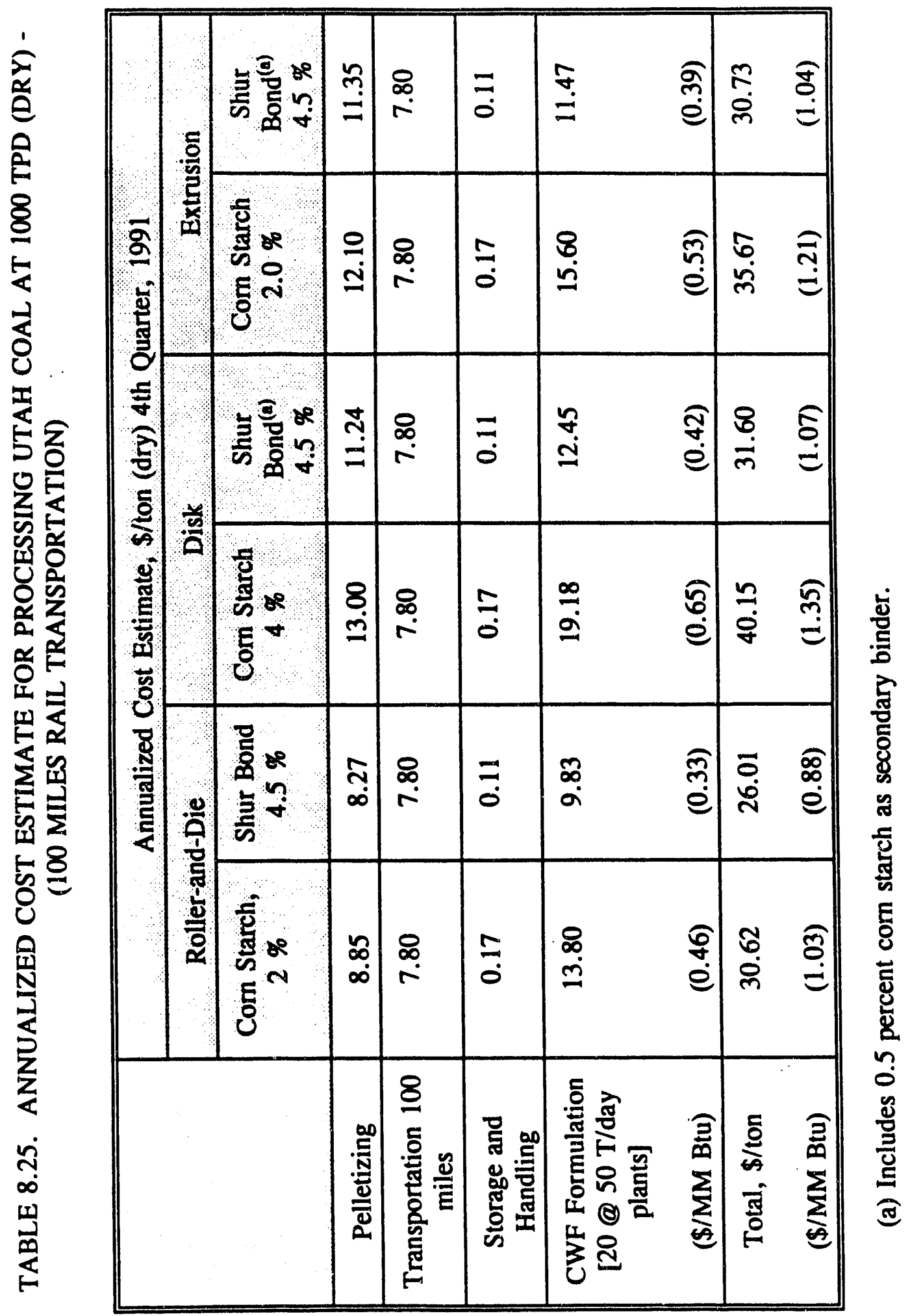




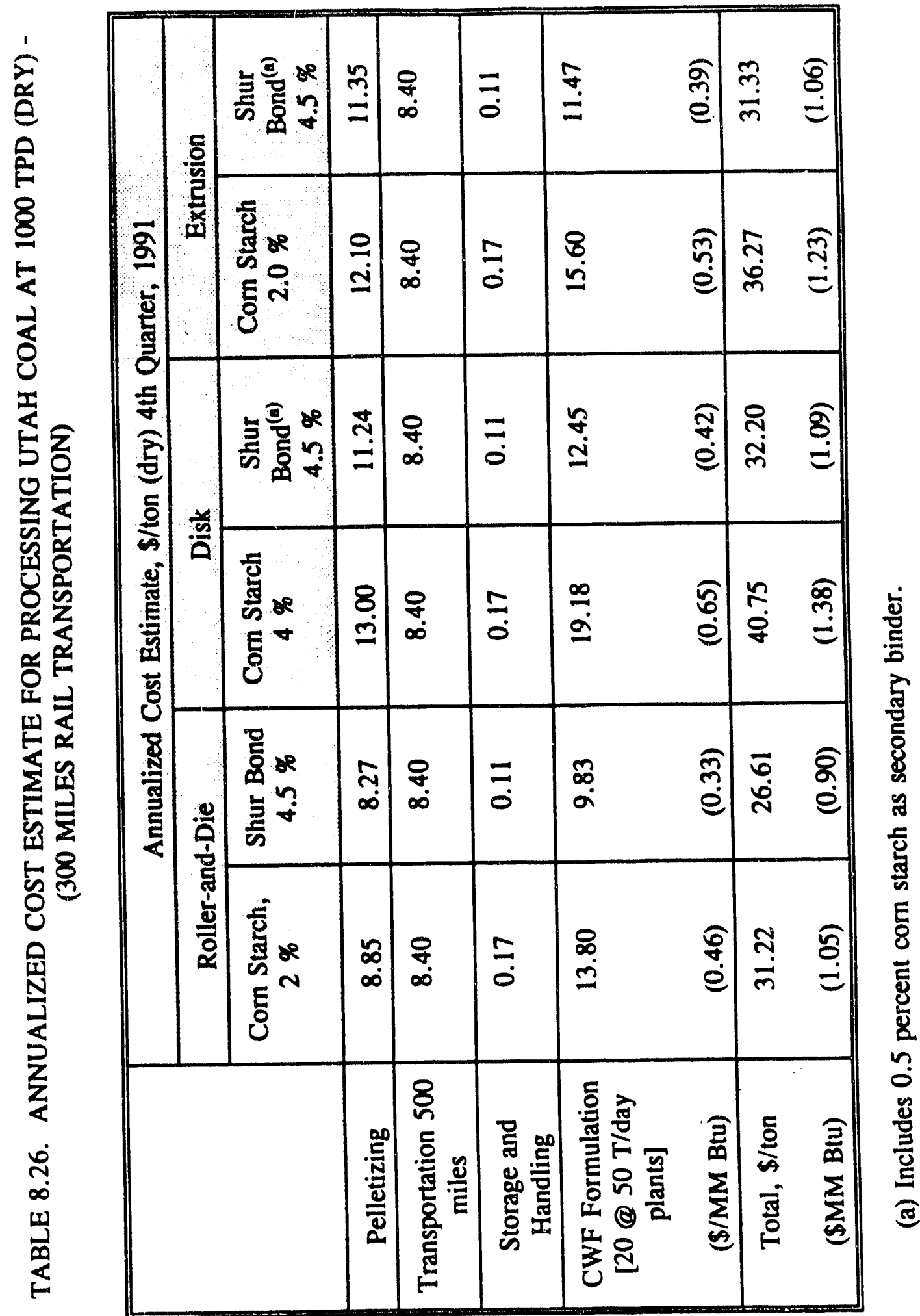




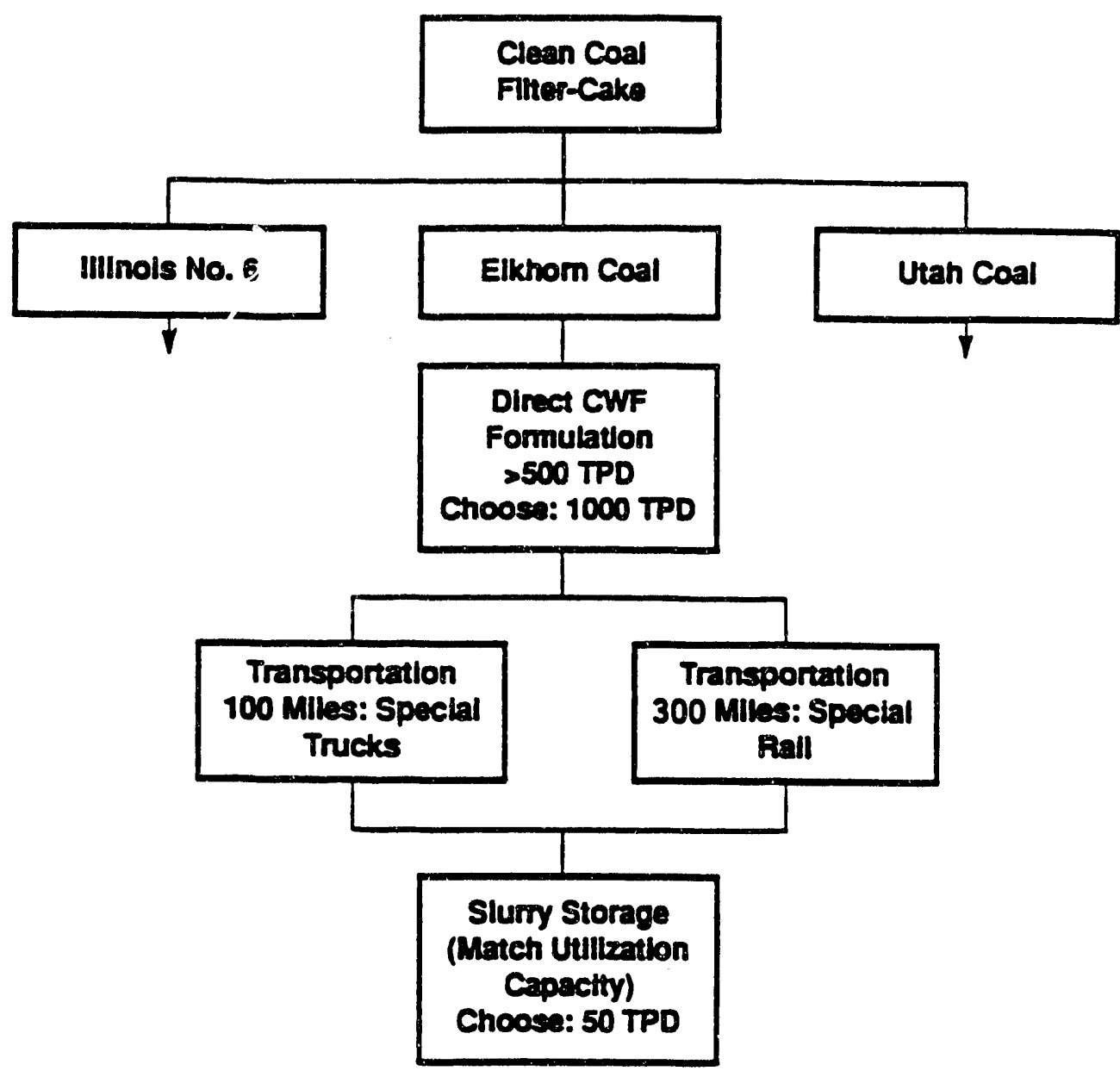

FIGURE 8.20. FLOW DIAGRAM TO ESTIMATE TOTAL ANNUALIZED COST FOR THE DIRECT-CWF APPROACH 
TABLE 8.27. ANNUALIZED COST ESTIMATE FOR DIRECT-CWF APPROACH FOR A 1000 TPD (DRY)- [100 MILES TRUCK TRANSPORTATION]

\begin{tabular}{|c|c|c|c||}
\hline \multirow{2}{*}{} & \multicolumn{3}{|c|}{ Annualized Cost Estimate, \$/ton (dry) 4th } \\
& Euarter, 1991 \\
\cline { 2 - 4 } & Elkhorn & Illinois No. 6 & Utah \\
\hline CWF Formulation & 23.09 & 16.89 & 16.71 \\
\hline $\begin{array}{c}\text { Transportation 100 } \\
\text { miles }\end{array}$ & 30.40 & 30.40 & 30.40 \\
\hline $\begin{array}{c}\text { Storage and } \\
\text { Handling }\end{array}$ & 0.84 & 0.84 & 0.84 \\
\hline $\begin{array}{c}\text { Total, \$/ton } \\
\text { (\$/MM Btu) }\end{array}$ & 54.33 & 48.13 & 47.95 \\
\hline
\end{tabular}

TABLE 8.28. ANNUALIZED COST ESTIMATE FOR DIRECT-CWF APPROACH FOR A 1000 TPD (DRY)- [300 MILES RAIL TRANSPORTATION]

\begin{tabular}{|c|c|c|c|}
\hline & \multicolumn{3}{|c|}{ Annualized Cost Estimate, \$/ton (dry) 4th } \\
& Quarter, 199.1 & \multicolumn{3}{|c|}{} \\
\cline { 2 - 4 } & Elkhorn & mlinois No. 6 & Utah \\
\hline CWF Formulation & 23.09 & 16.89 & 16.71 \\
\hline $\begin{array}{c}\text { Transportation 300 } \\
\text { miles }\end{array}$ & 33.00 & 33.00 & 33.00 \\
\hline $\begin{array}{c}\text { Storage and } \\
\text { Handling }\end{array}$ & 0.84 & 0.84 & 0.84 \\
\hline $\begin{array}{c}\text { Total, \$/ton } \\
\text { (\$/MM Btu) }\end{array}$ & 56.93 & 50.73 & 50.55 \\
\hline
\end{tabular}




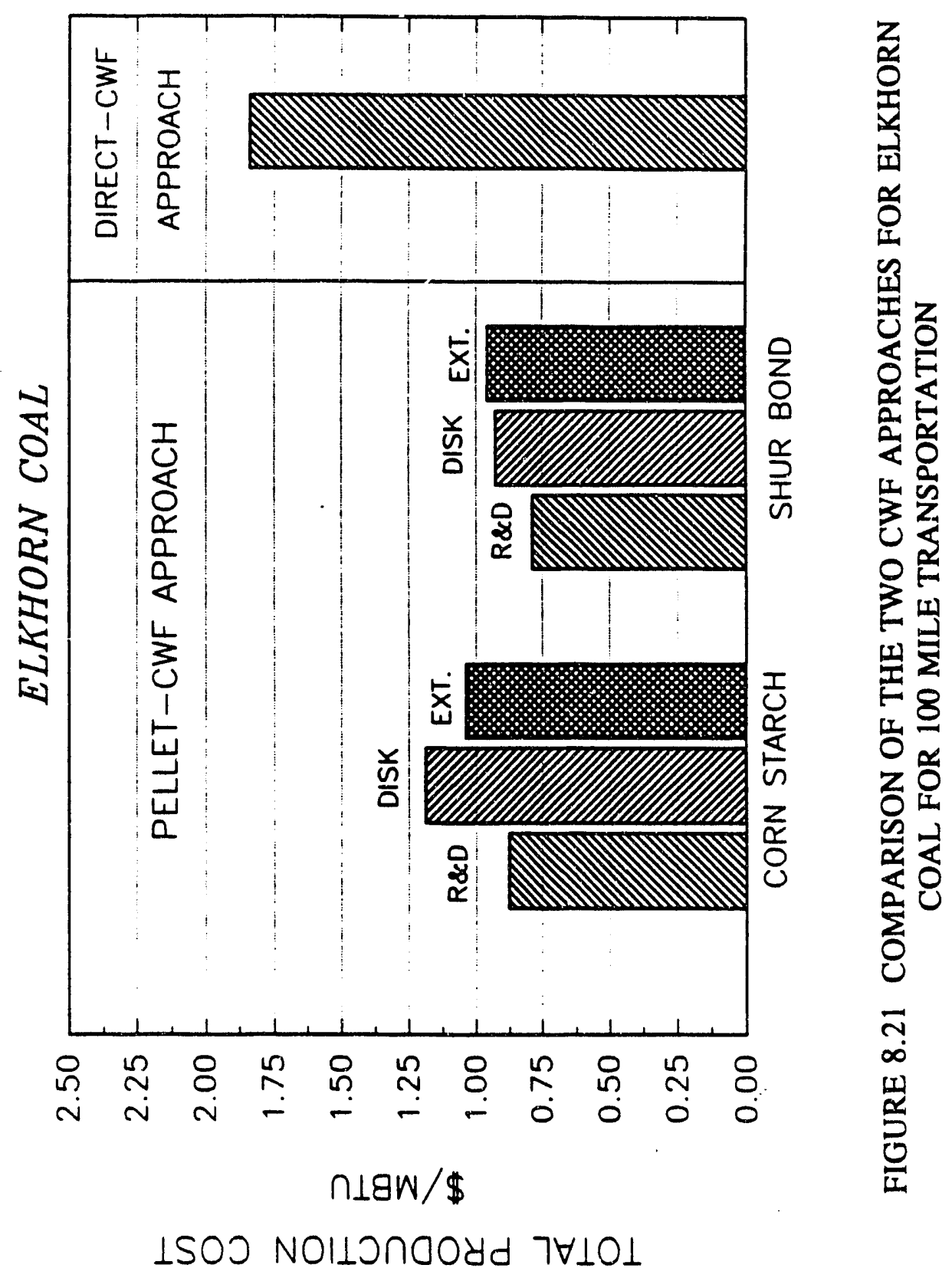




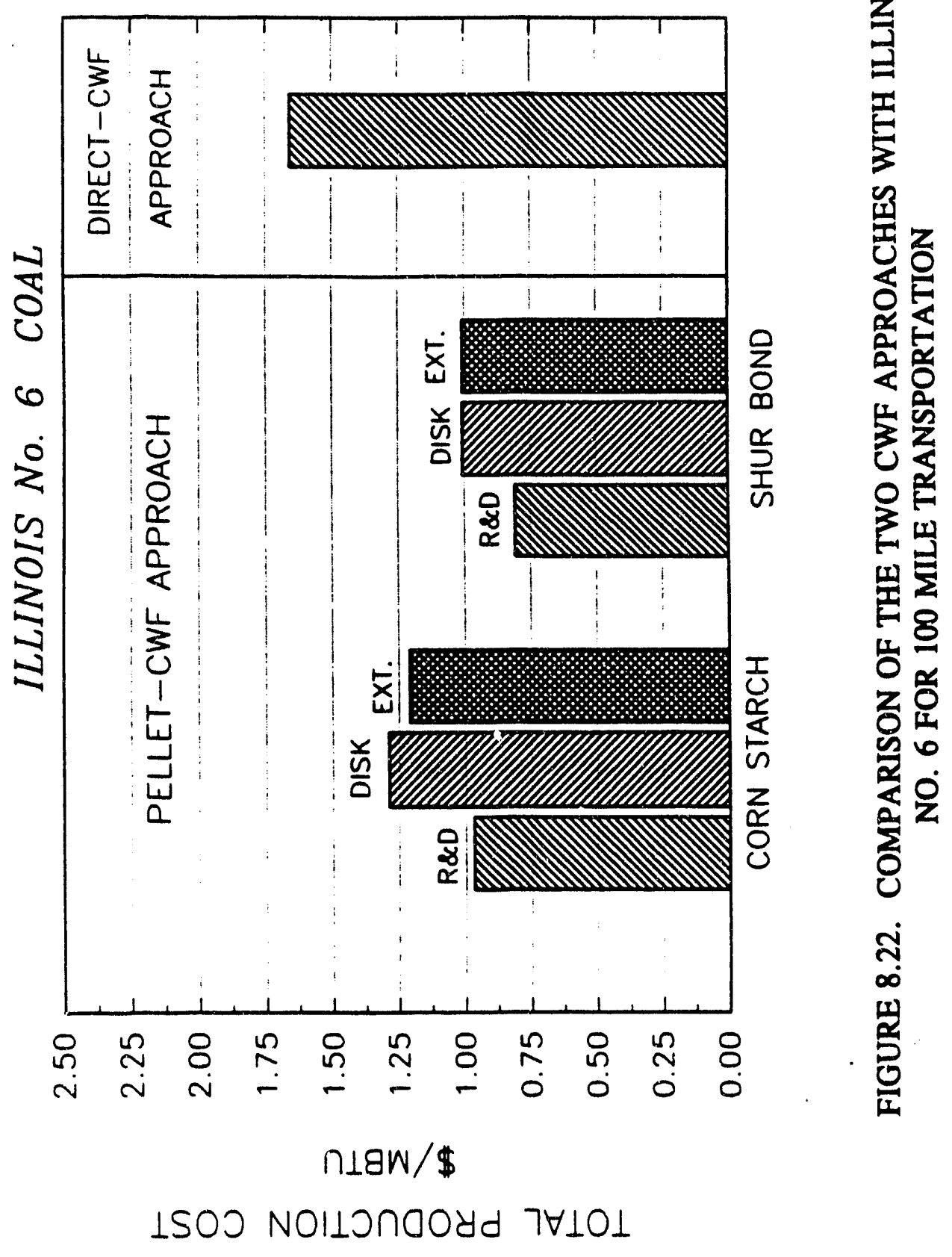




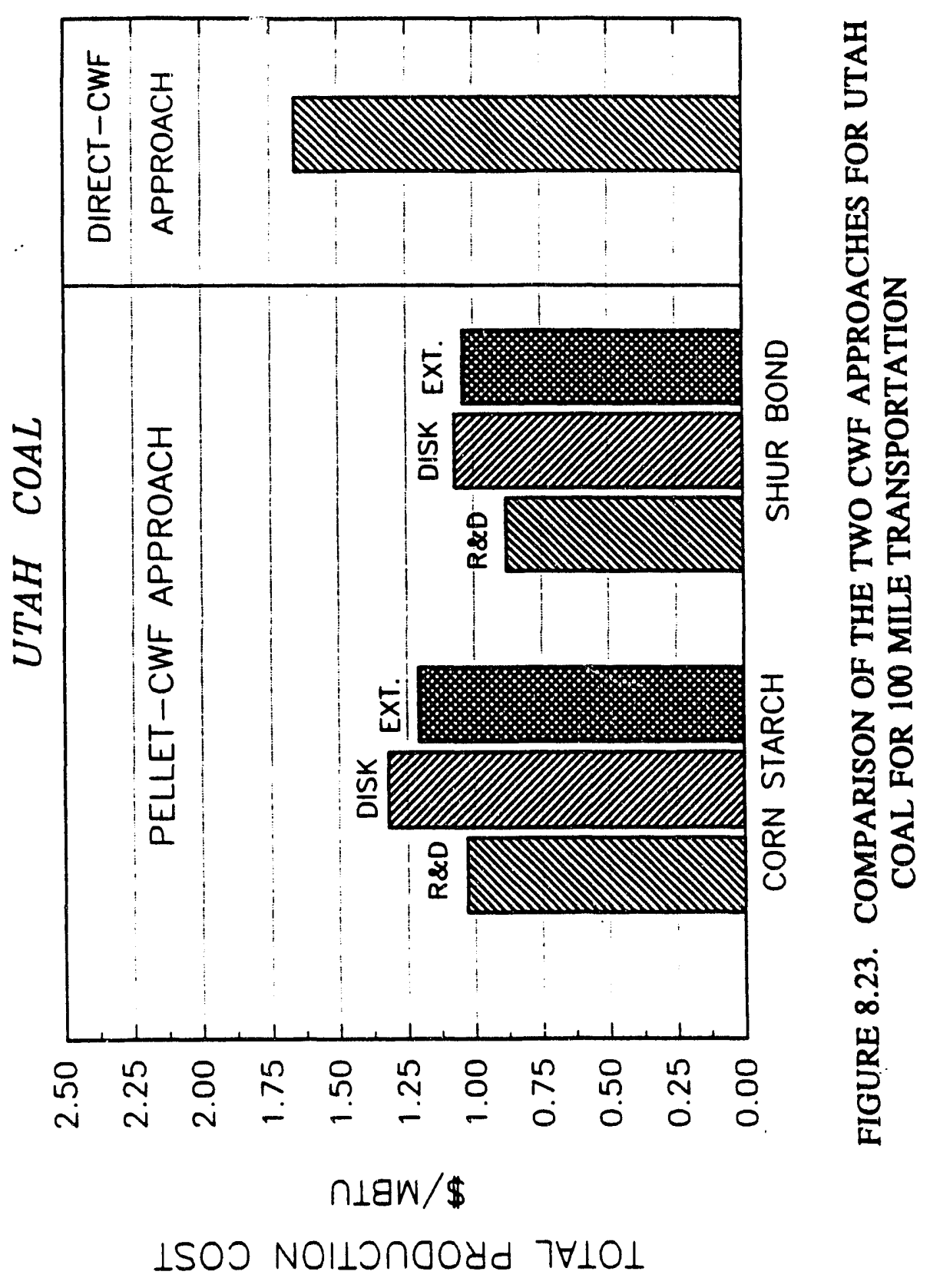


Figure 8.24 there was a definite break point. Beyond about 20 truck miles the costs favor the Pellet-CWF approach. This relationship is shown for the Elkhorn coal pelletized by the roller-and-die technique, for corn starch and Shur Bond bound pellets. The comparison is presented for both the truck and rail transportation modes.

Clearly, for the Elkhorn coal the Pellet-CWF approach was shown to be more economical for any distance of transportation. Similar comparison for Illinois No. 6 coal and Utah coal, presented in Figures 8.25 and 8.26, also favor the Pellet-CWF concept for distances greater than approximately 20 miles. Around this transition point (i.e., 20 miles), the total annualized cost for both the approaches are almost identical.

Based on the cost estimation evaluation conducted, the following was concluded:

- Pellet-CWF approach was found to be an economical method for the efficient handling, transporting and storing the beneficiated clean coal.

- Among the three pelletization processes, the roller-and-die technique had the lowest annualized cost for all three coals. It was also estimated that for plant sizes greater than 500 TPD the pelletization processes were econsmical.

- Annualized cost for CWF formulation was strongly influenced by the amount of reslurrying additives required. For the Pellet-CWF approach, the formulation cost was found to be more economic for CWF plant sizes greater than 25 TPD.

- Transportation distance was a major variable that strongly impacted the total production cost. In the Pellet-CWF approach the pellets were handled like lump coal, resulting in a significantly lower transportation cost.

- Estimated pelletization, handling, storage, transportation (100 miles), and reslurrying costs for Elkhorn coal bound with Shur Bond binder was (\$0.79/MM Btu total) exclusive of coal costs.

- Estimated direct CWF formulation, handling, storage, transportation (100 miles) costs for Elkhorn coal was (\$1.83/MM Btu) exclusive of coal costs. The Pellet-CWF approach became even more attractive as transportation distances increased. 

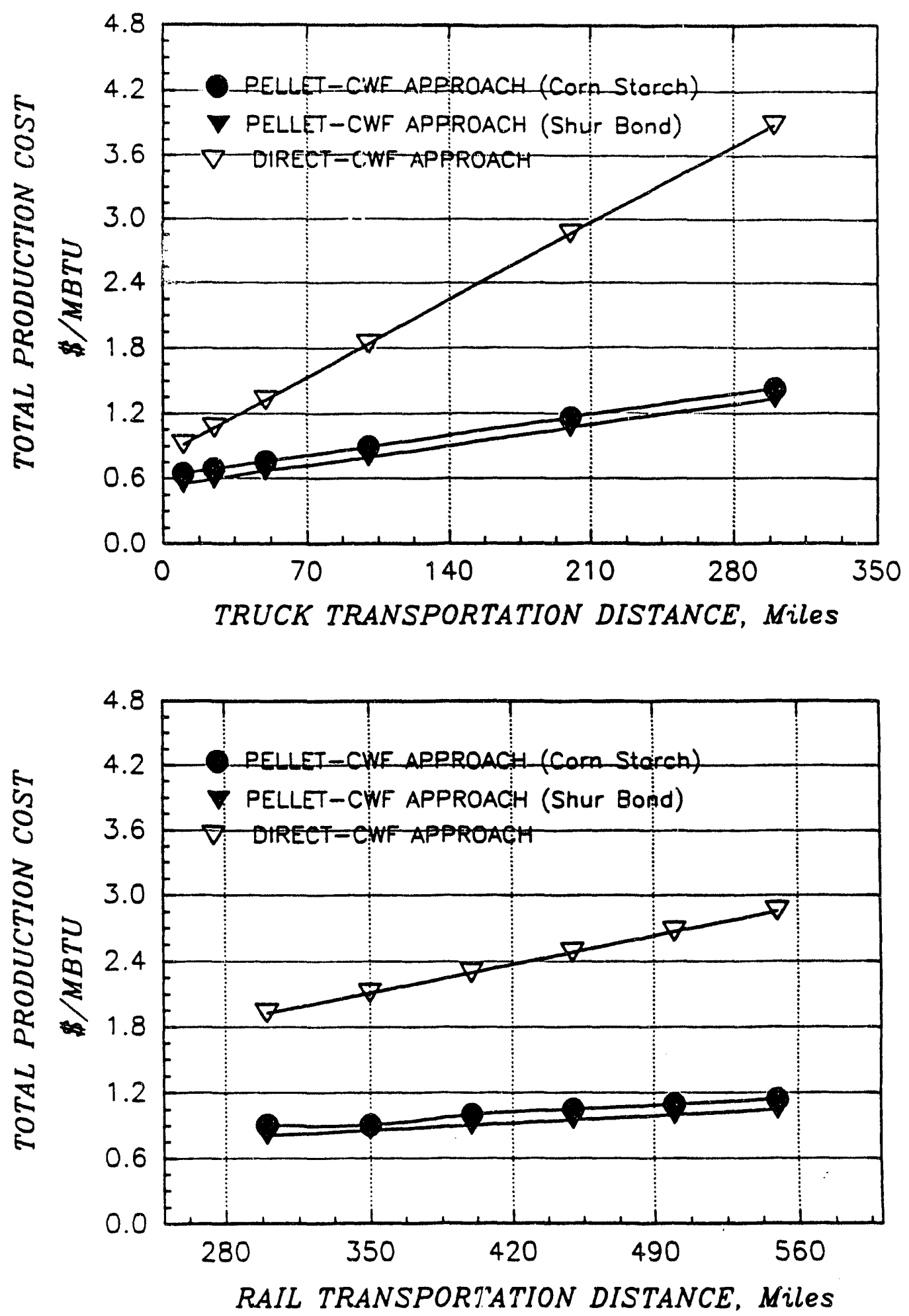

FIGURE 8.24. TOTAL ANNUALIZED COST COMPARISON FOR THE TWO APPROACHES AS A FUNCTION OF TRANSPORTATION DISTANCE FOR ELKHORN COAL PELLETS FROM ROLLER-AND-DIE PELLETIZATION 
212
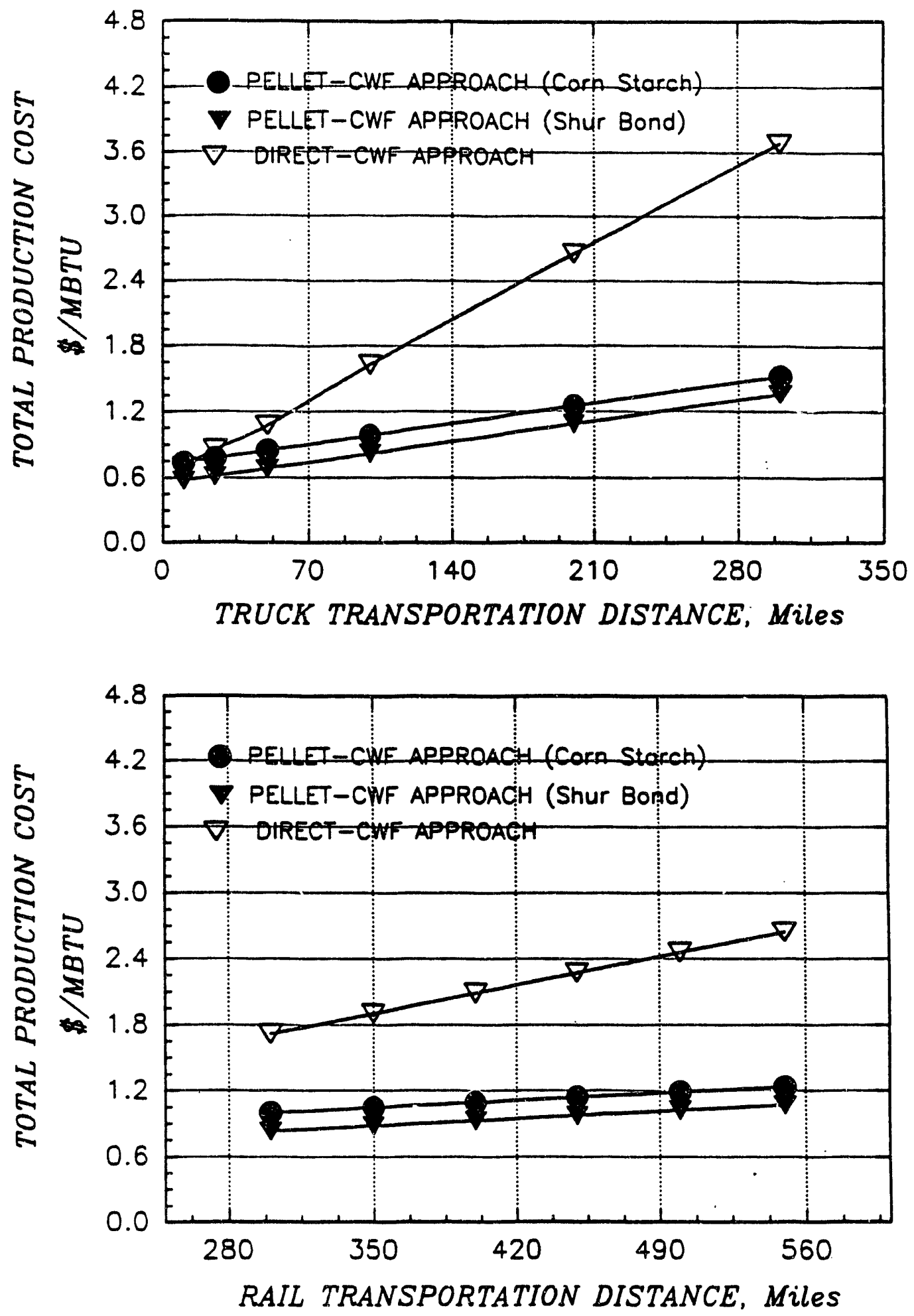

FIGURE 8.25. TOTAL ANNUALIZED COST COMPARISON FOR THE TWO APPROACHES AS A FUNCTION OF TRANSPORTATION DISTANCE FOR ILLINOIS No. 6 COAL PELLETS FROM ROLLER-AND-DIE PELLETIZATION 

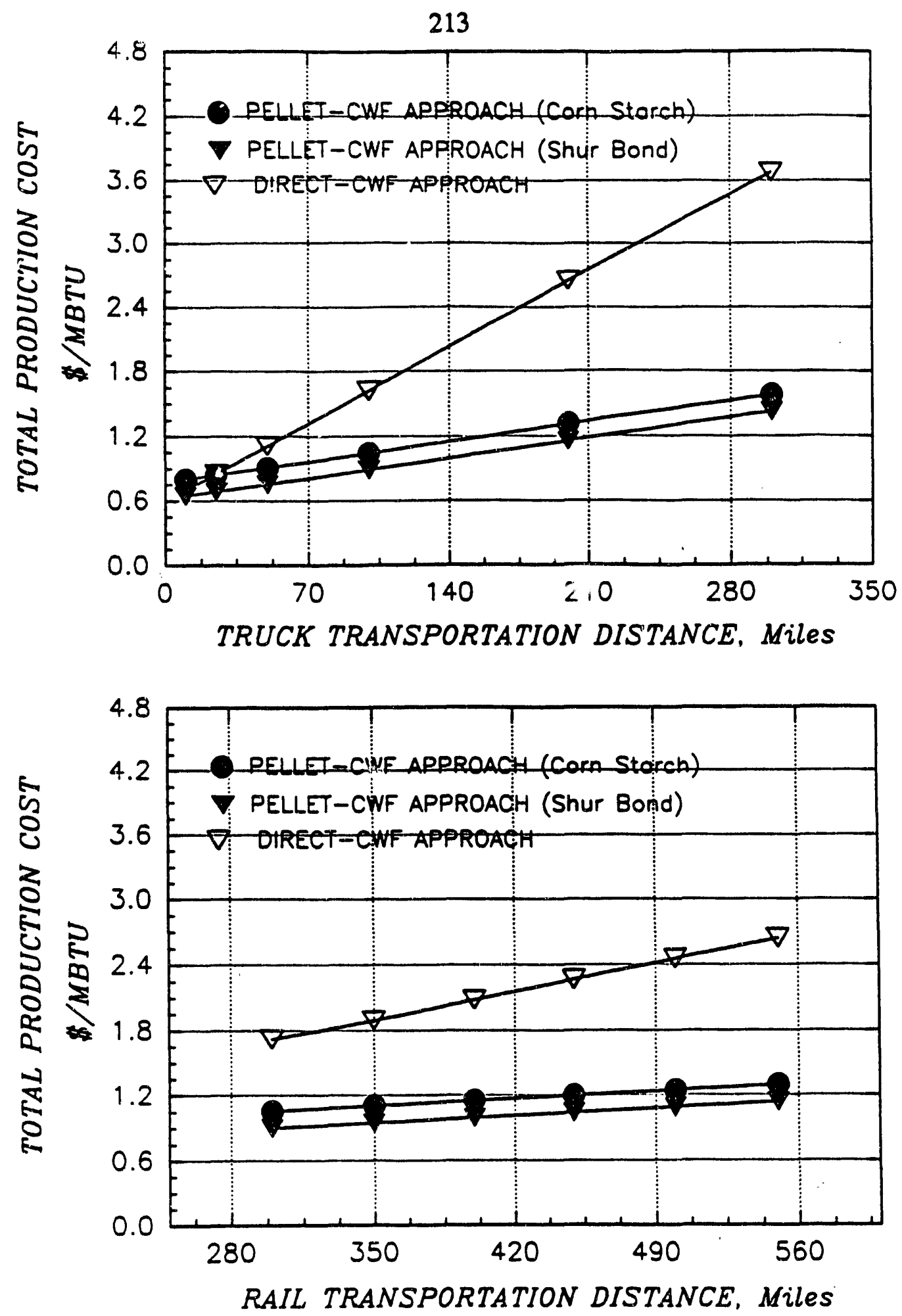

FIGURE 8.26. TOTAL ANNUALIZED COST COMPARISON FOR THE TWO APPROACHES AS A FUNCTION OF TRANSPORTATION DISTANCE FOR UTAH COAL PELLETS FROM ROLLER-AND-DIE PELLETIZATION 
- The total annualized cost estimate for processing, transportation, handling, and storing for the Pellet-CWF approach was lower than the Direct-CWF approach, for the Elkhorn coal. This was valid for any transportation distance.

- With Utah and Illinois No. 6 coals, the Pellet-CWF approach was also more economically favorable than the direct-CWF approach, but for transportation distances greater than 20 miles.

- As transportation distance increased, the Pellet-CWF approach became more attractive.

\subsection{Section 8 References}

1. Conkle, H. N., Raghavan, J. K., Jha, M. C., and Smit, F. J., "Pelletizing/Reslurrying as a Means of Distributing and Firing Clean Coal," Seventh Quarterly Progress Report prepared by Battelle Memorial Institute for the U. S. Department of Energy under Contract No. DE-AC22-90PC90166, June 9, 1992.

2. Wen, C. S., LeCren, R. T., Smit, F. J., and Hogsett, R. F., "Fuel Assessment for Gas Turbine Applications," Proceedings of the 15th International Conference on Coal \& Slurry Technology, Clearwater,Florida, April 24-26, 1990, pp 53-65.

3. Edgar, Thomas F., Coal Processing and Pollution Control, Chapter 4: Coal Transportation, Gulf Publishing Company, Houston (1983), p. 71. 


\subsection{CONCLUSIONS}

Significant accomplishments in the area of fine coal pelletization and pellet reslurrying have been achieved. This project has demonstrated that the coal pelletization processes can produce strong, durable clean-coal pellets which can be readily formulated into good quality CWF. The following conclusions were reached:

- Bench- and pilot-scale pellet production tests indicated that roller-and-die, disk, and extrusion pelletization techniques could be used to produce strong, durable, and waterproof pellets from ultra-fine, ultra-clean Elkhorn, Illinois, and Utah coals

- Binders, including corn starch, Shur Bond, and lignin sulfonate were demonstrated to be suitable for the Pellet-CWF approach

- Pellets from disk and extrusion pelletization could be handled similar to lump coal and transported via trucks or rail immediately from production. Also, these pellets could be stored in most of the storage modes for periods as long. as ten weeks. However, under the exposed-outdoor storage mode, storage periods longer than 4 weeks should be avoided.

- Roller-and-die pellets require about one-day of curing time before subjected to handling, transportation and storage operations. These pellets could also survive most of the storage modes for as long as 10 weeks. Again, under exposed-outdoor storage mode the pellets' survivability is reduced significantly.

- All pellets could be transported by trucks or rail-cars similar to raw mined coal with less than 5 percent fines generated over 4-5 hours of transportation.

- Slurry production tests indicated that low viscosity, stable, CWF could be produced. Pellets could be converted into CWF with viscosities below $500 \mathrm{cP}$ @ $100 \mathrm{sec}^{-1}$ shear rates at coal loadings of 55 wt. percent. 
- CWF formulation dosage for pellet reslurrying was typically about 50 percent less than that required to reslurry the filter-cake directly. Since Pellet-CWF is intended to be used immediately, no stabilizer is required.

- Economic analysis shower that among the three pelletization processes evaluated in the Pellet-CWF approach, the roller-and-die technique had the lowest annualized cost with all three coals. It was also estimated that plant sizes greater than 500 TPD are more economical.

- Annualized cost for CWF formulation in either of the two approaches was closely controlled by the amount of reslurrying additives required. For the Pellet-CWF approach, the formulation cost was estimated to be most economical for plant sizes greater than 25 TPD.

- Transportation distance was a major variable that impacted the total annualized cost. In the Pellet-CWF approach the pellets were handled like lump coal, resulting in a lower transportation cost than the Direct-CWF approach.

- The total annualized cost estimate for processing, handling, storing, and transfortation by the Pellet-CWF approach was lower than the Direct-CWF . approach for distances greater than 20 miles.

- Estimated pelletization, handling, storage, transportation (100 miles), and reslurrying costs for Elkhom coal bound with Shur Bond binder was (\$0.79/MM Btu total) exclusive of coal costs.

- Estimated direct CWF formulation, handling, storage, transportation (100 miles) costs for Elkhorn coal was (\$1.83/MM Btu) exclusive of coal costs. The Pellet-CWF approach became even more attractive as transportation distances increased.

- The Pellet-CWF approach offers several technical and economic incentives for further development and commercialization. 


\subsection{RECOMMENDATIONS}

Battelle recommends, based on the positive project results, that the Pellet-CWF process be further developed. We suggest a two-step approach: (1) more testing in a pilotplant scale (1 to 5 ton/hr) pelletization facility operated for longer durations and in conjunction with a pellet combustion program, and (2) evaluation and economic analysis based on the pilot-plant data combined with data from the two commercial roller-and-die pelletization plants now in operation. The data would provide the foundation for commercial plant design and technology transfer.

The objectives of the recommended effort would be to obtain more design data for the following areas:

- Maintenance requirements - determine the true wear rate of dies and rollers; this is needed because pelletizer maintenance is one of the major cost factors of roller-and-die pelletization costs.

- Pellet storage and handling characteristics - small scale tests indicate the pellets should be acceptable; larger scale tests more closely simulating true handling, storage, and transportation conditions are needed to better evaluate the pellets.

- Pellet grinding characteristics - testing indicated that the pellets could be broken down to approximately the same size as the feed clean coal before reconstitution; needed is an evaluation in a true air-swept roller-and-race pulverizer as used in pulverized coal combustion equipment to ensure acceptability.

- Pellet combustion characteristics - pellets made in previous programs have been successfully combusted and gasified; testing is needed, however, to assure that these ultra-low ash and sulfur coals can be burned with the same emission levels as the cleaned, un-pelletized coal. 
- Pellet production costs - preliminary estimates of production costs indicate the pellets are an attractive method to store, handle, and transport ultra-fine, ultraclean coals; these estimates should be expanded to include the experiences and data being generated in the two $30,000+$ tons per year commercial roller-anddie pelletization plants now in operation. 
APPENDIX A

PELLET TEST PROCEDIRES 


\section{APPENDIX A}

\section{PELLET TEST PROCEDURES}

Battelle surveyed the various tests identified in the literature, and where noted the values corresponding to a suggested "acceptable" pellet. (1) Based upon this review the following seven tests were selected for use in this program:

- Crushing Strength: green, cured, wet

- Tumble Durability

- "Ro-Tap" Durability

- Drop Resistance

- Freeze/Thaw Resistance

- Final Moisture: cured, after immersion

- Grindability.

Each is described below.

\section{Crushing Strength}

The compressive, or crushing, strength can be defined as the maximum crushing load a pellet can withstand before cracking or breaking. Research has shown that crushing strength, on a force per unit volume basis, is proportional to the square root of pellet volume.

\section{Force/volume $\propto \sqrt{ }$ volume}

Expressing crushing strength on a $\mathrm{lb}_{\mathrm{f}} / \mathrm{in}^{3}$ basis provided a more consistent pellet-to-ball-tobriquette comparison than expressions based on $\mathrm{lb}_{\mathrm{f}}, \mathrm{lb}_{\mathrm{f}} / \mathrm{in}^{2}$, or $\mathrm{lb}_{\mathrm{f}} /$ linear in. (length or diameter). Therefore, crushing strength is reported on a force/volume $\left(\mathrm{lb}_{\mathrm{f}} / \mathrm{in}^{3}\right)$ basis. Crushing strength is measured for "green" (immediately after production), "cured" (1 week 
after production), and "immersed" pellets (after water immersion for 2 hours). The test procedure is noted below.

Crushing Strength: 10 separate pellets of varying length (for cylindrical pellets) or varying diameter (for disk/drum pellets) are selected and placed between the plates of a standard spring compression tester. The top plate is lowered slowly until the pellet deforms or breaks. Using the indicating dial (which indicates the load at fracture) note the crushing force, $\mathrm{lb}_{\mathrm{f}}$, and pellet dimensions. Report the average crushing strength/unit volume (e.g., $\mathrm{lb}_{\mathrm{f}} / \mathrm{in}^{3}$ ).

Durability. This parameter is used to characterize the quality of the pellet against abrasion caused by the tumbling action and vibration forces encountered in handling operations. Two tests are included.

Tumble Test: Tumble $500 \mathrm{~g}$ of cured pellets in a $60-\mathrm{mm} \times 127-\mathrm{mm}$ wide bin at $50 \mathrm{rpm}$ for $10 \mathrm{~min}$. Place the charge onto a 4-mesh Tyler screen, gently shake, and note the weight residing on the screen. Report the durability index (DI) as:

$$
\begin{aligned}
& \mathrm{DI}=\text { (wt. of }+4 \text { mesh fraction }) \times 100 \\
& \text { (wt. of sample }=500 \mathrm{~g} \text { ) }
\end{aligned}
$$

Ro-Tap Test: Place $1 / 2$ lb of cured pellets on a 4 mesh Tyler screen.

Mechanically sieve (i.e., Ro-Tap) the charge for 10 minutes and measure the weight retained on the screen. Report the Ro-Tap Durability (RDI) Index as:

$$
\mathrm{RDI}=\frac{(w \mathrm{t} . \text { of }+4 \text { mesh fraction })}{(w t . \text { of sample })} \times 100
$$




\section{Drop Resistance}

This test determines the pellet's ability to survive impact. Typical situations of impact occur when pellets are dropped from a fixed height during production or transportation to storage areas. To characterize the resistance to impact the Drop Test has been adopted as a common mode of testing by several investigators.

Drop Test: Drop 10 green pellets from 1 and $5 \mathrm{ft}$ onto a concrete floor.

Report the average result, for each of the two drop distances, of pellets that remained intact as "pass," pellets that split into a few large pieces as "pass/fail" and those that breakup into many small pieces as "fail."

\section{Freeze/Thaw Resistance}

Coal pellets during transportation or storage may be subjected to cold climatic conditions that could alter the physical structure of the pellet. To characterize pellets exposed to these conditions a freeze/thaw test has been specified (modified ANSI/ASTM test No. C666).

Freeze/Thaw Test: One half $\mathrm{lb}$ of cured pellets is alternately placed in $4 \mathrm{C}$ (39 F) water for 2 hours, drained, then frozen at $-18 \mathrm{C}(0 \mathrm{~F})$ for 2 hours. After two such cycles, the pellets are drained and exposed to ambient room conditions for $\mathbf{4 8}$ hours. When the pellets reach equilibrium with the room conditions, gently hand-shake the pellets over a 4-mesh Tyler screen. Report the weatherability index (WI) as:

$$
W I=\frac{\text { wt. }(+4 \text { mesh }) \text { sample }}{\text { wt. of sample }} \times 100
$$




\section{Final Moisture}

The moisture level of the pellet/capsule is another important quality measure. Two measurements are specified.

Cured Pellet Final Moisture: Ten representative cured pellets are selected, ground by hand to less than $1 / 4$ in., mixed, and a representative sample measured for moisture following ASTM D-2961 procedures.

Immersed Pellet Final Moisture: Ten representative cured pellets are selected, immersed in water for 2 hours, and drained over a 4 mesh screen for 45 to 60 minutes (allowing the surface moisture to dry). The pellets are ground by hand to less than $1 / 4$ in., mixed, and a representative sample measured for moisture following ASTM procedures. This test may be performed in conjunction with the wet strength test.

\section{Grindability}

Grindability relates to the difficulty in reducing the pellets to micronized size for injection into the combustor. The standard Hardgrove Grindability Index test is used.

Hardgrove Grindability Index: Place a $50 \mathrm{~g}$ sample of cured pellets, preground and pre-screened to be smaller than a No. 16 sieve and larger than a No. 32 sieve, into a Hardgrove Grinding Machine. Operate the machine for 60 revolutions and note the weight of coal passing a No. 200 screen. Calculate the Hardgrove Grindability Index (HGI) in accordance with the procedures outline in ASTM D-409. 


\section{A-5}

\section{References}

1. Raghavan, J. K. and Conkle, H. N., "Physical Characteristics Measurements for Reconstituted Coal Pellets, " Proceedings of the 22nd Biennial Conference of The Institute of Briquetting and Agglomeration, San Antonio, Texas, November 4-6, 1991.

2. Lowery, H. H., Chemistry of Coal Utilization - Supplemental Volume, John Wiley and Sons, Inc., 1963, pp 128-133 


\section{APPENDIX B}

\section{RESLURRYING AMENABILITY TEST PROCEDURE}




\section{B-1}

\section{APPENDIX B}

\section{RESLURRYING AMENABILITY TEST PROCEDURE}

Revised October 2'8, 1991

\section{Objective}

Provide a standard procedure for preparing slurries so that the reslurryability of test pellets may be compared. The principal basis for comparison will be the ease (or rate) at which pellets can be disintegrated.

\section{Apparatus}

1. Cowles laboratory Dissolver, Model 1-VG, 0 to 4,500 rpm, 3-in. diameter Hi-Shear serrated edge impeller ( 0 to $3,500 \mathrm{ft} / \mathrm{min}$ tip speed) set $1-1 / 2$ in. above bottom of container or at $1 / 2$ slurry depth whichever is less, 7-in. diameter container with baffles, usual slurry depth $=4$ in. (2.5 liters $-1,600 \mathrm{~g}$ dry coal).

2. Three-in. diameter, 48 -mesh ( $0.3 \mathrm{~mm}$ opening) test sieve and vibrator.

3. Fann viscomeier and glass thermometer.

4. Coal drying oven and 3-place balance.

\section{Steps in Procedure}

1. Determine moisture in pellets.

2. Weigh out sufficient pellets to contain 1,600 grams dry weight (wet pellet weight $=$ $1,600 /(100$ - percent moisture in pellets). Prorate pellet, water, and dispersant additions in the event 1,600 grams dry weight of pellets are not available.

3. Calculate total weight of 55 percent coal + binder slurry to be produced from pellets $(1,600 / 0.55=2,909$ grams $)$. 


\section{B-2}

4. Calculate weight of A-23 solution required for 1,600 grams of coal + - binder. (A-23 solution $=1,600 *$ addition rate percent/43.)

a. Normally use addition rate of 1.3 percent A-23 for pellets with the starch binder.

b. Normally use addition rate of 0.74 percent A-23 for pellets with Shur Bond or lignin binders.

5. Calculate additional amount of water needes (additional water $=2,909$ - wet pellet weight - A-23 solution weight).

6. Clamp 7-in. diameter container into dissolver with impeller in position.

7. Place additional water (Step 5), A-23 solution (Step 6), and pellets (Step 2) into container.

8. Cover container to catch splashes during start-up. Run impeller 4 minutes at 4,500 rpm. Stop and dip out about $90 \mathrm{ml}$ for sieve test. Resume mixing for another 4 minutes ( 8 minutes total). Stop and dip out $90 \mathrm{ml}$ for viscosity and sieve test. Add 9 $\mathrm{ml}$ water to make-up for evaporation (14 $\mathrm{ml}$ for starch binder pellets). Resume mixing for another 8 rainutes (16 minutes total). Stop and remove container from machine. Place slurry into capped plastic sample containers.

9. Perform viscosity test on 8-minute and 16-minute slurry samples shortly after collection. Include a temperature measurement. Also dry between 2 and 7 grams of each sample for moisture/percent solids determination. Calculate coal + binder loading from percent solids $[$ coal + binder $=$ percent solids $* 100 /(100+A-23$ addition percent rate)].

10. Perform sieve tests on 4-minute, 8-minute, and 16-minute slurry samples. (Weigh slurry sample onto a tared 48-mesh sieve. Gently wash with a small stream of water from a wash bottle while vibrating the sieve. Dry and weigh residue while on sieve. Compare with the calculated dry weight of the slurry sample.)

11. Report coal loading and percent plus 48 mesh for 4-minute sample and the coal loading, percent plus 48 mesh, and viscosities at 100, 500,1,000 $\sec ^{-1}$ for the 8- and 16-minute samples. (Viscosity measurements on 4-minute samples are erratic because of the size of the pellet fragments remaining in those samples.) 

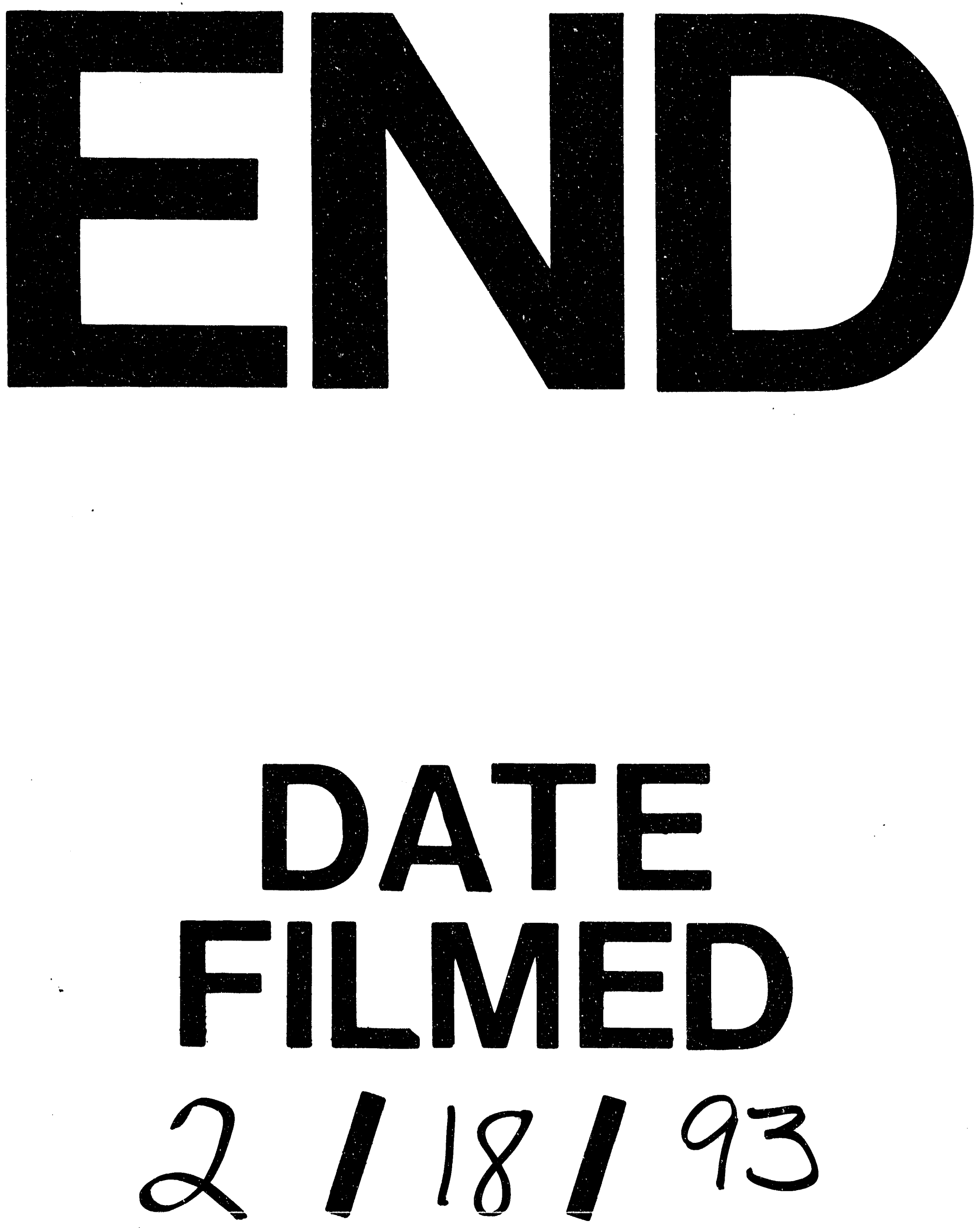
